RYNALDO ZANOTELE HEMERLY DE ALMEIDA

MODELAGEM DINÂMICA E CONTROLE DE ROBÔ MANIPULADOR DE ARQUITETURA PARALELA ASSIMÉTRICA

DE TRÊS GRAUS DE LIBERDADE 
RYNALDO ZANOTELE HEMERLY DE ALMEIDA

\section{MODELAGEM DINÂMICA E CONTROLE DE ROBÔ MANIPULADOR DE ARQUITETURA PARALELA ASSIMÉTRICA DE TRÊS GRAUS DE LIBERDADE}

Tese apresentada à Escola Politécnica da Universidade de São Paulo para obtenção do título de Doutor em Ciências no Programa de Engenharia Mecânica

Área de concentração: Engenharia Mecânica de Projeto de Fabricação

Orientador: Prof. Dr. Tarcisio Antonio Hess Coelho 
Este exemplar foi revisado e corrigido em relação à versão original, sob responsabilidade única do autor e com a anuência de seu orientador.

São Paulo, 09 de dezembro de 2013.

Assinatura do autor

Assinatura do orientador

FICHA CATALOGRÁFICA

Almeida, Rynaldo Zanotele Hemerly de

Modelagem dinâmica e controle de robô manipulador de arquitetura paralela assimétrica de três graus de liberdade /

R.Z.H. de Almeida. - versão corr. -- São Paulo, 2013.

$179 \mathrm{p}$.

Tese (Doutorado) - Escola Politécnica da Universidade de São Paulo. Departamento de Engenharia Mecatrônica e de Sistemas Mecânicos.

1.Robôs 2.Modelagem dinâmica 3.Controle não linear I.Universidade de São Paulo. Escola Politécnica. Departamento de Engenharia Mecatrônica e de Sistemas Mecânicos II.t. 
Nome: ALMEIDA, Rynaldo Zanotele Hemerly de

Título: Modelagem Dinâmica e Controle de Robô Manipulador de Arquitetura Paralela Assimétrica de Três Graus de Liberdade

Tese apresentada à Escola Politécnica da Universidade de São Paulo para obtenção do título de Doutor em Ciências no Programa de Engenharia Mecânica

Área de concentração: Engenharia Mecânica de Projeto de Fabricação

Aprovado em: 31/10/2013

Banca Examinadora

Prof. Dr. Tarcisio Antonio Hess Coelho

Universidade de São Paulo - Escola Politécnica

Prof. Dr. Agenor de Toledo Fleury

Universidade de São Paulo - Escola Politécnica

Prof. Dr. Eduardo Aoun Tannuri

Universidade de São Paulo - Escola Politécnica

Prof. Dr. João Carlos Mendes Carvalho

Universidade Federal de Uberlãndia - Faculdade de Engenharia Mecânica

Prof. Dr. Daniel Martins

Universidade Federal de Santa Catarina - Departamento de Engenharia Mecânica 
Ad scientiam 


\section{AGRADECIMENTOS}

Ao meu orientador, prof. Tarcisio, pelas valiosas instruções, pela inesgotável paciência e por sempre acreditar que meu trabalho traria frutos para a árvore do conhecimento.

Aos meus pais, pelo contínuo apoio e pela liberdade que sempre me deram para seguir meu próprio caminho.

A todos que me ajudaram a multiplicar o escasso tempo que eu tinha disponível para o desenvolvimento deste trabalho. Em especial, à minha cunhada Martha, por cuidar de meu filho, ao Marco D'Elia do IPT, por me permitir cumprir um horário de trabalho flexível no IPT, e ao Roberto Oshiro e ao Renato Yamassaki do GMSIE POLI-USP, por providenciarem periféricos e conexão de rede para meu computador.

Aos colegas de trabalho e amigos do IPT (incluindo ex-ipeteanos) e do GMSIE POLI-USP, que me incentivaram e que positivamente me cobravam sobre 0 andamento de meu trabalho. Em especial, ao Roberto Romano e ao Walter Ponge.

Ao meu filho, Pedro, que em sua tenra idade compreendeu que eu precisava dedicar mais tempo ao trabalho que à família nesses últimos tempos.

$E$, finalmente, à minha querida esposa, Paula, que está sempre ao meu lado nos mais variados caminhos que percorremos e com quem sempre posso compartilhar minhas dificuldades para ganhar força e seguir adiante. 


\section{RESUMO}

Este trabalho trata da modelagem dinâmica e do projeto de sistemas de controle para um robô manipulador de arquitetura paralela assimétrica de três graus de liberdade, correspondente a três translações de seu efetuador no espaço tridimensional, concebido para tarefas de pega-e-põe (pick-and-place). Dentre os desenvolvimentos teóricos, procurou-se estender, para toda gama de robôs paralelos e topologicamente assimétricos, a abrangência dos procedimentos aplicados inicialmente a este caso específico. Foram empregados o Método de Lagrange e o Princípio dos Trabalhos Virtuais na obtenção de modelos dinâmicos baseados em hipóteses simplificadoras de corpos rígidos de massas concentradas e de massas distribuídas. Para o projeto de controladores, foram utilizadas as técnicas de torque computado e torque computado estendido. As formulações correspondentes a estas técnicas foram aprimoradas de forma a permitir o cálculo de esforços de controle de modo equivalente tanto nas coordenadas dos atuadores como nas coordenadas do efetuador e em conformidade com os requisitos de resposta dinâmica definidos para o robô. Tais requisitos podem ser inclusive anisotrópicos, o que se julga ser mais apropriado para robôs paralelos assimétricos. Particularmente em relação ao robô analisado, foram avaliados efeitos de simplificação do modelo dinâmico e da discretização do controlador (incluindo discretização com dupla frequência de amostragem) sobre os erros de controle de posição. Percebeu-se que os requisitos de alto desempenho das tarefas de pega-epõe levam o projeto do controlador ao limite de validade da hipótese simplificadora de corpo rígido e da capacidade de processamento do hardware de controle. 


\begin{abstract}
This work deals with the dynamic modeling and the design of control systems for an asymmetric parallel manipulator robot with three degrees of freedom, related to three translations of its end-effector in the tridimensional space, conceived for pick-andplace tasks. Among the theoretical developments, one of them was the extension of the proposed procedures, initially applied to this specific case, to the whole class of topologically asymmetric and parallel mechanisms. The Lagrange Method and the Principle of Virtual work were employed in order to build dynamic models based on rigid body assumption with either lumped or distributed mass simplification hypothesis. For the controllers' design, computed torque and extended computed torque techniques were used. The formulations of such techniques were elaborated in order to allow the calculation of the control efforts to be executed equivalently both on the actuators coordinates and on the end-effector coordinates, in accordance with the dynamic response requirements defined for the robot. These requirements may be even anisotropic, what is considered to be more suitable for asymmetric parallel robots. Particularly about the analyzed robot, the effects of dynamic model simplification and controller discretization (including double sample rate discretization) on the position control errors were evaluated. It was realized that the high performance requirements for pick-and-place tasks push the controller design to the limit of validity of the rigid body assumption and of the control hardware processing capacity.
\end{abstract}


1 INTRODUÇÃO

1.1 CONTEXTO DE APLICAÇÃO E DESCRIÇÃO DA ARQUITETURA ANALISADA.

1.2 OBJETIVOS E PRINCIPAIS CONTRIBUIÇÕES .....................................16

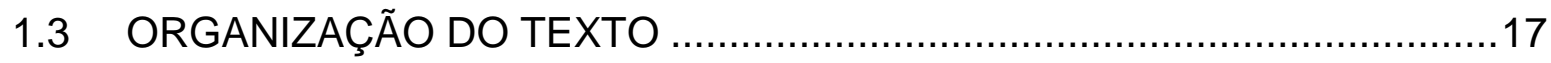

1.4 TRABALHOS PUBLICADOS EM REVISTAS E EM CONGRESSOS ..........17

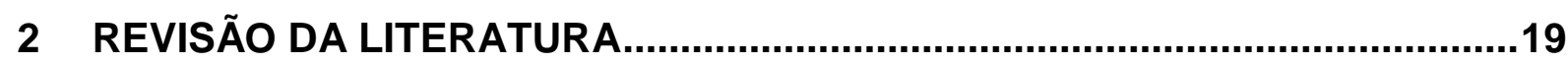

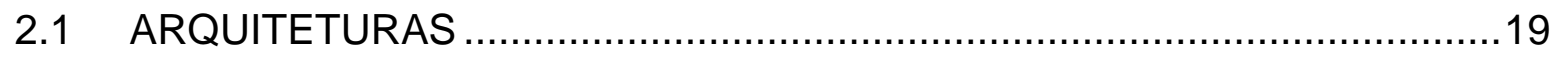

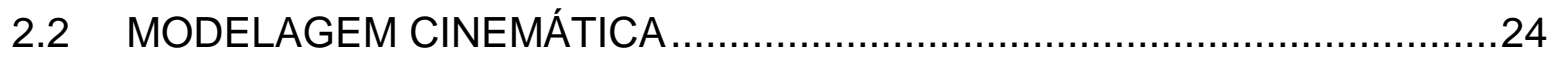

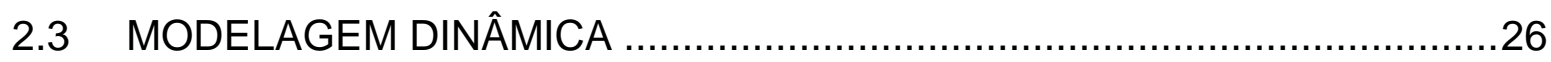

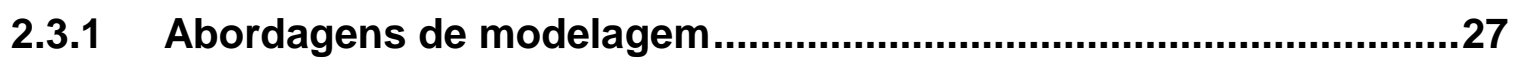

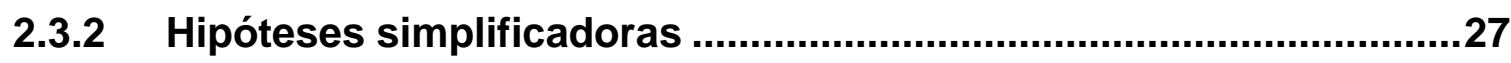

2.3.3 Simplificação pós-modelagem ...........................................................30

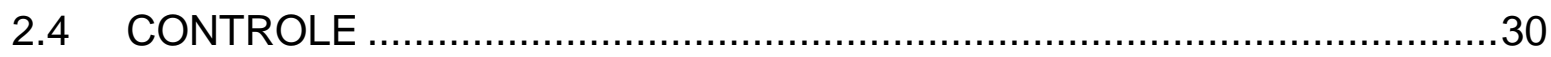

2.4.1 Variáveis monitoradas e variáveis controladas ..................................31

2.4.2 Dependência entre variáveis controladas .........................................33

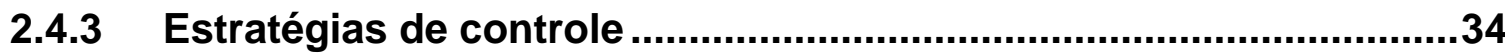

2.4.4 Limites de requisitos de desempenho de controle e observações sobre a frequência de amostragem do controlador .......................................38

2.4.5 Formulação e sintonização do controle por torque computado .....39

2.4.6 Formulação e sintonização do controle por torque computado

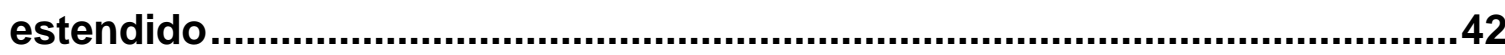

3 MODELAGEM E ANÁLISE CINEMÁTICA DO MECANISMO 2 RSS + PPaP...44

3.1 NOMENCLATURA E DIAGRAMA CINEMÁTICO ….................................44

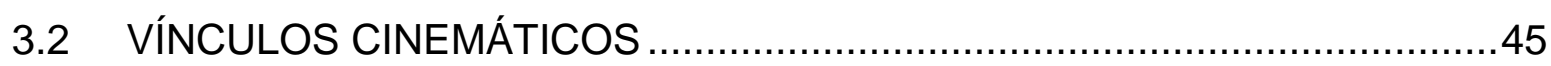

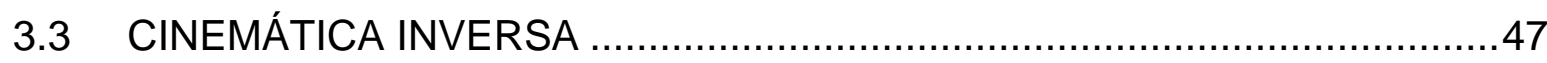




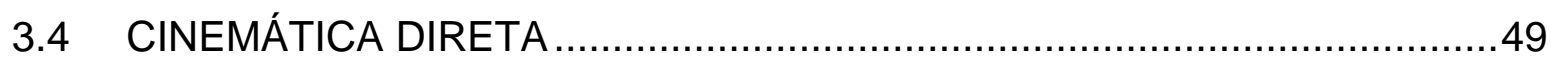

3.5 SINGULARIDADES E ESPAÇO DE TRABALHO ....................................51

4 MODELAGEM DINÂMICA DO MECANISMO 2 RSS + PPaP …......................56

4.1 MODELAGEM COM MASSAS DAS BARRAS CONCENTRADAS EM SUAS EXTREMIDADES

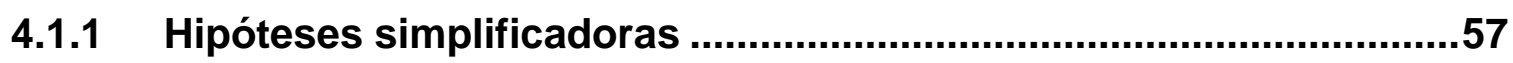

4.1.2 Modelagem pelo Princípio dos Trabalhos Virtuais ..........................58

4.1.3 Modelagem pelo Método de Lagrange............................................62

4.2 MODELAGEM COM MASSAS DAS BARRAS CONCENTRADAS EM SEUS

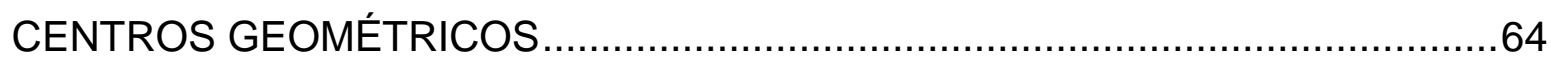

4.2.1 Hipóteses simplificadoras ............................................................64

4.2.2 Modelagem pelo Princípio dos Trabalhos Virtuais ............................64

4.3 MODELAGEM COM MASSAS DAS BARRAS DISTRIBUÍDAS..................66

4.3.1 Hipóteses simplificadoras .................................................................66

4.3.2 Modelagem pelo Princípio dos Trabalhos Virtuais ............................67

5 ANÁLISE DO MODELO DINÂMICO DO MECANISMO 2 RSS + PPaP .............70

5.1 VALIDAÇÃO DOS MODELOS DINÂMICOS .............................................70

5.2 ACELERAÇÃO MÁXIMA DO EFETUADOR EM FUNÇÃO DA SATURAÇÃO

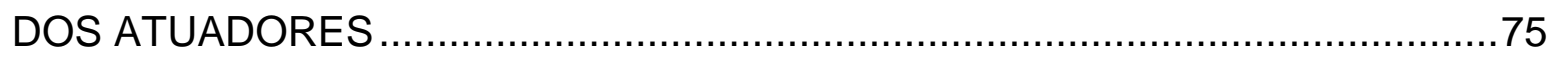

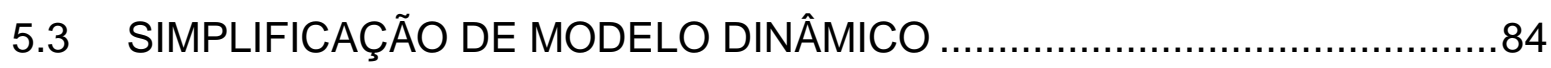

5.3.1 Procedimento de simplificação do modelo dinâmico .........................84

5.3.2 Modelos resultantes do procedimento de simplificação ..................90

6 ANÁLISE E APRIMORAMENTO DE FORMULAÇÕES DE ESTRATÉGIAS DE CONTROLE PARA APLICAÇÃO EM ROBOS PARALELOS ASSIMÉTRICOS .....92

6.1 CONTROLE POR TORQUE COMPUTADO APLICADO A EQUACIONAMENTO DINÂMICO COM VARIÁVEIS REDUNDANTES .92 
6.2 EQUIVALÊNCIA ENTRE CÁLCULO DE ESFORÇOS DE CONTROLE SOBRE VARIÁVEIS DOS ATUADORES E SOBRE VARIÁVEIS DO EFETUADOR NO CONTROLE POR TORQUE COMPUTADO .95

6.3 EQUIVALÊNCIA ENTRE CONTROLE POR TORQUE COMPUTADO ESTENDIDO E CONTROLE POR TORQUE COMPUTADO.

6.4 SINTONIZAÇÃO DO CONTROLE POR TORQUE COMPUTADO E POR TORQUE COMPUTADO ESTENDIDO PARA ROBÔS PARALELOS ASSIMÉTRICOS.

7 SIMULAÇÃO E ANÁLISE DE LEIS DE CONTROLE APLICADAS AO MECANISMO 2 RSS + PPaP .102

7.1 IMPLEMENTAÇÃO DO SISTEMA DE CONTROLE PARA O MECANISMO PARALELO EM MATLAB 102

7.1.1 Procedimento de integração numérica de modelo e controlador.102

7.1.2 Parâmetros nominais do modelo .103

7.1.3 Determinação de frequências estruturais do mecanismo 2 RSS + PPaP 104

7.1.4 Cálculo de ganhos de controle. 105

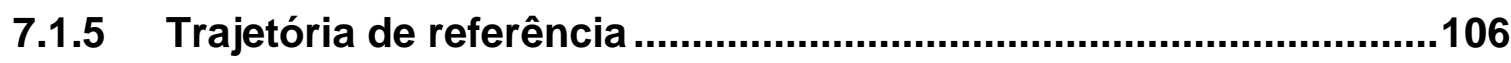

7.1.6 Critérios de cálculo de erros de controle 109

7.1.7 Definição de passo de integração e de frequências de amostragem 110

7.2 EQUIVALÊNCIA ENTRE CÁLCULO DE ESFORÇOS DE CONTROLE SOBRE VARIÁVEIS DOS ATUADORES E SOBRE VARIÁVEIS DO EFETUADOR NO CONTROLE POR TORQUE COMPUTADO 115

7.2.1 Ganhos iguais para todas as variáveis controladas .115

7.2.2 Ganhos diferentes entre variáveis controladas 121

7.3 EQUIVALÊNCIA ENTRE CONTROLE POR TORQUE COMPUTADO ESTENDIDO E CONTROLE POR TORQUE COMPUTADO. 126

7.3.1 Ganhos diferentes entre variáveis controladas 129 
7.4 EFEITOS DA SIMPLIFICAÇÃO DO MODELO E DA FREQUÊNCIA DE AMOSTRAGEM NOS ERROS DE CONTROLE.

7.4.1 Efeitos da frequência de amostragem sobre o erro de controle em malha fechada 132

7.4.2 Erros de controle e tempos de processamento em função da simplificação do modelo

8 CONCLUSÕES 142

9 REFERÊNCIAS BIBLIOGRÁFICAS 145

APÊNDICE A - DESENVOLVIMENTO DE EQUAÇÕES DE CINEMÁTICA INVERSA 153

APÊNDICE B - DESENVOLVIMENTO DE EQUAÇÕES DE CINEMÁTICA DIRETA 155

APÊNDICE C - DESENVOLVIMENTO DE EQUAÇÕES CINEMÁTICAS UTILIZADAS NA APLICAÇÃO DO PRINCÍPIO DOS TRABALHOS VIRTUAIS ...157 APÊNDICE D - DESENVOLVIMENTO DE EQUACIONAMENTO DINÂMICO PELO MÉTODO DE LAGRANGE 160

APÊNDICE E - EQUACIONAMENTO DE MATRIZES DE ROTAÇÃO ENTRE SISTEMA GLOBAL E SISTEMAS MÓVEIS. 163

APÊNDICE F - TABELAS COM IDENTIFICAÇÃO DE TERMOS DINÂMICOS E CLASSIFICAÇÃO DE TERMOS PREDOMINANTES 165 APÊNDICE G - IDENTIFICAÇÃO DE FREQUÊNCIAS NATURAIS ESTRUTURAIS DO MECANISMO 2 RSS + PPaP 170 ANEXO A - ESPECIFICAÇÕES DO ROBÔ ABB IRB360 FLEXPICKER 174 ANEXO B - ESPECIFICAÇÕES DO ROBÔ ADEPT QUATTRO s650H 177 


\section{INTRODUÇÃo}

As vantagens em se utilizar mecanismos de arquitetura paralela em relação aos de arquitetura serial são bem conhecidas: alta rigidez, baixo peso, resposta dinâmica rápida, alta precisão e alta capacidade de carga (KHALIL, DOMBRE, 2002; TSAI, 1999). Em algumas tarefas, como de operações de pega-e-põe (pick-andplace), essas vantagens superam suas limitações de espaço de trabalho reduzido e complexidade de modelagem cinemática e dinâmica.

Neste trabalho, foi dado foco ao desenvolvimento da modelagem dinâmica e de sistemas de controle para um robô de arquitetura paralela assimétrica cujo efetuador possui três graus de liberdade, correspondente a três translações, que foi concebido para aplicações de pega-e-põe. A partir deste caso particular, procurouse estender a abrangência dos procedimentos de modelagem dinâmica e de projeto de controladores para toda a gama de robôs paralelos assimétricos.

\subsection{CONTEXTO DE APLICAÇÃO E DESCRIÇÃO DA ARQUITETURA ANALISADA}

Nota-se que em algumas aplicações de manipulação, notadamente de pegae-põe, os requisitos de velocidade e rigidez não são os mesmos em todas as direções. Por exemplo, o descarregamento de produtos de uma esteira em uma linha de produção geralmente demanda maiores velocidades de manipulação na direção transversal do que na direção de movimentação da esteira. A partir dessa observação, encontra-se em desenvolvimento um robô manipulador de arquitetura paralela assimétrica no Departamento de Engenharia de Mecatrônica e de Sistemas Mecânicos da Escola Politécnica da Universidade de São Paulo.

Na Figura 1.1, pode-se observar uma ilustração do robô em desenvolvimento e a representação de seus membros na forma de grafos. Este robô, que foi inicialmente divulgado em (KUMAZAWA et al., 2009), possui três membros ativos que conectam uma base fixa a um efetuador (onde pode ser instalada uma garra ou outra ferramenta de interesse). Utilizando as letras $\mathrm{R}, \mathrm{P}$ e $\mathrm{S}$ para se referir a juntas de rotação, prismática e esférica, respectivamente, e o símbolo $\mathrm{Pa}$ para uma subcadeia do tipo paralelogramo articulado, seus dois membros laterais podem ser descritos como do tipo RSS enquanto seu membro central do tipo PPaP. As letras 
sublinhadas indicam juntas ativas. Assim, a arquitetura do mecanismo é do tipo $2 \underline{R} S S+\underline{P} P a P$.

Sua concepção teve por objetivo a obtenção de um mecanismo leve, com número reduzido de peças (comparado ao de outras arquiteturas paralelas como a Delta), cujo efetuador tivesse três graus de liberdade, correspondentes a três translações no espaço, para aplicações do tipo pega-e-põe. Para tanto, foi empregado o procedimento alternativo de síntese do tipo proposto por Hess-Coelho (2007), em que os graus de liberdade do efetuador são impostos por um dos membros (neste caso o membro central). Diferentemente do método de síntese do tipo tradicional, o membro que restringe os graus de liberdade do efetuador é definido como ativo. Após a definição desse primeiro membro, são adicionados outros membros que não interfiram nos graus de liberdade do efetuador, mas que permitam o controle de sua posição no espaço. Um quarto grau de liberdade, de rotação em relação a um eixo vertical, poderia ser posteriormente adicionado com a adição de um membro do tipo RUPUR ou com a inclusão de um atuador no atual efetuador do mecanismo, segundo uma arquitetura híbrida (paralelo/serial).

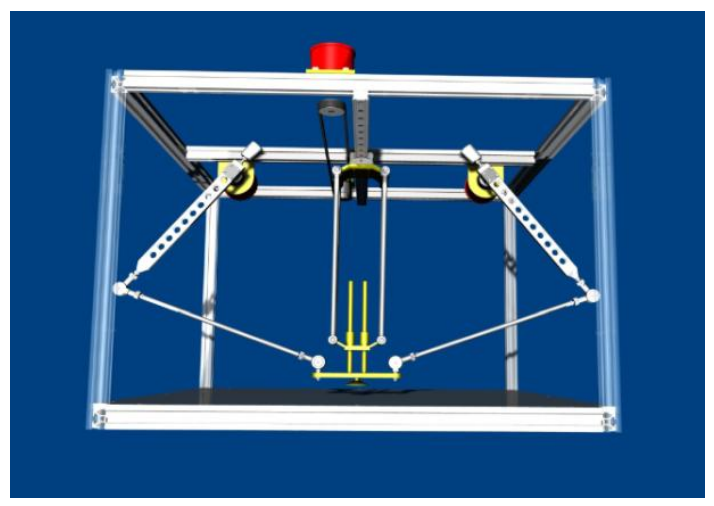

(a)

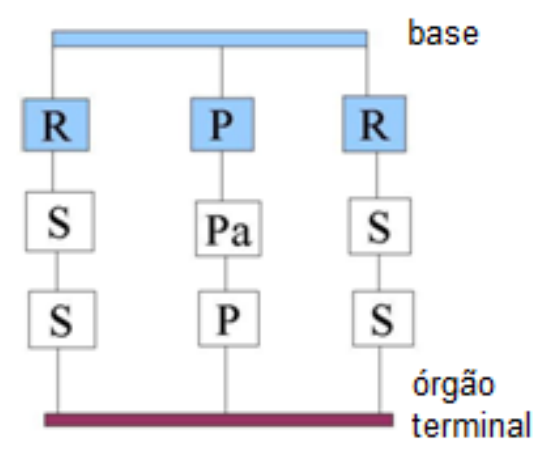

(b)

Figura 1.1 - Robô manipulador: (a) Ilustração, (b) representação em grafo (adaptado de Kumazawa et al. (2009))

Nota-se que o mecanismo apresenta planos de simetria geométrica. Porém, é topologicamente assimétrico, pois não respeita integralmente as condições de simetria definidas por Mohamed e Duffy (1985), em que (i) todos os membros devem ter a mesma sequência de juntas; (ii) todos os membros devem possuir, cada um, uma única junta ativa; (iii) a quantidade de membros deve ser igual a quantidade de graus de liberdade do efetuador. 
Na Figura 1.2 pode ser observado o estágio atual de construção do protótipo. A parte mecânica do robô está em estágio avançado de fabricação restando a montagem das articulações dos membros laterais com a base fixa e acoplamento com seus respectivos atuadores. A forma de acionamento da junta prismática está em definição, bem como o hardware para o sistema de controle.

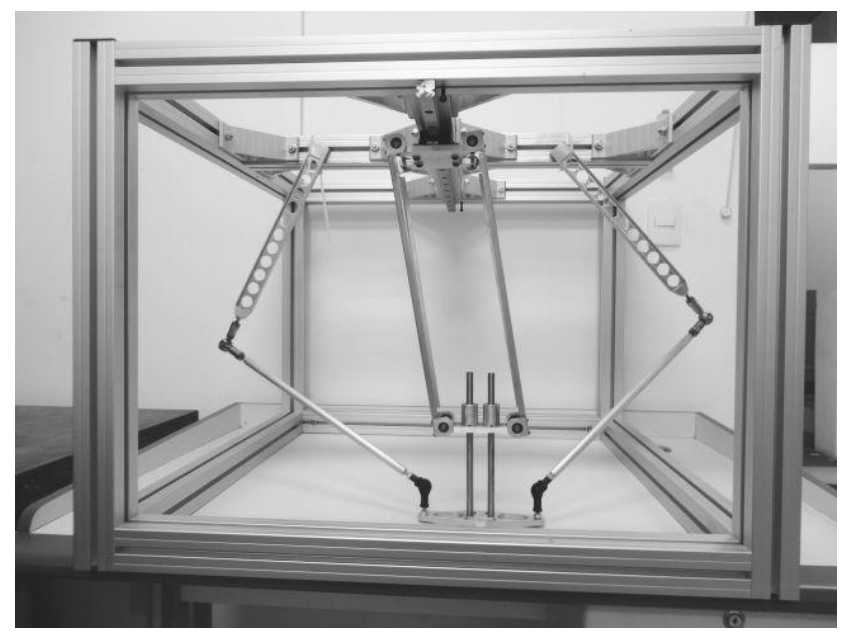

Figura 1.2 - Estágio atual de fabricação do protótipo do robô

O desenvolvimento de todas as atividades deste trabalho foi balizado por índices de desempenho de robôs manipuladores de arquitetura paralela disponíveis comercialmente, especificamente o FlexPicker IRB 360-3/1130 da ABB Robotics (ABB ROBOTICS, 2013) e o Adept Quattro s650H da Adept Technology (ADEPT TECHNOLOGY, 2010). Alguns índices de desempenho desses robôs são listados na Tabela 1.1. Mais detalhes podem ser observados nas especificações técnicas desses robôs, disponíveis nos Anexos A e B.

Tabela 1.1 - Índices de desempenho de robôs de arquitetura paralela disponíveis comercialmente

\begin{tabular}{|c|c|c|}
\cline { 2 - 3 } \multicolumn{1}{c|}{} & ABB IRB $\mathbf{3 6 0 - 3 / 1 1 3 0}$ & Adept Quattro s650H \\
\hline Volume de trabalho & $\varnothing 1130 \mathrm{~mm} \times 250 \mathrm{~mm}$ & $\varnothing 1300 \mathrm{~mm} \times 500 \mathrm{~mm}$ \\
\hline $\begin{array}{c}\text { Rempetibilidade } \\
\text { carga de } \mathbf{0 , 1} \mathbf{~ k g}\end{array}$ & $\pm 0,1 \mathrm{~mm}$ & $\pm 0,1 \mathrm{~mm}$ \\
\hline $\begin{array}{c}\text { Tempo de ciclo }(\mathbf{2 5 / 7 0 0 / 2 5 )} \mathbf{~ m m} \\
\text { carga de } \mathbf{0 , 1} \mathbf{~ k g}\end{array}$ & $0,4 \mathrm{~s}$ & $0,3 \mathrm{~s}$ \\
\hline $\begin{array}{c}\text { Tempo de ciclo }(\mathbf{9 0} / \mathbf{4 0 0} / \mathbf{9 0}) \mathbf{~ m m}, \\
\text { carga de } \mathbf{0 , 1} \mathbf{~ k g}\end{array}$ & - & $0,46 \mathrm{~s}$ \\
\hline Capacidade máxima de carga & $3 \mathrm{~kg}$ & - \\
\hline
\end{tabular}




\subsection{OBJETIVOS E PRINCIPAIS CONTRIBUIÇÕES}

Após o robô ter sido concebido, foi dado início ao presente trabalho, com os seguintes objetivos:

- Avaliar vantagens e desvantagens de abordagens de modelagem dinâmica de mecanismos paralelos;

- Realizar a modelagem dinâmica do mecanismo 2 RSS + PPaP;

- Avaliar vantagens e desvantagens de técnicas de controle de robôs paralelos, basicamente oriundas de técnicas de controle tradicionalmente aplicadas a robôs seriais;

- Projetar sistemas de controle para o robô em estudo e avaliar seus resultados por simulações numéricas.

Como resultado, as principais contribuições para o desenvolvimento científico foram a conclusão de um primeiro ciclo da espiral de projeto desta nova arquitetura - paralela assimétrica - e o aprimoramento de leis de controle para serem aplicadas a mecanismos paralelos assimétricos. A Figura 1.3 ilustra as etapas desenvolvidas neste trabalho, destacadas na cor preta, e etapas desenvolvidas ou em desenvolvimento por outras partes, representadas na cor cinza.

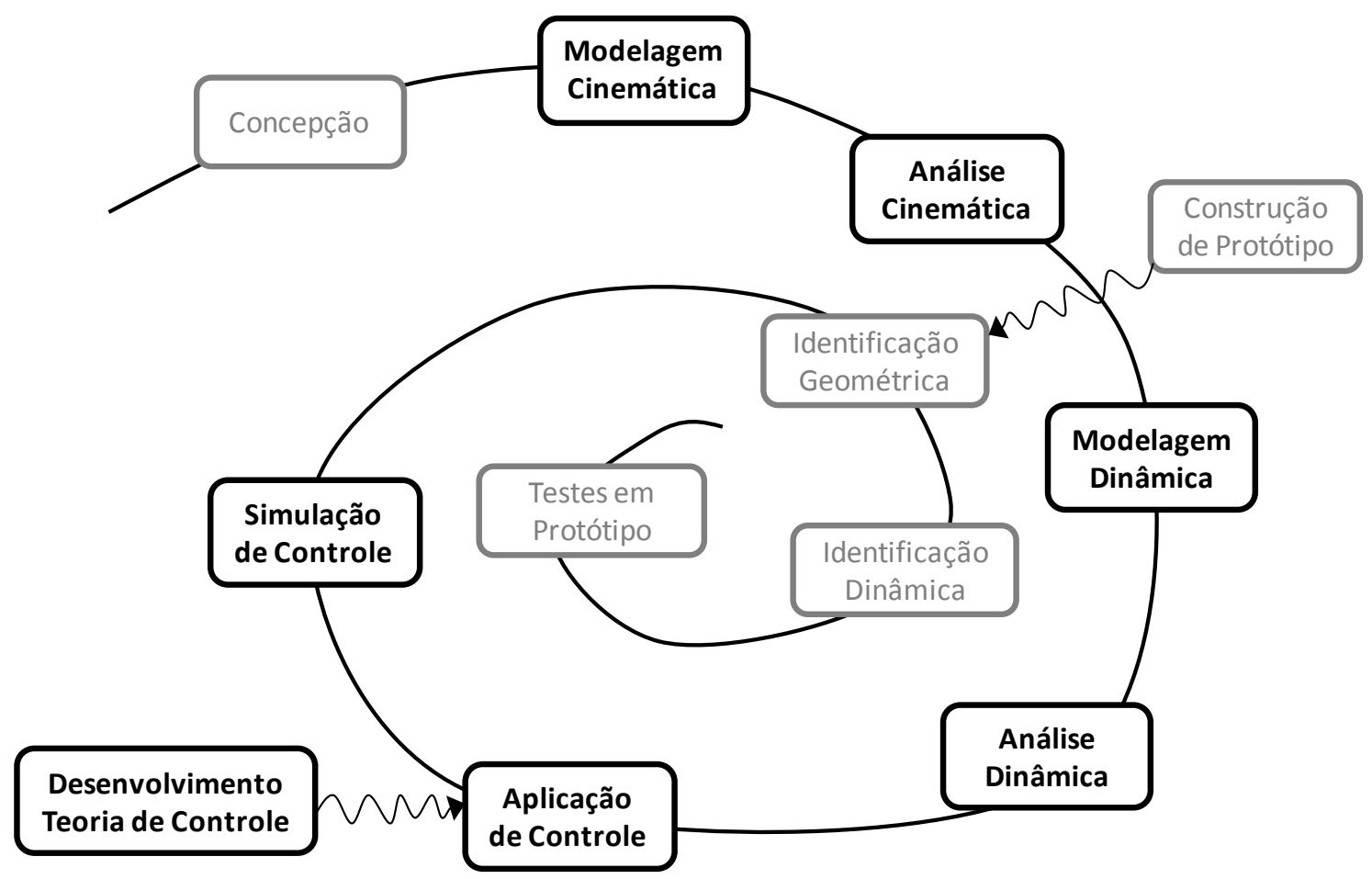

Figura 1.3 - Espiral de projeto do robô manipulador em desenvolvimento (em preto, atividades realizadas no presente trabalho) 


\subsection{ORGANIZAÇÃO DO TEXTO}

$\mathrm{Na}$ sequência deste texto, é apresentada, no Capítulo 2, uma revisão bibliográfica sobre arquiteturas, modelagem cinemática, modelagem dinâmica e controle de robôs paralelos, em que é possível observar as diferentes abordagens de modelagem e de técnicas de controle que podem ser aplicadas. Os Capítulos $3 \mathrm{e}$ 4 são dedicados à modelagem cinemática e dinâmica especificamente do robô em estudo. No capítulo 5 são realizadas análises dos modelos dinâmicos obtidos. Primeiramente é apresentada uma comparação entre os resultados de simulações baseadas nos modelos desenvolvidos nos Capítulos 3 e 4 e os resultados obtidos por simulação de modelo implementado em software comercial de modelagem e simulação de sistemas multi-corpos. Em seguida é feito um estudo de aceleração máxima do efetuador, limitada à saturação dos atuadores do robô. Esse capítulo é encerrado com a simplificação do modelo dinâmico do robô com o objetivo de tornálo computacionalmente eficiente para servir de base para o desenvolvimento de leis de controle. No capítulo 6 são apresentados aprimoramentos que foram realizados sobre técnicas de controle existentes para que sejam utilizadas de modo a melhor explorar as características particulares de mecanismos paralelos assimétricos. No Capítulo 7 são analisados resultados de simulações de controle do mecanismo com base no desenvolvimento realizado no capítulo 6 . Por fim, são apresentadas as conclusões deste trabalho no Capítulo 8.

\subsection{TRABALHOS PUBLICADOS EM REVISTAS E EM CONGRESSOS}

Parte do conteúdo desta tese foi publicada em anais de congressos e em revistas científicas, nos seguintes trabalhos:

- AlmeidA, R. Z. H, HeSS-COElHO, T. A., Dynamic Model of a 3-dof Asymmetric Parallel Mechanism, The Open Mechanical Engineering Journal, vol. 4, 2010

- AlmeidA, R. Z. H., HESS-COELHO, T. A., Structural synthesis, dynamic modeling and analysis of a 3-dof asymmetric parallel mechanism. In: IFToMM WORLD CONGRESS, 13, 2011, Guanajuato. Proceedings... Guanajuato: UCEA, 2011 
- AlMeIDA, R. Z. H., HESS-COELHO, T. A., Structural synthesis, dynamic modeling and analysis of a 3-DOF asymmetric parallel mechanism, Journal of Mechanics Engineering and Automation, v. 1, pp. 481-490, 2011

- ALMEIDA, R. Z. H., HESS-COELHO, T. A., Dynamic model simplification of an asymmetric parallel robot for the development of real time control system. In: INTERNATIONAL SYMPOSIUM ON DYNAMIC PROBLEMS OF MECHANICS - DINAME, 15, 2013, Búzios. Proceedings... Rio de Janeiro: UFRJ, 2013 


\section{REVISÃO DA LITERATURA}

\subsection{ARQUITETURAS}

Minsk $^{1}$ (1972 apud $\mathrm{CHOI}$ et al., 2003) foi o primeiro pesquisador a propor a utilização de mecanismos paralelos em robôs manipuladores industriais. Em seu trabalho, enumerou as vantagens de arquiteturas paralelas frente às seriais e fez algumas sugestões de uso da arquitetura Gough-Stewart, que foi uma das primeiras arquiteturas paralelas concebidas (GOUGH, 1956; STEWART, 1965). Essa é do tipo 6UPS, ou seja, possui seis membros compostos por sequência de juntas universal, prismática e esférica. Normalmente as juntas prismáticas são ativas e as juntas universais são substituídas por juntas esféricas, sem modificação das características cinemáticas do efetuador. A Figura 2.1 ilustra uma aplicação dessa arquitetura como máquina de testes de pneus, em que o mecanismo paralelo era controlado de forma a simular cargas de aterrissagem de aeronaves (GOUGH, 1956). A principal característica dessa arquitetura reside na sua alta rigidez e capacidade de movimentação do efetuador com seis graus de liberdade. Outros autores como Davliakos e Papadopoulos (2008) e Zubizarreta et al. (2011, 2013) também se dedicaram a aplicar a arquitetura Gough-Stewart em tarefas de manipulação.

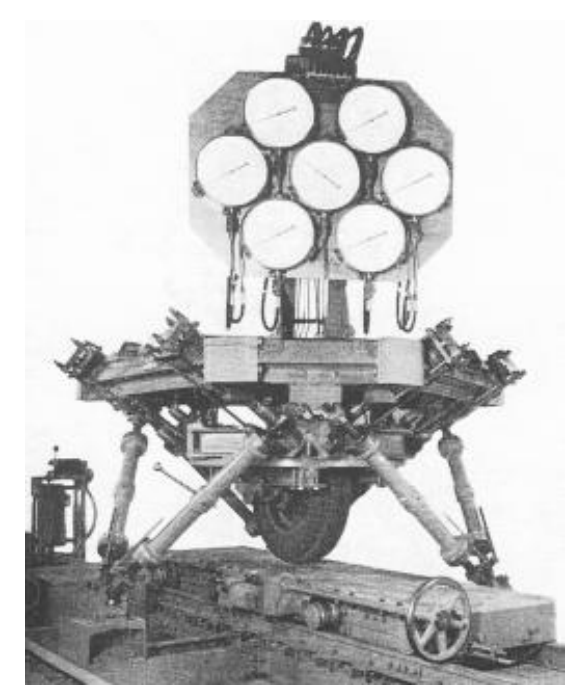

Figura 2.1 - Arquitetura Gough-Stewart como máquina de ensaios de pneus (GOUGH, 1956)

\footnotetext{
${ }^{1}$ MINSKY, M., Manipulator Design Vignettes, MIT AI Memo, n. 267, MTI AI Labo, 1972
} 
Uma das mais bem sucedidas arquiteturas robóticas concebidas especificamente para a tarefa de manipulação do tipo pega-e-põe foi a arquitetura DELTA proposta por Clavel (1988). Nesta arquitetura existem três membros que conectam a base fixa ao efetuador e são compostos, cada um, por junta de rotação ativa, barra superior e subcadeia do tipo paralelogramo articulado com juntas esféricas. Uma ilustração da arquitetura DELTA pode ser observada na figura 2.2a.

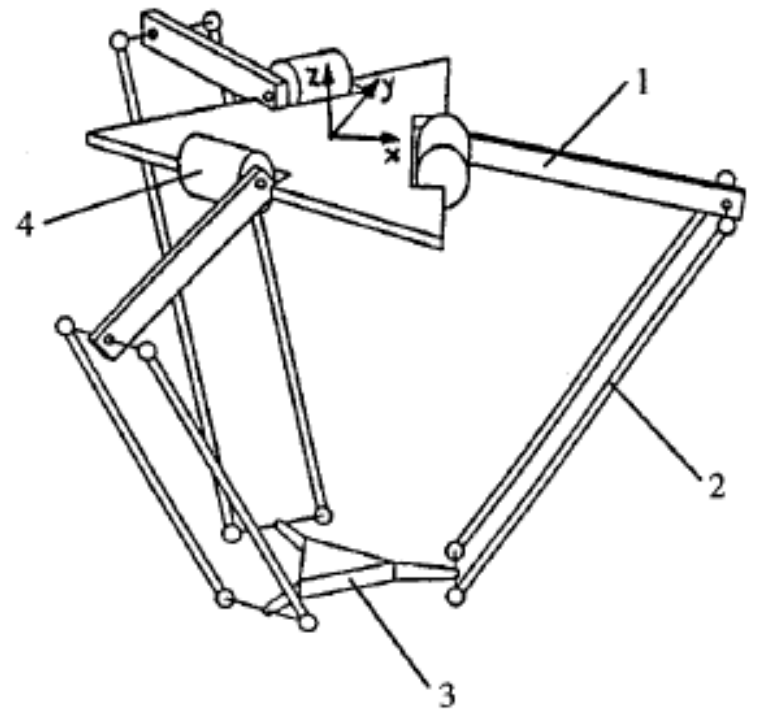

(a)

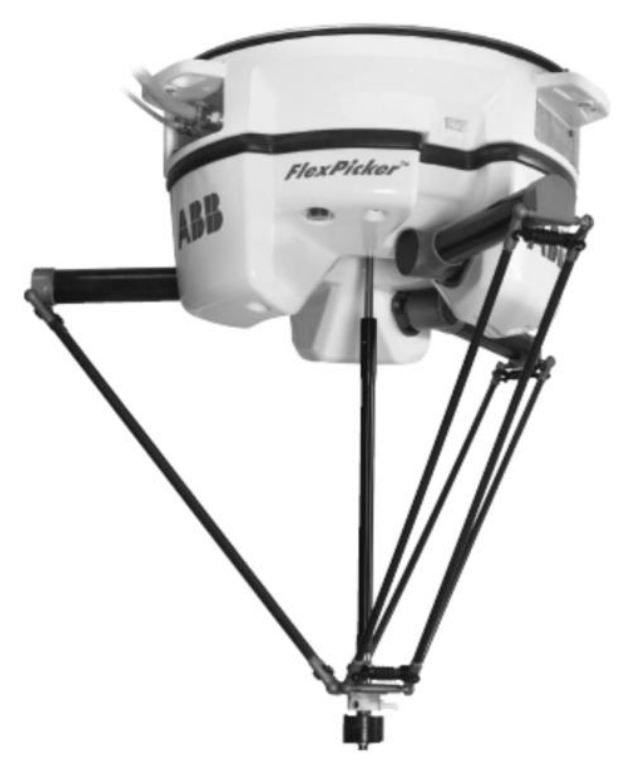

(b)

Figura 2.2 - Arquitetura DELTA (CLAVEL, 1988): (a) diagrama cinemático

(b) Manipulador comercial (ABB ROBOTICS, 2013)

Nessa arquitetura o efetuador fica restrito a três graus de liberdade, correspondentes a três translações no espaço, o que é interessante para aplicações do tipo pega-e-põe. O robô ABB IRB 360 Flexpicker da ABB (ver figura 2.2b) é um exemplo de produto comercial baseado na arquitetura DELTA. Além dos três movimentos de translação, é possível se obter ainda uma rotação em relação a um eixo vertical com a adição de mais um membro, central, composto por $\underline{R} U P U R$ (juntas de rotação, universal, prismática, universal e de rotação). Esta última junta, de rotação, deve conectar o efetuador da arquitetura DELTA de três graus de liberdade à extremidade do membro central adicionado, que passará a ser o novo efetuador, com quatro graus de liberdade, como mostra a figura 2.2b.

Outra arquitetura bastante eficiente foi concebida por Pierrot e Company (1999) e denominada H4. Foi desenvolvida ao longo dos anos (CHOI et al., 2003) 
até culminar na nova arquitetura Par4 (PIERROT et al., 2009). Esta é empregada no robô comercialmente disponível Adept Quattro da Adept Technology, que é considerado o robô de melhor desempenho disponível nos dias de hoje.

Em (PIERROT, COMPANY, 1999) é de fato apresentada uma família de arquiteturas com quatro graus de liberdade, três de translação e um de rotação. $O$ conceito básico foi estender as características da arquitetura delta com a adição de um quarto membro, idêntico aos outros três já existentes, e a adição de duas juntas de rotação na ligação dos membros ao efetuador, o que foi chamado de efetuador articulado (em oposição ao rígido existente na arquitetura delta), como mostra a figura 2.3. Além desta arquitetura, a família tem também como representante uma configuração na qual as juntas de rotação ativas são substituídas por juntas prismáticas ativas.

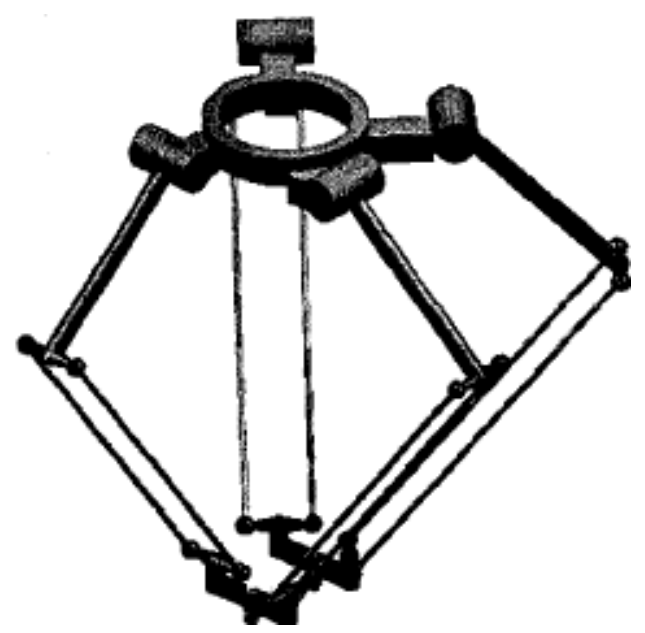

(a)

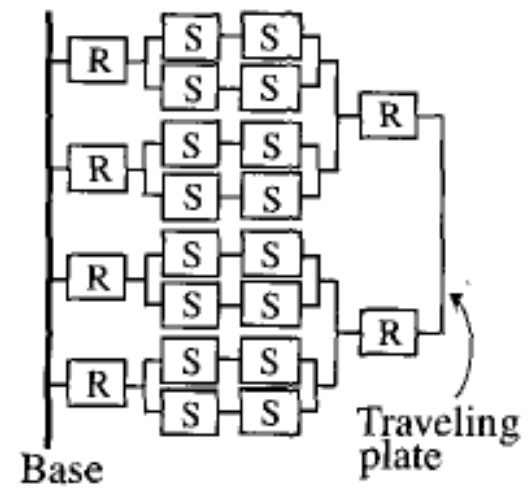

(b)

Figura 2.3 - Arquitetura H4 (PIERROT, COMPANY, 1999): (a) diagrama cinemático (b) representação em grafo

A principal diferença entre o $\mathrm{H} 4$ originalmente concebido e a nova arquitetura Par4 reside na reformulação do efetuador articulado, sendo que este foi substituído por um quadrilátero articulado. A figura 2.4 mostra vistas em perspectiva e superior do robô Adept Quattro.

Dentre outras arquiteturas propostas para robôs pega-e-põe, de três graus de liberdade de translação, encontram-se a $3 U \underline{P U}$ (juntas universal, prismática e universal) (TSAI, 1999), a 3PRC (juntas prismática, de rotação e cilíndrica) (LI, XU, 2009) apresentada na figura 2.5, a arquitetura Star (STAICU, 2009) que é composta por três quadriláteros articulados com juntas esféricas e é apresentada na figura 2.6, 
a 3RCC (CALLEGARI et al., 2006) apresentada na figura 2.7, e a 3ㄹRRR concebida por Kim e Tsai (2002) e apresentada na figura 2.8.

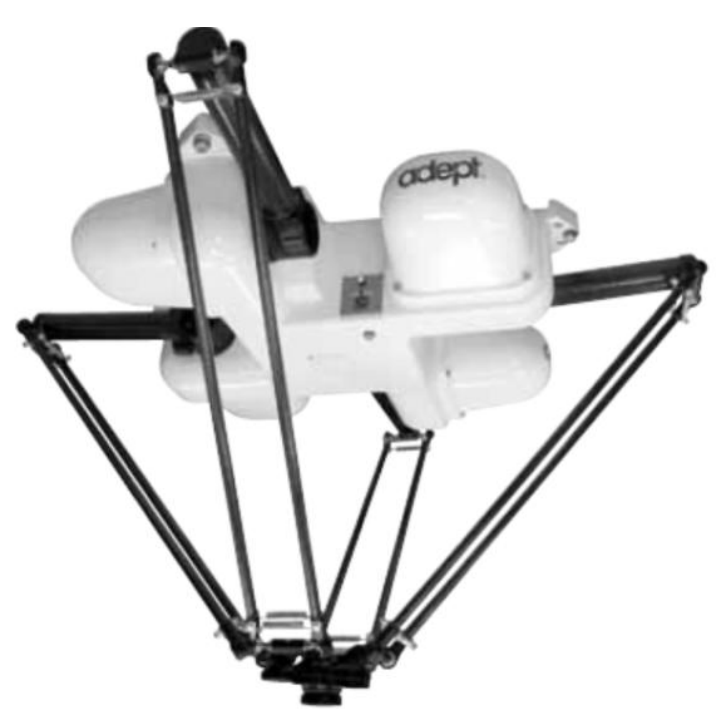

(a)

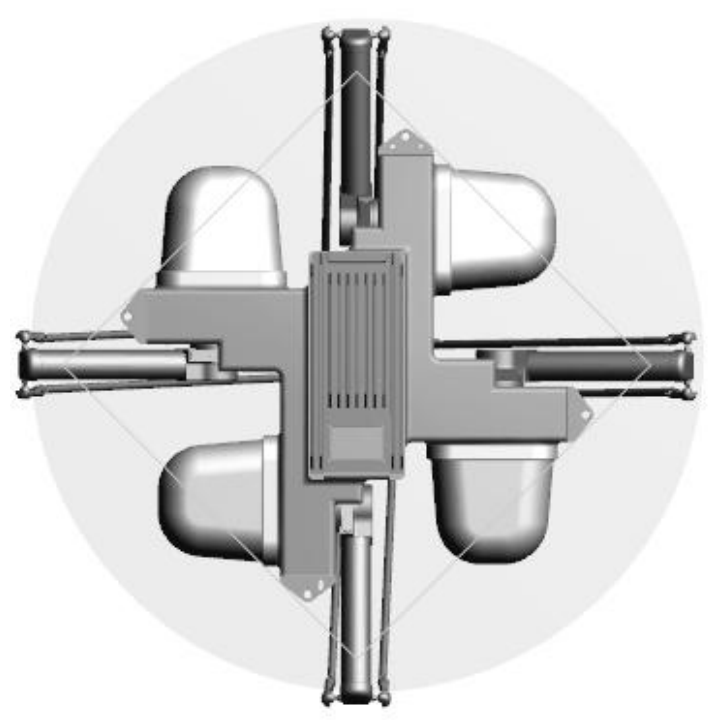

(b)

Figura 2.4 - Arquitetura Par4 (PIERROT et al., 2009): (a) vista em perspectiva (b) vista superior

Tanto a arquitetura proposta por $\mathrm{Li}$ e Xu (2009) como a por Callegari et al. (2006) dependem do alinhamento dos eixos de rotação de juntas específicas para que $O$ efetuador tenha translação pura. Já a peculiar arquitetura apresentada em (KIM, TSAI, 2002) possui modelagem menos complexa devido ao completo desacoplamento das equações cinemáticas do mecanismo. Entretanto, este possui vínculos em excesso e seu movimento é dependente de condições muito especiais de alinhamento de eixos das juntas. Isso demanda tolerâncias dimensionais e geométricas bastante restritas o que causa aumento de seus custos de fabricação e comprometimento de desempenho desses robôs.

Outras arquiteturas, como a 3RPS (juntas de rotação, prismática e esférica) estudada em (SOKOLOV, XIROUCHAKIS, 2007), possuem três graus de liberdade, porém, correspondem a uma translação e duas rotações do efetuador. Suas aplicações, assim como de mecanismos paralelos esféricos, não são de interesse neste estudo. 


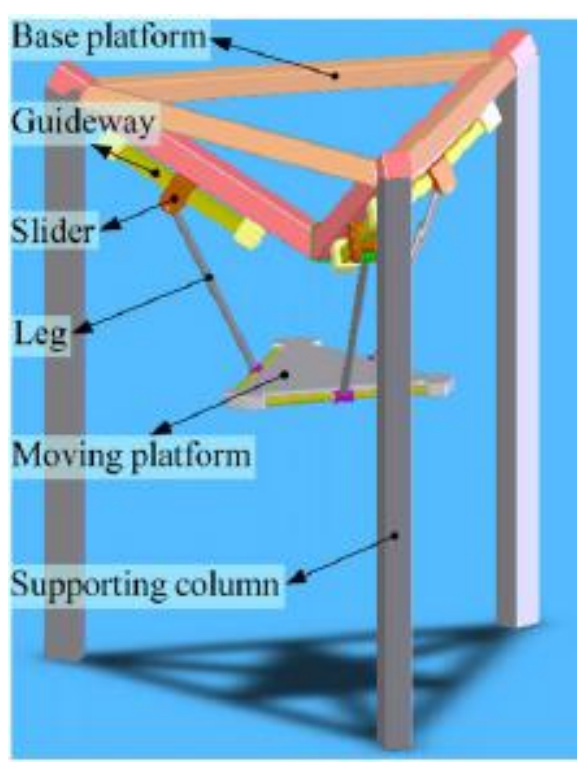

Figura 2.5 - Arquitetura 3ㄹRC (LI, XU, 2009)

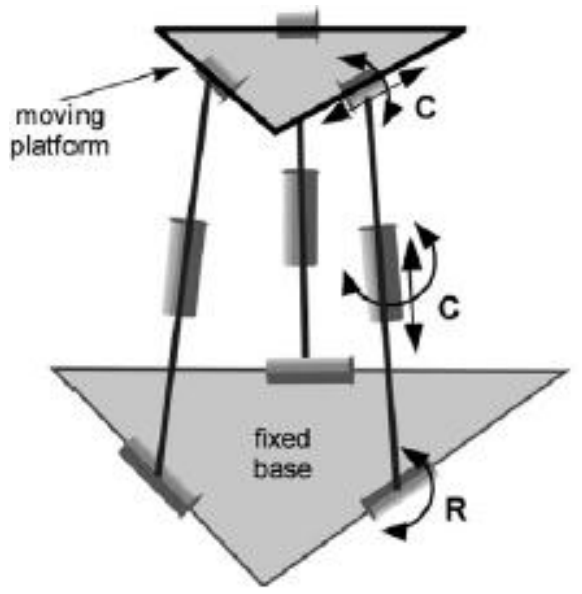

Figura 2.7 - Arquitetura 3ㄷC (CALLEGARI et al. 2006)

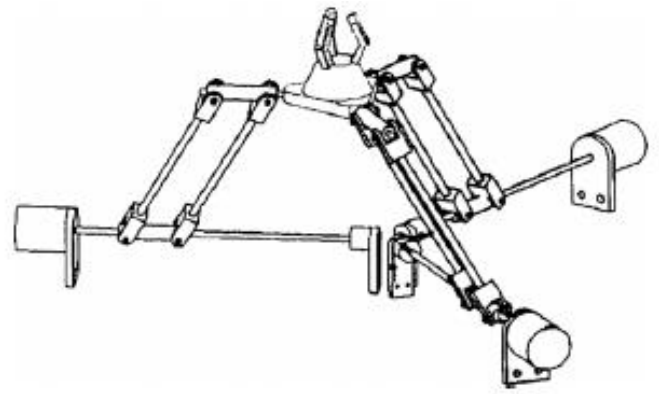

Figura 2.6 - Arquitetura Star (STAICU, 2009)

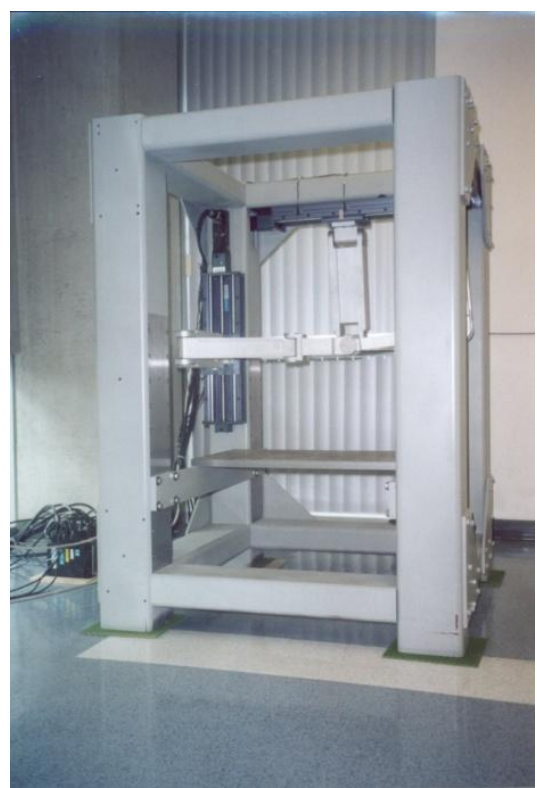

Figura 2.8 - Arquitetura 3ㄹRR (KIM, TSAI, 2002)

Nota-se que todas as arquiteturas apresentadas anteriormente simétricas, ou seja, todos os membros têm a mesma sequência de juntas e possuem uma única junta ativa, e a quantidade de membros e de graus de liberdade do efetuador são iguais (Mohamed, Duffy, 1985). Existem poucos trabalhos que lidam com arquiteturas assimétricas. A arquitetura Quadrupteron, por exemplo, proposta por 
Kong e Gosselin (2011) se trata de uma exceção em que é obtido robô de 4 graus de liberdade utilizando-se mecanismo assimétrico $1-\underline{C} R R+3 \underline{C} R R R$, como mostra a figura 2.9. Isto é consequência da preferência dos pesquisadores pela busca de arquiteturas que tenham comportamento o mais isotrópico possível, apesar de que ainda não haja um consenso sobre a métrica mais adequada para sua determinação (HUNT, 2003). Entretanto, como já comentado anteriormente, as aplicações de pega-e-põe normalmente possuem requisitos de velocidade e rigidez diferentes para cada uma das direções. Assim, isso é um fator motivador para o desenvolvimento do presente do trabalho, que trata de um robô manipulador com cadeia cinemática paralela assimétrica.

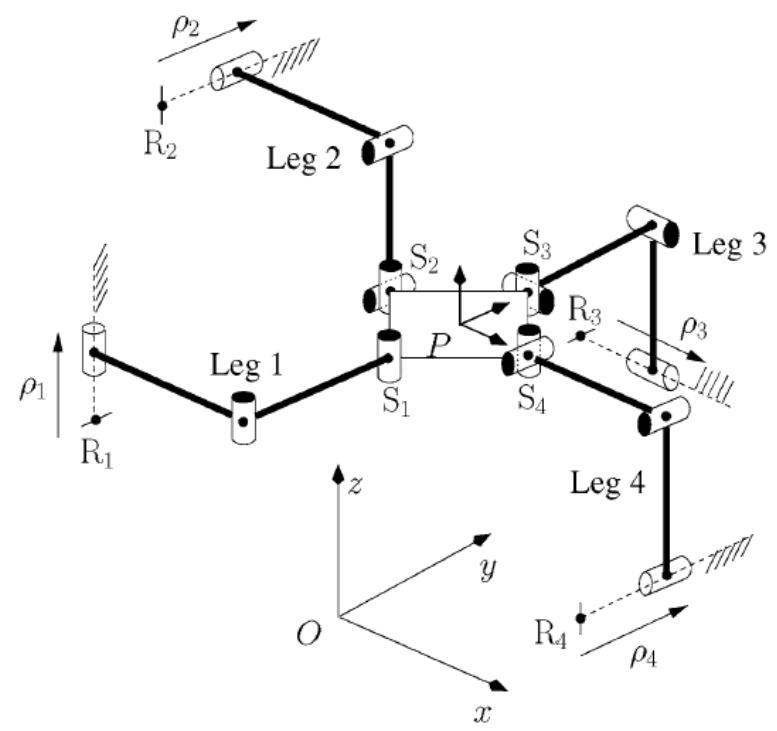

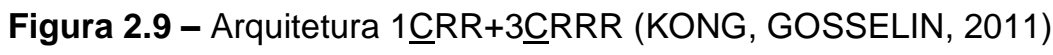

\subsection{MODELAGEM CINEMÁTICA}

Conforme a arquitetura do robô, as juntas que compõem seu mecanismo criam vínculos cinemáticos que restringem a movimentação de seu efetuador. Assim, podem ser utilizados variados conjuntos de coordenadas para descrever a posição e orientação do efetuador, sendo mais comum a utilização do conjunto de coordenadas correspondentes aos atuadores ou do conjunto de coordenadas correspondentes ao próprio efetuador em seu espaço de trabalho. Neste último caso, podem ser utilizadas coordenadas retangulares, cilíndricas ou esféricas, conforme a aplicação. 
A partir de equações de vínculos cinemáticos, podem-se isolar as coordenadas dos atuadores de forma a ser possível calcular seus valores em função das coordenadas do efetuador. O conjunto de equações escritas nessa forma (e suas derivadas) é denominado cinemática inversa do mecanismo (SICILIANO et al., 2009; TSAI, 1999). Caso se faça o isolamento das coordenadas do efetuador, serão encontradas as equações correspondentes ao que é denominado cinemática direta do mecanismo (SICILIANO et al., 2009; TSAI, 1999).

Apesar de existirem técnicas consagradas para a modelagem cinemática de mecanismos seriais, como o método das transformações homogêneas e a notação de Denavit-Hartenberg, essas técnicas geralmente não são adequadas para robôs paralelos e métodos específicos de modelagem são mais eficientes (KHALIL, DOMBRE, 2002; TSAI, 1999). Tsai (1999) cita como alternativas o método geométrico, em que se busca relacionar as características cinemáticas de forma mais intuitiva, e a teoria das helicoides, que foi aplicada, por exemplo, em (GALLARDO-ALVARADO et al., 2008) na modelagem de um manipulador de arquitetura híbrida paralelo-serial do tipo 2(3-RPS).

Outra particularidade de mecanismos de arquitetura paralela reside na maior dificuldade do desenvolvimento de suas equações de cinemática direta que de cinemática inversa (KHALIL, DOMBRE, 2002; TSAI, 1999). Muitas vezes, recorre-se a métodos numéricos para o cálculo da cinemática direta, ao invés de se fazer o desenvolvimento analítico, como, por exemplo, executado em (CHOI, 2010). Guenther et al (2012) tratam ainda dos problemas de integração numérica de equações cinemáticas, neste caso de cinemática inversa, de mecanismos paralelos.

Quando o desenvolvimento analítico é possível, é necessário ainda identificar quais das possíveis soluções matemáticas correspondem fisicamente ao robô (o que também deve ser realizado no desenvolvimento da cinemática inversa). A cinemática direta da plataforma de Stewart-Gough, por exemplo, apresenta 40 possíveis soluções (HUSTY, 1996).

Além de servirem de base para a modelagem dinâmica de mecanismos, e serem úteis para o desenvolvimento de leis de controle, incluindo a geração de trajetórias para o efetuador, as equações cinemáticas também podem ser empregadas na avaliação do espaço de trabalho do robô e na identificação de posições singulares através da análise de matrizes jacobianas que relacionam a 
derivada primeira das coordenadas dos atuadores com a derivada primeira das coordenadas do efetuador (TSAl, 1999). Detalhes sobre esse tipo de análise são apresentados na seção 3.5 .

\subsection{MODELAGEM DINÂMICA}

Para que se possam fazer simulações e desenvolver leis de controle para robôs manipuladores, é necessário encontrar modelos que sejam representativos de seus comportamentos dinâmicos. Além de servir de base para o projeto de controladores, os modelos dinâmicos também se mostram úteis no dimensionamento de peças e de juntas do mecanismo, e dos atuadores do robô. Apesar da modelagem e controle de manipuladores de arquitetura serial já se encontrar num estágio de desenvolvimento maduro, a modelagem dinâmica de manipuladores de arquitetura paralela não está bem desenvolvida (LI, XU, 2009).

Observando trabalhos da literatura, foi constatado que os pontos principais relacionados à modelagem dinâmica de mecanismos de arquitetura paralela são:

- Tipo de abordagem (Newton-Euler, Método de Lagrange, Princípio dos Trabalhos Virtuais) tendo em vista o grande número de vínculos e 0 acoplamento das equações cinemáticas geralmente encontrado em mecanismos paralelos;

- Hipóteses simplificadoras sobre inércias, ação da gravidade, atritos, folgas;

- Simplificação de modelo para aplicação em leis de controle em tempo real.

Nota-se que, além do desenvolvimento de equações correspondentes à dinâmica do robô, há preocupação em se obter modelos representativos, porém adequados para servirem de base para o desenvolvimento de leis de controle que possam ser executadas em tempo real em computadores industriais. Dessa forma, o modelo não pode ser demasiadamente complexo. Por isso, a definição de hipóteses simplificadoras é de extrema importância, pois está diretamente relacionada ao custo computacional necessário para execução do controle (LI, XU, 2009; WANG et al., 2007). Enquanto as hipóteses simplificadoras são adotadas antes do equacionamento, é possível ainda simplificar posteriormente o modelo, principalmente com a seleção de seus termos predominantes (WANG et al. , 2007). Wang et al. (2007) listam como outros meios de se aumentar a eficiência de 
execução de cálculo das equações dinâmicas a simplificação de equações por manipulação algébrica (por exemplo, fatoração) e a utilização de algoritmos paralelos.

\subsubsection{Abordagens de modelagem}

Alguns trabalhos aqui selecionados podem ser classificados da seguinte maneira, conforme a abordagem de modelagem adotada:

- Formulação de Newton-Euler: (WANG et al., 2007), (SHIAU, TSAI, 2007), (DASGUPTA, B., CHOUDHURY, 1999);

- Princípio dos Trabalhos Virtuais: (LI, XU, 2009), (STAICU, 2009), (GALLARDO-ALVARADO et al., 2008), (SOKOLOV, XIROUCHAKIS, 2007), (CALLEGARI, PALPACELLI, PRINCIPI, 2006), (ZHU et al., 2005), (GEIKE, MCPHEE, 2003);

- Método de Lagrange: (STAICU, 2009), (YEN, LAI, 2009), (AHMADI et al., 2008), (REN, MILLS, SUN, 2006);

- Método de Kane: (YANG et al., 2010), (GILLESPIE, 2003);

Observa-se uma forte tendência ao uso do Princípio dos Trabalhos Virtuais devido a sua característica de gerar equações matemáticas mais sintéticas que as outras abordagens, principalmente quando comparado com a de Newton-Euler (TSAI, 1999; SOKOLOV, XIRUOUCHAKIS, 2009; STAICU, 2009). Staicu (2009) empregou tanto o Princípio dos Trabalhos Virtuais quanto o Método de Lagrange e concluiu que o primeiro é mais eficiente.

Nota-se que o trabalho de Wang et al. (2007) utiliza a abordagem de NewtonEuler sobre a plataforma de Stewart-Gough, mas foi exigida certa manipulação algébrica para se chegar às equações dinâmicas de maneira reduzida.

\subsubsection{Hipóteses simplificadoras}

Normalmente é ponderada a relevância dos seguintes fenômenos para modelagem de mecanismos robóticos:

- Rigidez das peças (corpos rígidos ou flexíveis);

- Inércia das peças (massas concentradas ou distribuídas ou inexistentes); 
- Atrito das juntas (existência ou não)

- Folga das juntas (existência ou não);

- Rigidez das juntas (juntas rígidas ou flexíveis);

- Ação da gravidade (desprezar ou não ação da gravidade sobre membros);

- Dinâmica dos atuadores (existência ou não);

As inércias das peças dos membros do mecanismo podem ser incluídas no modelo de diversas formas. Em alguns trabalhos como (CHEMORI, SARTORINATAL, PIERROT, 2013; CHOI et al. 2003; CODOUREY, 1996; LI, XU, 2009), as massas de parte das barras dos mecanismos de seus robôs foram modeladas como concentradas em suas extremidades. Enquanto Choi et al. (2003) apenas divide as massas em duas porções iguais, Codourey (1996) considerou 2/3 da massa na parte superior da barra e 1/3 da massa na parte inferior da barra (que estava conectada ao efetuador). Essa escolha foi justificada pelo fato do momento de inércia de uma barra em relação a sua extremidade ser igual a:

$$
I=\frac{1}{3} m L^{2}
$$

em que $m$ é a massa da barra e $L$ seu comprimento.

Já Li e Xu (2009) concentraram a massa das barras conforme um valor ótimo de um parâmetro $w$ que representa a distância da posição da massa concentrada em relação às extremidades das barras (posições das articulações). É importante notar que a posição da massa concentrada que melhor representou uma barra de massa distribuída não foi coincidente com o centro de massa desta barra. No trabalho de Li e Xu (2009), por exemplo, o parâmetro $w$ ótimo foi de 0,58. Ressaltase que tal otimização foi baseada em simulações numéricas de movimentação do mecanismo. Portando é dependente do tipo de movimento imposto ao efetuador. Mesmo com o modelo de massas concentradas foram obtidos erros de apenas 1,25\% para o cálculo de torques de entrada necessários para trajetória pré-definida, quando comparado ao cálculo obtido com modelo de massa distribuída implementado no software Adams.

Em (STAICU, 2009; GALLARDO-ALVARADO et al., 2008; SOKOLOV, XIROUCHAKIS, 2007; CALLEGARI et al., 2006) foram desenvolvidos modelos de massas distribuídas. Porém Callegari et al. (2006) constatou que, para a sua 
arquitetura, os elementos fora da diagonal principal de matrizes de inércia baseadas no referencial fixo são em geral desprezíveis ou podem ser considerados constantes. Portanto apenas os termos da diagonal principal devem ser calculados a cada instante. Já Staicu (2009) desprezou a inércia das barras para a rotação em torno de seus próprios eixos.

Em relação à rigidez, normalmente as peças são consideradas perfeitamente rígidas. No entanto, existem trabalhos em que são consideradas como corpos flexíveis. Em (DA SILVA, 2009), por exemplo, são utilizadas, em sequência, técnicas de modelagem de barras flexíveis com elementos finitos e de redução de ordem do modelo em função da identificação de modos de vibração predominantes.

Sobre imperfeições de juntas, poucos trabalhos consideram efeitos de elasticidade e atrito, e mais rara ainda é a inclusão de efeitos de folgas. Nos trabalhos que incluem elasticidade e atrito, estes normalmente estão relacionados às juntas ativas do mecanismo como em (IDER, KORKMAZ, 2009; WANG et al., 2009). Em (SHIAU et al., 2007) foram incluídos flexibilidade, atrito e folga em todas as juntas. A flexibilidade foi modelada com inclusão de molas, as folgas de acordo com o contato de duas superfícies esféricas e o atrito como força viscosa, função do contato e da velocidade relativa entre peças. Nota-se que a flexibilidade e as folgas das juntas se refletem em grande aumento do número de graus de liberdade do mecanismo e, consequentemente, do número de coordenadas necessárias e da complexidade de equacionamento. Uma das principais conclusões a que Shiau et al. (2007) chegaram é que a frequência de ressonância estimada pelo modelo completo, com flexibilidade e folga de juntas, é menor que a estimada pelo modelo de juntas ideais, o que limita a largura de banda de controle do mecanismo.

A dinâmica dos atuadores normalmente é incluída, mas às vezes é bastante simplificada por termos proporcionais e/ou atrasos, como pode ser visto em (CHOI, 2003; CODOUREY, 1996). Entretanto, ressalta-se que Callegari et al. (2006) afirmam que os componentes de atuadores e de transmissões podem acumular até $30 \%$ da energia cinética do mecanismo. 


\subsubsection{Simplificação pós-modelagem}

Conforme apontado anteriormente, é possível se fazer simplificações do modelo após seu equacionamento. O trabalho de Wang et al. (2007) mostra que pode-se reduzir de $30 \%$ a $70 \%$ os cálculos para determinar os esforços necessários nos atuadores às custas de obtenção de erros de apenas $2 \%$. Em seu trabalho é mostrado que na expressão de cálculo de esforços dos atuadores para a arquitetura estudada havia inicialmente 18 termos, mas que poderia ser simplificada conforme o estágio de movimento (velocidade constante ou aceleração/desaceleração) e a intensidade das velocidades envolvidas (baixa, média e alta). Com isso foram obtidos seis diferentes submodelos. Três voltados para estágio de velocidade constante passaram a ter apenas 3, 7 e 9 termos, conforme a condição de intensidade de velocidade (baixa, média e alta, respectivamente). Os outros três, relacionados a estágios de aceleração/desaceleração, passaram a ter 7,11 e 13 termos. De forma resumida pode-se dizer que os termos relativos à ação da gravidade são predominantes para baixas velocidades e os termos relativos às inércias das peças passam a ser relevantes conforme se aumentam as velocidades e acelerações.

\subsection{CONTROLE}

As técnicas de controle permitem que o robô execute as atividades para as quais foi concebido, seja manipulação de objetos, seja a aplicação de esforços sobre o meio em que está inserido. Para o caso específico do presente trabalho, foi mantido o foco em técnicas de controle de posição para acompanhamento de trajetórias.

Devido à não linearidade e ao acoplamento entre variáveis do modelo dinâmico, e aos requisitos de alto desempenho de robôs paralelos, é necessário, em geral, o desenvolvimento de leis de controle não lineares, centralizadas e que sejam baseadas no modelo dinâmico do robô (WANG et al., 2009; ZUBIZARRETA et al., 2008).

As leis de controle observadas na literatura se diferenciam por:

- Tipo de variáveis controladas (coordenadas dos atuadores ou do efetuador);

- Dependência entre variáveis controladas (controle descentralizado ou centralizado); 
- Estratégia de controle empregada (PID, torque computado, preditivo, modos deslizantes, etc).

\subsubsection{Variáveis monitoradas e variáveis controladas}

A posição e a orientação de um robô podem ser descritas por variados conjuntos de coordenadas sendo os mais comuns o conjunto de coordenadas dos atuadores e o conjunto de coordenadas do efetuador. Da mesma forma, o controle do robô pode ser feito sobre as coordenadas dos atuadores, também denominado espaço das juntas (joint mode), ou sobre as coordenadas do efetuador, também denominado espaço de tarefas (task mode).

$\mathrm{Na}$ implementação do controle, é possível ainda inserir sensores no mecanismo do robô de forma independente do conjunto de coordenadas em que são calculados os esforços de controle. Pode-se, por exemplo:

- Medir coordenadas dos atuadores e calcular esforços de controle sobre esse mesmo conjunto de coordenadas;

- Medir coordenadas dos atuadores, mas calcular esforços de controle sobre as coordenadas do efetuador;

- Medir coordenadas do efetuador e calcular esforços de controle sobre esse mesmo conjunto de coordenadas.

A primeira opção, ilustrada na figura 2.10, é mais tradicional, e tem a vantagem da facilidade com que são feitas as medições das coordenadas dos atuadores. Nota-se que, como normalmente a geração de trajetórias é feita no espaço de tarefas e é necessário utilizar as equações de cinemática inversa para converter a trajetória para o espaço dos atuadores.

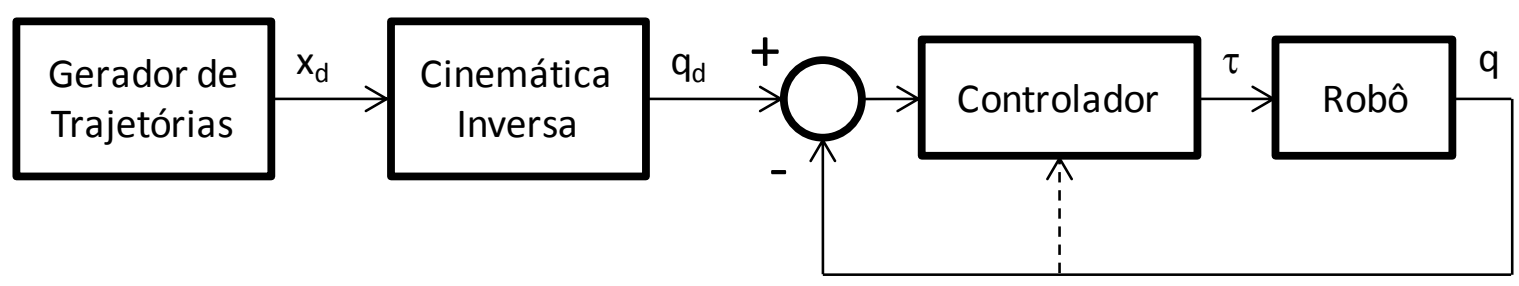

Figura 2.10 - Controle sobre coordenadas dos atuadores, medição dessas mesmas coordenadas 
Mantendo-se a medição sobre as coordenadas dos atuadores, mas executando-se o controle sobre as coordenadas do efetuador, consegue-se definir ganhos de controle de maneira mais intuitiva, pois estão relacionados diretamente com os requisitos de movimentação do efetuador. Mas é necessário utilizar equações de cinemática direta dentro do laço de controle do robô, como mostra a figura 2.11.

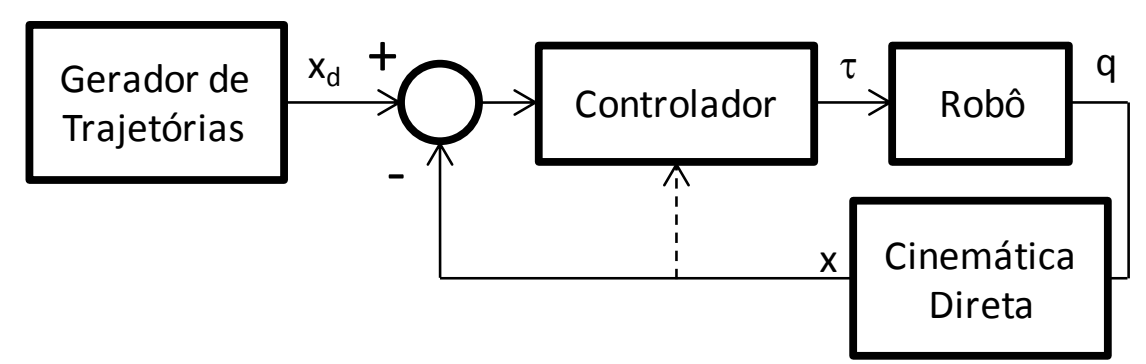

Figura 2.11 - Controle sobre coordenadas do efetuador, medição de coordenadas dos atuadores

Para que não haja a necessidade de cálculo da cinemática direta dentro do laço de controle, pode-se partir para a terceira opção, em que tanto o controle como as medições são realizadas sobre as coordenadas do efetuador, como ilustra a figura 2.12.

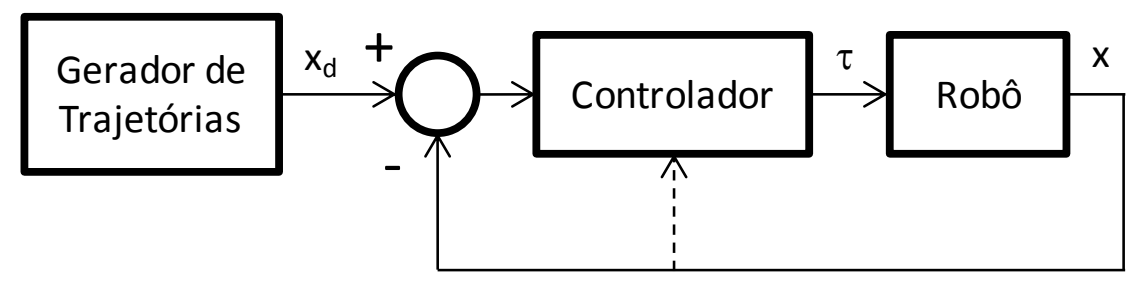

Figura 2.12 - Controle sobre coordenadas do efetuador, medição dessas mesmas coordenadas

Segundo Paccot, Andreff e Martinet (2009), o controle com medição e cálculo de esforços de controle no espaço das coordenadas do efetuador é mais acurado, pois evita a propagação dos erros de modelagem pelo mecanismo do robô desde os atuadores, posicionados na extremidade dos membros conectados à base fixa, até 0 efetuador, localizado nas extremidades opostas dos membros. Essa característica é menos sensível em robôs seriais, pois os atuadores estão dispostos ao longo do mecanismo robótico. 
Por outro lado, a medição das coordenadas do efetuador é mais difícil e muitas vezes inviável (tanto para robôs paralelos como para robôs seriais) (PACCOT, ANDREFF, MARINET, 2009).

Em oposição ao afirmado por Paccot, Andreff e Martinet (2009), os resultados de controle no espaço dos atuadores foram mais acurados que do espaço do efetuador em (ZUBIZARRETA et al., 2013). Entretanto, nesse trabalho são utilizadas coordenadas redundantes na lei de controle e não há correspondência direta ao que é tradicionalmente denominado espaços das juntas e do efetuador.

Já Li e Xu (2009), em especial, desenvolveram controle nas coordenadas do efetuador porque a modelagem assim desenvolvida resultou em equações dinâmicas mais compactas.

\subsubsection{Dependência entre variáveis controladas}

Em relação à dependência entre variáveis controladas nota-se que para grande parte dos robôs seriais pode-se realizar o controle de forma independente, ou desacoplada, pois as altas taxas de redução empregadas nas transmissões mecânicas desses robôs tornam os efeitos dinâmicos de seu movimento sobre cada atuador aproximadamente desacoplados (SICILIANO et al., 2009; CRAIG, 2005).

Porém, o acoplamento dinâmico existente entre variáveis controladas em robôs de arquitetura paralela requer o emprego de leis de controle centralizado, ou seja, cada entrada de controle pode ser função de quaisquer variáveis a serem controladas (WANG et al., 2009; ZUBIZARRETA et al., 2008).

Codourey (1996), em especial, implementou com sucesso leis de controle descentralizadas em um robô de arquitetura paralela utilizando uma matriz de correção de inércia do tipo:

$$
A=I_{b}+J^{T} M_{n} J
$$

em que $I_{b}$ é o momento de inércia da barra conectada diretamente ao eixo do motor, $M_{n}$ é a matriz de inércia, diagonal e constante, do efetuador e $J$ é a matriz jacobiana que relaciona as velocidades das coordenadas do espaço do efetuador com as coordenadas dos atuadores. 


\subsubsection{Estratégias de controle}

As principais estratégias aplicadas ao controle de robôs de arquitetura paralela identificadas na literatura foram:

- Controle por torque computado;

- Controle por torque computado feedforward;

- Controle por troque computado estendido;

- Controle por modos deslizantes;

- Controle preditivo;

- Controle por passividade.

O controle de robôs para alto desempenho é normalmente dividido em uma parte não linear, baseada no modelo dinâmico do manipulador, e uma parte de compensação de incertezas de modelagem (WANG et al., 2009; ZUBIZARRETA et al., 2013).

A parte baseada em modelo é geralmente desenvolvida segundo o método de torque computado (ZUBIZARRETA et al., 2013). Neste método adota-se uma entrada de controle que elimine as não linearidades do modelo dinâmico e que tenha um parâmetro que passará a ser a nova entrada de controle de um sistema dinâmico linear equivalente (SICILIANO et al., 2009; CRAIG, 2005; SLOTINE, LI, 1991).

Ressalva-se que a nomenclatura controle por torque computado não é única para se referir a esta abordagem. É utilizado torque computado (ou computedtorque) por Craig (2005) e Jazar (2010), entre outros. Porém, Siciliano et al. (2009) e Spong, Hutchinson e Vidyasagar (2005) o denominam Inverse Dynamics Control. Já Slotine e Li (1991) o chamam de Feedback Linearization na forma canônica (caso particular da técnica de Feedback Linearization).

Além de eliminar as não linearidades do modelo dinâmico, o método de torque computado é bastante interessante, pois se demonstra matematicamente que é possível definir leis de controle para as novas entradas do sistema linearizado de forma a se obter acompanhamento de trajetória segundo uma resposta dinâmica estável, mesmo na presença de incertezas de modelagem. Contudo, essas incertezas devem ser limitadas (SLOTINE, 1991; CRAIG, 2005). 
Dentre alguns trabalhos aplicados ao controle de manipuladores paralelos que empregam o controle por torque computado se encontram (LI, XU, 2009), com a arquitetura 3PRC, (CALLEGARI et al., 2006) com a arquitetura 3RCC, (DAVILIAKOS, PAPDOPOULOS, 2008), com arquitetura Stewart-Gough, e (YEN, LAI, 2009), com arquitetura similar a de Kim e Tsai (2002).

Em alguns trabalhos como (CALLEGARI et al., 2006; YEN, LAI, 2009; DAVILIAKOS, PAPADOPOULOS, 2008) a parte de compensação de incertezas foi implementada com sucesso utilizando-se controlador proporcional-derivativo (PD). No trabalho de Li e Xu (2009) também foi utilizado o PD, mas foram obtidos bons resultados apenas quando técnicas de controle robusto foram associadas ao controle por torque computado. Entretanto, acredita-se que estes resultados foram consequência das condições de simulação muito severas, nas quais foram induzidos desvios de $20 \%$ nos parâmetros de modelagem. No trabalho de Callegari et al. (2006), o PD associado ao torque computado foi eficiente mesmo com desvios induzidos de $10 \%$ a $5 \%$ dos parâmetros do modelo.

Aprimorando-se o controlador PD com a adição do termo integrativo, o controlador se torna capaz de rejeitar distúrbios (CRAIG, 2005). Já a variação do controlador PD denominada PD não linear possui ganhos proporcional e derivativo variáveis no tempo, dependentes das variáveis de estado do sistema dinâmico. Com isso melhora-se o desempenho do controlador (SHANG, CONG, 2009).

Numa variação da técnica de torque computado, o termo que corresponderia à compensação de não linearidades do modelo dinâmico do robô é adicionado diretamente, fora do laço de controle, numa abordagem feedforward, que é aqui denominada por torque computado feedforward. Apesar de alguns autores utilizarem essa nomenclatura (SICILIANO et al., 2009; SPONG, HUTCHINSON, VIDYASAGAR, 2005), alguns autores não a identificam com um nome específico e Khalil e Dombre (2002) a denominam Predictive Dynamic Control. Alguns trabalhos que partiram passa essa abordagem foram (WANG et al., 2009), para arquitetura Stewart-Gough, (CHOl et al., 2003) para arquitetura H4 e (CODOUREY, 1996) para a arquitetura delta. Note que, por estar fora do laço de controle, a parte feedforward do controlador pode ser calculada off-line, ou seja, antes da movimentação do robô (CRAIG, 2005). Dessa forma, é possível utilizar taxas de amostragem elevadas durante a execução do movimento. 
Em outra variação, simplificada, do controle por torque computado, a parte da lei de controle baseada em modelo pode fazer apenas a compensação de efeitos gravitacionais (SICILIANO et al., 2009; CRAIG, 2005). Esta abordagem é utilizada em (YANG et al., 2010) para controlar um mecanismo da arquitetura Stewart-Gough acionado por pistões hidráulicos. Entretanto, fica-se restrito a movimentos de baixo desempenho, pois os erros de modelagem sob altas velocidade e acelerações podem levar à instabilidade do sistema controlado.

Segundo Zubizarreta et al. (2013), as técnicas usuais de identificação dinâmica aplicadas a mecanismos paralelos não oferecem resultados de mesma qualidade que os obtidos para mecanismos seriais. Assim, mesmo utilizando modelos mais elaborados para o desenvolvimento de leis de controle por torque computado, os erros de modelagem podem resultar em instabilidade do sistema. Como alternativa, eles propõem uma ampliação da técnica de torque computado em que são inseridos sensores em juntas passivas e realizado o controle sobre variáveis redundantes para mitigar o efeito dos erros de modelagem. Tal técnica, primeiramente apresentada em (ZUBIZARRETA et al., 2008), é denominada controle por torque computado estendido. Foi empregada para o controle de mecanismo do tipo pentágono articulado (ZUBIZARRETA et al., 2008), plataforma Stewart-Gough (ZUBIZARRETA et al., 2011; 2013), e mecanismo plano do tipo 3ㅁRR (ZUBIZARRETA et al., 2012). Em geral, os resultados são melhores com a adição de sensores nas juntas passivas. Porém, foi constatado que, em alguns casos, não há ganho com a adição desse sensores ao robô.

Alternativamente, pode-se utilizar controle adaptativo e controle de modos deslizantes (SICILIANO et al., 2009; CRAIG, 2005).

No controle adaptativo alguns parâmetros do modelo são estimados durante a movimentação do robô, de forma a se minimizar os erros de modelagem (SLOTINE, LI, 1991). Entretanto, apesar de ter sido aplicada com sucesso no controle de robôs manipuladores seriais (WANG, XIE, 2009) essa técnica não é aconselhada para manipuladores de alto desempenho devido seu alto custo computacional (WANG et al., 2009).

O controle por modos deslizantes se baseia na definição de uma superfície de deslizamento, função do erro de acompanhamento de trajetória, seguindo condições matemáticas específicas e de uma correspondente lei de controle que garantem 
que, para qualquer condição inicial, o erro de controle atinge a superfície de deslizamento em um tempo finito e tende a zero de maneira exponencial após atingida a superfície de controle. Nota-se que controle de modos deslizantes necessita de um termo descontínuo para compensar incertezas de modelagem, o que resulta em chattering (oscilação de alta frequência em torno da trajetória requerida) (SLOTINE, LI, 1991). O chattering pode ser suavizado com a definição de uma camada limite, em torno da superfície de deslizamento, dentro da qual o termo descontínuo não é utilizado. Entretanto, isso pode comprometer o desempenho para o acompanhamento de trajetória (SLOTINE, LI, 1991).

Dentre alguns trabalhos que aplicaram o controle de modos deslizantes a robôs de arquitetura paralela encontram-se (CHEMORI, SARTORI-NATAL, PIERROT, 2013; HESSELBACH et al., 2004). Hesselbach et. al (2004) concluem que o controle por modos deslizantes apresenta melhores resultados em termos de robustez quando comparado ao controle por torque computado.

Outra alternativa para o controle de mecanismos paralelos é a utilização de técnicas de controle preditivo, que tiveram suas origens no controle de plantas de processos químicos, mas vem sendo aplicados em variadas áreas. Essas técnicas se baseiam na utilização de um modelo para predição das saídas da planta controlada, no cálculo de esforço de controle que minimizaria uma função objetivo, avaliada num intervalo de tempo futuro, e aplicação efetiva apenas do valor inicial desse sinal de esforço de controle calculado (CAMACHO, BORDONS, 2000). Assim, para cada instante de tempo, é necessário refazer a minimização da função objetivo.

A técnica mais tradicional pertencente a essa família é a de controle preditivo generalizado, proposto por Clarke, Mohtadi e Tuffs (1987). Nesta técnica é requisitado que o modelo da planta seja linear e discreto. Isso faz com que a minimização da função objetivo possa ser feita de forma genérica a priori. Outra técnica da mesma família é a de controle preditivo funcional, em que são prédefinidas expressões matemáticas paramétricas que compõem o sinal de controle na minimização da função objetivo.

De forma similar ao controle preditivo generalizado, o controle preditivo funcional também se baseia num modelo linear da planta. Por isso, para o controle de mecanismos paralelos, essas técnicas foram empregadas em conjunto com técnicas não lineares como a de torque computado. Ou seja, o controle preditivo 
correspondia apenas à parte linear do controlador (LARA-MOLINA, 2012; VIVAS, POIGNET, 2005; BOHM, BELDA, VALÁSEK, 2002).

Duchaine, Bouchard e Gosselin (2007), em particular, utilizaram o controle preditivo sobre o modelo não linear de um robô paralelo de seis graus de liberdade, mas fizeram hipóteses simplificadoras sobre a predição das saídas do modelo para que fosse possível resolver a priori o problema de minimização da função objetivo.

Outra abordagem de controle encontrada na literatura se trata do controle por passividade, em que os esforços de controle correspondem à dissipação de energia cinética e potencial do mecanismo de forma a leva-lo para uma configuração, estável, de mínima energia. Essa configuração de mínima energia tem significado exclusivamente matemático, não físico, e é definida conforme a posição ou trajetória que se deseja obter no efetuador (KHALIL, DOMBRE, 2002; SPONG, HUTCHINSON, VIDYASAGAR, 2005). Alguns exemplos de aplicação dessa técnica em mecanismos de arquitetura paralela podem ser observados em (LI, XU, 2009; NEVES et al 2011), em que foram realizados, respectivamente, o controle do mecanismo $3 \underline{P} R C$ e de uma variação de dois graus de liberdade da arquitetura $\mathrm{H} 4$. Foi concluído nesses trabalhos que o controle por passividade é mais robusto que o controle por torque computado.

\subsubsection{Limites de requisitos de desempenho de controle e observações sobre a frequência de amostragem do controlador}

Em todas as abordagens apresentadas anteriormente, observa-se que há sempre parâmetros a serem definidos nas leis de controle. De um modo geral, na expectativa de se obter máximo desempenho, procura-se alcançar sistemas controlados equivalentes a sistema de segunda ordem com amortecimento crítico e frequência natural igual à metade da menor frequência natural estrutural do mecanismo (KHALIL, DOMBRE, 2002; CRAIG, 2005). A preocupação do desempenho do robô frente as suas frequências estruturais também é observada em (DA SILVA, 2009), conforme ilustra a figura 2.13 , em que a largura de banda de controle é limitada pelas frequências naturais do mecanismo. Zubizarreta et al. (2008) confirmam essa limitação e afirmam que acurácia e alto desempenho são requisitos conflitantes. 


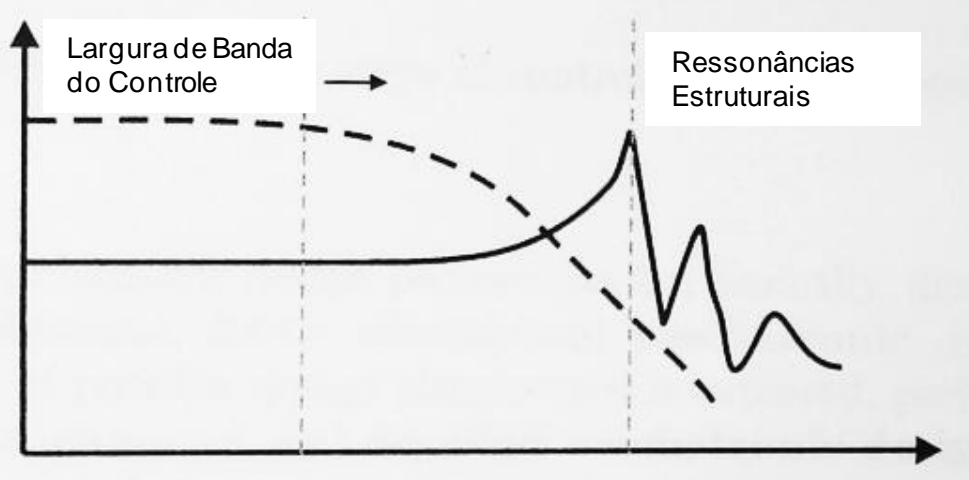

Figura 2.13 - Largura de banda de controle versus frequências de ressonância da estrutura do robô, adaptado de (DA SILVA, 2009)

Outra questão de aspecto prático se trata da discretização do controlador. As leis de controle baseadas nos modelos dinâmicos de mecanismos paralelos podem ter custo computacional elevado e os efeitos de discretização do controlador podem ser significativos. Segundo Franklin, Powell e Workman (1992), é necessário utilizar frequências de amostragem aproximadamente 50 vezes maiores que a largura de banda do controle e quantização do sinal com ao menos 16 bits para que os efeitos de discretização do controlador se tornem desprezíveis.

Para que seja possível aumentar a frequência de amostragem do controlador sem aumento significativo do custo computacional, é possível operar o controlador com dupla frequência de amostragem, uma, mais baixa, para a parte não linear e outra, mais alta, para a parte linear (CRAIG, 2005).

$\mathrm{Na}$ literatura foram encontrados trabalhos que utilizaram controladores para mecanismos paralelos com frequência de amostragem única de até $2000 \mathrm{~Hz}$ (CHEMORI, SARTORI-NATAL, PIERROT, 2013; HESSELBACH et al., 2004). Já para o caso de dupla frequência de amostragem, o robô comercial Adept Quattro s650H (ADEPT TECHNOLOGY, 2013) utiliza frequência de $8000 \mathrm{~Hz}$ para a parte linear ("servo") do controlador (ver Anexo B).

\subsubsection{Formulação e sintonização do controle por torque computado}

Conforme apontado anteriormente, o controle por torque computado é baseado na escolha de um esforço de controle que compense as não linearidades 
do modelo dinâmico e resulte em um modelo dinâmico linearizado, que possa ser controlado com técnicas tradicionais.

Assim, utilizando-se notação similar a de Craig (2005), dado o modelo dinâmico do robô na forma:

$$
M(\boldsymbol{q}) \ddot{\boldsymbol{q}}+H(\boldsymbol{q}, \dot{\boldsymbol{q}})+G(\boldsymbol{q})=\boldsymbol{\tau}
$$

em que $\boldsymbol{q}$ é um vetor constituído das coordenadas a serem controladas, $M(\boldsymbol{q})$ se trata de uma matriz de inércia, $H(\boldsymbol{q}, \dot{\boldsymbol{q}})$ corresponde a termos de aceleração centrípeta e de Coriolis, $G(\boldsymbol{q})$ contempla efeitos gravitacionais e $\boldsymbol{\tau}$ corresponde aos esforços aplicados pelos atuadores, define-se o seguinte esforço de controle

$$
\tau=\alpha \tau^{\prime}+\beta
$$

com,

$$
\begin{gathered}
\boldsymbol{\alpha}=M(\boldsymbol{q}) \\
\boldsymbol{\beta}=H(\boldsymbol{q}, \dot{\boldsymbol{q}})+G(\boldsymbol{q})
\end{gathered}
$$

Assim, admitindo que o modelo seja exato, a dinâmica do sistema torna-se equivalente a de um sistema linear de massa unitária e desacoplado, em relação à nova entrada $\boldsymbol{\tau}^{\prime}$ :

$$
\ddot{\boldsymbol{q}}=\boldsymbol{\tau}^{\prime}
$$

E ainda, definido-se $\boldsymbol{\tau}^{\prime}$ igual a:

$$
\begin{gathered}
\boldsymbol{\tau}^{\prime}=\ddot{\boldsymbol{q}}_{\boldsymbol{d}}+K_{d} \dot{\widetilde{\boldsymbol{q}}}+K_{p} \widetilde{\boldsymbol{q}} \\
\widetilde{\boldsymbol{q}}=\boldsymbol{q}_{\boldsymbol{d}}-\boldsymbol{q}
\end{gathered}
$$

em que $\widetilde{\boldsymbol{q}}$ é o erro de acompanhamento de trajetória e $\boldsymbol{q}_{\boldsymbol{d}}$ é a trajetória desejada, fica-se com uma dinâmica de erro igual a: 


$$
\ddot{\widetilde{\boldsymbol{q}}}+K_{d} \dot{\widetilde{\boldsymbol{q}}}+K_{p} \widetilde{\boldsymbol{q}}=0
$$

que pode ter seu desempenho ajustado pelos elementos das matrizes de ganho $K_{d}$ e $K_{p}$.

A Figura 2.14 ilustra o controle por torque computado, em que é destacada a parte de compensação de não linearidades do modelo, resultando em um sistema linearizado.

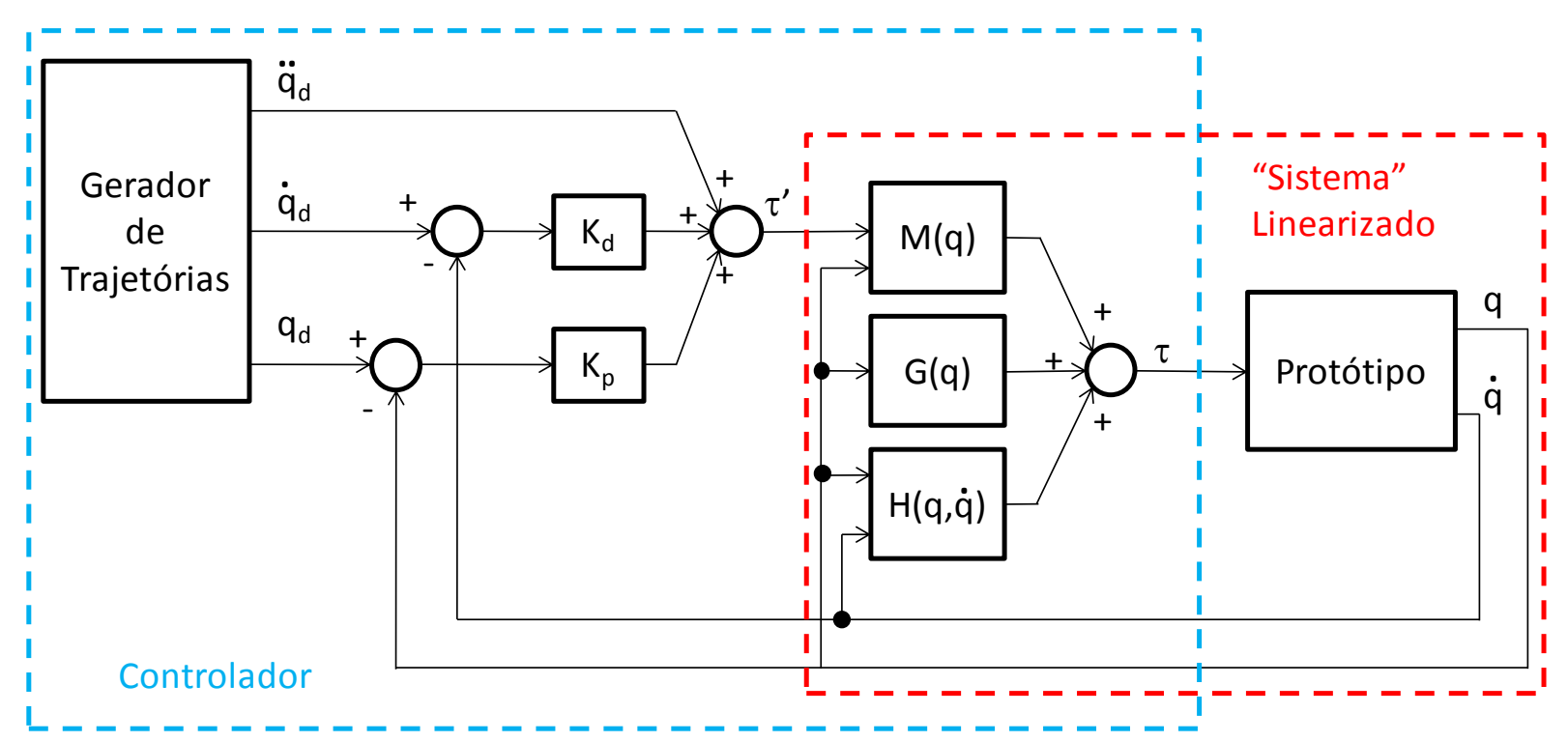

Figura 2.14 - Diagrama de controle por torque computado

Normalmente as matrizes de ganho $K_{d}$ e $K_{p}$ são definidas diagonais, com base nas equações 2.11 e 2.12, para se obter resposta equivalente a de segunda ordem, com parâmetro de amortecimento igual a 1 para se obter amortecimento crítico (KHALIL, DOMBRE, 2002), ou ligeiramente inferior a um, obtendo-se amortecimento subcrítico, e frequência natural correspondente aos requisitos de desempenho do robô, limitadas à metade de sua menor frequência estrutural (KHALIL, DOMBRE, 2002; CRAIG, 2005).

$$
K_{p}=\left[\begin{array}{lll}
\omega_{1}^{2} & & \\
& \ddots & \\
& & \omega_{n}^{2}
\end{array}\right]
$$




$$
K_{d}=\left[\begin{array}{lll}
2 \zeta_{1} \omega_{1} & & \\
& \ddots & \\
& & 2 \zeta_{n} \omega_{n}
\end{array}\right]
$$

Khalil e Dombre (2002) observam também que, apesar de diminuir os erros de controle, o aumento dos ganhos faz com que os polos fiquem mais próximos da região de instabilidade do sistema em malha fechada.

Ressalta-se que o controle assim concebido requer os valores tanto de posição como de velocidade das juntas dos atuadores. A medição direta dessas velocidades tem restrições práticas e, normalmente, são feitas estimativas a partir de medições de posições. Porém, a simples derivação de sinais de posição faz com que sejam amplificados ruídos de medição. Assim, devem-se projetar observadores de estado para essa tarefa (CHEMORI, SARTORI-NATAL, PIERROT, 2011; HESSELBACH et al., 2004).

\subsubsection{Formulação e sintonização do controle por torque computado estendido}

No controle por torque computado estendido, são inseridos sensores em juntas passivas do mecanismo, cujas coordenadas também passam a ser controladas. Assim, denominando as juntas ativas, monitoradas, por $\boldsymbol{q}_{a}$ e as juntas passivas monitoradas por $\boldsymbol{q}_{s}$, define-se um novo conjunto de coordenadas controladas, com redundância, $\boldsymbol{q}_{c}$, conforme a equação 2.13 .

$$
\boldsymbol{q}_{c}=\left[\begin{array}{l}
\boldsymbol{q}_{a} \\
\boldsymbol{q}_{s}
\end{array}\right]
$$

Procedendo de forma similar ao controle por torque computado tradicional, um robô modelado conforme a equação 2.14 pode ser controlado utilizando entradas de controle definidas pelas equações 2.15 a 2.19 .

$$
\begin{gathered}
M\left(\boldsymbol{q}_{c}\right) \ddot{\boldsymbol{q}}_{c}+H\left(\boldsymbol{q}_{c}, \dot{\boldsymbol{q}}_{c}\right)+G\left(\boldsymbol{q}_{c}\right)=\boldsymbol{\tau} \\
\boldsymbol{\tau}=\boldsymbol{\alpha} \boldsymbol{\tau}^{\prime}+\boldsymbol{\beta}
\end{gathered}
$$




$$
\begin{gathered}
\boldsymbol{\alpha}=M\left(\boldsymbol{q}_{c}\right) \\
\boldsymbol{\beta}=H\left(\boldsymbol{q}_{c}, \dot{\boldsymbol{q}}_{c}\right)+G\left(\boldsymbol{q}_{c}\right) \\
\boldsymbol{\tau}^{\prime}=\ddot{\boldsymbol{q}}_{c d}+K_{d} \dot{\boldsymbol{q}}_{c}+K_{p} \widetilde{\boldsymbol{q}}_{c} \\
\widetilde{\boldsymbol{q}}_{c}=\boldsymbol{q}_{c d}-\boldsymbol{q}_{c}
\end{gathered}
$$

É importante notar que o modelo dinâmico deve ser elaborado com base no conjunto de coordenadas com redundância $\boldsymbol{q}_{c}$, assim como a geração de trajetória deve ser calculada para todo esse conjunto de coordenadas.

A sintonização é feita de modo similar ao do controle por torque computado tradicional. Em (ZUBIZARRETA et al., 2013) os ganhos foram ajustados de forma a resultar em sobressinal de $5 \%$ e tempo de pico de 0,05 s para resposta à degrau para cada uma das variáveis controladas. Em (ZUBIZARRETA et al., 2011, 2012), os parâmetros de resposta temporal adotados foram $5 \%$ de sobressinal e $0,1 \mathrm{~s}$ de tempo de pico. 


\section{MODELAGEM E ANÁLISE CINEMÁTICA DO MECANISMO 2 RSS + PPaP}

Conforme relatado no capítulo anterior, é necessário estabelecer conjuntos de coordenadas que identifiquem a posição das peças do mecanismo e encontrar equações cinemáticas que relacionem os movimentos nas juntas dos atuadores com movimentos do efetuador e demais peças previamente à modelagem dinâmica e ao desenvolvimento de leis de controle. Neste capítulo são definidos os conjuntos de coordenadas de interesse, a nomenclatura utilizada na modelagem e o desenvolvimento de equações de cinemática direta e inversa do mecanismo 2 RSS + PPaP. Ao fim do capítulo, são ilustradas algumas configurações de singularidade do mecanismo e empregadas as equações cinemáticas no levantamento de seções do espaço de trabalho do mecanismo.

\subsection{NOMENCLATURA E DIAGRAMA CINEMÁTICO}

Para representar a posição dos atuadores e a posição do efetuador do robô no espaço, foram definidos os vetores $\boldsymbol{q}$ e $\boldsymbol{x}$ de coordenadas:

$$
\begin{gathered}
\boldsymbol{q}=\left[\begin{array}{l}
q_{1} \\
q_{2} \\
q_{3}
\end{array}\right] \\
\boldsymbol{x}=\boldsymbol{x}_{G}=\left[\begin{array}{l}
x_{1} \\
x_{2} \\
x_{3}
\end{array}\right]
\end{gathered}
$$

em que os caracteres em negrito são utilizados para indicar que a variável é vetorial.

A definição de cada um dos termos destes vetores pode ser observada no diagrama cinemático apresentado na Figura 3.1. Nota-se que é utilizado um sistema coordenado retangular para o efetuador. Neste diagrama também são definidos parâmetros de comprimentos $\left(a_{i}, l, L\right)$, massas de barras do mecanismo $\left(m_{i}\right)$ e massa da carga manipulada $(M)$. Naturalmente, as massas serão utilizadas apenas na modelagem dinâmica do mecanismo. 


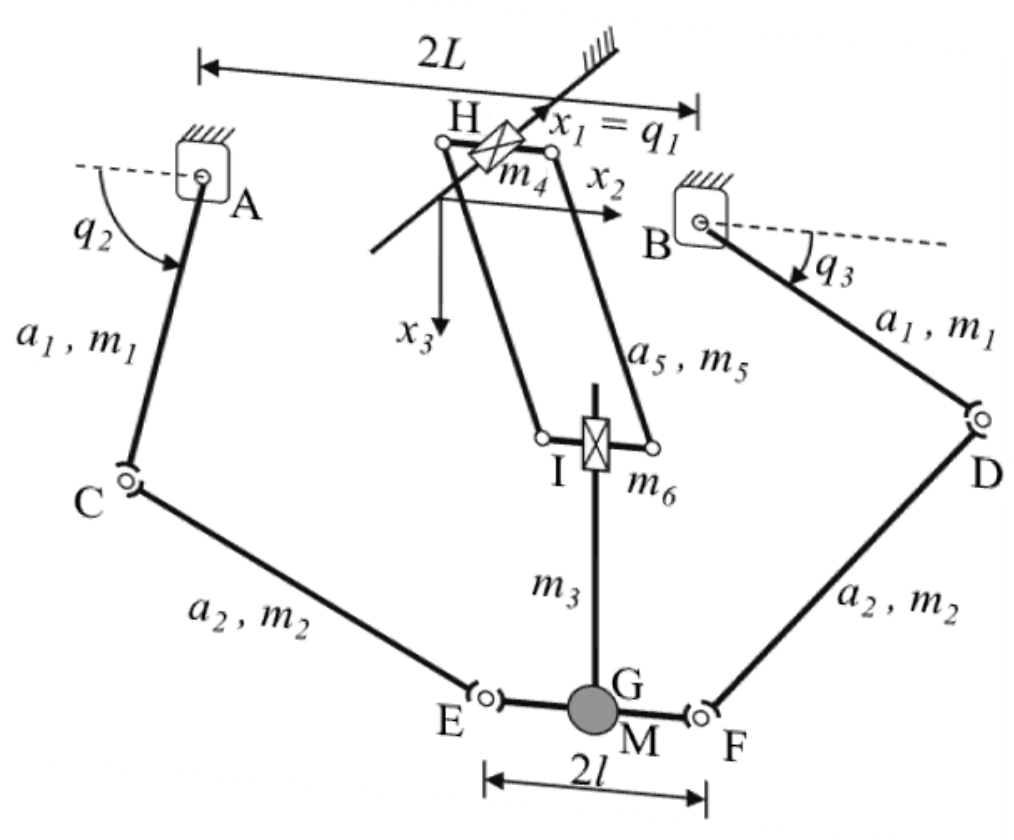

Figura 3.1 - Coordenadas utilizadas para representação da posição dos atuadores e do efetuador

\subsection{VÍNCULOS CINEMÁTICOS}

De acordo com as dimensões das peças e dos graus de liberdade restritos pelas juntas que compões as cadeias cinemáticas do mecanismo, ficam estabelecidos vínculos entre as coordenadas dos atuadores e do efetuador, que podem ser expressos por meio de equações matemáticas.

Especificamente para a translação do efetuador na direção $x_{1}$, tem-se que a coordenada $x_{1}$ é idêntica à coordenada $q_{1}$. Isto é consequência da particular arquitetura deste mecanismo.

Além disso, as distâncias entre os pontos $\mathrm{C}$ e $\mathrm{E}$, e entre os pontos $\mathrm{D}$ e $\mathrm{F}$ são constantes. Assim, levantam-se as seguintes equações vinculares:

$$
\left\{\begin{array}{c}
x_{1}-q_{1}=0 \\
x_{1}^{2}+\left(x_{2}-l+L+a_{1} \cos q_{2}\right)^{2}+\left(x_{3}-a_{1} \operatorname{senq}_{2}\right)^{2}-a_{2}^{2}=0 \\
x_{1}^{2}+\left(x_{2}+l-L-a_{1} \cos q_{3}\right)^{2}+\left(x_{3}-a_{1} \operatorname{senq}_{3}\right)^{2}-a_{2}^{2}=0
\end{array}\right.
$$

Nota-se que as equações cinemáticas do mecanismo em estudo são parcialmente desacopladas, o que simplifica significativamente o desenvolvimento 
analítico destas equações e o cálculo com valores numéricos para suas variáveis e parâmetros.

Derivando essas expressões em relação ao tempo, encontra-se:

$$
\left\{\begin{array}{c}
\dot{x}_{1}-\dot{q}_{1}=0 \\
2 x_{1} \dot{x}_{1}+2\left(x_{2}-l+L+a_{1} \cos q_{2}\right)\left(\dot{x}_{2}-a_{1} \dot{q}_{2} \operatorname{senq}_{2}\right)+2\left(x_{3}-a_{1} \operatorname{sen} q_{2}\right)\left(\dot{x}_{3}-a_{1} \dot{q}_{2} \cos q_{2}\right)=0 \\
2 x_{1} \dot{x}_{1}+2\left(x_{2}-l+L+a_{1} \cos q_{2}\right)\left(\dot{x}_{2}-a_{1} \dot{q}_{2} \operatorname{sen} q_{2}\right)+2\left(x_{3}-a_{1} \operatorname{sen} q_{2}\right)\left(\dot{x}_{3}-a_{1} \dot{q}_{2} \cos q_{2}\right)=0
\end{array}\right.
$$

Que pode ser reescrita na forma:

$$
J_{x} \dot{\boldsymbol{x}}=J_{q} \dot{\boldsymbol{q}}
$$

em que as matrizes jacobianas $J_{x}$ e $J_{q}$ são compostas pelos seguintes termos:

$$
\begin{gathered}
J_{x}=\left[\begin{array}{ccc}
1 & 0 \\
x_{1} & \left(x_{2}-l+L+a_{1} \cos q_{2}\right) & \left(x_{3}-a_{1} \operatorname{sen} q_{2}\right) \\
x_{1} & \left(x_{2}+l-L-a_{1} \cos q_{3}\right) & \left(x_{3}-a_{1} \operatorname{sen} q_{3}\right)
\end{array}\right] \\
J_{q}=\left[\begin{array}{ccc}
J_{q 11} & 0 & 0 \\
0 & J_{q 22} & 0 \\
0 & 0 & J_{q 33}
\end{array}\right] \\
J_{q 22}=\left(x_{2}-l+L+a_{1} \cos q_{2}\right)\left(a_{1} \operatorname{sen} q_{2}\right)+\left(x_{3}-a_{1} \operatorname{sen} q_{2}\right)\left(a_{1} \cos q_{2}\right) \\
J_{q 33}=\left(x_{2}+l-L-a_{1} \cos q_{3}\right)\left(a_{1} \operatorname{sen} q_{3}\right)+\left(x_{3}-a_{1} \operatorname{sen} q_{3}\right)\left(a_{1} \cos q_{3}\right)
\end{gathered}
$$

Derivando a equação 3.5 em relação ao tempo, encontra-se a relação matemática entre as acelerações das juntas ativas e acelerações do efetuador, como indica a equação 3.11.

$$
\dot{J}_{x} \dot{\boldsymbol{x}}+J_{x} \ddot{\boldsymbol{x}}=\dot{J}_{q} \dot{\boldsymbol{q}}+J_{q} \ddot{\boldsymbol{q}}
$$


em que:

$$
\begin{aligned}
& \dot{J}_{x}=\left[\begin{array}{ccc}
0 & 0 & 0 \\
\dot{x}_{1} & \left(\dot{x}_{2}-a_{1} \dot{q}_{2} s e n q_{2}\right) & \left(\dot{x}_{3}-a_{1} \dot{q}_{2} \cos q_{2}\right) \\
\dot{x}_{1} & \left(\dot{x}_{2}+a_{1} \dot{q}_{3} s e n q_{3}\right) & \left(\dot{x}_{3}-a_{1} \dot{q}_{3} \cos q_{3}\right)
\end{array}\right] \\
& \dot{J}_{q}=\left[\begin{array}{ccc}
0 & 0 & 0 \\
0 & \dot{J}_{q 22} & 0 \\
0 & 0 & \dot{J}_{q 33}
\end{array}\right] \\
& \dot{J}_{q 22}=\left(\dot{x}_{2}-a_{1} \dot{q}_{2} \operatorname{senq}_{2}\right)\left(a_{1} \operatorname{senq}_{2}\right)+\left(x_{2}-l+L+a_{1} \cos q_{2}\right)\left(a_{1} \dot{q}_{2} \cos q_{2}\right)+\left(\dot{x}_{3}\right. \\
& \left.-a_{1} \dot{q}_{2} \cos q_{2}\right)\left(a_{1} \cos q_{2}\right)-\left(x_{3}-a_{1} \operatorname{sen}_{2}\right)\left(a_{1} \dot{q}_{2} \operatorname{sen} q_{2}\right) \\
& \dot{J}_{q 33}=-\left(\dot{x}_{2}+a_{1} \dot{q}_{3} \operatorname{senq}_{3}\right)\left(a_{1} \operatorname{senq}_{3}\right)-\left(x_{2}+l-L-a_{1} \cos q_{3}\right)\left(a_{1} \dot{q}_{3} \cos q_{3}\right)+\left(\dot{x}_{3}\right. \\
& \left.-a_{1} \dot{q}_{3} \cos q_{3}\right)\left(a_{1} \cos q_{3}\right)-\left(x_{3}-a_{1} \operatorname{senq}_{3}\right)\left(a_{1} \dot{q}_{3} \operatorname{senq}_{3}\right)
\end{aligned}
$$

\subsection{CINEMÁTICA INVERSA}

A partir do sistema de equações 3.3, podem-se isolar as coordenadas dos atuadores de forma a ser possível calcular seus valores em função das coordenadas do efetuador.

Para o caso especial do mecanismo do robô em estudo, a coordenada $q_{1}$ pode ser facilmente isolada, pois está desacoplada das outras coordenadas. A solução do sistema algébrico não linear para as coordenadas $q_{2}$ e $q_{3}$, que está apresentada em detalhes no Apêndice A, resulta em:

$$
\begin{aligned}
& q_{2}=2 \operatorname{arctg}\left(\frac{-k_{21} \pm \sqrt{k_{21}^{2}+k_{22}^{2}-k_{23}^{2}}}{\left(k_{23}-k_{22}\right)}\right) \\
& q_{3}=2 \operatorname{arctg}\left(\frac{-k_{31} \pm \sqrt{k_{31}^{2}+k_{32}^{2}-k_{33}^{2}}}{\left(k_{33}-k_{32}\right)}\right)
\end{aligned}
$$


em que:

$$
\begin{gathered}
k_{21}=-2 x_{3} a_{1} \\
k_{22}=2\left(x_{2}-l+L\right) a_{1} \\
k_{23}=x_{1}^{2}+\left(x_{2}-l+L\right)^{2}+x_{3}^{2}+a_{1}^{2}-a_{2}^{2} \\
k_{31}=-2 x_{3} a_{1} \\
k_{32}=-2\left(x_{2}+l-L\right) a_{1} \\
k_{33}=x_{1}^{2}+\left(x_{2}+l-L\right)^{2}+x_{3}^{2}+a_{1}^{2}-a_{2}^{2}
\end{gathered}
$$

Note que existem quatro soluções, independentes, para cada uma das incógnitas $q_{2}$ e $q_{3}$ (duas soluções da equação de segundo grau e duas soluções para a função arco-tangente). Entretanto, verifica-se que são encontradas, de fato, duas soluções para cada incógnita, pois as outras duas são coincidentes às primeiras, com uma volta de defasagem no ciclo trigonométrico. A Figura 3.2 mostra as duas soluções possíveis para cada um dos ângulos $q_{2}$ e $q_{3}$ (a sub-cadeia central foi suprimida para simplificar o diagrama). Por combinação, encontram-se quatro possíveis soluções que são fisicamente válidas para o problema.

Eventualmente, poderiam ser encontradas soluções complexas conjugadas, que indicariam que a posição em análise não pertence ao espaço de trabalho do mecanismo.

Em termos de aplicação, é considerada válida apenas a solução que respeite as condições:

$$
\left\{\begin{array}{l}
0<q_{2}<\pi / 2 \\
0<q_{3}<\pi / 2
\end{array}\right.
$$




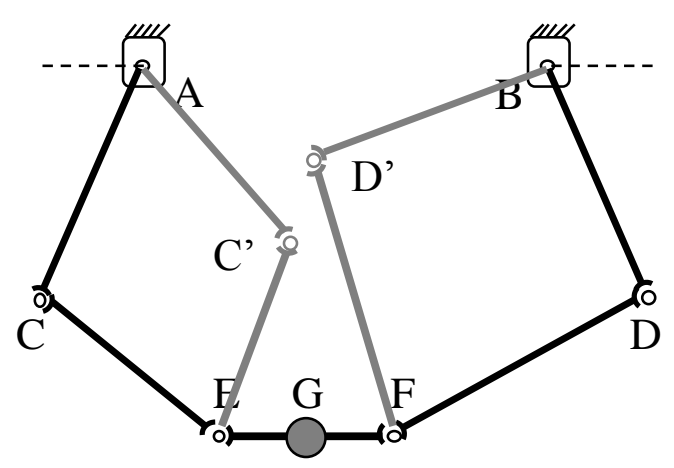

Figura 3.2 - Possíveis soluções para a cinemática inversa do mecanismo

Uma vez encontradas as relações com as quais seja possível calcular $\boldsymbol{q}$ a partir de $\boldsymbol{x}$, o cálculo de $\dot{\boldsymbol{q}}$ e $\ddot{\boldsymbol{q}}$ a partir de $\dot{\boldsymbol{x}}$ e $\ddot{\boldsymbol{x}}$ é obtido por solução de sistemas lineares.

Multiplicando os dois lados da equação 3.5 por $J_{q}^{-1}$, encontra-se:

$$
\dot{\boldsymbol{q}}=J_{q}^{-1} J_{x} \dot{\boldsymbol{x}}=J_{q x} \dot{\boldsymbol{x}}
$$

em que

$$
J_{q x}=J_{q}^{-1} J_{x}
$$

A partir da equação 3.11 , isola-se $\ddot{\boldsymbol{q}}$.

$$
\ddot{\boldsymbol{q}}=J_{q}^{-1}\left(\dot{j}_{x} \dot{\boldsymbol{x}}+J_{x} \ddot{\boldsymbol{x}}-\dot{J}_{q} \dot{\boldsymbol{q}}\right)=J_{q x} \ddot{\boldsymbol{x}}+j_{q x}
$$

em que,

$$
j_{q x}=J_{q}^{-1}\left(\dot{J}_{x} \dot{\boldsymbol{x}}-\dot{J}_{q} \dot{\boldsymbol{q}}\right)
$$

\subsection{CINEMÁTICA DIRETA}

A partir do sistema de equações 3.3, podem-se isolar as coordenadas do efetuador de forma a ser possível calcular seus valores em função das coordenadas dos atuadores. O desenvolvimento desse equacionamento, que está disponível em 
detalhes no Apêndice $B$, resulta no isolamento da coordenada $x_{3}$ por solução de uma equação de segundo grau, indicada na equação 3.29 e cálculo de $x_{2}$ em função de $x_{3}$, conforme a equação 3.30 :

$$
\begin{gathered}
\left(c_{2}+1\right) x_{3}^{2}+\left(2 c_{1} c_{2}+2 c_{2} k_{2}+2 k_{4}\right) x_{3}+\left(c_{1}^{2}+2 c_{1} k_{2}+k_{2}^{2}+k_{4}^{2}+k_{1}\right)=0 \\
x_{2}=c_{1}+c_{2} x_{3}
\end{gathered}
$$

em que:

$$
\begin{gathered}
k_{1}=q_{1}^{2}-a_{2}^{2} \\
k_{2}=-l+l+a_{1} \cos q_{2} \\
k_{3}=l-L-a_{1} \cos q_{3} \\
k_{4}=-a_{1} \operatorname{sen} q_{2} \\
k_{5}=-a_{1} \operatorname{sen} q_{3} \\
c_{1}=-\frac{\left(k_{2}^{2}+k_{4}^{2}+k_{1}-k_{3}^{2}-k_{5}^{2}-k_{1}\right)}{2\left(k_{2}-k_{3}\right)} \\
c_{2}=-\frac{\left(k_{4}-k_{5}\right)}{\left(k_{2}-k_{3}\right)}
\end{gathered}
$$

Assim, existem duas possíveis soluções para o problema, que são ilustradas na Figura 3.3 (a sub-cadeia central foi suprimida para simplificar o diagrama).

Será admitido neste estudo que o efetuador sempre se encontra abaixo das juntas esféricas C e D. Dessa forma, a identificação da solução válida para $x_{3}$ fica bastante simples. Basta tomar o maior valor entre os dois calculados, desde que sejam soluções reais. Soluções complexas conjugadas indicam que a posição não pertence ao espaço de trabalho do mecanismo. 


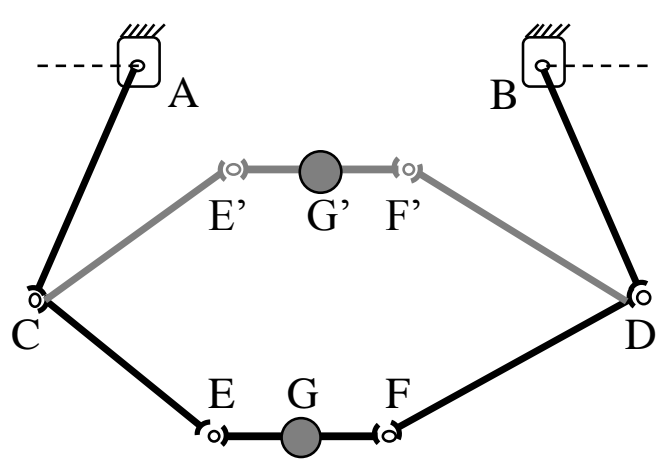

Figura 3.3 - Possíveis soluções para a cinemática direta do mecanismo

Note que poderia ter sido feito desenvolvimento análogo, mas que resultasse em uma equação do segundo grau para a coordenada $x_{2}$. Nesse caso, a identificação da solução válida não teria a mesma simplicidade.

Para as equações de velocidade e aceleração, basta realizar procedimento análogo ao utilizado na cinemática inversa resolvendo-se sistemas algébricos de equações lineares. Assim,

$$
\begin{gathered}
\dot{\boldsymbol{x}}=J_{x}^{-1} J_{q} \dot{\boldsymbol{q}}=J_{x q} \dot{\boldsymbol{q}} \\
\ddot{\boldsymbol{x}}=J_{x}^{-1}\left(\dot{J}_{q} \dot{\boldsymbol{q}}+J_{q} \ddot{\boldsymbol{q}}-J_{x} \dot{\boldsymbol{x}}\right)=J_{x q} \ddot{\boldsymbol{q}}+j_{x q}
\end{gathered}
$$

em que,

$$
\begin{gathered}
J_{x q}=J_{x}^{-1} J_{q} \\
j_{x q}=J_{x}^{-1}\left(\dot{J}_{q} \dot{\boldsymbol{q}}-\dot{J}_{x} \dot{\boldsymbol{x}}\right)
\end{gathered}
$$

\subsection{SINGULARIDADES E ESPAÇO DE TRABALHO}

Além de relacionar as velocidades nos atuadores com as velocidades do efetuador, as matrizes $J_{x}$ e $J_{q}$ podem ser utilizadas para a análise de posições singulares do mecanismo (TSAI, 1999). Quando o mecanismo atinge a fronteira de seu espaço de trabalho, o determinante de $J_{q}$ é igual a zero. Um exemplo dessa condição pode ser observada na figura 3.4a, em que a sub-cadeia central foi suprimida para simplificar o diagrama. Por outro lado, o determinante de $J_{x}$ ser igual 
a zero indica que o mecanismo se encontra em uma posição não controlável pelos atuadores, como exemplifica a figura 3.4b. Neste exemplo os atuadores correspondentes às coordenadas $q_{2}$ e $q_{3}$ não são capazes de suportar forças aplicadas ao efetuador na direção vertical. Nota-se que em ambos os casos, há alinhamento na direção de barras do mecanismo.

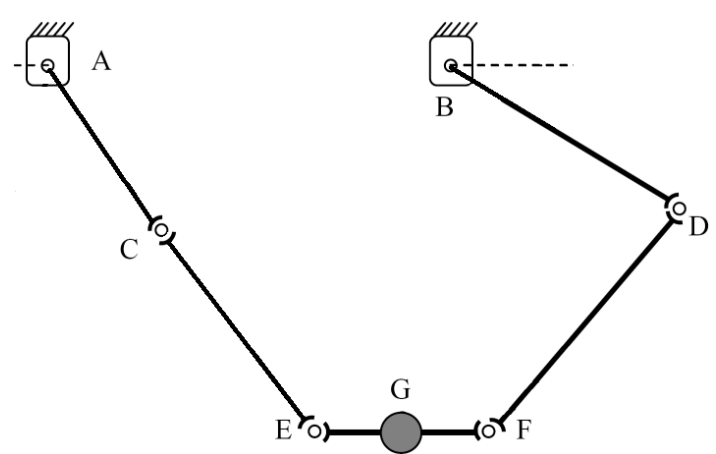

(a)

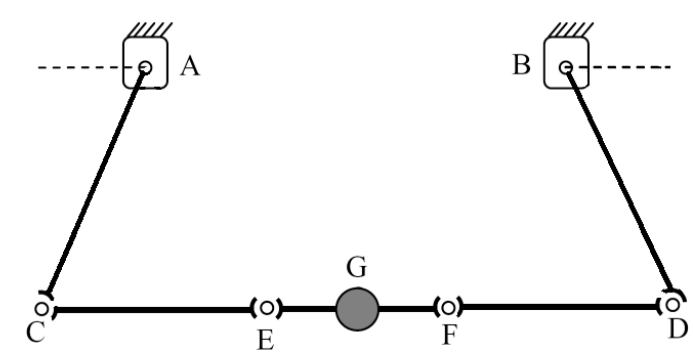

(b)

Figura 3.4 - Singularidades: (a) fronteira do espaço de trabalho (b) posição não controlável

Utilizando as equações 3.5 a 3.10 e evitando-se posições de singularidades, Kumazawa et al. (2009) levantaram o espaço de trabalho do robô manipulador proposto, cuja geometria pode ser observada na Figura 3.5.

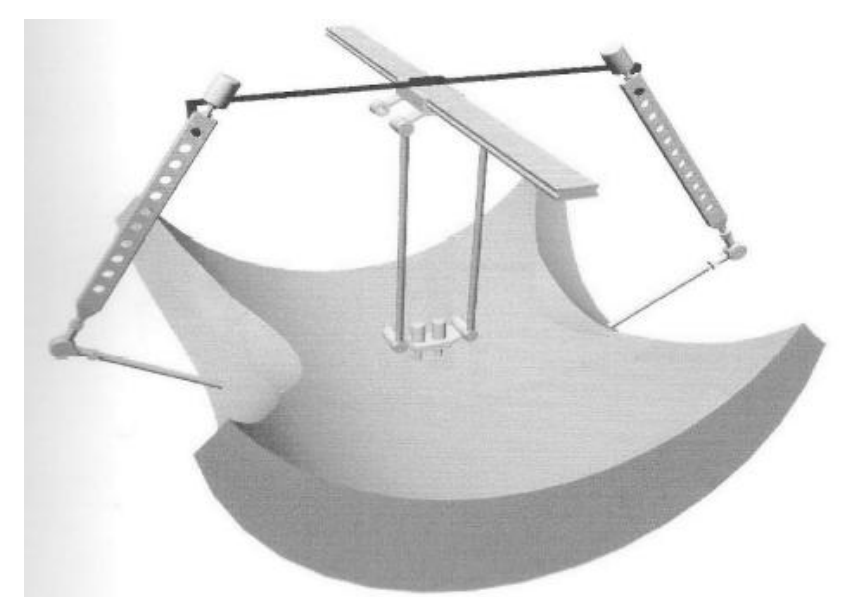

Figura 3.5 - Geometria do espaço de trabalho do robô (adaptado de Kumazawa et al. (2009))

Nota-se que a geometria do espaço de trabalho é complexa, característica não favorável e comum à maioria dos robôs de arquitetura paralela. Ajustando-se as dimensões das peças do mecanismo, é possível amenizar essa desvantagem 
aproximando-se a geometria do espaço de trabalho aos requisitos de movimentação da aplicação destinada ao robô.

Considerando os parâmetros geométricos da tabela 3.1, foi feita uma avaliação, por discretização numérica, do espaço de trabalho do mecanismo, como mostram as figuras 3.6 a 3.9 .

Tabela 3.1 - Parâmetros geométricos do mecanismo

\begin{tabular}{|c|c|}
\hline Parâmetros & $\begin{array}{c}\text { Valores } \\
\text { [mm] }\end{array}$ \\
\hline$a_{1}$ & 350 \\
\hline$a_{2}$ & 450 \\
\hline$l$ & 80 \\
\hline$a_{4}$ & 100 \\
\hline$a_{5}$ & 380 \\
\hline$a_{6}$ & 100 \\
\hline$L$ & 160 \\
\hline
\end{tabular}

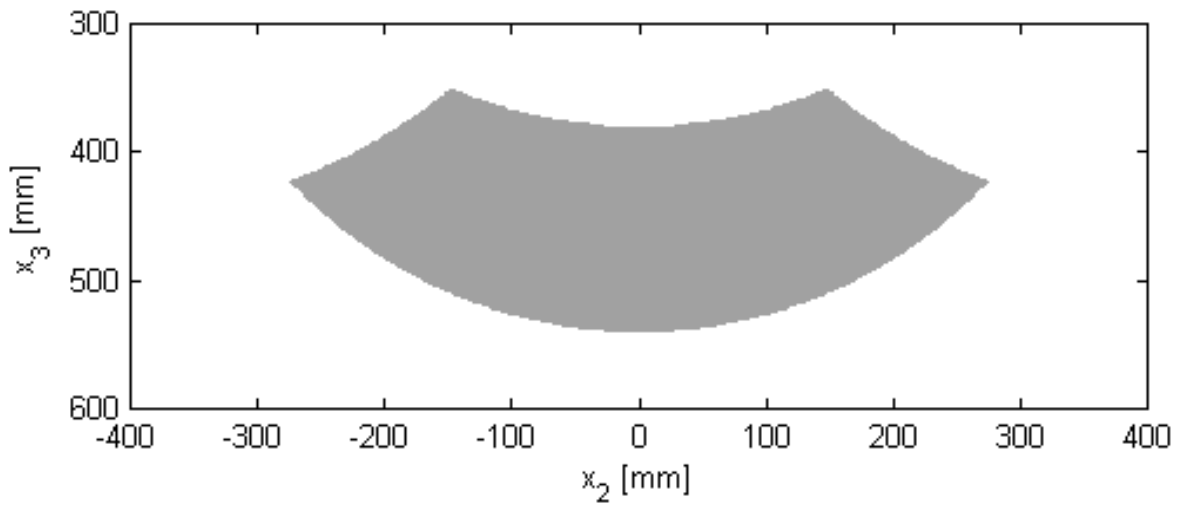

Figura 3.6 - Espaço de trabalho: seção $x_{1}=0 \mathrm{~mm}$

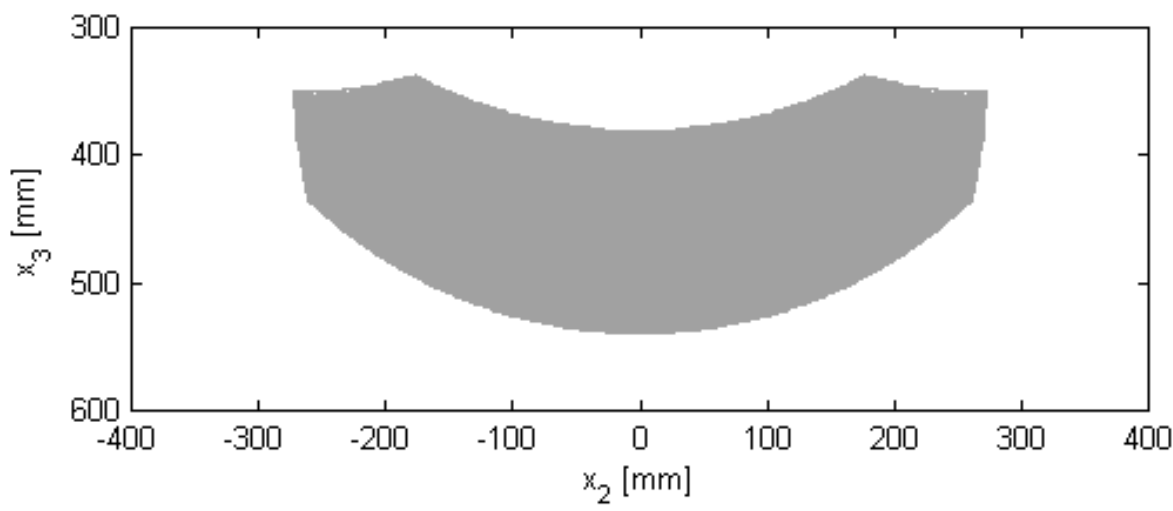


Figura 3.7 - Espaço de trabalho: seção $x_{1}=280 \mathrm{~mm}$

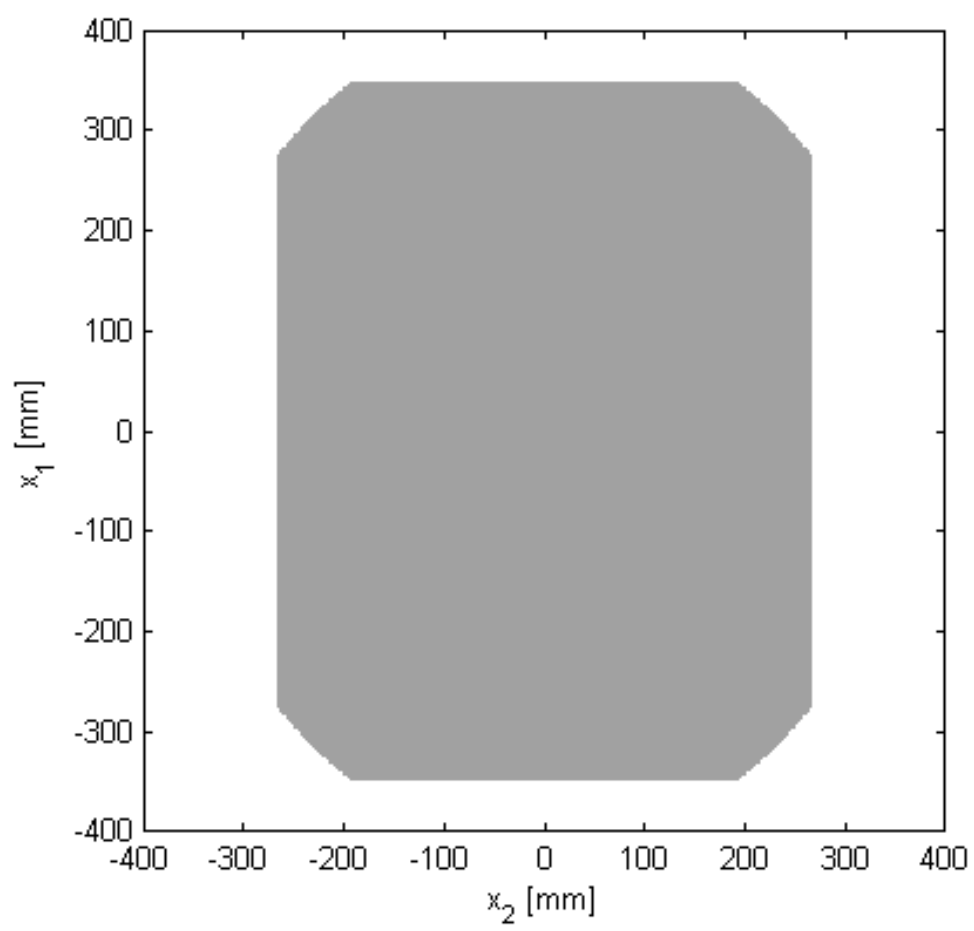

Figura 3.8 - Espaço de trabalho: seção $x_{3}=430 \mathrm{~mm}$

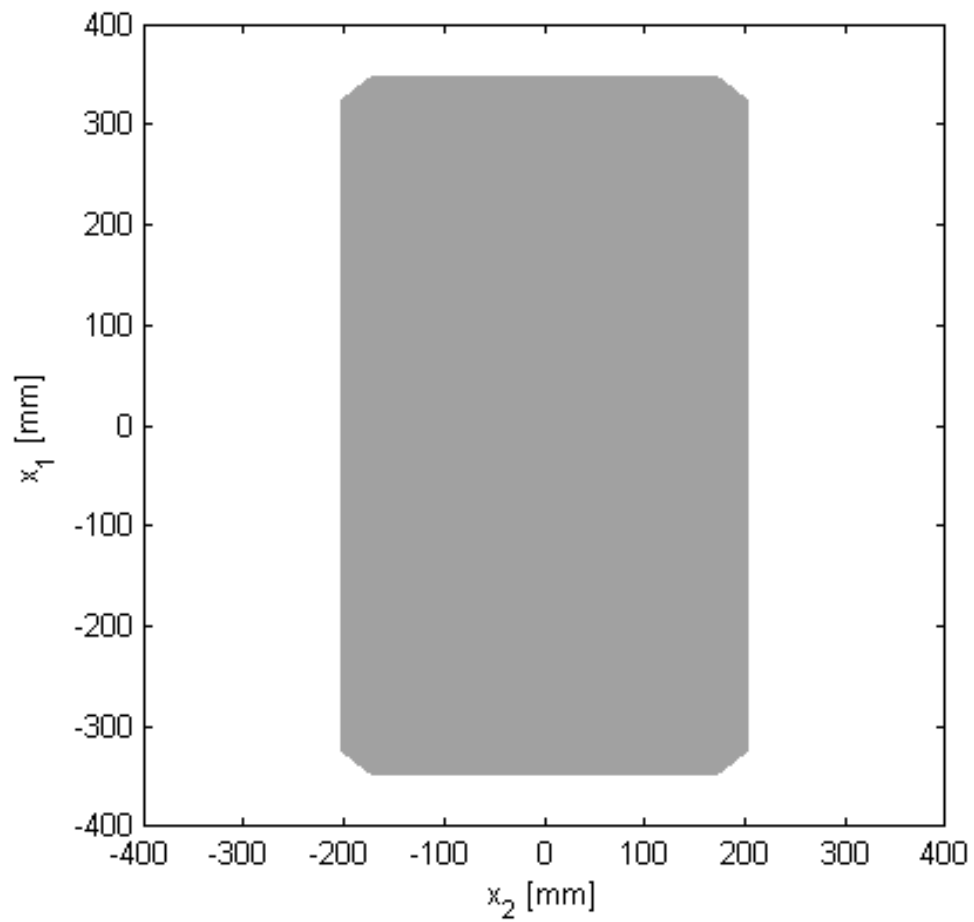

Figura 3.9 - Espaço de trabalho: seção $x_{3}=480 \mathrm{~mm}$ 
Assim, foi identificado que o espaço de trabalho do mecanismo, considerando os parâmetros geométricos da tabela 3.1, contém um volume de formato hexaédrico de $280 \mathrm{~mm}$ de largura $\left(-140 \leq x_{2} \leq 140 \mathrm{~mm}\right), 560 \mathrm{~mm}$ de comprimento $(-280 \leq$ $\left.x_{1} \leq 280\right)$ e $50 \mathrm{~mm}$ de altura $\left(430 \leq x_{3} \leq 480\right)$. As trajetórias para simulação do controle do mecanismo, apresentadas no capítulo 7, ficaram restritas a esse volume. 


\section{MODELAGEM DINÂMICA DO MECANISMO 2 RSS + PPaP}

De acordo com a tendência observada na revisão da literatura, optou-se por utilizar o princípio dos trabalhos virtuais e o método de Lagrange na modelagem dinâmica do robô manipulador. Tal escolha foi baseada pela característica geral dos métodos de energia resultarem em equações matemáticas mais sintéticas quando comparados com a formulação de Newton-Euler. Caso este último fosse empregado, existiria um grande número de forças e momentos internos relativos às restrições de movimento das juntas do mecanismo, que somariam cinquenta e duas incógnitas ao problema (cinco para cada uma das oito juntas de um grau de liberdade, três para cada uma das quatro juntas de três graus de liberdade).

Sabe-se também que é de grande importância a escolha das coordenadas que serão utilizadas como base da modelagem, pois estas podem simplificar o equacionamento ou torná-lo bastante complexo. No entanto, como a aplicação do mecanismo em estudo está relacionada ao controle de posição do efetuador em função da movimentação das juntas ativas, optou-se por utilizar as próprias coordenadas $\boldsymbol{q}$ e $\boldsymbol{x}$ definidas anteriormente como conjunto de coordenadas para a modelagem dinâmica.

Por se tratar de um sistema de três graus de liberdade, são necessárias apenas três coordenadas para representar de maneira única o posicionamento de todas as peças do mecanismo. Dessa forma, apenas as coordenadas dos atuadores, ou apenas as coordenadas do efetuador, ou ainda outros conjuntos de três coordenadas agrupando coordenadas do efetuador e dos atuadores seriam suficientes. Porém, as equações do problema são mais facilmente elaboradas se todas as seis coordenadas forem utilizadas simultaneamente. Assim, deve-se optar entre dois caminhos, tanto se utilizado o Princípio dos Trabalhos Virtuais como o Método de Lagrange:

- Alternativa 1 - utilizar as equações de vínculo para eliminar três coordenadas redundantes e finalizar a modelagem com as três coordenadas independentes restantes;

- Alternativa 2 - introduzir multiplicadores de Lagrange, modelar abstraindo as variáveis como independentes e solucionar as equações de movimento nas quais o cálculo dos multiplicadores de Lagrange força o restabelecimento dos vínculos. 
Para o sistema em análise, a utilização do Método de Lagrange com a eliminação de variáveis redundantes a partir das equações de vínculo se mostrou muito trabalhosa, pois as expressões finais tanto da cinemática inversa como da cinemática direta são muito longas. Mas, pelo Princípio dos Trabalhos Virtuais não há a mesma dificuldade, pois a eliminação de coordenadas redundantes ocorre nas funções derivada primeira e segunda das coordenadas, envolvendo apenas a solução de sistemas algébricos lineares, como pode ser observado nas equações 3.5 e 3.11. Dessa forma, optou-se por aplicar:

- Princípio dos Trabalhos Virtuais com eliminação de variáveis redundantes, seguindo a alternativa 1 ;

- Método de Lagrange com multiplicadores de Lagrange, seguindo a alternativa 2.

São apresentados a seguir dois modelos obtidos com hipóteses de massas concentradas e um modelo com hipótese de massas distribuídas. Apenas para o primeiro modelo de massas concentradas foram empregados os dois métodos de modelagem anteriormente sugeridos. Para os demais, foi utilizado exclusivamente 0 Princípio dos Trabalhos Virtuais, por se mostrar mais eficiente. Grande parte dessas seções foi publicada em (ALMEIDA, HESS-COELHO, 2010).

\subsection{MODELAGEM COM MASSAS DAS BARRAS CONCENTRADAS EM SUAS EXTREMIDADES}

\subsubsection{Hipóteses simplificadoras}

Nesta primeira abordagem, são consideradas as seguintes hipóteses simplificadoras:

- Barras equivalentes a duas massas concentradas, cada uma com metade da massa total da barra, dispostas nas extremidades de uma barra sem massa e perfeitamente rígida.

- Juntas de rotação, esféricas e prismáticas ideais (rígidas, sem atrito e sem folga);

A escolha da modelagem das massas como concentradas nas extremidades das barras simplifica enormemente o equacionamento, pois a posição de todas as 
massas pode ser facilmente descrita em função das coordenadas das juntas ativas ou das coordenadas do efetuador.

\subsubsection{Modelagem pelo Princípio dos Trabalhos Virtuais}

De acordo com o Princípio dos Trabalhos Virtuais (MEIROVICH, 2003) a somatória dos trabalhos virtuais realizados por todos os esforços sobre o sistema, incluindo esforços de atuadores, forças de inércias relativas às acelerações das massas concentradas e forças peso, é igual a zero. Assim:

$$
\begin{aligned}
\boldsymbol{\tau} \delta \boldsymbol{q}-\left(m_{1 e}+\right. & \left.m_{2 e}\right) \ddot{\boldsymbol{x}_{C}} \delta \boldsymbol{x}_{C}-\left(2 m_{2 e}+m_{3}+M\right) \ddot{\boldsymbol{x}} \delta \boldsymbol{x}-\left(m_{1 e}+m_{2 e}\right) \ddot{\boldsymbol{x}_{D}} \delta \boldsymbol{x}_{D} \\
& -\left(m_{4}+2 m_{5 e}\right) \ddot{\boldsymbol{x}_{H}} \delta \boldsymbol{x}_{H}-\left(2 m_{5 e}+m_{6}\right) \ddot{\boldsymbol{x}_{I}} \delta \boldsymbol{x}_{I}+\left(m_{1 e}+m_{2 e}\right) \boldsymbol{g} \delta \boldsymbol{x}_{C} \\
& +\left(2 m_{2 e}+m_{3}+M\right) \boldsymbol{g} \delta \boldsymbol{x}+\left(m_{1 e}+m_{2 e}\right) \boldsymbol{g} \delta \boldsymbol{x}_{D}+\left(2 m_{5 e}+m_{6}\right) \boldsymbol{g} \delta \boldsymbol{x}_{I}=0
\end{aligned}
$$

Em que relações vetoriais do tipo $\ddot{x}_{C} \delta x_{C}$ são produtos escalares, as coordenadas dos pontos $\mathrm{C}, \mathrm{D}, \mathrm{H}$ e L são baseadas em sistemas de coordenadas retangulares coincidentes ao do efetuador, $\boldsymbol{\tau}=\left[\begin{array}{lll}\tau_{1} & \tau_{2} & \tau_{3}\end{array}\right]^{T}$ representa os esforços nos atuadores, $\quad \boldsymbol{g}=\left[\begin{array}{lll}0 & 0 & g\end{array}\right]^{T}=\left[\begin{array}{lll}0 & 0 & 9,81\end{array}\right]^{T} \mathrm{~m} / \mathrm{s}^{2}$ o vetor aceleração da gravidade e $m_{i e}$ são iguais a metade das massas $m_{i}$.

Pelas restrições cinemáticas, encontram-se as relações entre deslocamentos virtuais apresentadas nas equações, cujos desenvolvimentos estão apresentados no Apêndice C.

$$
\begin{gathered}
\delta y_{C 2}=a_{1} \operatorname{sen} q_{2} \delta q_{2} \\
\delta x_{C 3}=a_{1} \cos q_{2} \delta q_{2} \\
\delta x_{D 2}=-a_{1} \operatorname{sen} q_{3} \delta q_{3} \\
\delta x_{D 3}=a_{1} \cos q_{3} \delta q_{3} \\
\delta x_{H 1}=\delta x_{1}
\end{gathered}
$$




$$
\begin{gathered}
\delta x_{I 1}=\delta x_{1} \\
\delta x_{I 2}=\delta x_{2} \\
\delta x_{I 3}=\frac{-x_{2}}{\sqrt{a_{5}^{2}-x_{2}^{2}}} \delta x_{2} \\
\delta \boldsymbol{x}=J_{x}^{-1} J_{q} \delta \boldsymbol{q}=J_{x q} \delta \boldsymbol{q}
\end{gathered}
$$

Substituindo as expressões dos deslocamentos virtuais na somatória dos trabalhos virtuais, chega-se a:

$$
\begin{aligned}
\tau_{1} \delta q_{1}+\tau_{2} \delta q_{2} & +\tau_{3} \delta q_{3}-\left(m_{1 e}+m_{2 e}\right) \ddot{x_{C 2}}\left(a_{1} s e n q_{2}\right) \delta q_{2}-\left(m_{1 e}+m_{2 e}\right) \ddot{x_{C 3}}\left(a_{1} \cos q_{2}\right) \delta q_{2} \\
& -\left(2 m_{2 e}+m_{3}+M\right)\left(\ddot{x_{1}} \delta q_{1}+\ddot{x_{2}}\left(J_{x q 21} \delta q_{1}+J_{x q 22} \delta q_{2}+J_{x q 23} \delta q_{3}\right)\right. \\
& \left.+\ddot{x_{3}}\left(J_{x q 31} \delta q_{1}+J_{x q 32} \delta q_{2}+J_{x q 33} \delta q_{3}\right)\right)-\left(m_{1 e}+m_{2 e}\right) \ddot{x_{D 2}}\left(-a_{1} s e n q_{3}\right) \delta q_{3} \\
& -\left(m_{1 e}+m_{2 e}\right) \ddot{x_{D 3}}\left(a_{1} \cos q_{3}\right) \delta q_{3}-\left(m_{4}+2 m_{5 e}+m_{6}\right) \ddot{x_{1}} \delta q_{1} \\
& -\left(2 m_{5 e}+m_{6}\right) \ddot{x_{I 2}}\left(J_{x q 21} \delta q_{1}+J_{x q 22} \delta q_{2}+J_{x q 23} \delta q_{3}\right) \\
& -\left(2 m_{5 e}+m_{6}\right) \ddot{x_{I 3}}\left(\frac{-x_{2}}{\sqrt{a_{5}^{2}-x_{2}^{2}}}\right)\left(J_{x q 21} \delta q_{1}+J_{x q 22} \delta q_{2}+J_{x q 23} \delta q_{3}\right) \\
& +\left(m_{1 e}+m_{2 e}\right) g\left(a_{1} \cos q_{2}\right) \delta q_{2} \\
& +\left(2 m_{2 e}+m_{3}+M\right) g\left(J_{x q 31} \delta q_{1}+J_{x q 32} \delta q_{2}+J_{x q 33} \delta q_{3}\right) \\
& +\left(m_{1 e}+m_{2 e}\right) g\left(a_{1} \cos q_{3}\right) \delta q_{3} \\
& +\left(2 m_{5 e}+m_{6}\right) g\left(\frac{-x_{2}}{\sqrt{a_{5}^{2}-x_{2}^{2}}}\right)\left(J_{x q 21} \delta q_{1}+J_{x q 22} \delta q_{2}+J_{x q 23} \delta q_{3}\right)=0
\end{aligned}
$$

Como a somatória dos trabalhos virtuais deve ser igual a zero para quaisquer deslocamentos virtuais $\delta q_{1}, \delta q_{2}$ e $\delta q_{3}$, conclui-se que as somatórias dos termos que multiplicam cada um desses deslocamentos vale zero. Assim: 


$$
\begin{aligned}
\tau_{1}=\left(2 m_{2 e}+\right. & \left.m_{3}+M\right)\left(\ddot{x}_{1}+\ddot{x}_{2} J_{x q 21}+\ddot{x}_{3} J_{x q 31}\right)+\left(m_{4}+2 m_{5 e}+m_{6}\right) \ddot{x}_{1} \\
& +\left(2 m_{5 e}+m_{6}\right) \ddot{x}_{I 2} J_{x q 21}+\left(2 m_{5 e}+m_{6}\right) \ddot{x_{I 3}}\left(\frac{-x_{2}}{\sqrt{a_{5}^{2}-x_{2}^{2}}}\right) J_{x q 21} \\
& -\left(2 m_{2 e}+m_{3}+M\right) g J_{x q 31}-\left(2 m_{5 e}+m_{6}\right) g\left(\frac{-x_{2}}{\sqrt{a_{5}^{2}-x_{2}^{2}}}\right) J_{x q 21}
\end{aligned}
$$

$$
\begin{aligned}
\tau_{2}=\left(m_{1 e}+\right. & \left.m_{2 e}\right) \ddot{x_{C 2}}\left(a_{1} \operatorname{senq}_{2}\right)+\left(m_{1 e}+m_{2 e}\right) \ddot{x_{C 3}}\left(a_{1} \cos q_{2}\right) \\
& +\left(2 m_{2 e}+m_{3}+M\right)\left(\ddot{x_{2}} J_{x q 22}+\ddot{x_{3}} J_{x q 32}\right)+\left(2 m_{5 e}+m_{6}\right) \ddot{x_{I 2}} J_{x q 22} \\
& +\left(2 m_{5 e}+m_{6}\right) \ddot{x_{I 3}}\left(\frac{-x_{2}}{\sqrt{a_{5}^{2}-x_{2}^{2}}}\right) J_{x q 22}-\left(m_{1 e}+m_{2 e}\right) g\left(a_{1} \cos q_{2}\right) \\
& -\left(2 m_{2 e}+m_{3}+M\right) g J_{x q 32}-\left(2 m_{5 e}+m_{6}\right) g\left(\frac{-x_{2}}{\sqrt{a_{5}^{2}-x_{2}^{2}}}\right) J_{x q 22}
\end{aligned}
$$

$$
\begin{aligned}
\tau_{3}=\left(2 m_{2 e}+\right. & \left.m_{3}+M\right)\left(\ddot{x_{2}} J_{x q 23}+\ddot{x}_{3} J_{x q 33}\right)+\left(m_{1 e}+m_{2 e}\right) \ddot{x_{D 2}}\left(-a_{1} s e n q_{3}\right) \\
& +\left(m_{1 e}+m_{2 e}\right) \ddot{x_{D 3}}\left(a_{1} \cos q_{3}\right)+\left(2 m_{5 e}+m_{6}\right) \ddot{x_{I 2}} J_{x q 23} \\
& +\left(2 m_{5 e}+m_{6}\right) \ddot{x_{I 3}}\left(\frac{-x_{2}}{\sqrt{a_{5}^{2}-x_{2}^{2}}}\right) J_{x q 23}-\left(2 m_{2 e}+m_{3}+M\right) g J_{x q 33} \\
& -\left(m_{1 e}+m_{2 e}\right) g\left(a_{1} \cos q_{3}\right)-\left(2 m_{5 e}+m_{6}\right) g\left(\frac{-x_{2}}{\sqrt{a_{5}^{2}-x_{2}^{2}}}\right) J_{x q 23}
\end{aligned}
$$

Dessa forma, a partir de um movimento requerido, pode-se calcular os esforços necessários nos atuadores do robô.

Reescrevendo as equações 4.12 a 4.14 apenas em função das coordenadas $\boldsymbol{q}$ e $\boldsymbol{x}$, e de suas derivadas, são obtidas as equações 4.15 a 4.17 . 


$$
\begin{aligned}
{\left[\left(2 m_{2 e}+m_{3}\right.\right.} & \left.+M)+\left(m_{4}+2 m_{5 e}+m_{6}\right)\right] \ddot{q}_{1} \\
& +\left[\left(2 m_{2 e}+m_{3}+M\right) J_{x q 21}+\left(2 m_{5 e}+m_{6}\right) J_{x q 21}\right. \\
& \left.+\left(2 m_{5 e}+m_{6}\right) x_{2}^{2}\left(a_{5}^{2}-x_{2}^{2}\right)^{-1} J_{x q 21}\right] \ddot{x}_{2}+\left[\left(2 m_{2 e}+m_{3}+M\right) J_{x q 31}\right] \ddot{x}_{3} \\
& +\left[\left(2 m_{5 e}+m_{6}\right)\left(\dot{x}_{2}^{2}+\left(x_{2} \dot{x}_{2}\right)^{2}\left(a_{5}^{2}-x_{2}^{2}\right)^{-\frac{3}{2}}\right)\left(x_{2}\left(a_{5}^{2}-x_{2}^{2}\right)^{-\frac{1}{2}}\right) J_{x q 21}\right] \\
& +\left[-\left(2 m_{2 e}+m_{3}+M\right) J_{x q 31}+\left(2 m_{5 e}+m_{6}\right) x_{2}\left(a_{5}^{2}-x_{2}^{2}\right)^{-\frac{1}{2}} J_{x q 21}\right] g=\tau_{1}
\end{aligned}
$$

$$
\begin{aligned}
{\left[\left(m_{1 e}+m_{2 e}\right)\right.} & \left.\left(a_{1} \operatorname{senq}_{2}\right)^{2}+\left(m_{1 e}+m_{2 e}\right)\left(a_{1} \cos q_{2}\right)^{2}\right] \ddot{q}_{2} \\
& +\left[\left(2 m_{2 e}+m_{3}+M\right) J_{x q 22}+\left(2 m_{5 e}+m_{6}\right) J_{x q 22}\right. \\
& \left.+\left(2 m_{5 e}+m_{6}\right) x_{2}^{2}\left(a_{5}^{2}-x_{2}^{2}\right)^{-1} J_{x q 22}\right] \ddot{x}_{2}+\left[\left(2 m_{2 e}+m_{3}+M\right) J_{x q 32}\right] \ddot{x}_{3} \\
& +\left[( 2 m _ { 5 e } + m _ { 6 } ) \left(\dot{x}_{2}^{2}\left(a_{5}^{2}-x_{2}^{2}\right)^{-\frac{1}{2}}\right.\right. \\
& \left.\left.+\left(x_{2} \dot{x}_{2}\right)^{2}\left(a_{5}^{2}-x_{2}^{2}\right)^{-\frac{3}{2}}\right)\left(x_{2}\left(a_{5}^{2}-x_{2}^{2}\right)^{-\frac{1}{2}}\right) J_{x q 22}\right] \\
& +\left[-\left(m_{1 e}+m_{2 e}\right)\left(a_{1} \cos q_{2}\right)-\left(2 m_{2 e}+m_{3}+M\right) J_{x q 32}\right. \\
& \left.+\left(2 m_{5 e}+m_{6}\right) x_{2}\left(a_{5}^{2}-x_{2}^{2}\right)^{-\frac{1}{2}} J_{x q 22}\right] g=\tau_{2}
\end{aligned}
$$

$$
\begin{aligned}
{\left[\left(m_{1 e}+m_{2 e}\right)\right.} & \left.\left(-a_{1} \operatorname{senq}_{3}\right)^{2}+\left(m_{1 e}+m_{2 e}\right)\left(a_{1} \cos q_{3}\right)^{2}\right] \ddot{q}_{3} \\
& +\left[\left(2 m_{2 e}+m_{3}+M\right) J_{x q 23}+\left(2 m_{5 e}+m_{6}\right) J_{x q 23}\right. \\
& \left.+\left(2 m_{5 e}+m_{6}\right) x_{2}^{2}\left(a_{5}^{2}-x_{2}^{2}\right)^{-1} J_{x q 23}\right] \ddot{x}_{2}+\left[\left(2 m_{2 e}+m_{3}+M\right) J_{x q 33}\right] \ddot{x}_{3} \\
& +\left[( 2 m _ { 5 e } + m _ { 6 } ) \left(\dot{x}_{2}^{2}\left(a_{5}^{2}-x_{2}^{2}\right)^{-\frac{1}{2}}\right.\right. \\
& \left.\left.+\left(x_{2} \dot{x}_{2}\right)^{2}\left(a_{5}^{2}-x_{2}^{2}\right)^{-\frac{3}{2}}\right)\left(x_{2}\left(a_{5}^{2}-x_{2}^{2}\right)^{-\frac{1}{2}}\right) J_{x q 23}\right] \\
& +\left[-\left(m_{1 e}+m_{2 e}\right)\left(a_{1} \cos q_{3}\right)-\left(2 m_{2 e}+m_{3}+M\right) J_{x q 33}\right. \\
& \left.+\left(2 m_{5 e}+m_{6}\right) x_{2}\left(a_{5}^{2}-x_{2}^{2}\right)^{-\frac{1}{2}} J_{x q 23}\right] g=\tau_{3}
\end{aligned}
$$

Ou ainda, utilizando notação matricial, chega-se a:

$$
M_{\tau q} \ddot{\boldsymbol{q}}+M_{\tau x} \ddot{\boldsymbol{x}}+H_{\tau}+G_{\tau}=\boldsymbol{\tau}
$$

em que $M_{\tau q}$ e $M_{\tau x}$ correspondem a matrizes de inércia, $H_{\tau}$ corresponde a termos de aceleração centrípeta e de Coriolis, e $G_{\tau}$ corresponde a termos gravitacionais. 
Nota-se que essa equação diferencial foge do formato comumente utilizado para robôs seriais (indicado na equação 2.3), pois está escrita em função de variáveis redundantes ( $\boldsymbol{q}$ e $\boldsymbol{x}$ neste caso).

\subsubsection{Modelagem pelo Método de Lagrange}

Pelo Método de Lagrange com a introdução dos multiplicadores de Lagrange, encontra-se um balanço entre as variações de energias cinética e potencial, e a existência de esforços externos e vínculos (MEIROVITCH, 2003), utilizando o seguinte equacionamento:

$$
\begin{gathered}
\frac{d}{d t}\left(\frac{\partial L}{\partial \dot{q}_{k}}\right)-\frac{\partial L}{\partial q_{k}}=Q_{k}+\sum_{l=1}^{m} \lambda_{l} a_{l k} \\
k=1,2, \ldots, n \\
a_{l k}=\frac{\partial g_{l}}{\partial q_{k}} \\
g_{l}\left(q_{1}, q_{2}, \ldots, q_{n}\right)=0 \\
l=1,2, \ldots, m
\end{gathered}
$$

em que $g_{l}$ são as funções dos vínculos, cujas derivadas parciais em relação às coordenadas generalizadas $q_{k}$ podem ser entendidas como contribuições às forças generalizadas $Q_{k}$, ponderadas pelos multiplicadores de Lagrange $\lambda_{l}$. Para o sistema em análise, $k$ é igual a 6 (três coordenadas dos atuadores mais três coordenadas do efetuador) e $m$ é igual a 3 (três equações de vínculo).

As expressões de energia cinética e de energia potencial são:

$$
\begin{aligned}
T=\frac{1}{2}\left(m_{1 e}+\right. & \left.m_{2 e}\right)\left(a_{1} \dot{q_{2}}\right)^{2}+\frac{1}{2}\left(2 m_{2 e}+m_{3}+M\right)\left({\dot{x_{1}}}^{2}+{\dot{x_{2}}}^{2}+{\dot{x_{3}}}^{2}\right) \\
& +\frac{1}{2}\left(m_{1 e}+m_{2 e}\right)\left(a_{1} \dot{q}_{3}\right)^{2}+\frac{1}{2}\left(m_{4}+2 m_{5 e}+m_{6}\right) \dot{x}_{1}{ }^{2} \\
& +\frac{1}{2}\left(2 m_{5 e}+m_{6}\right)\left(\frac{a_{5}^{2}}{a_{5}^{2}-x_{2}^{2}}\right){\dot{x_{2}}}^{2}
\end{aligned}
$$




$$
\begin{gathered}
V=-\left(m_{1 e}+m_{2 e}\right) g a_{1} \operatorname{senq}_{2}-\left(2 m_{2 e}+m_{3}+M\right) g x_{3}-\left(m_{1 e}+m_{2 e}\right) g a_{1} \operatorname{senq}_{3} \\
-\left(2 m_{5 e}+m_{6}\right) g \sqrt{a_{5}^{2}-x_{2}^{2}}
\end{gathered}
$$

As derivadas parciais das equações de vínculo e das expressões de energia cinética e potencial podem ser observadas no Apêndice D. A partir dessas derivadas, encontram-se as seguintes equações de movimento de acordo com o método de Lagrange:

$$
\begin{gathered}
0=\tau_{1}-\lambda_{1} \\
\left(m_{1 e}+m_{2 e}\right) a_{1}^{2} \ddot{q}_{2}-\left(m_{1 e}+m_{2 e}\right) g a_{1} \cos q_{2} \\
=\tau_{2}+\lambda_{2}\left[-2\left(x_{2}-l+L+a_{1} \cos q_{2}\right) a_{1} \operatorname{senq}_{2}-2\left(x_{3}-a_{1} \operatorname{sen} q_{2}\right) a_{1} \cos q_{2}\right]
\end{gathered}
$$

$$
\begin{aligned}
& \left(m_{1 e}+m_{2 e}\right) a_{1}^{2} \ddot{q}_{3}-\left(m_{1 e}+m_{2 e}\right) g a_{1} \cos q_{3} \\
& \quad=\tau_{3}+\lambda_{3}\left[2\left(x_{2}+l-L-a_{1} \cos q_{2}\right) a_{1} \operatorname{sen} q_{3}-2\left(x_{3}-a_{1} \operatorname{sen} q_{3}\right) a_{1} \cos q_{3}\right]
\end{aligned}
$$

$$
\left(2 m_{2 e}+m_{3}+M+m_{4}+2 m_{5 e}+m_{6}\right) \ddot{x_{1}}=\lambda_{1}+\lambda_{2} 2 x_{1}+\lambda_{3} 2 x_{1}
$$

$$
\begin{gathered}
\left(2 m_{2 e}+m_{3}+M\right) \ddot{x}_{2}+\left(2 m_{5 e}+m_{6}\right)\left[\frac{a_{5}^{2} x_{2}{\dot{x_{2}}}^{2}}{\left(a_{5}^{2}-x_{2}^{2}\right)^{2}}+\left(\frac{a_{5}^{2}}{a_{5}^{2}-x_{2}^{2}}\right) \ddot{x_{2}}+\frac{g x_{2}}{\sqrt{a_{5}^{2}-x_{2}^{2}}}\right] \\
=\lambda_{2} 2\left(x_{2}-l+L+a_{1} \cos q_{2}\right)+\lambda_{3} 2\left(x_{2}+l-L-a_{1} \cos q_{3}\right)
\end{gathered}
$$

$$
\left(2 m_{2 e}+m_{3}+M\right) \ddot{x_{3}}-\left(2 m_{2 e}+m_{3}+M\right) g=\lambda_{2} 2\left(x_{3}-a_{1} \operatorname{senq}_{2}\right)+\lambda_{3} 2\left(x_{3}-a_{1} \operatorname{senq}_{3}\right)
$$

Dessa forma, a partir de um movimento requerido, pode se calcular os esforços necessários nos atuadores (concomitantemente aos valores dos multiplicadores de Lagrange) pela solução de um sistema algébrico linear de seis equações e seis incógnitas (três esforços e três multiplicadores de Lagrange). 
Fazendo-se o desenvolvimento analítico das equações 4.24 a 4.29, com a eliminação dos multiplicadores de Lagrange, foi verificado que essas são idênticas às equações 4.12 a 4.14, obtidas pelo Princípio dos Trabalhos Virtuais, como era esperado.

\subsection{MODELAGEM COM MASSAS DAS BARRAS CONCENTRADAS EM SEUS CENTROS GEOMÉTRICOS}

\subsubsection{Hipóteses simplificadoras}

Nesta abordagem, são consideradas as seguintes hipóteses simplificadoras:

- barras equivalentes a barras sem massa e perfeitamente rígidas, cada uma com uma massa concentrada em seu centro geométrico;

- juntas de rotação, esféricas e prismáticas ideais (rígidas, sem atrito e sem folga).

A escolha da modelagem das massas como concentradas nos centros geométricos das barras se justifica por este ser um modelo parcial, menos complexo, do modelo de massas distribuídas que será posteriormente apresentado.

\subsubsection{Modelagem pelo Princípio dos Trabalhos Virtuais}

Antes de aplicar o Princípio dos trabalhos virtuais, é importante notar que o deslocamento virtual e a aceleração de um ponto de uma barra rígida pode ser calculado a partir dos deslocamentos virtuais e acelerações de outros dois pontos pertencentes à barra. Para barra $\mathrm{CE}$, por exemplo, pode se usar os pontos $\mathrm{C}$ e $\mathrm{E}$ como referência para o cálculo do deslocamento virtual e aceleração de seu centro geométrico da seguinte forma:

$$
\begin{aligned}
\delta \boldsymbol{x}_{C E} & =\frac{\delta x_{C}+\delta x_{E}}{2} \\
\ddot{x}_{C E} & =\frac{\ddot{x}_{C}+\ddot{x}_{E}}{2}
\end{aligned}
$$


Essas relações são muito úteis para essa abordagem porque os deslocamentos virtuais e acelerações dos pontos $E$ e $F$ são idênticos ao do efetuador, e dos pontos C e D podem ser facilmente calculados em função do movimento das juntas ativas de coordenadas $q_{2}$ e $q_{3}$.

Dessa forma, a somatória de trabalhos virtuais relativos à força e momentos dos atuadores, forças de inércia e forças gravitacionais apresentada na equação 4.32 deve valer zero.

Substituindo as expressões dos deslocamentos virtuais (equações 4.2 a 4.10) na somatória dos trabalhos virtuais na equação 4.32 e agrupando os termos dependentes de $\delta q_{1}, \delta q_{2}$ e $\delta q_{3}$, encontram-se as equações 4.33 a 4.35 .

$$
\begin{gathered}
\boldsymbol{\tau} \delta \boldsymbol{q}-m_{1} \frac{\ddot{\boldsymbol{x}}_{C}}{2} \frac{\delta \boldsymbol{x}_{C}}{2}-m_{2}\left(\frac{\ddot{\boldsymbol{x}}_{C}+\ddot{\boldsymbol{x}}_{E}}{2}\right)\left(\frac{\delta \boldsymbol{x}_{C}+\delta \boldsymbol{x}_{E}}{2}\right)-\left(m_{3}+M\right) \ddot{\boldsymbol{x}} \delta \boldsymbol{x}-m_{1} \frac{\ddot{\boldsymbol{x}}_{D}}{2} \frac{\delta \boldsymbol{x}_{D}}{2} \\
-m_{2}\left(\frac{\ddot{\boldsymbol{x}}_{D}+\ddot{\boldsymbol{x}}_{F}}{2}\right)\left(\frac{\delta \boldsymbol{x}_{D}+\delta \boldsymbol{x}_{F}}{2}\right)-m_{4} \ddot{\boldsymbol{x}}_{H} \delta \boldsymbol{x}_{H}-2 m_{5}\left(\frac{\ddot{\boldsymbol{x}}_{H}+\ddot{\boldsymbol{x}}_{I}}{2}\right)\left(\frac{\delta \boldsymbol{x}_{H}+\delta \boldsymbol{x}_{I}}{2}\right) \\
-m_{6} \ddot{\boldsymbol{x}}_{I} \delta \boldsymbol{x}_{I}+m_{1} \boldsymbol{g} \frac{\delta \boldsymbol{x}_{C}}{2}+m_{2} \boldsymbol{g}\left(\frac{\delta \boldsymbol{x}_{C}+\delta \boldsymbol{x}_{E}}{2}\right)+\left(m_{3}+M\right) \boldsymbol{g} \delta \boldsymbol{x}+m_{1} \boldsymbol{g} \frac{\delta \boldsymbol{x}_{D}}{2} \\
+m_{2} \boldsymbol{g}\left(\frac{\delta \boldsymbol{x}_{D}+\delta \boldsymbol{x}_{F}}{2}\right)+2 m_{5} \boldsymbol{g} \frac{\delta \boldsymbol{x}_{I}}{2}+m_{6} \boldsymbol{g} \delta \boldsymbol{x}_{I}=0 \\
\tau_{1}=K_{1}+\left(K_{4}+K_{5}\right) J_{x q 21}+K_{6} J_{x q 31} \\
\tau_{2}=K_{2}+\left(K_{4}+K_{5}\right) J_{x q 22}+K_{6} J_{x q 33} \\
\tau_{3}=K_{3}+\left(K_{4}+K_{5}\right) J_{x q 23}+K_{6} J_{x q 33}
\end{gathered}
$$

em que:

$$
\begin{gathered}
K_{1}=\left(\frac{m_{2}}{4}+m_{3}+m_{4}+2 m_{5}+m_{6}+M\right) \ddot{q}_{1} \\
K_{2}=\left(\left(m_{1}+m_{2}\right)\left(\frac{a_{1}^{2} \ddot{q}_{2}}{4}-\frac{g a_{1} \cos q_{2}}{2}\right)+\frac{m_{2} a_{1}}{4}\left(\ddot{x}_{2} \sin q_{2}+\ddot{x}_{3} \cos q_{2}\right)\right)
\end{gathered}
$$




$$
K_{3}=\left(\left(m_{1}+m_{2}\right)\left(\frac{a_{1}^{2} \ddot{q}_{3}}{4}-\frac{g a_{1} \cos q_{3}}{2}\right)+\frac{m_{2} a_{1}}{4}\left(-\ddot{x}_{2} \sin q_{3}+\ddot{x}_{3} \cos q_{3}\right)\right)
$$

$$
\begin{gathered}
K_{4}=\left(\frac{m_{2} a_{1}}{4}\left(\ddot{q}_{2} \sin _{2}+\dot{q}_{2}^{2} \cos q_{2}-\ddot{q}_{3} \operatorname{sen}_{3}-\dot{q}_{3}^{2} \cos q_{3}\right)\right. \\
\left.+\left(\frac{m_{2}}{2}+m_{3}+\frac{m_{5}}{2}+m_{6}+M\right) \ddot{x}_{2}\right) \\
K_{5}=\left[\left(\frac{m_{5}}{2}+m_{6}\right)\left(\left(\dot{x}_{2}^{2}+x_{2} \ddot{x}_{2}\right)\left(a_{5}^{2}-x_{2}^{2}\right)^{-\frac{1}{2}}+\left(x_{2} \dot{x}_{2}\right)^{2}\left(a_{5}^{2}-x_{2}^{2}\right)^{-\frac{3}{2}}\right)\right. \\
\left.+\left(m_{5}+m_{6}\right) g\right] x_{2}\left(a_{5}^{2}-x_{2}^{2}\right)^{-1 / 2} \\
K_{6}=\left(\frac{m_{2} a_{1}}{4}\left(\ddot{q}_{2} \cos q_{2}-\dot{q}_{2}^{2} \sin q_{2}+\ddot{q}_{3} \cos q_{3}-\dot{q}_{3}^{2} \sin q_{3}\right)+\left(\frac{m_{2}}{2}+m_{3}+M\right) \ddot{x}_{3}\right. \\
\left.-\left(m_{2}+m_{3}+M\right) g\right)
\end{gathered}
$$

Assim, a partir de um movimento requerido, pode se calcular os esforços necessários nos atuadores.

\subsection{MODELAGEM COM MASSAS DAS BARRAS DISTRIBUÍDAS}

\subsubsection{Hipóteses simplificadoras}

Nesta abordagem, são consideradas as seguintes hipóteses simplificadoras:

- barras homogêneas e perfeitamente rígidas;

- juntas de rotação, esféricas e prismáticas ideais (rígidas, sem atrito e sem folga). 


\subsubsection{Modelagem pelo Princípio dos Trabalhos Virtuais}

Para estender o modelo anterior, de massas concentradas nos centros geométricos das barras, para o caso de massas homogeneamente distribuídas, basta incluir na somatória de trabalhos virtuais termos relativos aos torques devido a inércia à rotação das barras. Devem ser incluídos os termos listados a seguir para as barras que possuem eixo de rotação com direção constante.

Para a barra AC:

$$
-I_{A C x 1} \ddot{q}_{2} \delta q_{2}
$$

Para a barra BD:

$$
-I_{B D x 1} \ddot{q}_{3} \delta q_{3}
$$

Para as barras do paralelogramo articulado:

$$
-I_{H I x 1} \ddot{\theta}_{H} \delta \theta_{H}=-I_{H I x 1} \ddot{\theta}_{H} \frac{\delta x_{2}}{a_{5} \sin \theta_{H}}
$$

Os símbolos $I_{A C x 1}, I_{B D x 1}, I_{H I x 1}$ correspondem aos momentos de inércia das barras $\mathrm{AC}, \mathrm{BD}$, e do paralelogramo articulado em relação aos seus eixos principais que são paralelos à direção $x_{2}$, e $\theta_{H}$ é o ângulo entre as barras do paralelogramo articulado e a direção horizontal, definido de modo análogo a $q_{2}$.

Para as barras CE e DF, cujos vetores velocidade angular possuem direções variáveis no tempo, é necessário incluir os termos a seguir.

Para a barra CE:

$$
\left(-\boldsymbol{I}_{C E} \dot{\boldsymbol{\omega}}_{C E}-\boldsymbol{\omega}_{C E} \wedge\left(\boldsymbol{I}_{C E} \boldsymbol{\omega}_{C E}\right)\right) \delta \boldsymbol{\Theta}_{C E}
$$

Para a barra DF:

$$
\left(-\boldsymbol{I}_{D F} \dot{\boldsymbol{\omega}}_{D F}-\boldsymbol{\omega}_{D F} \wedge\left(\boldsymbol{I}_{D F} \boldsymbol{\omega}_{D F}\right)\right) \delta \boldsymbol{\Theta}_{D F}
$$


em que $\boldsymbol{I}_{C E}$ e $\boldsymbol{I}_{D F}$ são as matrizes de inércia das barras CE e DF em relação a sistemas coordenados localizados nos centros de massa dessas barras e com direções paralelas às direções $x_{1}, x_{2}$ e $x_{3}$, os parâmetros $\boldsymbol{\omega}_{C E}, \boldsymbol{\omega}_{D F}, \delta \boldsymbol{\Theta}_{C E}$ e $\delta \boldsymbol{\Theta}_{D F}$ são as velocidades angulares e deslocamentos virtuais das mesmas barras, e o símbolo $\wedge$ representa produto vetorial. As matrizes de inércia $\boldsymbol{I}_{C E}$ e $\boldsymbol{I}_{D F}$ podem ser calculadas por (TSAI, 1999):

$$
\begin{gathered}
\boldsymbol{I}_{C E}=R_{C E} \overline{\boldsymbol{I}}_{C E} R_{C E}^{T} \\
\boldsymbol{I}_{D F}=R_{D F} \overline{\boldsymbol{I}}_{D F} R_{D F}^{T}
\end{gathered}
$$

em que $\overline{\boldsymbol{I}}_{C E}$ e $\overline{\boldsymbol{I}}_{D F}$ são as matrizes principais de inércia das barras e $R_{C E}$ e $R_{D F}$ são as matrizes de rotação entre os sistemas coordenados relativos às direções principais das barras (solidários a estas) e os sistemas coordenados paralelos às direções $x_{1}$, $x_{2}$ e $x_{3}$. O cálculo das matrizes $R_{C E}$ e $R_{D F}$ em função das coordenadas $\boldsymbol{q}$ e $\boldsymbol{x}$ está detalhado no Apêndice $E$.

Tanto para a barra CE como para a barra DF, o vetor velocidade angular e sua derivada podem ser calculados a partir dos vetores velocidade e aceleração dos pontos de suas extremidades, assumindo que o vetor velocidade angular é sempre ortogonal a direção longitudinal da barra. Em outras palavras, não há rotação da barra em relação ao seu eixo longitudinal.

Para a barra CE, por exemplo, sua velocidade angular pode ser obtida por:

$$
\boldsymbol{\omega}_{C E}=\left[\begin{array}{l}
\left(x_{E 2}-x_{C 2}\right)\left(\dot{x}_{E 3}-\dot{x}_{C 3}\right)-\left(x_{E 3}-x_{C 3}\right)\left(\dot{x}_{E 2}-\dot{x}_{C 2}\right) \\
\left(x_{E 3}-x_{C 3}\right)\left(\dot{x}_{E 1}-\dot{x}_{C 1}\right)-\left(x_{E 1}-x_{C 1}\right)\left(\dot{x}_{E 3}-\dot{x}_{C 3}\right) \\
\left(x_{E 1}-x_{C 1}\right)\left(\dot{x}_{E 2}-\dot{x}_{C 2}\right)-\left(x_{E 2}-x_{C 2}\right)\left(\dot{x}_{E 1}-\dot{x}_{C 1}\right)
\end{array}\right]
$$

Simplificando e rearranjando a equação 4.49, encontra-se:

$$
\boldsymbol{\omega}_{E C}=J_{\omega q} \dot{\boldsymbol{q}}+J_{\omega x} \dot{\boldsymbol{x}}
$$

em que: 


$$
\begin{gathered}
J_{\omega q}=\frac{1}{a_{2}^{2}}\left[\begin{array}{ccc}
0 & {\left[-\left(x_{2}-l+L\right) a_{1} \cos q_{2}+x_{3} a_{1} \sin q_{2}-a_{1}^{2}\right]} & 0 \\
0 & a_{1} x_{1} \cos q_{2} & 0 \\
0 & -a_{1} x_{1} \sin q_{2} & 0
\end{array}\right] \\
J_{\omega x}=\frac{1}{a_{2}^{2}}\left[\begin{array}{ccc}
x_{3}-a_{1} \sin q_{2} & -\left(x_{3}-a_{1} \sin q_{2}\right) & x_{2}-l+L+a_{1} \cos q_{2} \\
-\left(x_{2}-l+L+a_{1} \cos q_{2}\right) & 0 & -x_{1}
\end{array}\right]
\end{gathered}
$$

Assim:

$$
\delta \boldsymbol{\Theta}_{\mathrm{CE}}=J_{\omega q} \delta \boldsymbol{q}+J_{\omega x} \delta \boldsymbol{x}=\left(J_{\omega q}+J_{\omega x} J_{x}^{-1} J_{q}\right) \delta \boldsymbol{q}
$$

Substituindo a equação 4.53 na equação 4.45 , o trabalho virtual relativo ao torque devido à inércia à rotação da barra CE pode ser calculado por:

$$
\left(-\boldsymbol{I}_{C E} \dot{\boldsymbol{\omega}}_{C E}-\boldsymbol{\omega}_{C E} \wedge\left(\boldsymbol{I}_{C E} \boldsymbol{\omega}_{C E}\right)\right)\left(\left(J_{\omega q}+J_{\omega x} J_{x}^{-1} J_{q}\right) \delta \boldsymbol{q}\right)
$$

que pode ser rearranjado na seguinte forma:

$$
\left[\left(J_{\omega q}+J_{\omega x} J_{x}^{-1} J_{q}\right)^{T}\left(-\boldsymbol{I}_{C E} \dot{\boldsymbol{\omega}}_{C E}-\boldsymbol{\omega}_{C E} \wedge\left(\boldsymbol{I}_{C E} \boldsymbol{\omega}_{C E}\right)\right)\right] \delta \boldsymbol{q}
$$

A mesma estratégia pode ser aplicada à barra DF, encontrando-se:

$$
\left[\left(J_{\omega q}+J_{\omega x} J_{x}^{-1} J_{q}\right)^{T}\left(-\boldsymbol{I}_{D F} \dot{\boldsymbol{\omega}}_{D F}-\boldsymbol{\omega}_{D F} \wedge\left(\boldsymbol{I}_{D F} \boldsymbol{\omega}_{D F}\right)\right)\right] \delta \boldsymbol{q}
$$

Finalmente, é necessário inserir os termos 4.38, 4.39, 4.40, 4.51 e 4.52 na somatória da equação 4.32 e agrupar os termos dependentes de $\delta q_{1}, \delta q_{2}$ e $\delta q_{3}$ para finalizar o modelo dinâmico de massas distribuídas. 


\section{ANÁLISE DO MODELO DINÂMICO DO MECANISMO 2 RSS + PPaP}

\subsection{COMPARAÇÃO DOS MODELOS DINÂMICOS}

A fim de se verificar o correto desenvolvimento das equações dos modelos dinâmicos, foram realizadas simulações de movimentação do mecanismo utilizando duas plataformas distintas, Matlab da MathWorks e Adams da MSC Software, em que eram calculados os esforços necessários nos atuadores a partir de um movimento requerido no efetuador do mecanismo.

No Matlab, foram implementadas as equações desenvolvidas nos capítulos 3 e 4. Já no Adams, foi necessária apenas a definição das peças (dimensões e propriedades de massa) e a definição das juntas (vínculo entre as peças) numa interface do tipo CAD. O modelo nesse ambiente pode ser observado na Figura 5.1.

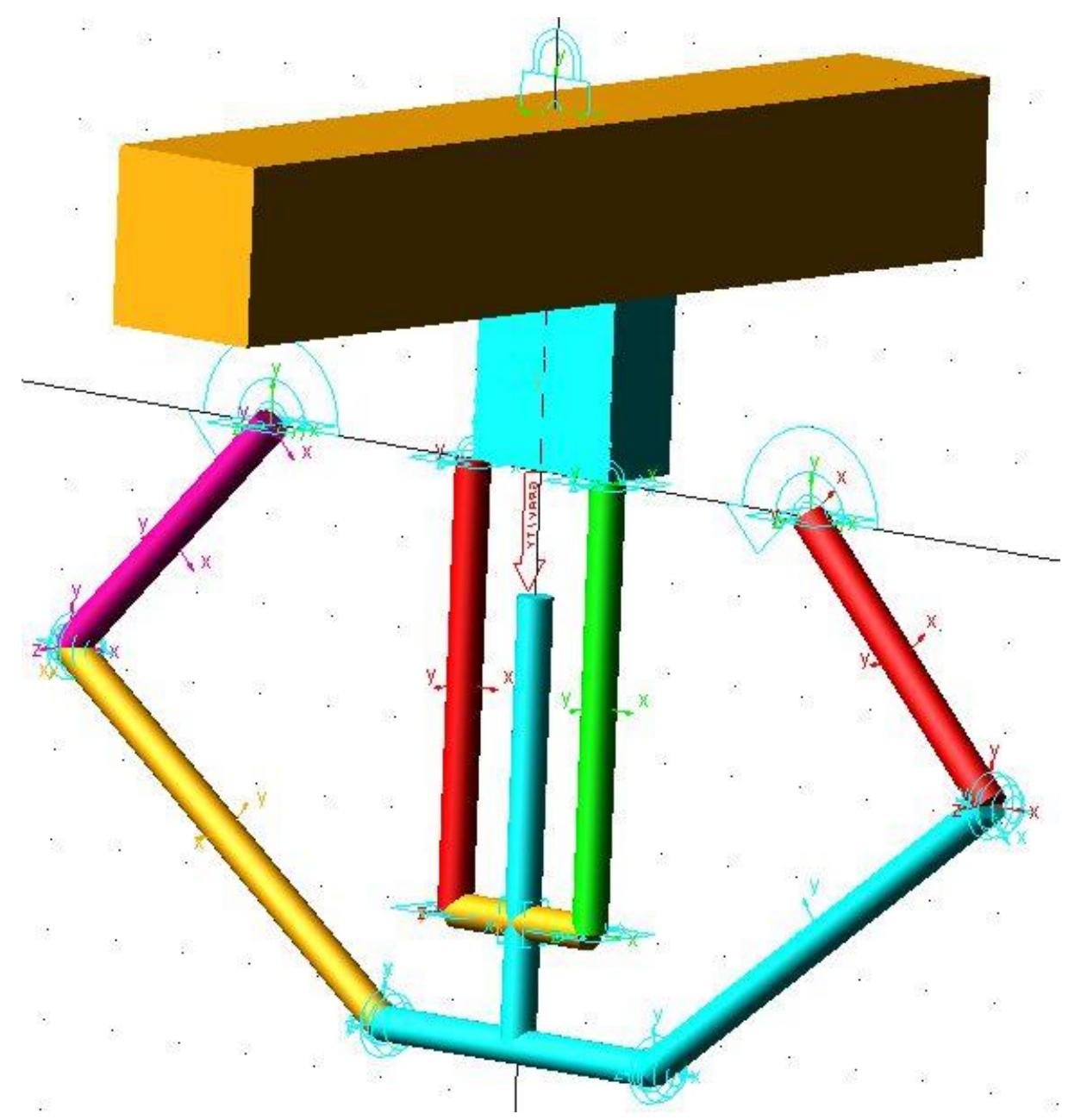

Figura 5.1 - Modelo do mecanismo elaborado no software Adams 
Nota-se que no Adams o cálculo de esforços necessários nos atuadores é realizado através de algoritmos numéricos para solução dinâmica de sistemas multicorpos. Assim, seu uso possui limitações para análise do modelo e, principalmente, para o desenvolvimento de leis de controle de posição do robô em tempo real.

Para os cálculos de esforços nos atuadores foram utilizadas as dimensões e massas indicadas na Tabela 5.1. Note que a massa da carga manipulada foi considerada igual a zero para que as características dinâmicas do mecanismo fossem evidenciadas.

Tabela 5.1 - Parâmetros geométricos e inerciais

\begin{tabular}{|c|c|c|}
\hline $\begin{array}{c}\text { Comprimentos } \\
{[\mathrm{mm}]}\end{array}$ & $\begin{array}{c}\text { Massas } \\
{[\mathbf{k g}]}\end{array}$ & $\begin{array}{c}\text { Momentos de inércia } \\
{\left[\mathbf{k g} \cdot \mathbf{m m}^{2}\right]}\end{array}$ \\
\hline$a_{1}=200$ & $m_{1}=0,2$ & $I_{1_{-} x l}=671,7$ \\
\hline \multirow{2}{*}{$a_{2}=300$} & & $I_{2_{-} x l}=2258$ \\
\hline & $m_{2}=0,3$ & $I_{2_{-} x 2}=15,0$ \\
\hline$l=100$ & & $I_{2_{-} \times 3}=2258$ \\
\hline$a_{4}=100$ & $m_{3}=0,45$ & - \\
\hline$a_{5}=250$ & $m_{4}=0,1$ & - \\
\hline$a_{6}=100$ & $m_{5}=0,5$ & $I_{5_{-} x 2}=2616$ \\
\hline$L=200$ & $m_{6}=0,1$ & - \\
\hline- & - & - \\
\hline & $M=0($ sem carga $)$ & - \\
\hline
\end{tabular}

A fim de se fazer com que o efetuador alcançasse variadas posições, velocidades e acelerações, foram impostas às juntas ativas os seguintes movimentos baseados em funções senoidais:

$$
\begin{gathered}
q_{1}(t)=C_{1} \sin \left(\mathrm{c}_{1} \mathrm{t}\right) \\
q_{2}(t)=\pi / 4+C_{2} \sin \left(\mathrm{c}_{2} \mathrm{t}\right) \\
q_{3}(t)=\pi / 4+C_{3} \sin \left(\mathrm{c}_{3} \mathrm{t}\right)
\end{gathered}
$$

Os valores numéricos utilizados para as constantes das equações 5.1 a 5.3 podem ser observados na tabela 5.2. 
Tabela 5.2 - Parâmetros de funções de movimentos de entrada

\begin{tabular}{|c|c|}
\hline Parâmetro & Valor \\
\hline$C_{1}[\mathrm{~mm}]$ & 100 \\
\hline$c_{1}[\mathrm{rad} / \mathrm{s}]$ & 2 \\
\hline$C_{2}[\mathrm{rad}]$ & $\pi / 12$ \\
\hline$c_{2}[\mathrm{rad} / \mathrm{s}]$ & 5 \\
\hline$C_{3}[\mathrm{rad}]$ & $\pi / 12$ \\
\hline$c_{3}[\mathrm{rad} / \mathrm{s}]$ & 7 \\
\hline
\end{tabular}

A figura 5.2 mostra a posição do efetuador como consequência das funções de entrada em posição das juntas ativas. Durante o movimento, o efetuador chega a atingir $0,6 \mathrm{~m} / \mathrm{s}$ e $3,9 \mathrm{~m} / \mathrm{s}^{2}$.

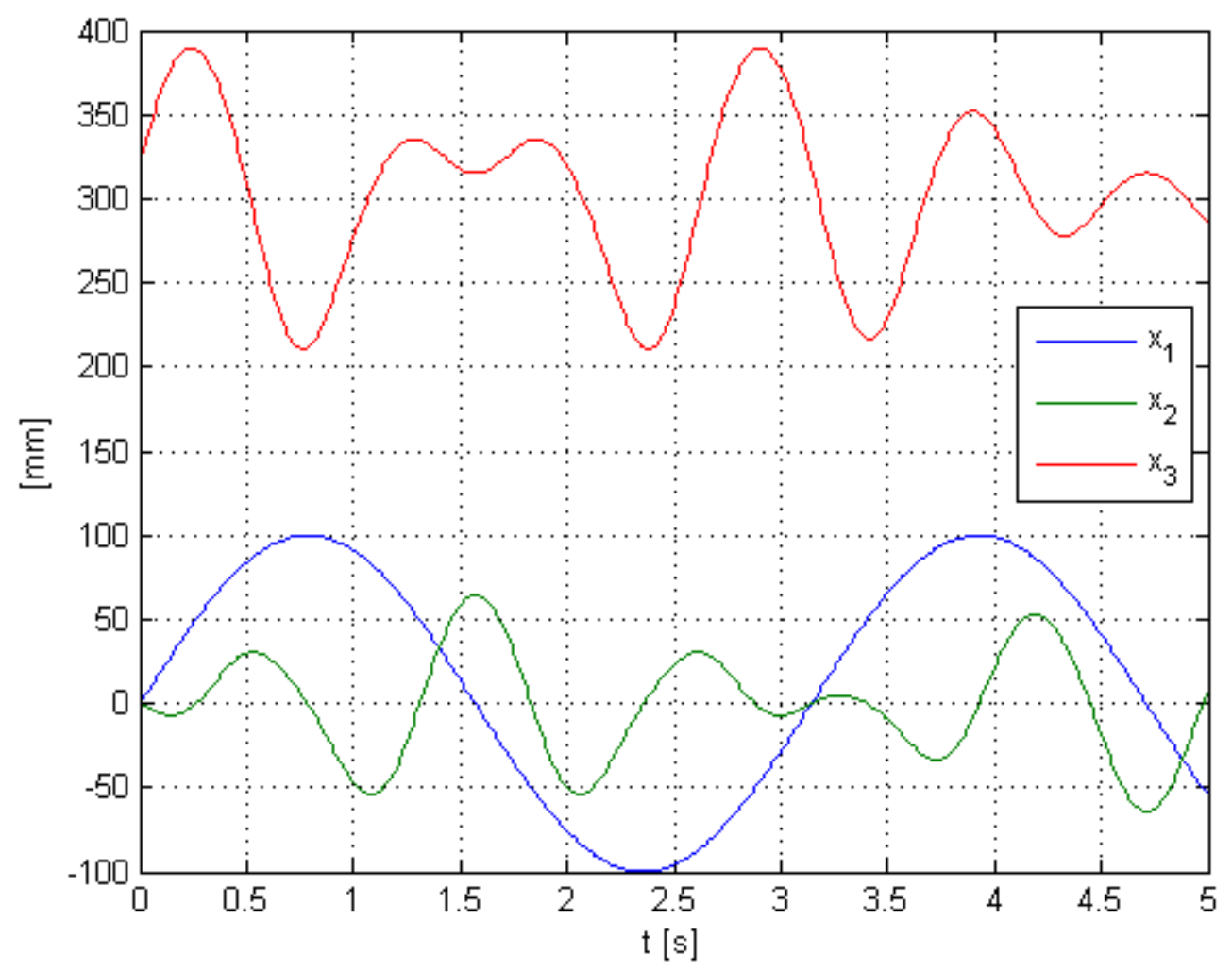

Figura 5.2 - Posição do efetuador ao longo do tempo

Foram implementadas no Matlab as equações sob as três diferentes hipóteses simplificadoras (massas concentradas nas extremidades das barras, massas concentradas nos centros das barras e massas distribuídas). Já no Adams, 
apenas o modelo de massas distribuídas foi implementado. Podem ser observados nas figuras 5.3 a 5.5 os esforços requeridos nos atuadores calculados no Adams e calculados para cada um dos modelos implementados no Matlab: massas distribuídas (MD), massas concentradas nos centros das barras (MC) e massas concentradas nas extremidades das barras (MCe).

Nota-se que o modelo de massas distribuídas implementado no Matlab possui boa correspondência com o modelo implementado no Adams e que entre os modelos de massas concentradas, o que concentra as massas nos centros das barras apresenta resultados mais próximos aos do modelo de massas distribuídas. Percebe-se ainda que os resultados dos dois outros modelos, de massas concentradas, envolvem os resultados de massas distribuídas. De fato, o modelo de massas concentradas nos centros geométricos das barras faz com que os momentos de inércia da barra em relação ao seu centro de massa sejam iguais a zero, enquanto o modelo de massa concentradas nas extremidades das barras correspondem a momentos de inércia superiores aos do modelo de massas distribuídas.

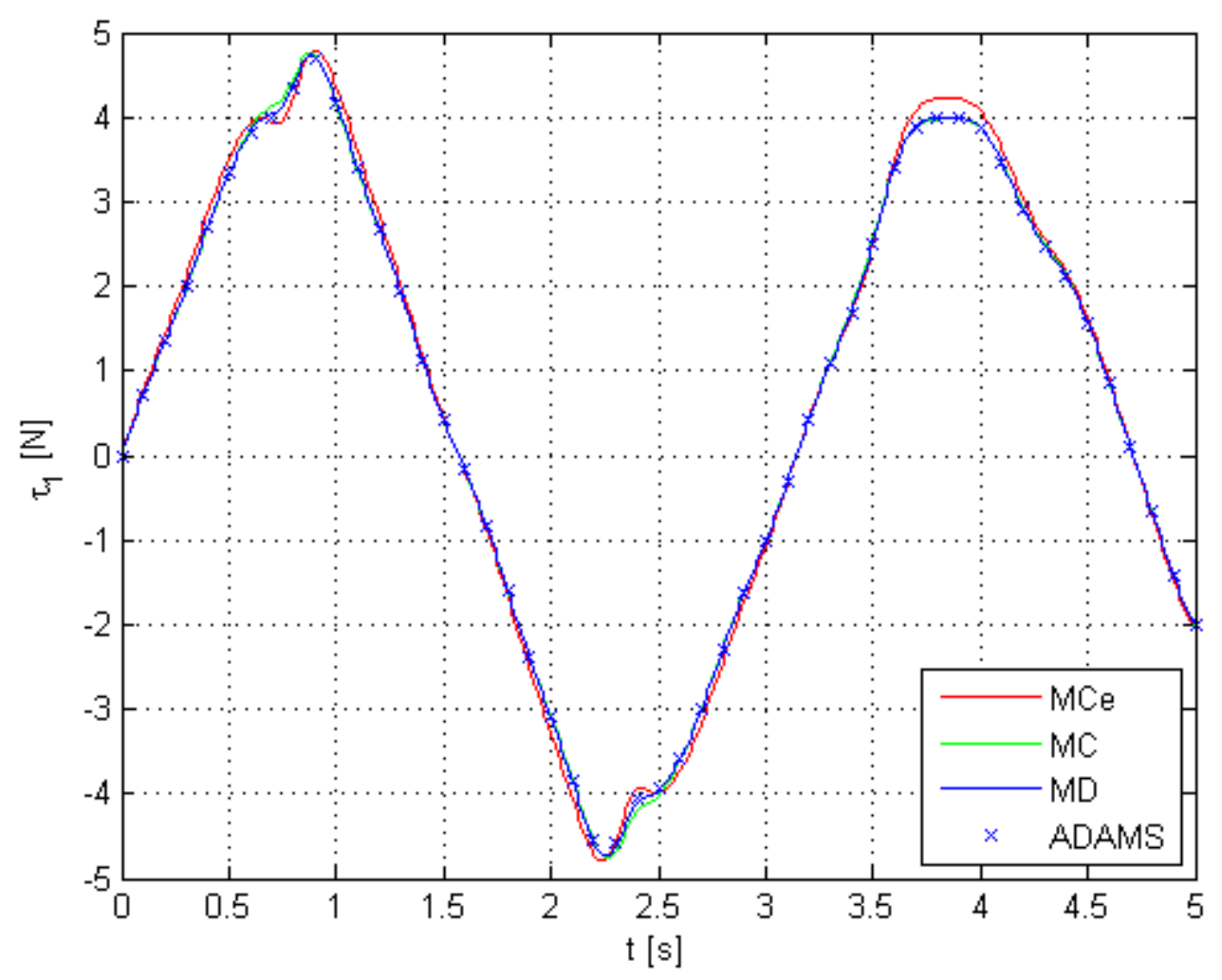

Figura 5.3 - Evolução da força $\tau_{1}$ ao longo do tempo 


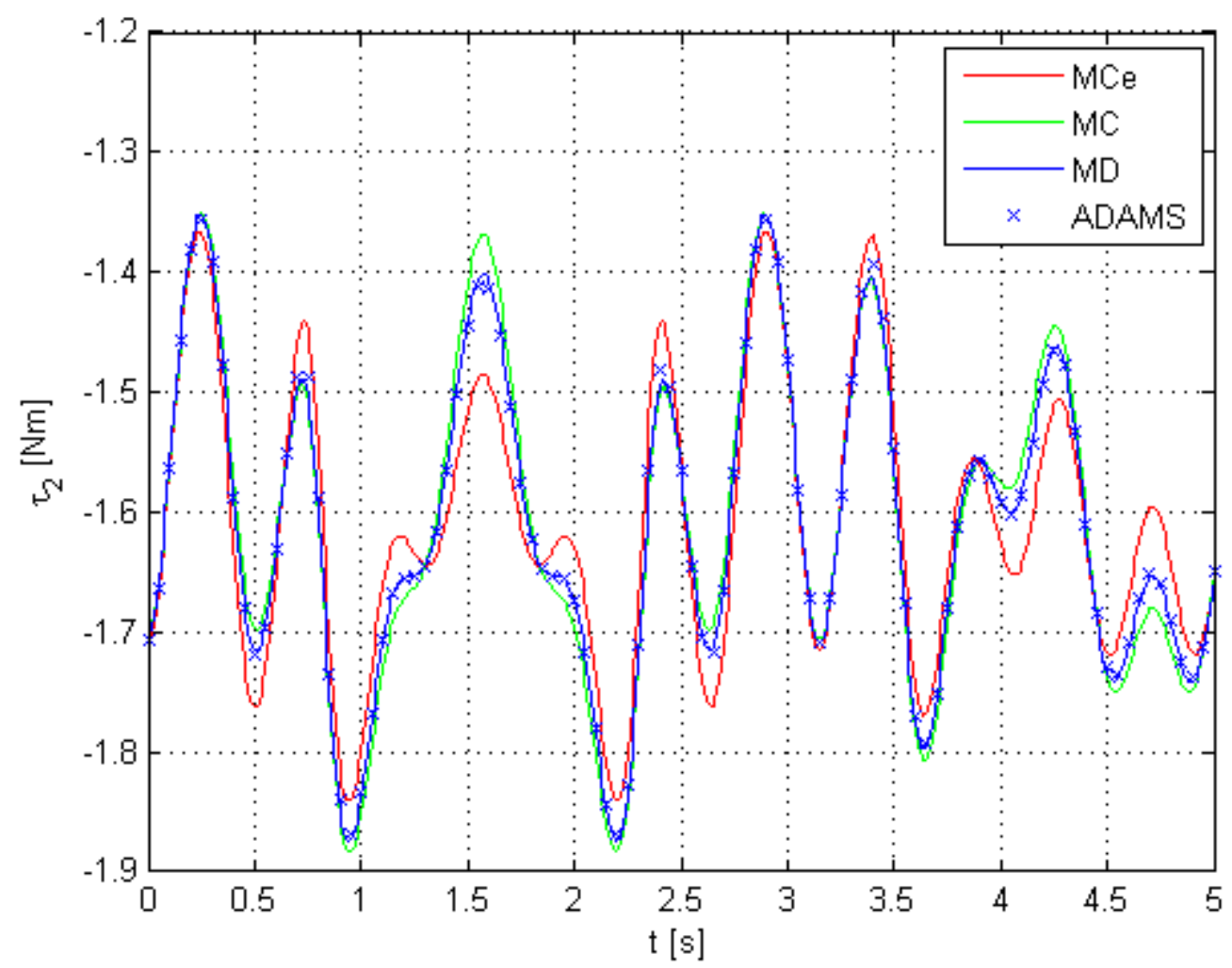

Figura 5.4 - Evolução do torque $\tau_{2}$ ao longo do tempo

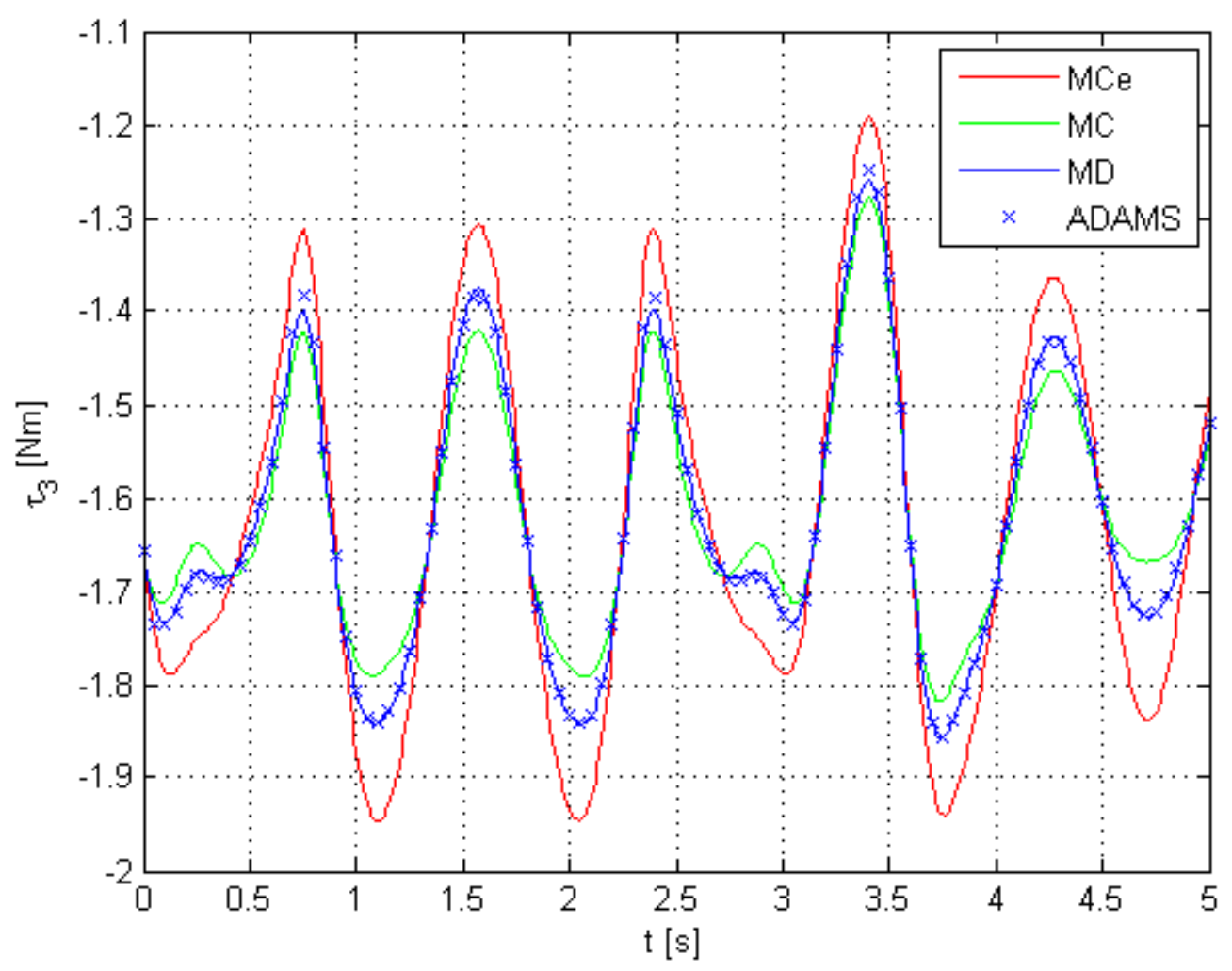

Figura 5.5 - Evolução do torque $\tau_{3}$ ao longo do tempo 
Na tabela 5.3 são apresentados os erros médios dos modelos implementados no Matlab em relação ao modelo implementado no Adams. Foram calculadas as razões da média RMS (Root Mean Square) dos erros no tempo sobre a média RMS dos esforços obtidos no Adams ao longo do tempo.

Tabela 5.3 - Parâmetros de funções de movimentos de entrada

\begin{tabular}{|c|c|c|c|}
\cline { 2 - 4 } \multicolumn{1}{c|}{} & erro $\boldsymbol{\tau}_{\mathbf{1}}[\%]$ & erro $\boldsymbol{\tau}_{\mathbf{2}}[\%]$ & erro $\boldsymbol{\tau}_{\mathbf{3}}[\%]$ \\
\hline Massas distribuídas & 0,65 & 0,33 & 0,33 \\
\hline $\begin{array}{c}\text { Massas concentras } \\
\text { nos centros }\end{array}$ & 1,56 & 1,07 & 1,79 \\
\hline $\begin{array}{c}\text { Massas concentradas } \\
\text { nas extremidades }\end{array}$ & 4,31 & 2,10 & 3,55 \\
\hline
\end{tabular}

A partir desses resultados, foi considerado que os desenvolvimentos dos modelos analíticos estavam corretos e deu-se prosseguimento à análise dinâmica do robô exclusivamente com as equações desenvolvidas nos capítulos 3 e 4, deixandose de utilizar o modelo implementado no software Adams.

\subsection{ACELERAÇÃO MÁXIMA DO EFETUADOR EM FUNÇÃO DA SATURAÇÃO DOS ATUADORES}

Utilizando as equações de modelagem dinâmica, foi realizada uma análise para determinação da aceleração máxima que poderia ser obtida no efetuador, em função da saturação dos atuadores do robô. Grande parte dessa seção foi publicada em (ALMEIDA, HESS-COELHO, 2011a, 2011b), porém com parâmetros geométricos e inerciais diferentes dos aqui utilizados. Nesta seção foram utilizados os parâmetros apresentados na tabela 5.4, mais próximos das características do protótipo do robô em fabricação.

Considerando-se que o mecanismo partia do repouso, com o efetuador posicionado no plano $x_{3}=480 \mathrm{~mm}$ e com $-280 \leq x_{1} \leq 280 \mathrm{~mm}$ e $-140 \leq x_{2} \leq$ $140 \mathrm{~mm}$, foram calculadas as acelerações máximas atingíveis pelo efetuador no sentido positivo de cada uma das direções $x_{1}, x_{2}$ e $x_{3}$, limitadas por valores, constantes, de esforços correspondentes à de saturação de cada atuador. Nota-se que se simplificou a análise não incluindo a dinâmica dos próprios atuadores. 
Tabela 5.4 - Parâmetros geométricos e inerciais

\begin{tabular}{|c|c|c|}
\hline $\begin{array}{c}\text { Comprimentos } \\
{[\mathbf{m m}]}\end{array}$ & $\begin{array}{c}\text { Massas } \\
{[\mathbf{k g}]}\end{array}$ & $\begin{array}{c}\text { Momentos de inércia } \\
{\left[\mathbf{k g} \cdot \mathbf{m m}^{2}\right]}\end{array}$ \\
\hline$a_{1}=350$ & $m_{1}=0,124$ & $I_{I_{-} x 1}=1262$ \\
\hline \multirow{2}{*}{$a_{2}=450$} & & $I_{2_{-} x l}=1722$ \\
\hline & $m_{2}=0,102$ & $I_{2_{-} x 2}=1,84$ \\
\hline$l=80$ & & $I_{2_{-} x 3}=1722$ \\
\hline$a_{4}=100$ & $m_{3}=0,200$ & - \\
\hline$a_{5}=380$ & $m_{4}=0,391$ & - \\
\hline$a_{6}=100$ & $m_{5}=0,137$ & $I_{5_{-} x 2}=1648$ \\
\hline$L=160$ & $m_{6}=0,235$ & - \\
\hline- & - & - \\
\hline & $M=0$ (sem carga $)$ & - \\
\hline
\end{tabular}

Utilizando-se o modelo de massas distribuídas e vetor de saturação de força $[\mathrm{N}]$ e torques $[\mathrm{Nm}]$ de entrada igual a $\boldsymbol{\tau}_{\boldsymbol{s a t}}=\left[\begin{array}{lll}100 & 10 & 10\end{array}\right]^{T}$ foram obtidos os resultados apresentados nas figuras 5.6 a 5.8 .

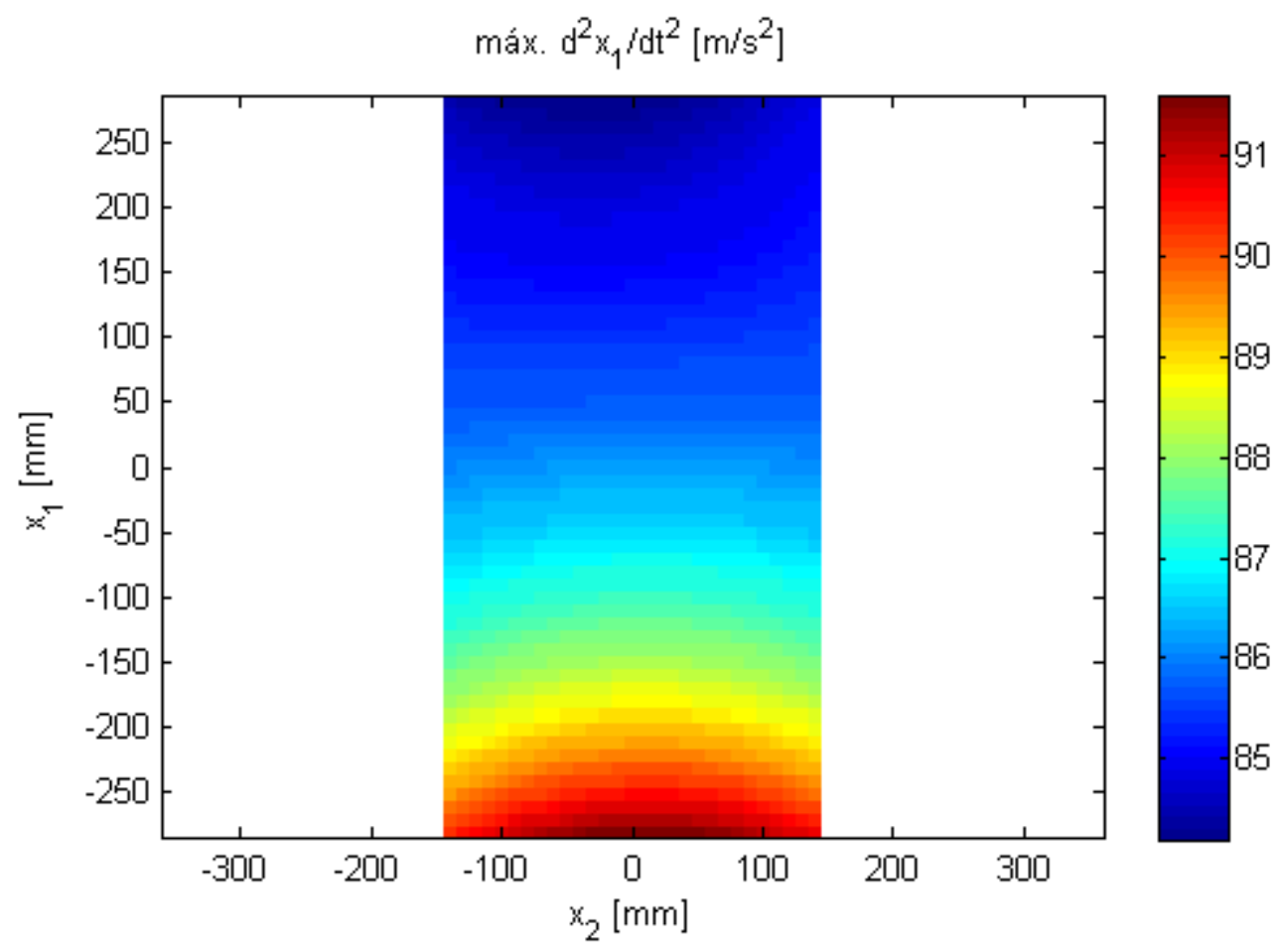

Figura 5.6 - Massas distribuídas, máxima aceleração $\left(\mathrm{m} / \mathrm{s}^{2}\right)$ na direção $x_{1}$ 


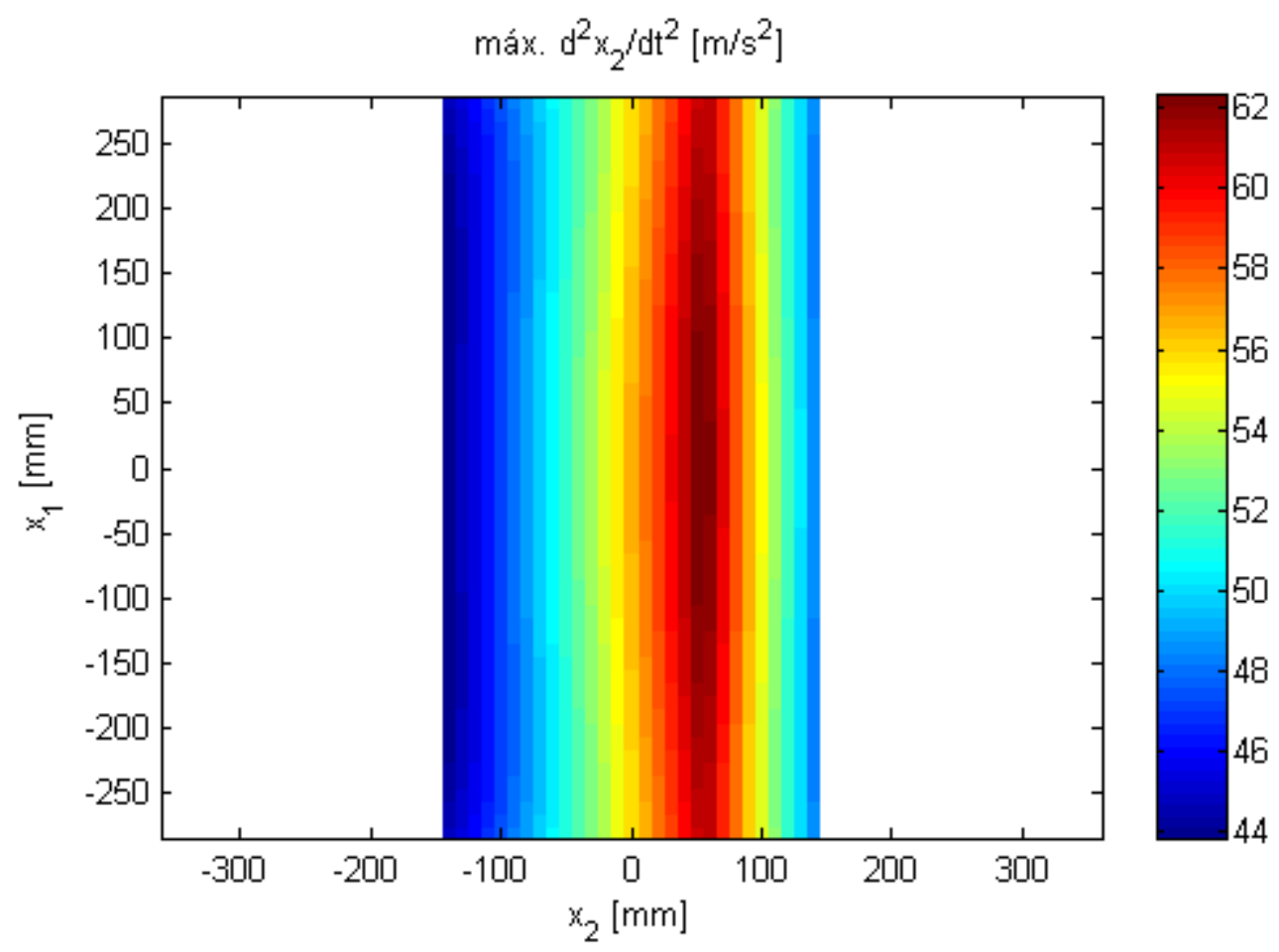

Figura 5.7 - Massas distribuídas, máxima aceleração $\left(\mathrm{m} / \mathrm{s}^{2}\right)$ na direção $x_{2}$

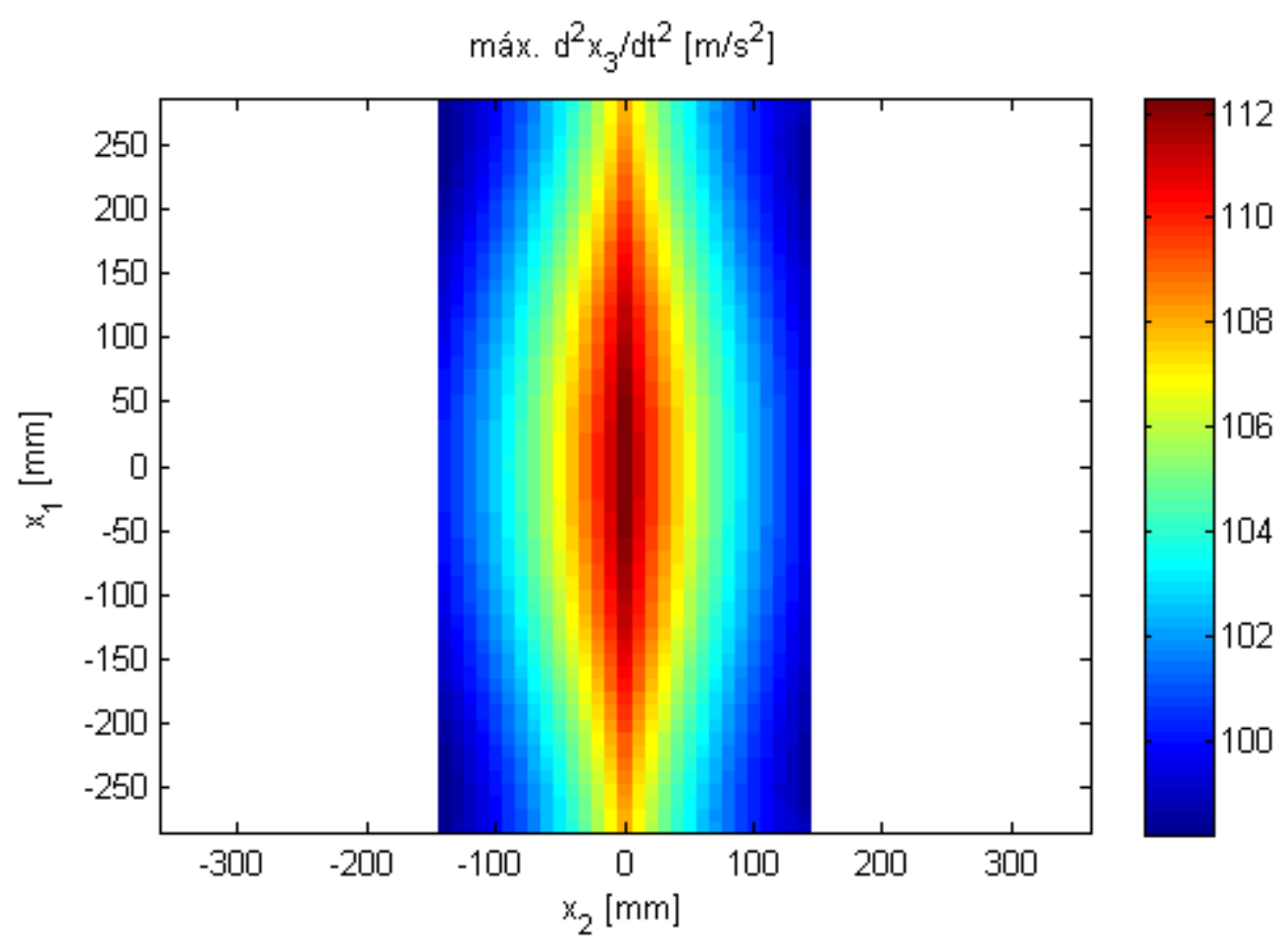

Figura 5.8 - Massas distribuídas: máxima aceleração $\left(\mathrm{m} / \mathrm{s}^{2}\right)$ na direção $x_{3}$ 
Pode-se observar na figura 5.6 que a aceleração máxima no sentido positivo da direção $x_{1}$ fica contida no intervalo [84;92] $\mathrm{m} / \mathrm{s}^{2}$ nas condições de saturação prédefinidas. A variação dessa aceleração ao longo do espaço de trabalho do mecanismo é em parte consequência do ganho mecânico variável entre as coordenadas dos atuadores e do efetuador. Porém, é na maior parte consequência de efeitos gravitacionais na dinâmica do mecanismo. É mais fácil se aproximar do que se afastar do plano $x_{1}=0 \mathrm{~mm}$. Isto sugere que seja avaliada a possibilidade de se adicionar molas ou contra-pesos ao mecanismo para compensar efeitos gravitacionais.

Para as acelerações nos sentidos positivos das direções $x_{2}$ e $x_{3}$, nota-se que os maiores valores são atingidos em regiões centrais do espaço de trabalho do mecanismo. Na direção $x_{2}$ os valores de aceleração máxima são mais sensíveis à posição do efetuador.

O mesmo procedimento de análise foi aplicado ao modelo de massas concentradas nos centros geométricos das barras. Seus resultados podem ser observados nas figuras 5.9 a 5.11 .

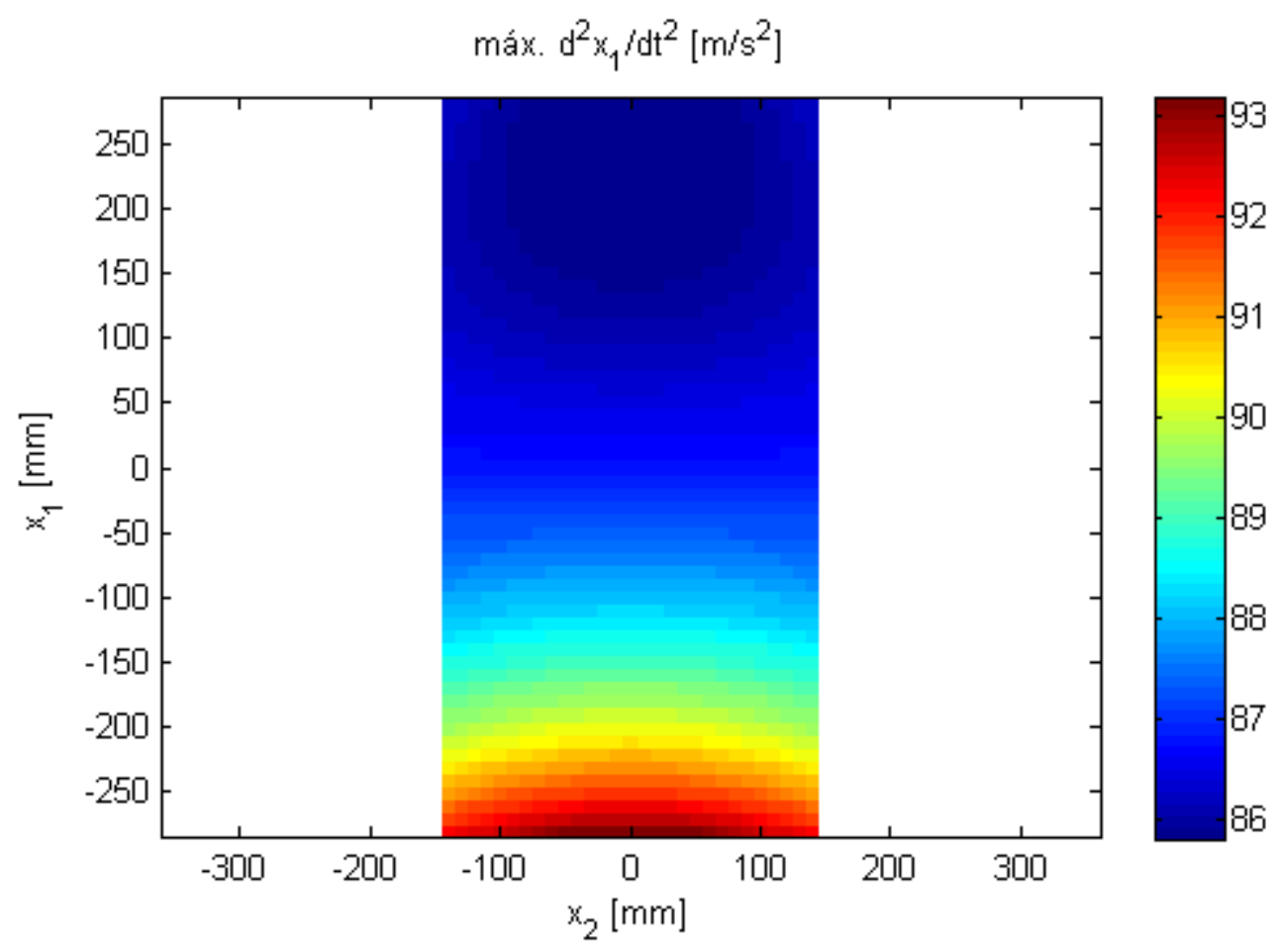

Figura 5.9 - Massas concentradas, máxima aceleração $\left(\mathrm{m} / \mathrm{s}^{2}\right)$ na direção $x_{1}$ 


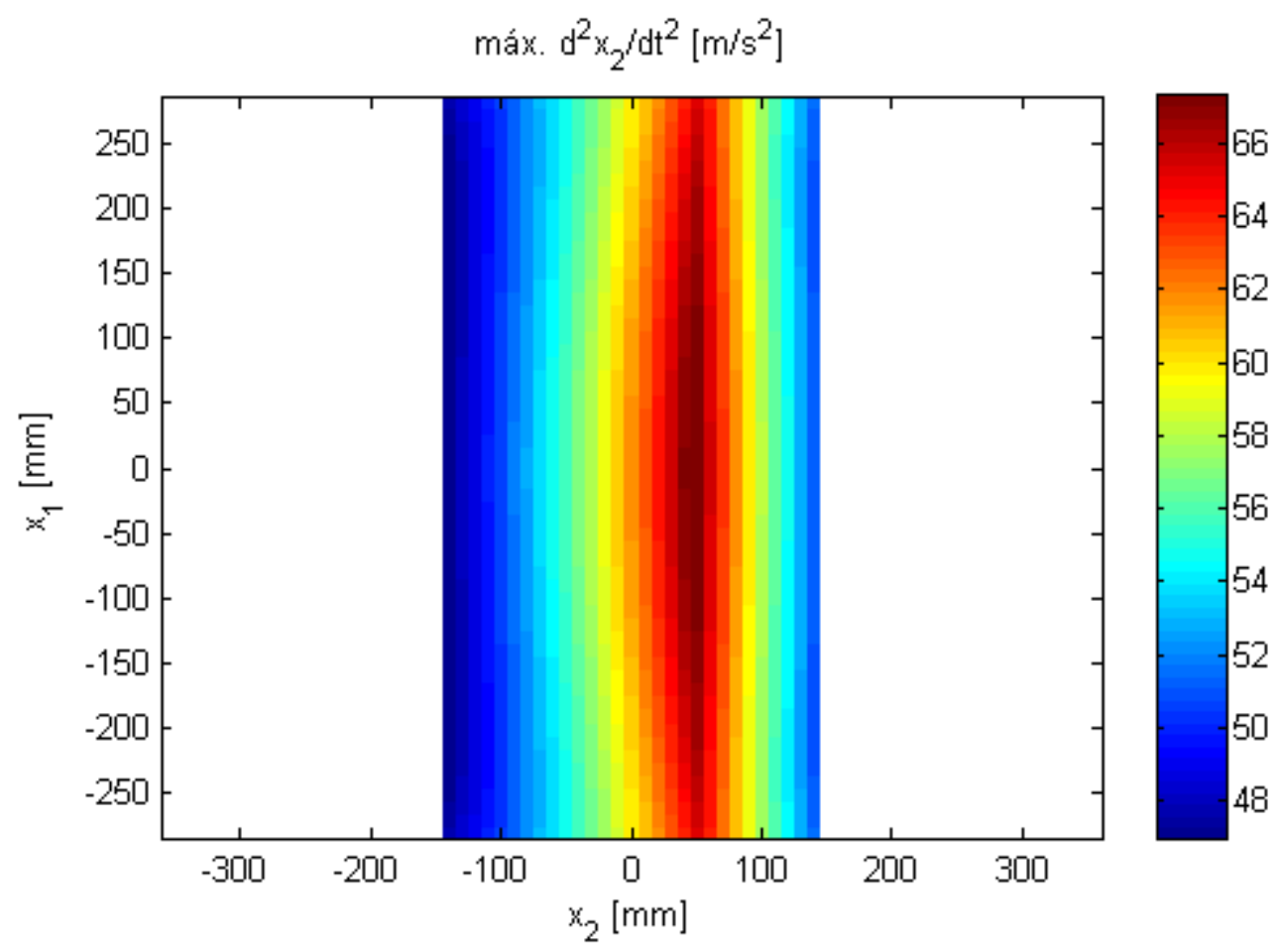

Figura 5.10 - Massas concentradas, máxima aceleração $\left(\mathrm{m} / \mathrm{s}^{2}\right)$ na direção $x_{2}$

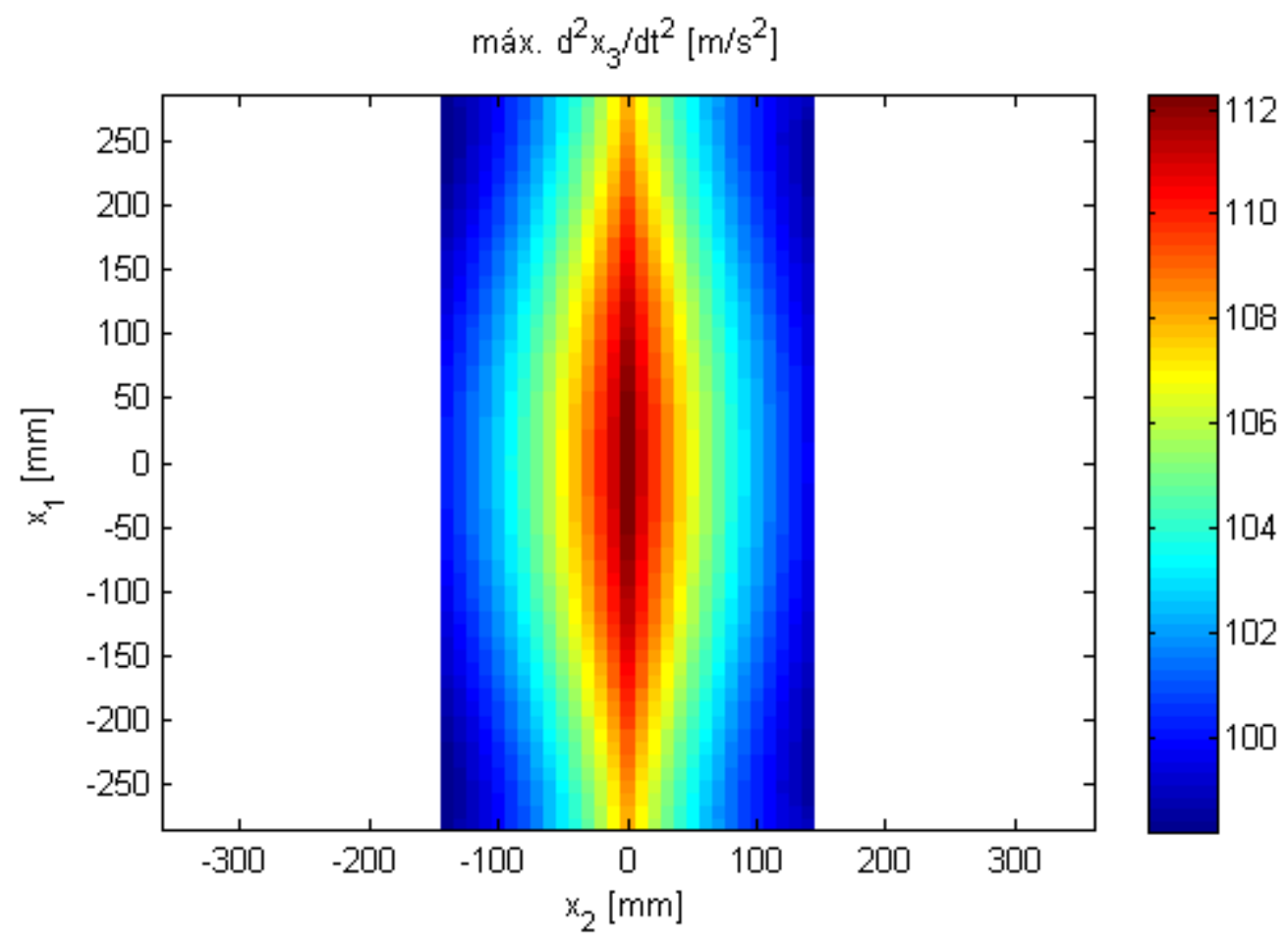

Figura 5.11 - Massas concentradas, máxima aceleração $\left(\mathrm{m} / \mathrm{s}^{2}\right)$ na direção $x_{3}$ 
Confirmando os resultados obtidos na seção 5.1, o modelo de massas concentradas nos centros geométricos das barras se revela como uma boa aproximação do modelo de massas distribuídas. Como o modelo de massas concentradas tem menor custo computacional, foi utilizado nas simulações seguintes.

A fim de se analisarem as características dinâmicas do mecanismo numa hipótese de compensação de efeitos gravitacionais, o valor da aceleração da gravidade foi imposto igual a zero. Pode ser observada na figura 5.12 a pequena influência dos dois membros laterais sobre a máxima aceleração na direção $x_{1}$, que aumenta conforme o efetuador se afasta do plano $x_{1}$ igual a zero. A figura 5.13 mostra que sem 0 efeito gravitacional o mapa de acelerações na direção $x_{2}$ fica perfeitamente simétrico, o que não ocorreu na figura 5.10. Não são observadas diferenças qualitativas para as acelerações na direção $x_{3}$, apresentadas na figura 5.14 , apenas um decréscimo de aproximadamente $10 \mathrm{~m} / \mathrm{s}^{2}$ em suas intensidades.

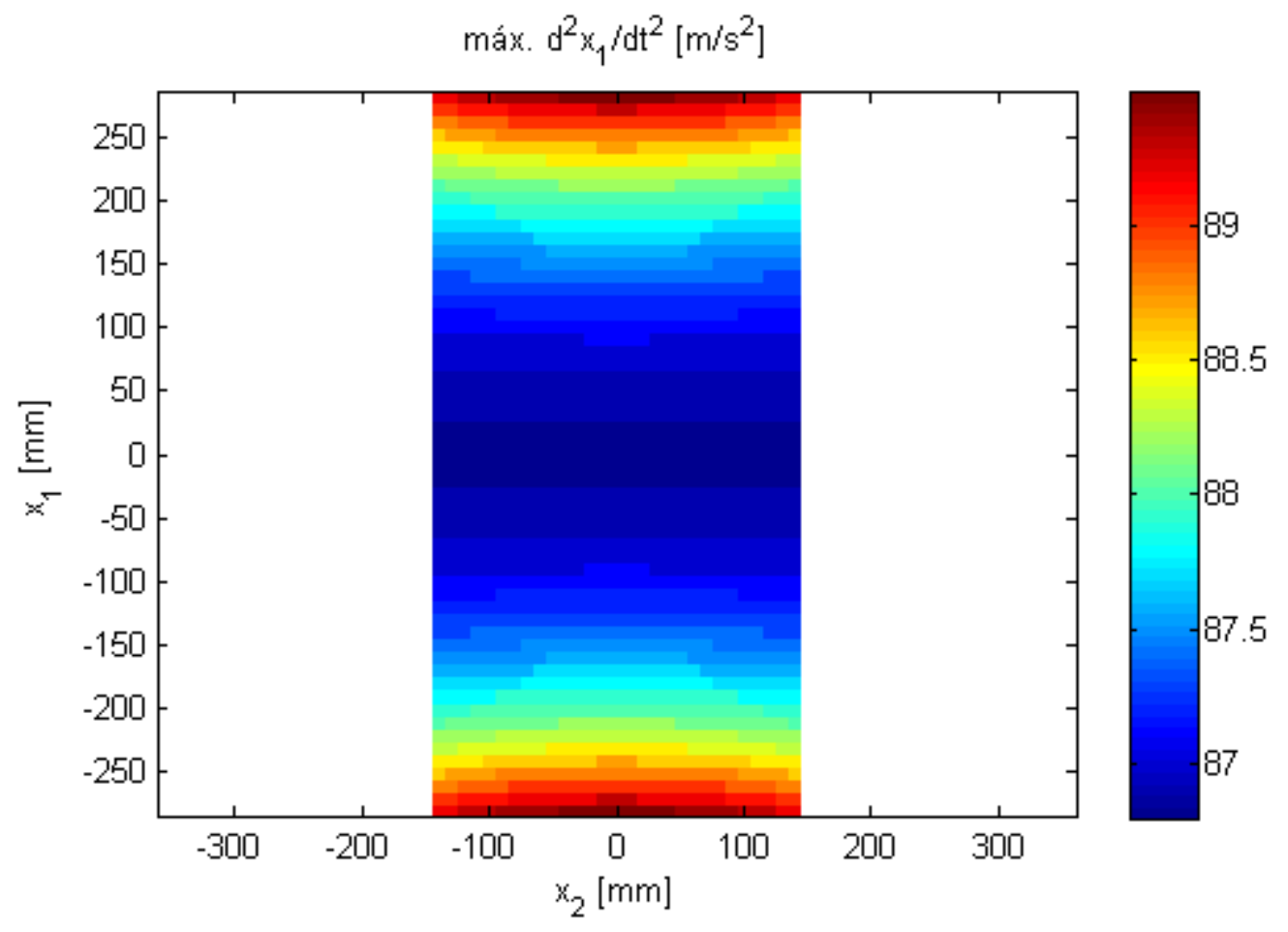

Figura 5.12 - Massas concentradas, sem gravidade, máxima aceleração $\left(\mathrm{m} / \mathrm{s}^{2}\right)$ na direção $x_{1}$ 


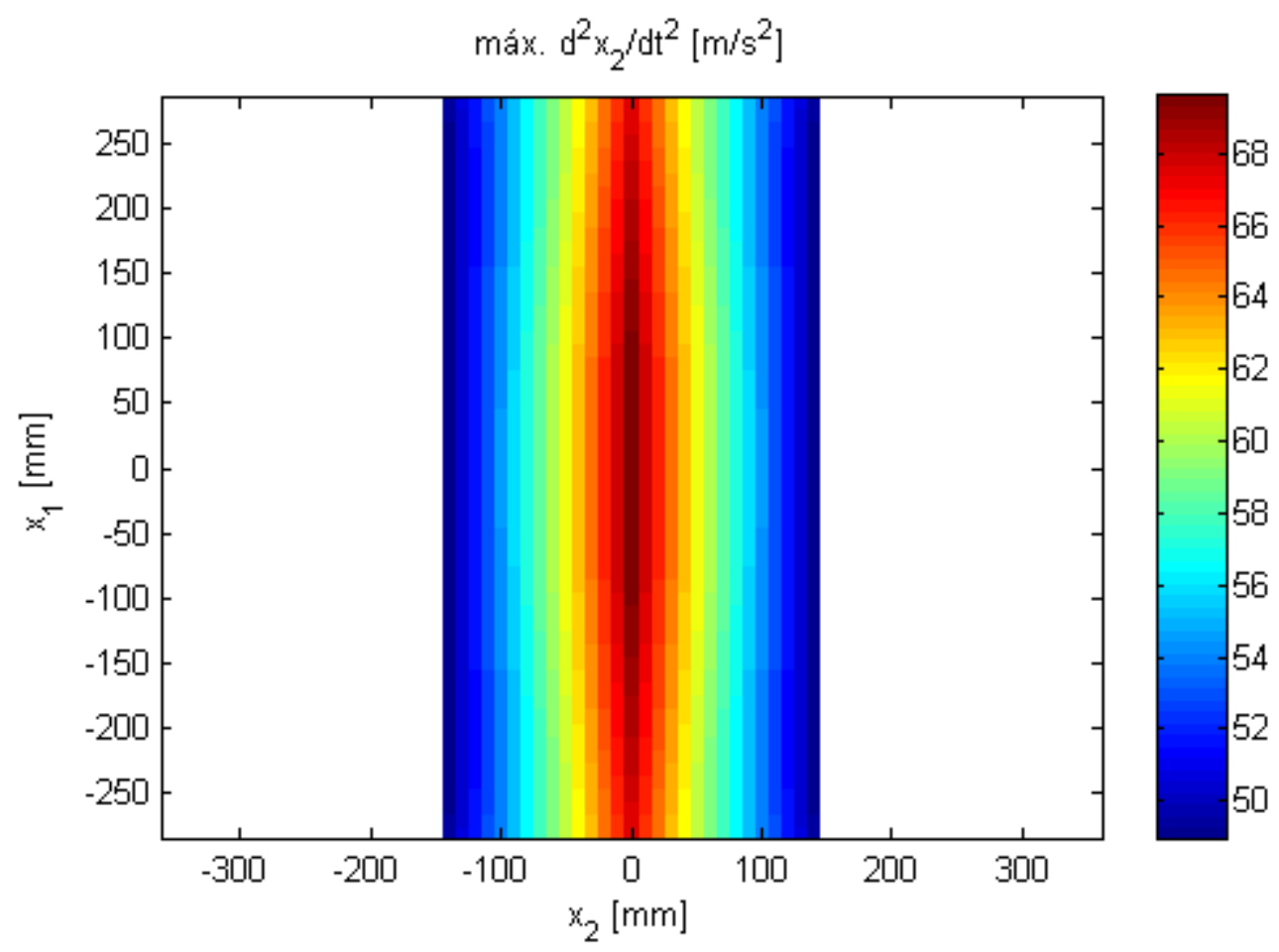

Figura 5.13 - Massas concentradas, sem gravidade, máxima aceleração $\left(\mathrm{m} / \mathrm{s}^{2}\right)$ na direção $x_{2}$

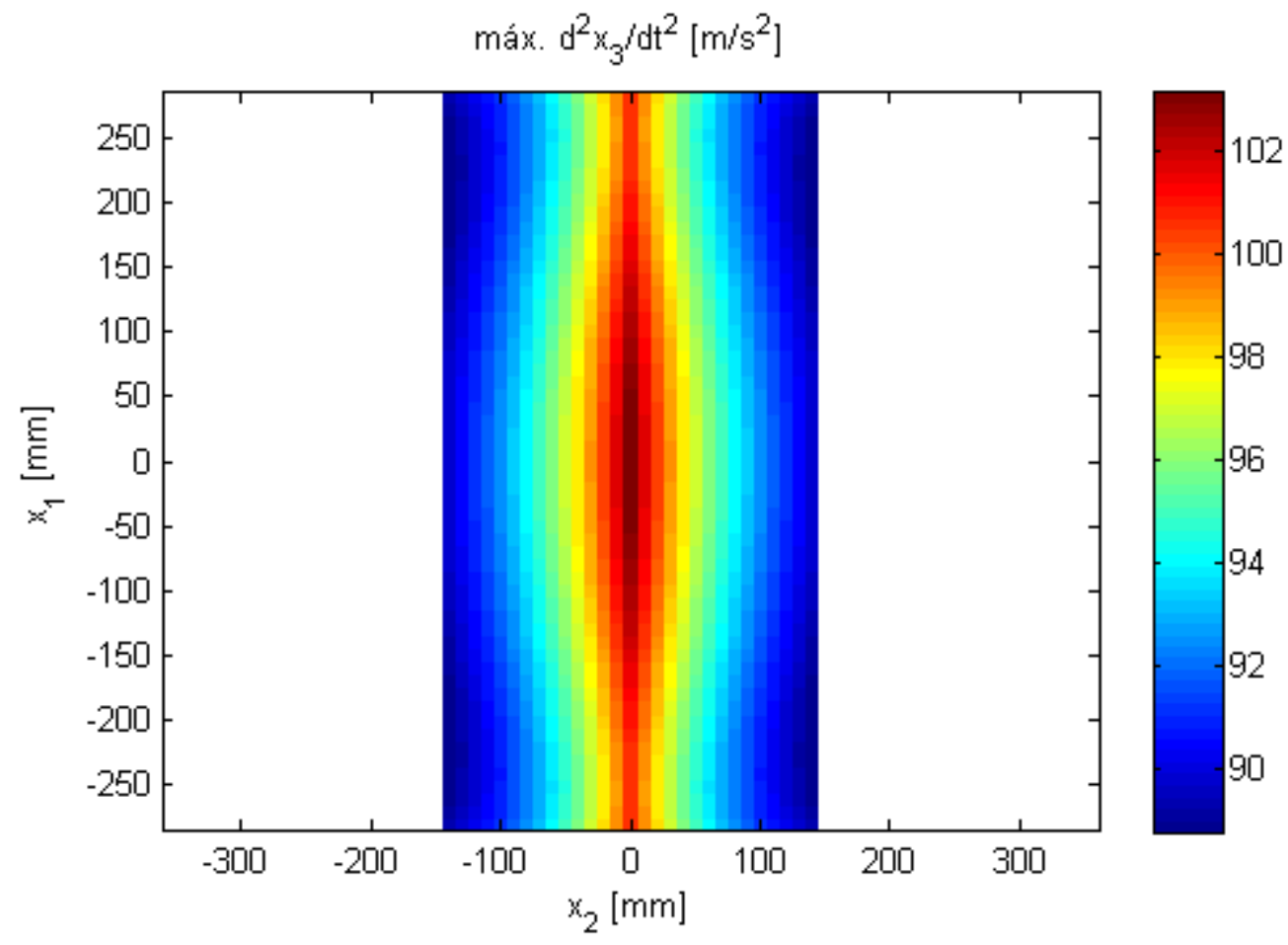

Figura 5.14 - Massas concentradas, sem gravidade, máxima aceleração $\left(\mathrm{m} / \mathrm{s}^{2}\right)$ na direção $x_{3}$ 
Mudando 0 vetor de saturação dos atuadores para $\tau_{\text {sat }}=\left[\begin{array}{llll}200 & 10 & 10\end{array}\right]^{T} \mathrm{e}$ considerando novamente a existência da gravidade, foram obtidos os resultados apresentados nas figuras 5.15 a 5.17 .

Percebe-se que, apesar de existir alguma influência dos dois membros laterais sobre a máxima aceleração na direção $x_{1}$, ao se dobrar a força de saturação do atuador sobre a junta prismática, as máximas acelerações naquela direção são aproximadamente dobradas. Ao mesmo tempo, pouca diferença pode ser observada nas outras direções. Isto mostra que embora o mecanismo tenha arquitetura paralela e equações dinâmicas acopladas, seus termos predominantes não estão acoplados. Assim, as capacidades dos atuadores podem ser escolhidas com certa independência, conforme os requisitos de desempenho de movimentação em cada direção.

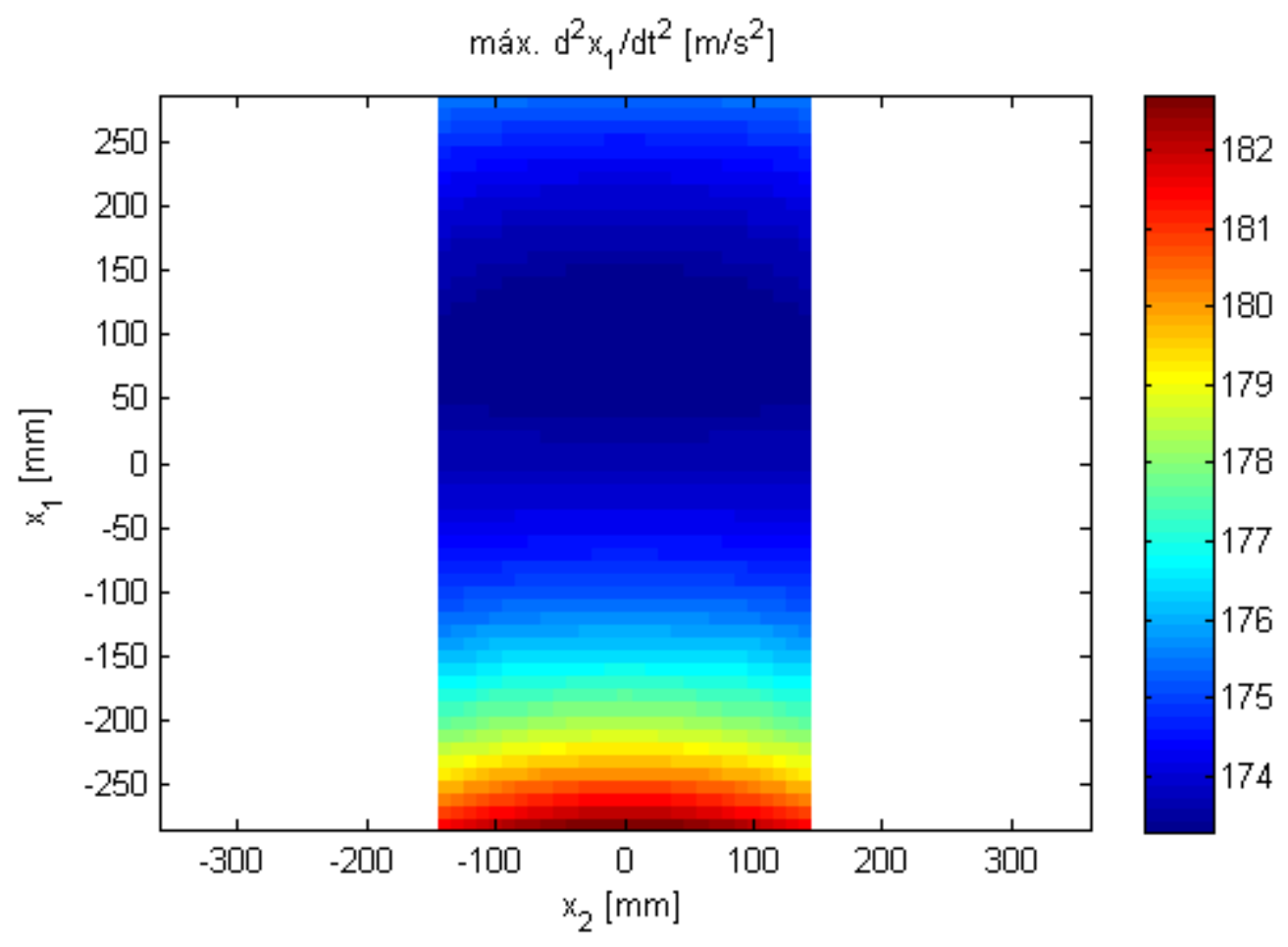

Figura 5.15 - Massas concentradas, força de saturação dobrada, máxima aceleração $\left(\mathrm{m} / \mathrm{s}^{2}\right)$ na direção $x_{1}$ 


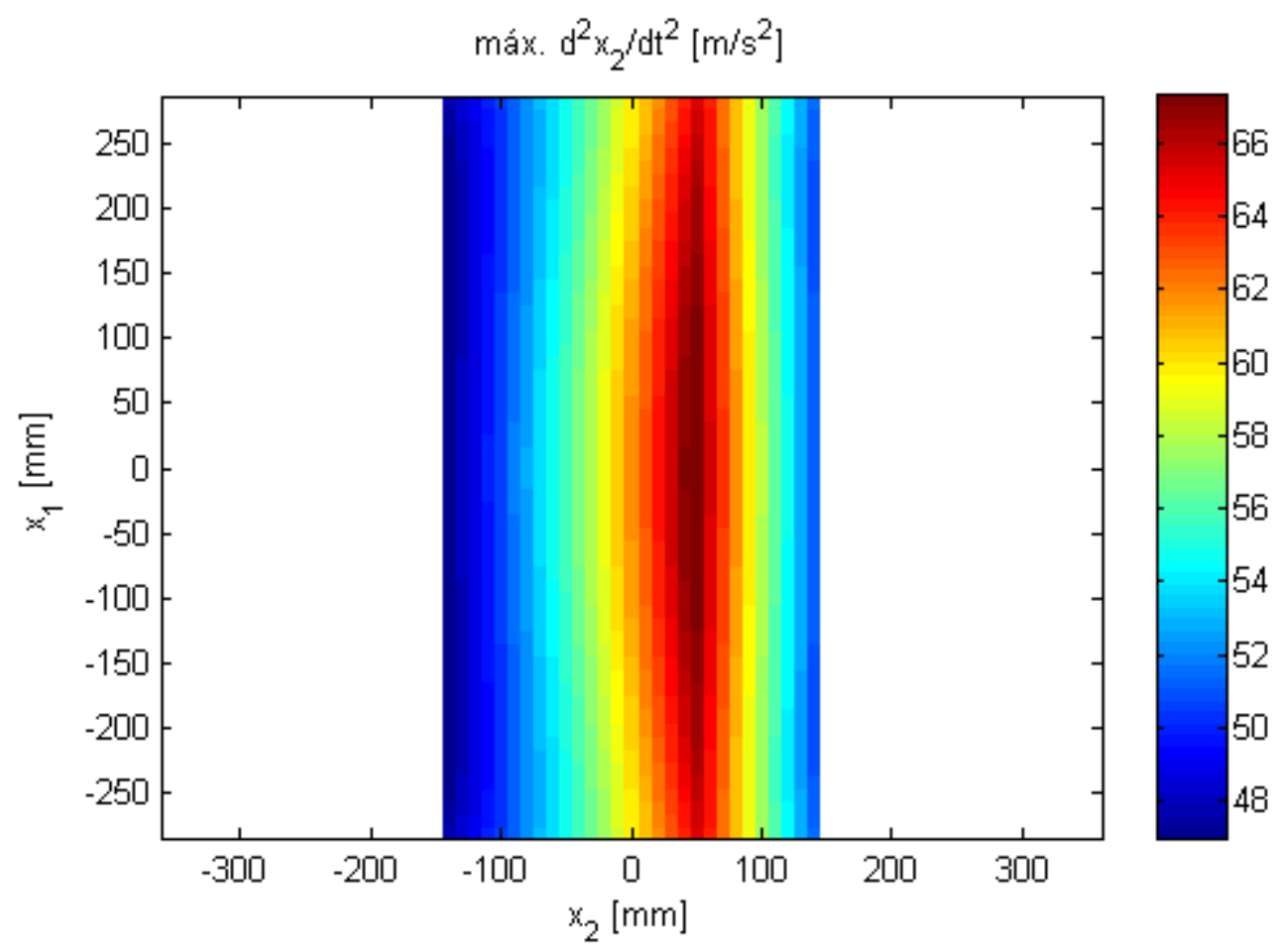

Figura 5.16 - Massas concentradas, força de saturação dobrada, máxima aceleração $\left(\mathrm{m} / \mathrm{s}^{2}\right)$ na direção $x_{2}$

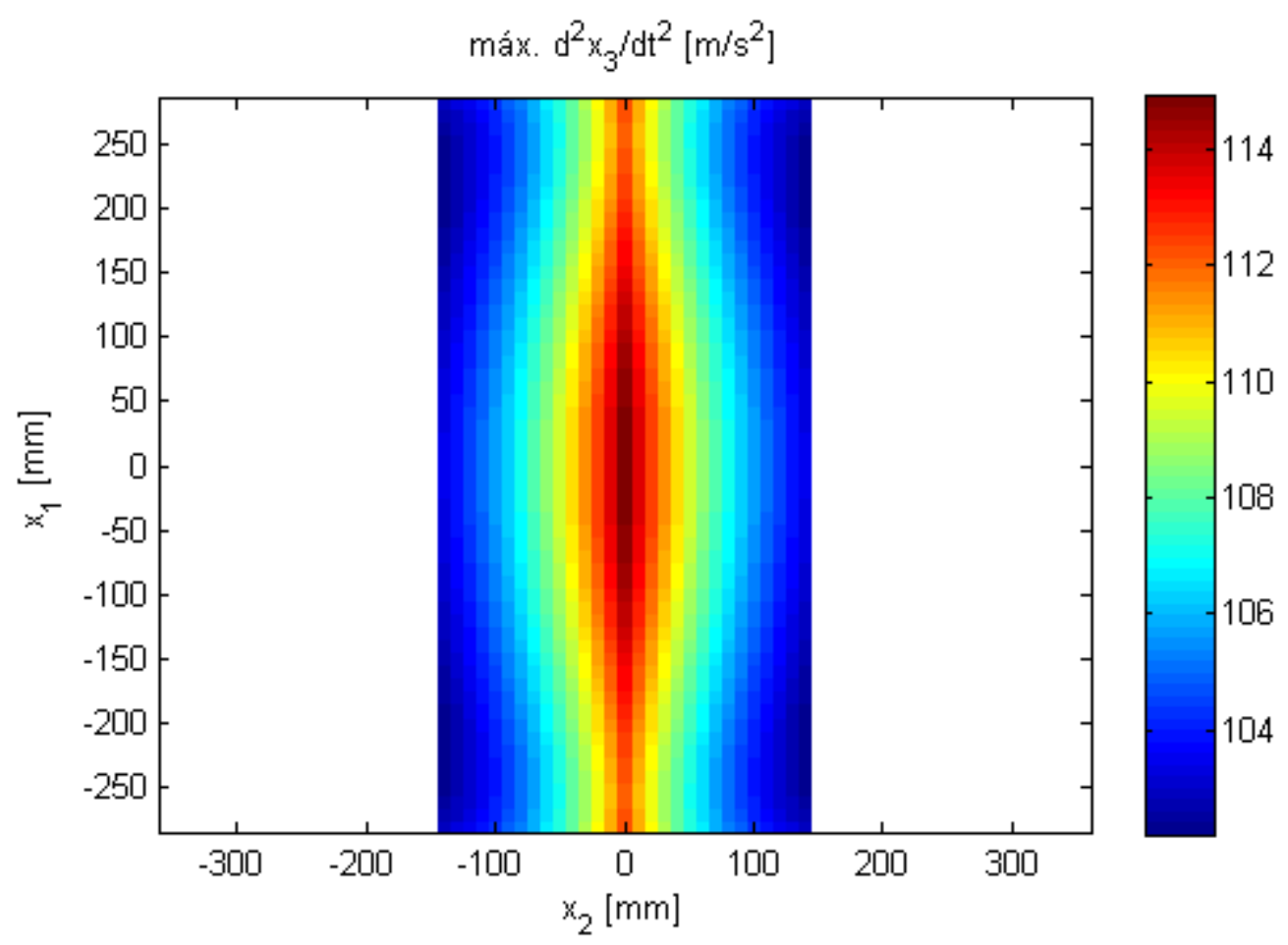

Figura 5.17 - Massas concentradas, força de saturação dobrada, máxima aceleração $\left(\mathrm{m} / \mathrm{s}^{2}\right)$ na direção $x_{3}$ 


\subsection{SIMPLIFICAÇÃO DE MODELO DINÂMICO}

De maneira similar à proposta em (WANG et al., 2007), foi realizada uma análise para identificação de termos predominantes das equações dinâmicas do mecanismo, pois longas expressões geralmente não são adequadas para serem utilizadas em leis de controle executadas em hardware industrial e precisam ser simplificadas (WANG et al., 2007). Grande parte dessa seção foi publicada em (ALMEIDA, HESS-COELHO, 2013), porém com parâmetros geométricos e inerciais diferentes dos aqui utilizados. Nesta seção foram utilizados os parâmetros apresentados na tabela 5.4, mais próximos das características do protótipo do robô em fabricação.

\subsubsection{Procedimento de simplificação do modelo dinâmico}

As expressões de cálculo de esforços nos atuadores sob a hipótese de massas distribuídas foram separadas em termos que possuíam unidade de força para a junta prismática ativa e unidade de torque para as juntas de rotação ativas. Foram identificados 19 termos para o cálculo de $\tau_{1}$ e 23 termos para o cálculo de $\tau_{2}$ e $\tau_{3}$, originados de efeitos dinâmicos gravitacionais, inerciais e de aceleração de Coriolis, conforme explicitado nas tabelas F.1 a F.3 do Apêndice F.

O método numérico aqui proposto para a simplificação do modelo dinâmico possui basicamente dois passos. O primeiro se trata da identificação da importância de cada termo quando o robô executa um movimento pré-definido. O segundo é relativo à seleção de termos, do mais importante para o menos importante, até que as porcentagens médias acumuladas da força e dos torques dos atuadores atinjam um valor desejado.

Diferentemente de Wang et al. (2007), que utilizou trajetórias de linhas retas e arcos de circunferência com estágios de aceleração, velocidade constante e desaceleração, foi imposto ao mecanismo um movimento de teste definido pelas equações 5.1 a 5.3 .

Para cada instante de tempo, foi calculado o valor porcentual da razão entre 0 quadrado de cada termo e o quadrado do esforço no atuador (força ou torque). 
Então, foram calculadas as porcentagens médias, que representavam a importância dos termos, e realizada a seleção dos termos mais significativos.

Foram impostas três condições de velocidades/acelerações: baixa, média e alta, definidas pelos parâmetros listados na tabela 5.5. Embora o mecanismo tenha sido concebido para constituir um robô manipulador para tarefas de pega-e-põe, vislumbra-se seu uso como máquina de exercícios fisioterápicos interativos para a reabilitação de membros superiores de pacientes humanos. Para essa aplicação, a movimentação do mecanismo estaria na condição de baixas velocidades e acelerações. Já em sua aplicação original, estaria na condição de médias e altas velocidades e acelerações.

Tabela 5.5 - Parâmetros de funções de movimentos de entrada

\begin{tabular}{|c|c|c|c|}
\cline { 2 - 4 } \multicolumn{1}{c|}{} & \multicolumn{3}{c|}{ Condições de velocidades e acelerações } \\
\hline Parâmetro & Baixa & Média & Alta \\
\hline$C_{1}[\mathrm{~mm}]$ & 150 & 150 & 150 \\
\hline$c_{1}[\mathrm{rad} / \mathrm{s}]$ & 1,07 & 5,35 & 10,7 \\
\hline$C_{2}[\mathrm{rad}]$ & $\pi / 6$ & $\pi / 6$ & $\pi / 6$ \\
\hline$c_{2}[\mathrm{rad} / \mathrm{s}]$ & 1,05 & 5,25 & 10,5 \\
\hline$C_{3}[\mathrm{rad}]$ & $\pi / 6$ & $\pi / 6$ & $\pi / 6$ \\
\hline$c_{3}[\mathrm{rad} / \mathrm{s}]$ & $-1,03$ & $-5,15$ & $-10,3$ \\
\hline & & & \\
\hline
\end{tabular}

As figuras 5.18 a 5.20 mostram a importância média de cada termo no cálculo de $\tau_{1}, \tau_{2}$ e $\tau_{3}$ utilizando-se os parâmetros listados na tabela 5.5 e 1000 segundos de duração de simulação com período de amostragem de 0,3 s.

É evidente que existem termos que são predominantes no cálculo dos esforços. Observa-se ainda que a importância de alguns termos varia intensamente em função da velocidade e da aceleração imposta ao robô. Basicamente, efeitos gravitacionais são mais importantes para velocidades e acelerações baixas, enquanto efeitos inerciais se tornam mais importantes com o aumento da velocidade e da aceleração. 


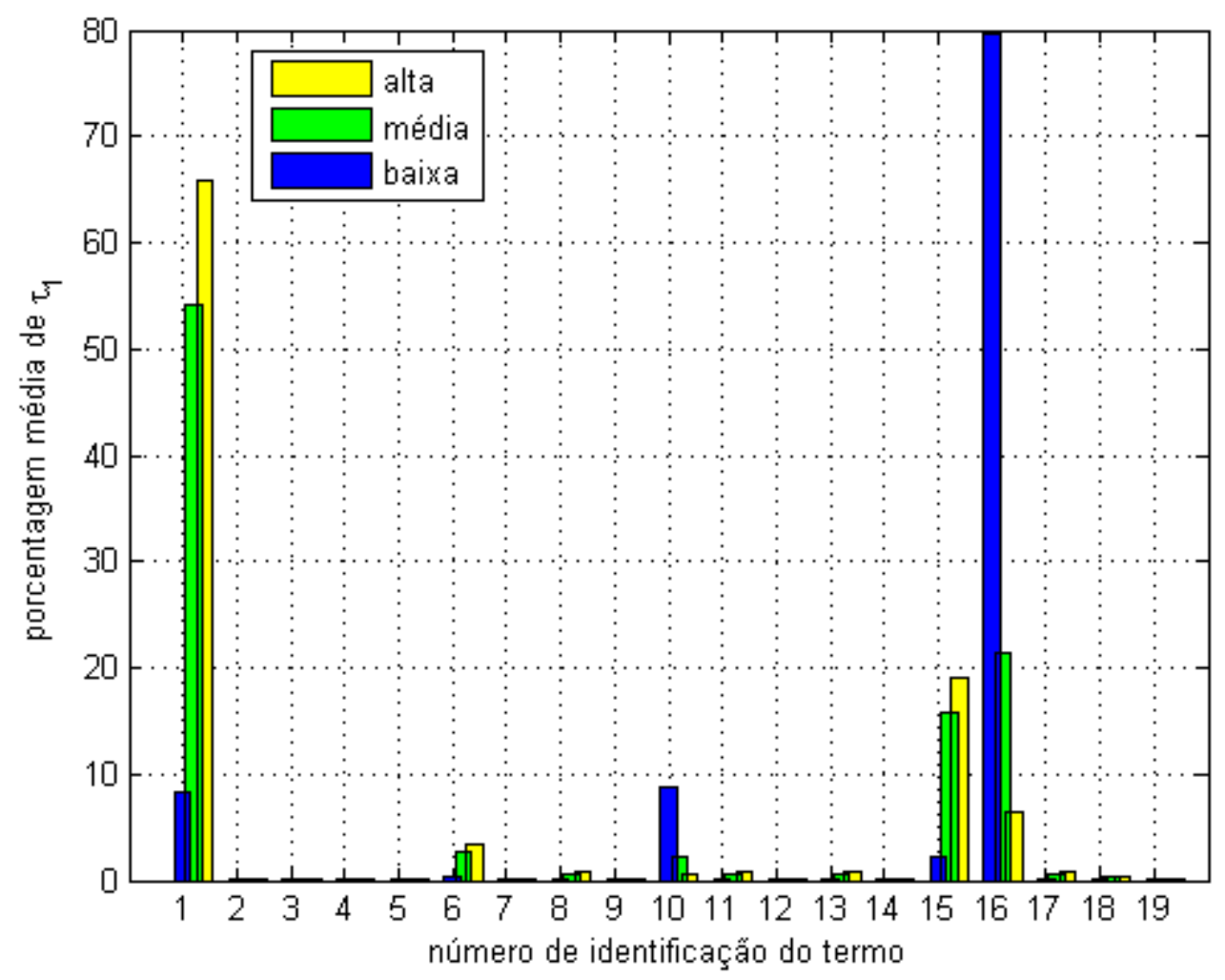

Figura 5.18 - Porcentagem média de cada termo no cálculo de $\tau_{1}$ para baixa (azul) e alta (verde) velocidade/aceleração

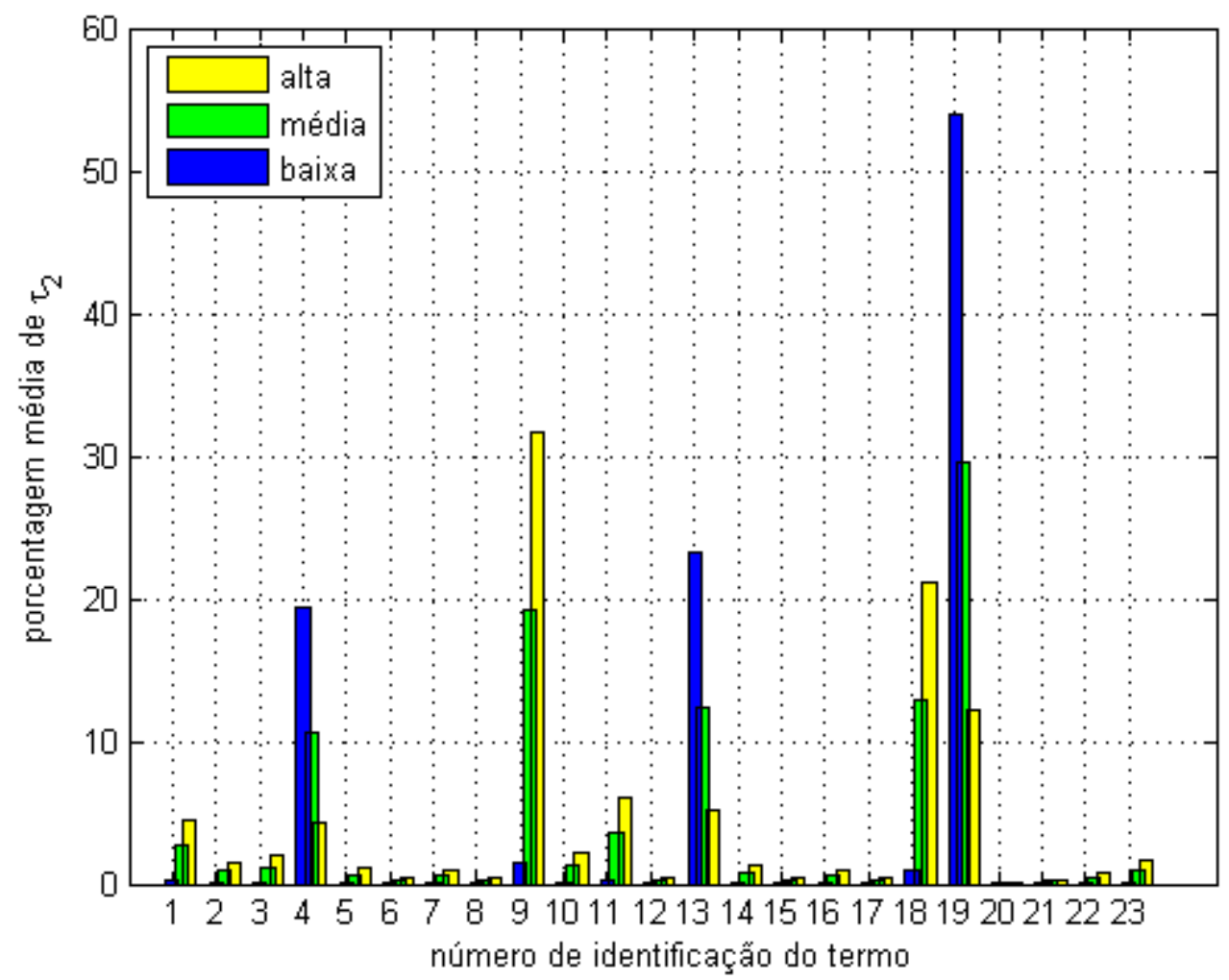

Figura 5.19 - Porcentagem média de cada termo no cálculo de $\tau_{2}$ para baixa (azul) e alta (verde) velocidade/aceleração 


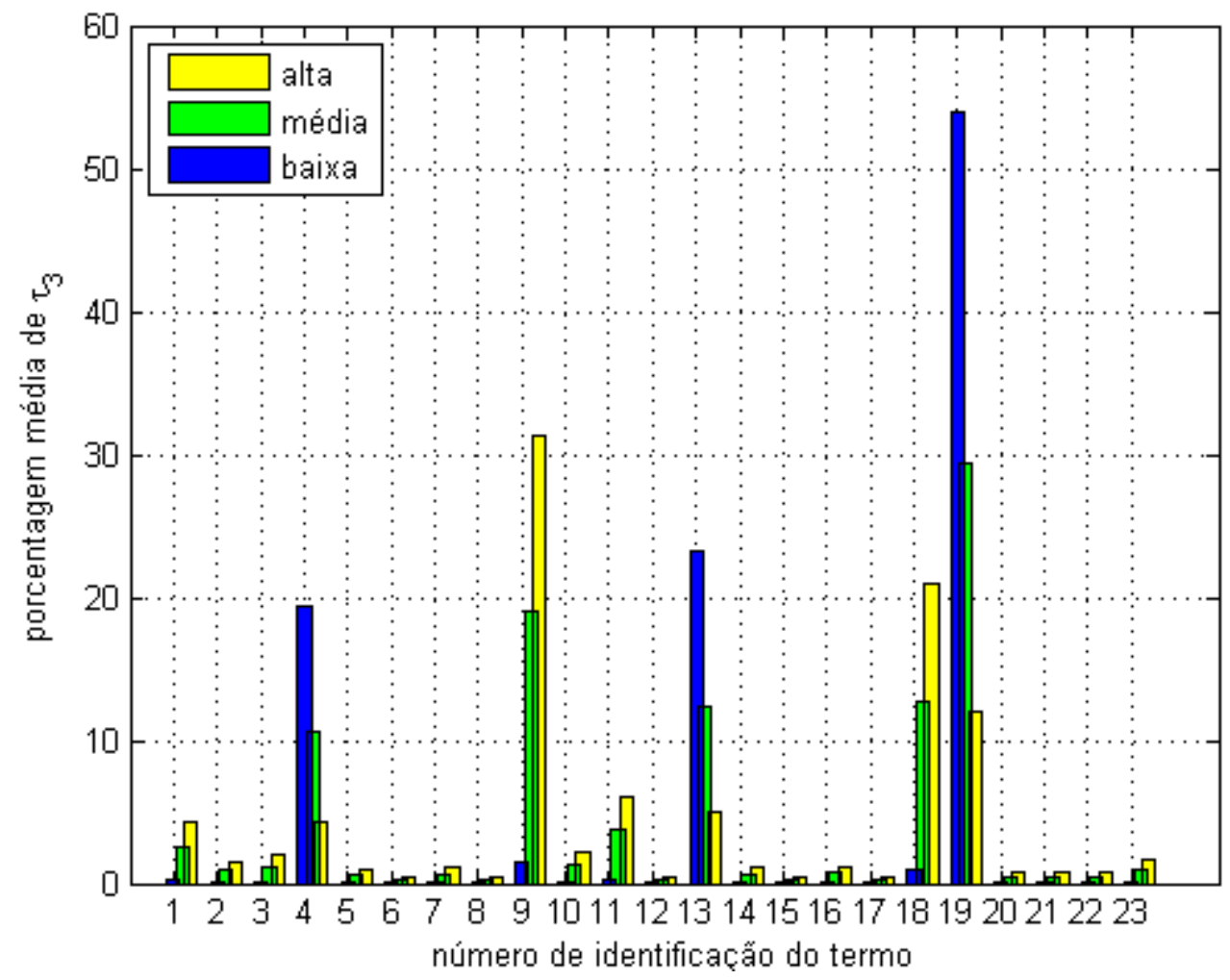

Figura 5.20 - Porcentagem média de cada termo no cálculo de $\tau_{3}$ para baixa (azul) e alta (verde) velocidade/aceleração

Por exemplo, para o cálculo da força $\tau_{1}$, o termo 16 , que é relativo à ação da gravidade sobre o efetuador é mais significativo em baixas velocidades/acelerações. Porém, sua importância diminui drasticamente para velocidades e acelerações médias e altas. Já os termos 1 e 15, relativos à inércia do membro central sob aceleração na direção $x_{1}$ e à inércia do efetuador sob aceleração na direção $x_{3}$, são mais significativos em altas velocidades e acelerações.

Para o cálculo dos torques $\tau_{2}$ e $\tau_{3}$, os termos gravitacionais 19, 13 e 4 foram os mais importantes para baixas velocidade e acelerações enquanto os termos inerciais 9 e 18 são predominantes sob altas velocidade e aceleração.

Realizando-se agora a seleção de termos do mais significativo para o menos significativo, obtém-se os resultados apresentados nas figuras 5.21 a 5.23 , que mostram a porcentagem acumulada média para os esforços dos atuadores em função da quantidade de termos selecionados. Observa-se que, sob baixa velocidade/aceleração, as percentagens médias acumuladas dos esforços dos atuadores iniciam em valores mais altos e rapidamente atingem mais de $90 \%$. Quando a velocidade e a aceleração são aumentadas, há uma tendência da importância dos termos ficar mais distribuída e é necessário acumular mais termos para se alcançar um determinado nível de porcentagem média acumulada. 


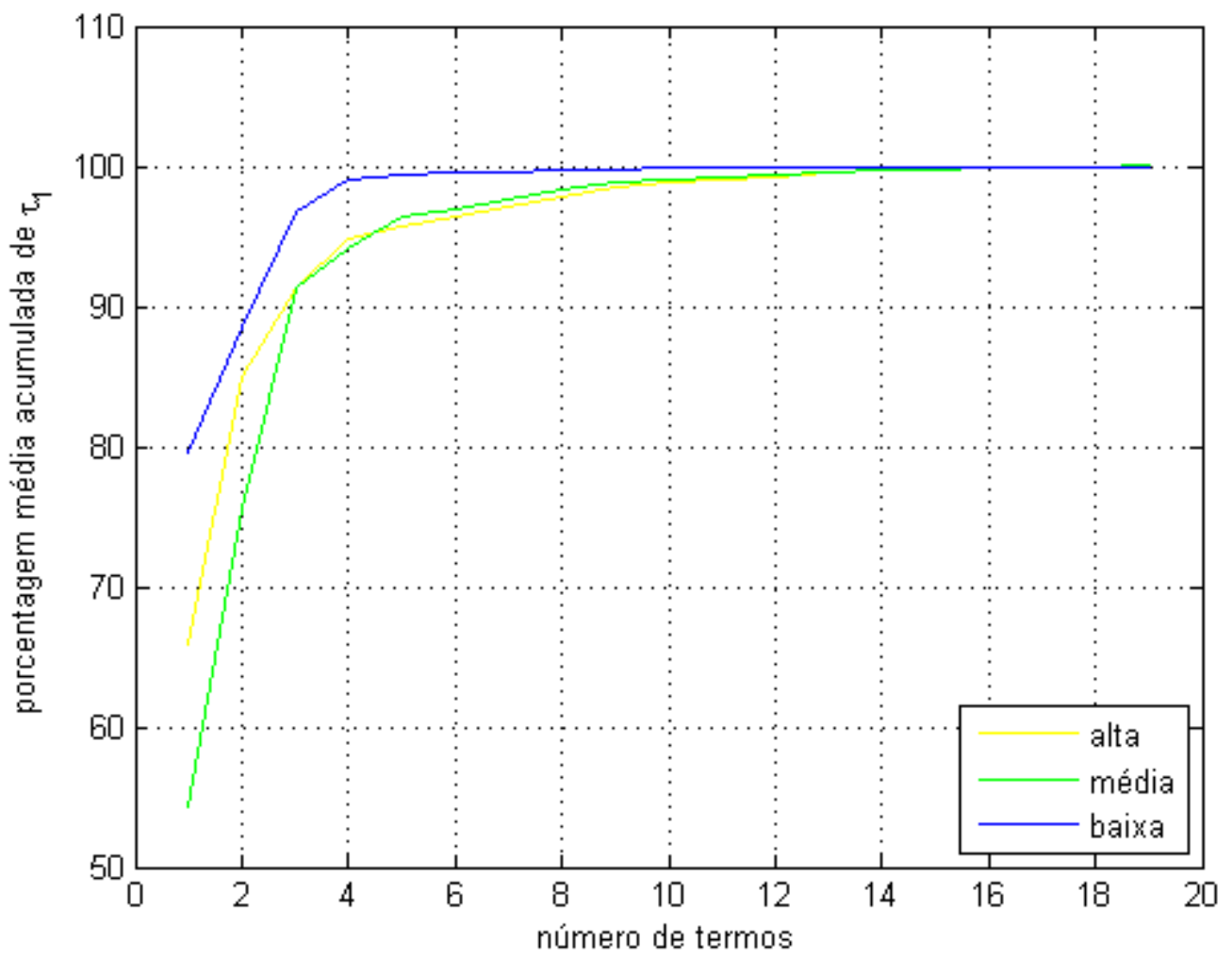

Figura 5.21 - Porcentagem média de cada termo no cálculo de $\tau_{1}$ para baixa (azul) e alta (verde) velocidade/aceleração

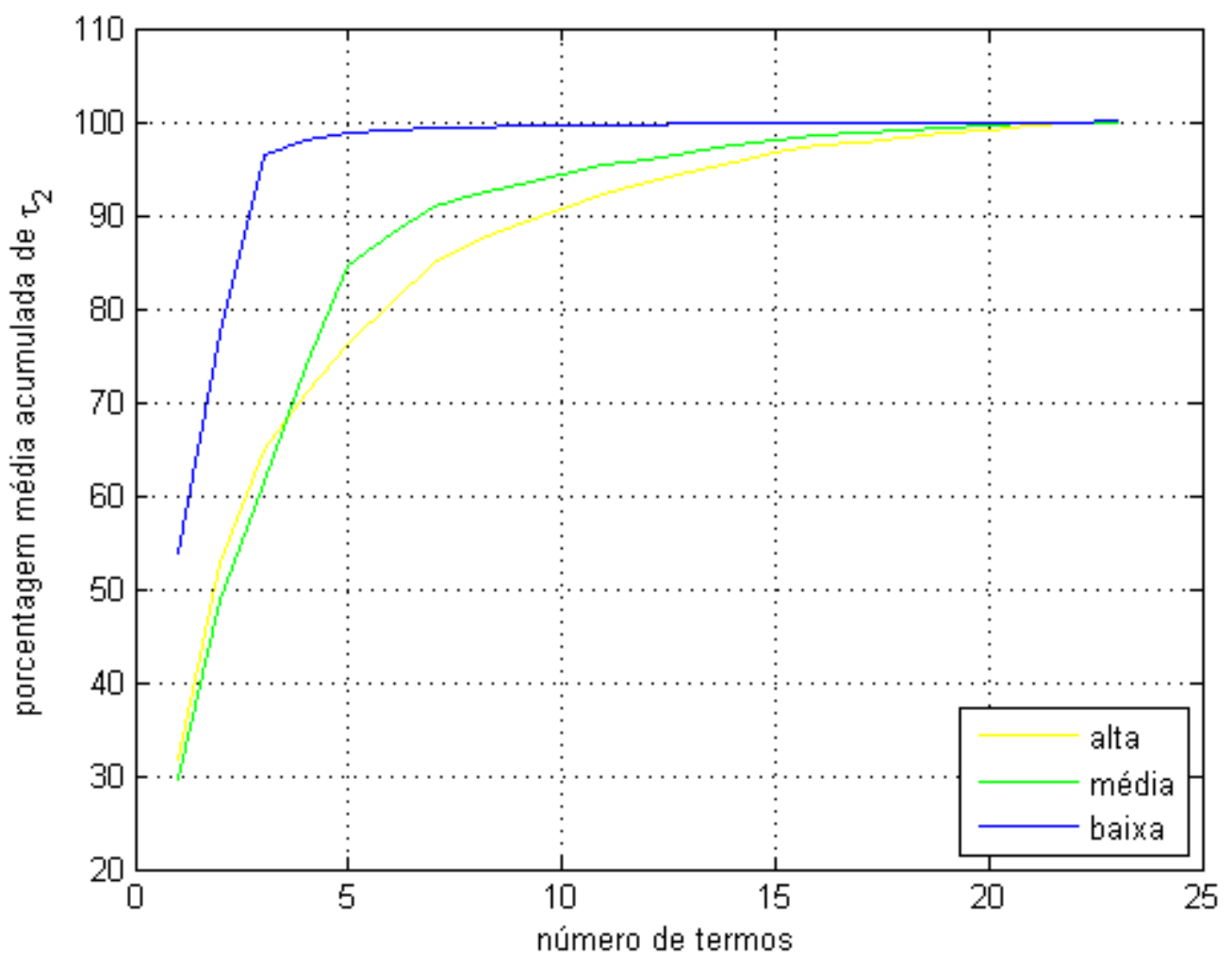

Figura 5.22 - Porcentagem média de cada termo no cálculo de $\tau_{2}$ para baixa (azul) e alta (verde) velocidade/aceleração 


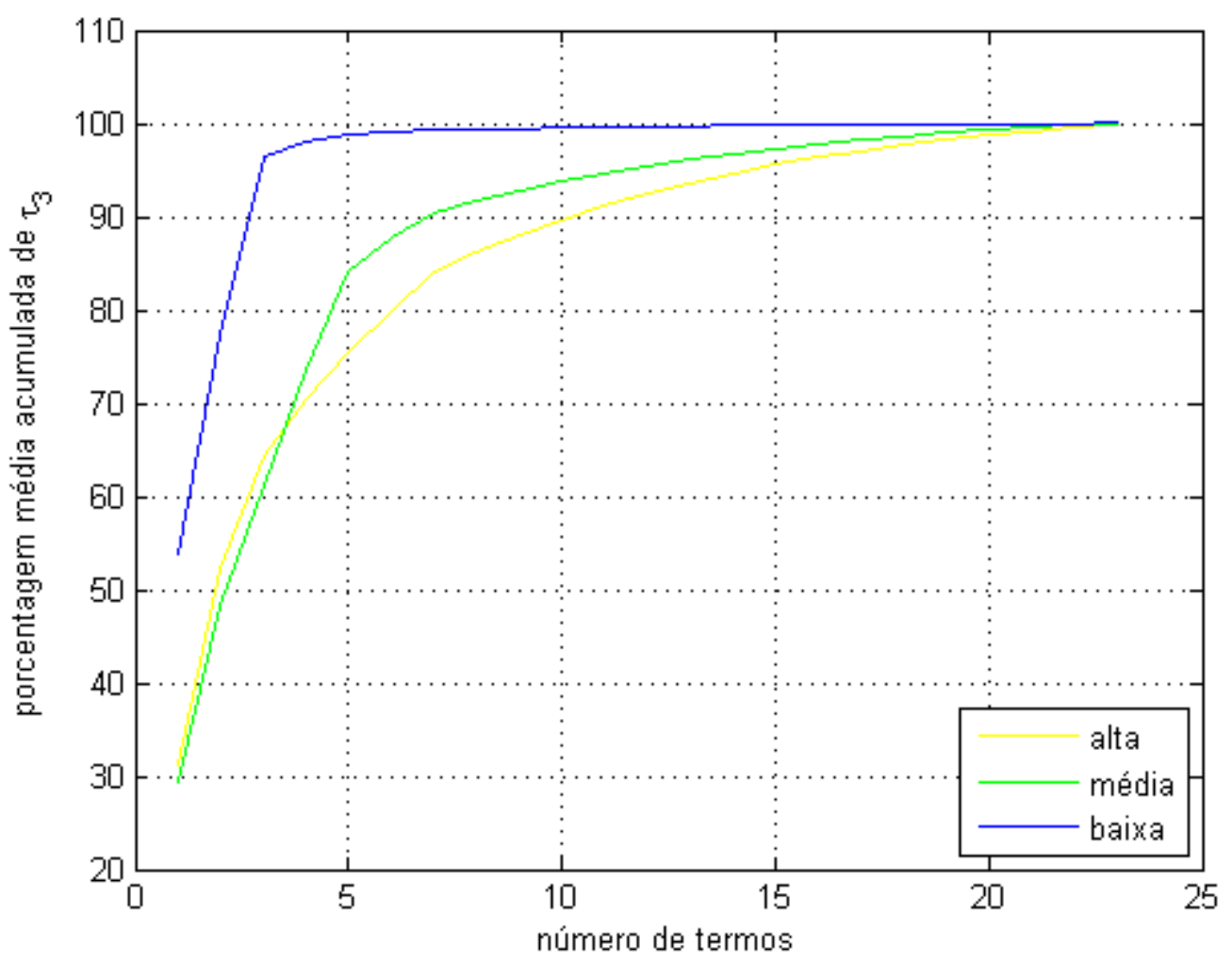

Figura 5.23 - Porcentagem média de cada termo no cálculo de $\tau_{3}$ para baixa (azul) e alta (verde) velocidade/aceleração

Fixando-se limiares de $95 \%$ e de $98 \%$ de porcentagem média acumulada, foi necessário selecionar as quantidades de termos indicadas na tabela 5.6.

Tabela 5.6 - Quantidade de termos selecionados

\begin{tabular}{|c|c|c|c|}
\hline \multirow{2}{*}{$\begin{array}{l}\text { Porcentagem Média } \\
\text { Acumulada }\end{array}$} & \multicolumn{3}{|c|}{ Quantidade de termos } \\
\hline & $\begin{array}{c}\text { Baixas } \\
\text { velocidade/aceleração }\end{array}$ & $\begin{array}{c}\text { Médias } \\
\text { velocidade/aceleração }\end{array}$ & $\begin{array}{c}\text { Altas } \\
\text { velocidade/aceleração }\end{array}$ \\
\hline $95 \%$ de $\tau_{1}$ & 3 & 5 & 6 \\
\hline $95 \%$ de $\tau_{2}$ & 3 & 11 & 14 \\
\hline $95 \%$ de $\tau_{3}$ & 3 & 12 & 15 \\
\hline $98 \%$ de $\tau_{1}$ & 4 & 8 & 9 \\
\hline $98 \%$ de $\tau_{2}$ & 5 & 16 & 18 \\
\hline $98 \%$ de $\tau_{3}$ & 5 & 17 & 19 \\
\hline
\end{tabular}

Observa-se que, sob baixas velocidades e acelerações, com limiar de 95\%, as equações dinâmicas podem ser simplificadas para apenas três termos cada, o que representa redução de aproximadamente $80 \%$ do número de termos. Já para altas velocidades e acelerações, com limiar de $98 \%$, a redução na quantidade de 
termos necessários foi de aproximadamente $50 \%$ para o cálculo de $\tau_{1}$ e de aproximadamente $20 \%$ para os cálculos de $\tau_{2}$ e $\tau_{3}$.

Nota-se também certo padrão em que o número de termos necessários para o cálculo de $\tau_{2}$ e $\tau_{3}$ é aproximadamente o dobro do necessário para $\tau_{1}$.

Os erros médio (RMS) e máximo no cálculo dos esforços necessários nos atuadores, consequentes da utilização de modelos simplificados conforme a tabela 5.6, podem ser observados na tabela 5.7.

Tabela 5.7 - Erros médios RMS e máximos nos cálculos dos esforços nos atuadores

\begin{tabular}{|c|c|c|c|c|c|c|}
\hline \multirow{2}{*}{$\begin{array}{c}\text { Porcentagem } \\
\text { média } \\
\text { acumulada }\end{array}$} & \multicolumn{2}{|c|}{ Baixa vel. / acel. } & \multicolumn{2}{c|}{ Média vel. / acel. } & \multicolumn{2}{c|}{ Alta vel. / acel. } \\
\cline { 2 - 7 } & $\begin{array}{c}\text { Erro méd. } \\
{[\%]}\end{array}$ & $\begin{array}{c}\text { Erro máx. } \\
{[\%]}\end{array}$ & $\begin{array}{c}\text { Erro méd. } \\
{[\%]}\end{array}$ & $\begin{array}{c}\text { Erro máx. } \\
\text { [\%] }\end{array}$ & $\begin{array}{c}\text { Erro méd. } \\
\text { [\%] }\end{array}$ & $\begin{array}{c}\text { Erro máx. } \\
\text { [\%] }\end{array}$ \\
\hline $95 \%$ de $\tau_{1}$ & 3,8 & 40,0 & 3,5 & 26,2 & 2,0 & 10,5 \\
\hline $95 \%$ de $\tau_{2}$ & 3,0 & 9,8 & 4,6 & 10,9 & 2,7 & 6,6 \\
\hline $95 \%$ de $\tau_{3}$ & 3,0 & 9,8 & 3,6 & 7,8 & 3,4 & 6,8 \\
\hline $98 \%$ de $\tau_{1}$ & 0,8 & 2,7 & 1,1 & 5,1 & 0,7 & 3,5 \\
\hline $98 \%$ de $\tau_{2}$ & 0,9 & 2,5 & 1,5 & 2,6 & 1,4 & 3,0 \\
\hline $98 \%$ de $\tau_{3}$ & 0,9 & 2,8 & 1,8 & 6,9 & 1,2 & 3,3 \\
\hline
\end{tabular}

Esses resultados mostram que apesar dos erros médios serem pequenos, os erro máximos, notadamente para o limiar de $95 \%$, são significativos. Portanto a eficácia do desenvolvimento de leis de controle baseadas nesses modelos simplificados deve ser criteriosamente avaliada.

\subsubsection{Modelos resultantes do procedimento de simplificação}

Após a execução do procedimento de seleção de termos predominantes, foi detectado que, apesar da similaridade entre os dois braços laterais do mecanismo, o procedimento numérico de identificação da importância dos termos das expressões de cálculo dos torques $\tau_{2}$ e $\tau_{3}$ não revelou exatamente a mesma importância para termos correspondentes nas expressões de cálculo desses torques. Da mesma 
forma, alguns termos de cálculo da força $\tau_{1}$ possuem correspondência entre si, devido à simetria geométrica do mecanismo. Assim, foi adicionado outro critério na seleção dos termos predominantes de forma a manter similaridade de comportamento dinâmico em relação a posições simétricas do espaço de trabalho do robô. Foram consideradas como classificações finais as médias entre as classificações de um termo e de seu termo correspondente. Nas tabelas F.4 a F.5 do Apêndice F são apresentados os resultados iniciais e finais das classificações dos termos seguindo esse procedimento.

Conforme comentado anteriormente, na tabela 5.6 foi observado que, para se alcançar determinada porcentagem média acumulada, é necessário coletar aproximadamente $o$ dobro de números de termos para os cálculos de $\tau_{2}$ e $\tau_{3}$ em relação ao número de termos para o cálculo de $\tau_{1}$. Assim, foi feita a seleção progressiva de termos apresentadas na tabela 5.8 de forma a se obter sete modelos simplificados para o mecanismo em estudo. Tais modelos são utilizados no capítulo 7 para a avaliação dos efeitos de simplificação de modelagem sobre os erros de controle de posição do robô.

Tabela 5.8 - Modelos simplificados selecionados para projeto de controladores

\begin{tabular}{|c|c|c|c|}
\hline \multirow{2}{*}{$\begin{array}{c}\text { Identificação } \\
\text { do modelo }\end{array}$} & \multicolumn{2}{|c|}{$\begin{array}{c}\text { Termos para cálculo de } \\
\text { esforços nos atuadores }\end{array}$} & Observações \\
\cline { 2 - 3 } & $\tau_{1}$ & $\tau_{2}$ e $\tau_{3}$ & \\
\hline A & 3 & 6 & Somente termos de massas concentradas \\
\hline B & 4 & 8 & Somente termos de massas concentradas \\
\hline C & 5 & 10 & $\begin{array}{r}\text { Termos de massas distribuídas apenas do } \\
\text { paralelogramo }\end{array}$ \\
\hline D & 7 & 14 & $\begin{array}{r}\text { Termos de massas distribuídas apenas do } \\
\text { paralelogramo }\end{array}$ \\
\hline E & 9 & 18 & $\begin{array}{r}\text { Termos de massas distribuídas incluem inércia à } \\
\text { rotação das barras CE e DF }\end{array}$ \\
\hline F & 10 & 20 & $\begin{array}{r}\text { Termos de massas distribuídas incluem inércia à } \\
\text { rotação das barras CE e DF }\end{array}$ \\
\hline G & 11 & 22 & $\begin{array}{r}\text { Termos de massas distribuídas incluem inércia à } \\
\text { rotação das barras CE e DF }\end{array}$ \\
\hline
\end{tabular}

É importante notar que apenas a partir do modelo $E$ são incluídos termos correspondentes às inércias à rotação das barras CE e DF do mecanismo, que tornam as expressões computacionalmente mais custosas pois é necessário realizar os cálculos cinemáticos de rotação dessas barras. 


\section{ANÁLISE E APRIMORAMENTO DE FORMULAÇÕES DE ESTRATÉGIAS DE CONTROLE PARA APLICAÇÃO EM ROBOS PARALELOS ASSIMÉTRICOS}

Algumas estratégias de controle que foram apresentadas na seção 2.4, podem ser reescritas ou aprimoradas para aplicação específica em robôs paralelos, conforme explicado nas seções a seguir.

\subsection{CONTROLE POR TORQUE COMPUTADO APLICADO A EQUACIONAMENTO DINÂMICO COM VARIÁVEIS REDUNDANTES}

Para facilitar o equacionamento do modelo dinâmico do robô, foram utilizadas, em conjunto, tanto as coordenadas dos atuadores como as coordenadas do efetuador. Dessa forma, a equação diferencial que rege seu comportamento dinâmico pode ser escrita na forma indicada pela equação 4.18 , aqui reapresentada na equação 6.1 :

$$
M_{\tau q} \ddot{\boldsymbol{q}}+M_{\tau \chi} \ddot{\boldsymbol{x}}+H_{\tau}+G_{\tau}=\boldsymbol{\tau}
$$

em que $M_{\tau q}$ e $M_{\tau x}$ correspondem a matrizes de inércia, $H_{\tau}$ corresponde a termos de aceleração centrípeta e de Coriolis, e $G_{\tau}$ corresponde a termos gravitacionais.

Essa equação diferencial, que foge do formato comumente utilizado para robôs seriais (indicado na equação 2.3), deve ser solucionada em conjunto com equações algébricas correspondentes às equações de vínculos entre as coordenadas empregadas na modelagem.

Para a aplicação da técnica de controle por torque computado, é necessário eliminar variáveis redundantes. Böhn, Belda e Valásek (2002) aplicam matrizes de transformações de coordenadas para essa tarefa, porém, não foi possível ter acesso ao trabalho de referência ${ }^{1}$ que trata da elaboração dessas matrizes. Já Hahn (2003) utiliza software de manipulação simbólica para eliminação de variáveis redundantes.

No presente trabalho, propõe-se que seja feita a eliminação exclusiva dos termos de derivada segunda das variáveis redundantes, com a utilização de ferramentas similares às utilizadas por Siciliano et al. (2009) e Khalil e Dombre

\footnotetext{
${ }^{1}$ STEJSKAL, V., VALÁSEK, M., Kinematics and dynamics of machinery. Marcel Dekker, 1996.
} 
(2002) para mudança de variável do controle no espaço dos atuadores para o controle no espaço do efetuador.

Utilizando a equação 3.39, pode-se reescrever a equação 6.1 da seguinte forma:

$$
M_{\tau q} \ddot{\boldsymbol{q}}+M_{\tau x}\left(J_{x q} \ddot{\boldsymbol{q}}+j_{x q}\right)+H_{\tau}+G_{\tau}=\boldsymbol{\tau}
$$

Colocando $\ddot{q}$ em evidência, obtém-se:

$$
\left(M_{\tau q}+M_{\tau x} J_{x q}\right) \ddot{\boldsymbol{q}}+M_{\tau x} j_{x q}+H_{\tau}+G_{\tau}=\boldsymbol{\tau}
$$

Definindo-se:

$$
\begin{gathered}
M_{\tau q}^{*}=M_{\tau q}+M_{\tau x} J_{x q} \\
H_{\tau q}^{*}=M_{\tau x} j_{x q}+H_{\tau}
\end{gathered}
$$

encontra-se uma equação diferencial compatível com a técnica de torque computado:

$$
M_{\tau q}^{*} \ddot{\boldsymbol{q}}+H_{\tau q}^{*}+G_{\tau}=\boldsymbol{\tau}
$$

Ressalta-se que foi feita a eliminação apenas dos termos de derivada segunda das variáveis redundantes. Assim, os termos $M_{\tau q}^{*}$ e $G_{\tau}$ são dependentes de $\boldsymbol{q}$ e $\boldsymbol{x}$, e o termo $H_{\tau}^{*}$ é dependente de $\boldsymbol{q}, \dot{\boldsymbol{q}}, \boldsymbol{x}$ e $\dot{\boldsymbol{x}}$.

Utilizando-se como esforço de controle:

$$
\begin{gathered}
\boldsymbol{\tau}=M_{\tau q}^{*} \boldsymbol{\tau}^{\prime}+H_{\tau q}^{*}+G_{\tau} \\
\boldsymbol{\tau}^{\prime}=\ddot{\boldsymbol{q}}_{d}+K_{d q} \dot{\widetilde{\boldsymbol{q}}}+K_{p q} \widetilde{\boldsymbol{q}} \\
\widetilde{\boldsymbol{q}}=\boldsymbol{q}_{d}-\boldsymbol{q}
\end{gathered}
$$


em que $\boldsymbol{q}_{d}$ define a trajetória desejada nas coordenadas dos atuadores, fica-se com a seguinte dinâmica de erro para o sistema:

$$
\ddot{\widetilde{\boldsymbol{q}}}+K_{d q} \dot{\widetilde{\boldsymbol{q}}}+K_{p q} \widetilde{\boldsymbol{q}}=0
$$

Definindo-se os ganhos $K_{d q}$ e $K_{p q}$ adequadamente, os erros de acompanhamento de trajetória convergem exponencialmente à zero.

De forma análoga ao realizado acima, pode-se tomar como base a equação 3.27 para reescrever o modelo dinâmico do robô em função das derivadas segundas das variáveis do efetuador, obtendo-se:

$$
M_{\tau x}^{*} \ddot{\boldsymbol{x}}+H_{\tau x}^{*}+G_{\tau}=\boldsymbol{\tau}
$$

em que:

$$
\begin{gathered}
M_{\tau x}^{*}=M_{\tau x}+M_{\tau q} J_{q x} \\
H_{\tau x}^{*}=M_{\tau q} j_{q x}+H_{\tau}
\end{gathered}
$$

Assim, pode-se realizar o controle sobre as variáveis do efetuador utilizandose o seguinte esforço de controle:

$$
\begin{gathered}
\boldsymbol{\tau}=M_{\tau x}^{*} \boldsymbol{\tau}^{\prime}+H_{\tau x}^{*}+G_{\tau} \\
\boldsymbol{\tau}^{\prime}=\ddot{\boldsymbol{x}}_{d}+K_{d x} \dot{\tilde{\boldsymbol{x}}}+K_{p x} \widetilde{\boldsymbol{x}} \\
\tilde{\boldsymbol{x}}=\boldsymbol{x}_{d}-\boldsymbol{x}
\end{gathered}
$$

Nota-se que apesar de terem sido utilizadas as variáveis dos atuadores e do efetuador no desenvolvimento acima, essa formulação pode ser empregada de forma mais ampla no controle de sistemas dinâmicos com quaisquer variáveis redundantes, utilizando-se a técnica de torque computado. Basta determinar previamente as relações cinemáticas que fazem a correspondência entre derivadas 
primeiras e segundas das variáveis redundantes e das variáveis sobre as quais será de fato realizado o controle.

\subsection{EQUIVALÊNCIA ENTRE CÁLCULO DE ESFORÇOS DE CONTROLE SOBRE VARIÁVEIS DOS ATUADORES E SOBRE VARIÁVEIS DO EFETUADOR NO CONTROLE POR TORQUE COMPUTADO}

A parte não linear da técnica de controle por torque computado resulta em um sistema linear, desacoplado, de massas unitárias, que é controlado com técnicas tradicionais de controle linear. De acordo com as coordenas empregadas, pode-se realizar o controle tanto no espaço dos atuadores como no espaço do efetuador. Entretanto, os ganhos para a parte linear do controlador são usualmente calculados da mesma forma, independentemente das coordenadas utilizadas. A fim de se verificar os efeitos dessa conduta, foi feito o desenvolvimento e comparação das equações de controle por torque computado baseada nos dois espaços de trabalho.

Para o torque computado aplicado no espaço dos atuadores, substituindo as equações 6.4, 6.5 e 6.8 na equação 6.7, encontra-se:

$$
\boldsymbol{\tau}=\left(M_{\tau q}+M_{\tau x} J_{x q}\right)\left(\ddot{\boldsymbol{q}}_{d}+K_{d q} \dot{\widetilde{\boldsymbol{q}}}+K_{p q} \widetilde{\boldsymbol{q}}\right)+M_{\tau x} j_{x q}+H_{\tau}+G_{\tau}
$$

Rearranjando os termos da equação 6.17, obtém-se:

$$
\boldsymbol{\tau}=\left(M_{\tau q}+M_{\tau x} J_{x q}\right) \ddot{\boldsymbol{q}}_{d}+\left(M_{\tau q}+M_{\tau x} J_{x q}\right)\left(K_{d q} \dot{\overrightarrow{\boldsymbol{q}}}+K_{p q} \widetilde{\boldsymbol{q}}\right)+M_{\tau x} j_{x q}+H_{\tau}+G_{\tau}
$$

Partindo agora para o torque computado aplicado ao espaço do efetuador, substituindo as equações $6.12,6.13$ e 6.15 na equação 6.14 , encontra-se:

$$
\boldsymbol{\tau}=\left(M_{\tau x}+M_{\tau q} J_{q x}\right)\left(\ddot{\boldsymbol{x}}_{d}+K_{d x} \dot{\tilde{\boldsymbol{x}}}+K_{p x} \tilde{\boldsymbol{x}}\right)+M_{\tau q} j_{q x}+H_{\tau}+G_{\tau}
$$

Aplicando-se a equação 3.39 para a trajetória desejada para o efetuador, obtém-se:

$$
\ddot{x_{d}}=J_{x q d} \ddot{q}_{\boldsymbol{d}}+j_{x q d}
$$


Substituindo a equação 6.20 na equação 6.19 :

$\boldsymbol{\tau}=\left(M_{\tau x}+M_{\tau q} J_{q x}\right)\left(J_{x q d} \ddot{\boldsymbol{q}_{d}}+j_{x q d}+K_{d x} \dot{\tilde{\boldsymbol{x}}}+K_{p x} \widetilde{\boldsymbol{x}}\right)+M_{\tau q} j_{q x}+H_{\tau}+G_{\tau}$

Rearranjando os termos da equação 6.21, encontra-se:

$$
\begin{aligned}
\boldsymbol{\tau}=\left(M_{\tau x} J_{x q d}\right. & \left.+M_{\tau q} J_{q x} J_{x q d}\right) \ddot{\boldsymbol{q}}_{d}+\left(M_{\tau x}+M_{\tau q} J_{q x}\right)\left(K_{d x} \dot{\tilde{\boldsymbol{x}}}+K_{p x} \widetilde{\boldsymbol{x}}\right)+M_{\tau x} j_{x q d}+H_{\tau}+G_{\tau} \\
& +M_{\tau q}\left(J_{q x} j_{x q d}+j_{q x}\right)
\end{aligned}
$$

Percebe-se que há certa similaridade entre as equações 6.22 e 6.18, mas não é possível afirmar que sejam equivalentes. Porém, na hipótese de pequenos erros de controle, podem-se fazer as seguintes aproximações:

$$
\begin{gathered}
M_{\tau x} J_{x q d} \approx M_{\tau x} J_{x q} \\
J_{x q d} \approx J_{q x}{ }^{-1} \Rightarrow M_{\tau q} J_{q x} J_{x q d} \approx M_{\tau q} \\
\dot{\tilde{\boldsymbol{x}}} \approx J_{x q} \dot{\tilde{\boldsymbol{q}}} \\
\tilde{\boldsymbol{x}} \approx J_{x q} \widetilde{\boldsymbol{q}} \\
M_{\tau x} j_{x q d} \approx M_{\tau x} j_{x q} \\
J_{q x} j_{x q d}+j_{q x} \approx J_{q x} j_{x q}+j_{q x}
\end{gathered}
$$

Além disso, multiplicando a equação 3.39 por $J_{q x}$, obtém-se:

$$
J_{q x} \ddot{x}=\ddot{\boldsymbol{q}}+J_{q x} j_{x q}
$$

Somando a equação 6.29 com a equação 3.27 , encontra-se: 


$$
J_{q x} \ddot{\boldsymbol{x}}+\ddot{\boldsymbol{q}}=\ddot{\boldsymbol{q}}+J_{q x} j_{x q}+J_{q x} \ddot{\boldsymbol{x}}+j_{q x} \Rightarrow J_{q x} j_{x q}+j_{q x}=0
$$

Assim, com base nas equações 6.23 a 6.28 e 6.30, a equação 6.22 pode ser modificada para a seguinte forma:

$$
\boldsymbol{\tau}=\left(M_{\tau x} J_{x q}+M_{\tau q}\right) \ddot{\boldsymbol{q}_{\boldsymbol{d}}}+\left(M_{\tau x}+M_{\tau q} J_{q x}\right)\left(K_{d x} J_{x q} \dot{\widetilde{\boldsymbol{q}}}+K_{p x} J_{x q} \widetilde{\boldsymbol{q}}\right)+M_{\tau x} j_{x q}+H_{\tau}+G_{\tau}
$$

Para mecanismos paralelos topologicamente simétricos, as matrizes $K_{d x} \mathrm{e}$ $K_{p x}$ são usualmente definidas como diagonais, com os elementos de suas diagonais principais iguais entre si. Nessas condições, os produtos $K_{d x} J_{x q}$ e $K_{p x} J_{x q}$ são comutativos, como mostram as equações 6.32 e 6.33 .

$$
\begin{aligned}
& K_{d x} J_{x q}=k_{d x} I_{3} J_{x q}=J_{x q} k_{d x} I_{3}=J_{x q} K_{d x} \\
& K_{p x} J_{x q}=k_{p x} I_{3} J_{x q}=J_{x q} k_{p x} I_{3}=J_{x q} K_{p x}
\end{aligned}
$$

em que $k_{d x}$ e $k_{p x}$ se tratam de valores escalares e $I_{3}$ de uma matriz identidade de dimensão $3 \times 3$.

Substituindo as equações 6.32 e 6.33 na equação 6.31, obtém-se:

$$
\boldsymbol{\tau}=\left(M_{\tau x} J_{x q}+M_{\tau q}\right) \ddot{\boldsymbol{q}_{\boldsymbol{d}}}+\left(M_{\tau x} J_{x q}+M_{\tau q}\right)\left(K_{d x} \dot{\tilde{\boldsymbol{q}}}+K_{p x} \widetilde{\boldsymbol{q}}\right)+M_{\tau x} j_{x q}+H_{\tau}+G_{\tau}
$$

Assim, definindo-se as matrizes de ganho no espaço do efetuador idênticas às matrizes de ganho no espaço dos atuadores, a equação 6.34 se torna equivalente à equação 6.18. Portanto, sob a hipótese de pequenos erros de controle, é indiferente a definição de ganhos de controle no espaço dos atuadores ou no espaço do efetuador caso as matrizes de ganho sejam diagonais, com os elementos de suas diagonais principais iguais entre si.

Para um caso mais geral, percebe-se que se definindo as matrizes $K_{d x}$ e $K_{p x}$ conforme as equações 6.35 e 6.36 , também é alcançada a equivalência entre as equações 6.34 e 6.18 . 


$$
\begin{aligned}
& K_{d x}=J_{x q} K_{d q} J_{x q}^{-1} \\
& K_{p x}=J_{x q} K_{p q} J_{x q}^{-1}
\end{aligned}
$$

Isolando-se os ganhos relativos ao controle no espaço dos atuadores, obtémse:

$$
\begin{aligned}
& K_{d q}=J_{x q}^{-1} K_{d x} J_{x q} \\
& K_{p q}=J_{x q}^{-1} K_{p x} J_{x q}
\end{aligned}
$$

Assim, sob a hipótese de pequenos erros de controle, é possível calcular quais são as matrizes de ganho que tornam o controle no espaço dos atuadores equivalente ao controle no espaço do efetuador e vice-versa.

\subsection{EQUIVALÊNCIA ENTRE CONTROLE POR TORQUE COMPUTADO ESTENDIDO E CONTROLE POR TORQUE COMPUTADO}

De forma similar ao procedimento apresentado na seção 6.2, será agora feito o desenvolvimento das equações do controle por torque computado estendido para verificação de sua equivalência ao controle por torque computado tradicional.

Dado um sistema dinâmico equacionado com variáveis redundantes como o representado na equação 6.1, a entrada de controle utilizando-se a técnica de torque computado estendido seria igual a:

$$
\begin{gathered}
\boldsymbol{\tau}=\left[\begin{array}{ll}
M_{\tau q} & M_{\tau x}
\end{array}\right] \boldsymbol{\tau}^{\prime}+H_{\tau}+G_{\tau} \\
\boldsymbol{\tau}^{\prime}=\left[\begin{array}{l}
\ddot{\boldsymbol{q}}_{d}+K_{d q} \dot{\overrightarrow{\boldsymbol{q}}}+K_{p q} \widetilde{\boldsymbol{q}} \\
\ddot{\boldsymbol{x}}_{d}+K_{d x} \dot{\tilde{\boldsymbol{x}}}+K_{p x} \widetilde{\boldsymbol{x}}
\end{array}\right]
\end{gathered}
$$

em que $\boldsymbol{\tau}^{\prime}$ passa a ser uma matriz $6 \times 1$ 
Ressalta-se que as variáveis redundantes também devem ser monitoradas quando utilizada essa técnica.

Substituindo a equação 6.40 na equação 6.39 , e executando o produto matricial, obtém-se:

$$
\boldsymbol{\tau}=M_{\tau q}\left(\ddot{\boldsymbol{q}}_{d}+K_{d q} \dot{\tilde{\boldsymbol{q}}}+K_{p q} \widetilde{\boldsymbol{q}}\right)+M_{\tau x}\left(\ddot{\boldsymbol{x}}_{d}+K_{d x} \dot{\tilde{\boldsymbol{x}}}+K_{p x} \widetilde{\boldsymbol{x}}\right)+H_{\tau}+G_{\tau}
$$

Substituindo a equação 6.20 na equação 6.41 , e rearranjando os termos, encontra-se:

$$
\boldsymbol{\tau}=\left(M_{\tau q}+M_{\tau x} J_{x q d}\right) \ddot{\boldsymbol{q}}_{d}+M_{\tau q}\left(K_{d q} \dot{\tilde{\boldsymbol{q}}}+K_{p q} \widetilde{\boldsymbol{q}}\right)+M_{\tau x}\left(K_{d x} \dot{\tilde{\boldsymbol{x}}}+K_{p x} \widetilde{\boldsymbol{x}}\right)+M_{\tau x} j_{x q d}+H_{\tau}+G_{\tau}
$$

Sob a hipótese de pequenos erros de controle, podem ser utilizadas as aproximações apresentadas nas equações $6.23,6.25,6.26$ e 6,27, obtendo-se:

$$
\boldsymbol{\tau}=\left(M_{\tau q}+M_{\tau x} J_{x q}\right) \ddot{\boldsymbol{q}}_{d}+M_{\tau q}\left(K_{d q} \dot{\boldsymbol{q}}+K_{p q} \widetilde{\boldsymbol{q}}\right)+M_{\tau x}\left(K_{d x} J_{x q} \dot{\widetilde{\boldsymbol{q}}}+K_{p x} J_{x q} \widetilde{\boldsymbol{q}}\right)+M_{\tau x} j_{x q}+H_{\tau}+G_{\tau}
$$

Definindo-se as matrizes $K_{d x}$ e $K_{p x}$ conforme as equações 6.44 e 6.45, é alcançada a equivalência entre as equações 6.43 e 6.18 .

$$
\begin{aligned}
& K_{d x}=J_{x q} K_{d q} J_{x q}^{-1} \\
& K_{p x}=J_{x q} K_{p q} J_{x q}^{-1}
\end{aligned}
$$

Note que apesar das equações 6.44 e 6.45 serem idênticas às equações 6.35 e 6.36, seus significados são diferentes. Enquanto no controle por torque computado tradicional são utilizadas ou as matrizes $K_{d q}$ e $K_{p q}$ ou as matrizes $K_{d x}$ e $K_{p x}$, no controle por torque computado as quatro matrizes de ganho são utilizadas simultaneamente. Assim, o uso das equações 6.35 e 6.36 é opcional. Mas, o emprego das equações 6.44 e 6.45 é obrigatório para que o sistema controlado se comporte dinamicamente conforme projetado. 
Para o caso particular em que as matrizes de ganho são diagonais, com os elementos de suas diagonais principais iguais entre si, as equações 6.44 e 6.45 ficam reduzidas a:

$$
\begin{aligned}
& K_{d x}=K_{d q} \\
& K_{p x}=K_{p q}
\end{aligned}
$$

Portanto, a forma com que o controle por torque computado estendido vem sendo empregado (ZUBIZARRETA et al., 2008, 2011, 2012, 2013), com ganhos iguais para todas as coordenadas, é teoricamente equivalente ao controle por torque computado tradicional sob a hipótese de pequenos erros de controle. Na prática, em que existem erros de modelagem, a diferença de desempenho do controlador por torque computado estendido é consequência da medição direta de variáveis redundantes.

\subsection{SINTONIZAÇÃO DO CONTROLE POR TORQUE COMPUTADO E POR TORQUE COMPUTADO ESTENDIDO PARA ROBÔS PARALELOS ASSIMÉTRICOS}

A sintonização do controle por torque computado, em seu equacionamento tradicional, é realizada por ajuste dos ganhos das matrizes $K_{d}$ e $K_{p}$ da equação 2.10. Conforme já apresentado na seção 2.4.5, os ganhos são usualmente determinados de forma a se obter dinâmica para erros de posição equivalentes a de sistemas de segunda ordem, caracterizados por polos de determinados amortecimentos e frequências naturais, limitadas à metade da menor frequência estrutural do mecanismo.

Normalmente, utilizam-se matrizes de ganhos diagonais, cujos elementos da diagonal principal são idênticos entre si. Entretanto, para o caso de mecanismos paralelos assimétricos, as características particulares dessas arquiteturas seriam melhor exploradas caso fossem definidos ganhos distintos para cada variável controlada, pois seus membros não são topologicamente idênticos, em conformidade com a isotropia de seus requisitos de movimentação. 
Assim, os ganhos para as variáveis correspondentes a direções de movimentação de alto desempenho poderiam ser ajustados até o limite permissível pela menor frequência estrutural do mecanismo e os ganhos para as demais variáveis poderiam ser relaxados para que a resposta do sistema fosse suavizada e para que os polos da dinâmica dos erros de posição em malha fechada se afastassem da região de instabilidade.

Especula-se ainda que, caso os termos predominantes da dinâmica do mecanismo apresentem desacoplamento entre variáveis controladas e a movimentação do mecanismo na direção com maior requisito de desempenho não excite significativamente os modos de vibração de menores frequências, os maiores ganhos poderiam ultrapassar o limite hoje estabelecido, correspondentes à metade da menor frequência de vibração estrutural do mecanismo.

Independentemente do critério de estipulação dos limites para os ganhos do controlador, deve-se, primeiramente, definir o conjunto de variáveis sobre o qual os ganhos serão projetados e sobre o qual será executado o controle. Caso seja o mesmo conjunto de variáveis, pode-se implementar o controle empregando as equações desenvolvidas na seção 6.1. Caso sejam diferentes, é necessário utilizar equações como as equações 6.35 e 6.36 para que seja obtida a resposta dinâmica desejada. É importante lembrar que as equações 6.35 e 6.36 foram deduzidas sob a hipótese de pequenos erros de controle e a validade delas deve ser verificada conforme a aplicação.

No controle por torque computado estendido, todas as variáveis são utilizadas para o controle. Assim, devem-se definir os ganhos em um conjunto de coordenadas, conforme a conveniência de projeto, e calcular os ganhos para as coordenas redundantes, dentro do laço de controle, utilizando as equações $6.44 \mathrm{e}$ 6.45 . 


\section{SIMULAÇÃo E ANÁlise DE LEIS DE CONTROLE APLICADAS AO MECANISMO 2 RSS + PPaP}

A partir do desenvolvimento dos modelos cinemático e dinâmico do mecanismo 2 RSS + PPaP, apresentados nos capítulos 3 a 5, foram realizadas simulações de controle desse mecanismo baseando-se nas técnicas de torque computado e torque computado estendido. $\mathrm{Na}$ seção 7.1 são explicados os procedimentos gerais utilizados para determinação de parâmetros de simulação e execução das simulações. Em seguida, são apresentadas nas seções 7.2 e 7.3 simulações que exemplificam a validade das equações desenvolvidas no capítulo 6 para controle de mecanismos paralelos assimétricos. Por fim, na seção 7.4 são avaliados os efeitos de simplificação do modelo dinâmico e de discretização do controlador sobre os erros de controle. Nota-se que as seções 7.2 e 7.3 mostram resultados esperados para qualquer mecanismo paralelo, de acordo com o equacionamento desenvolvido no capítulo 6 , e utiliza o particular mecanismo em estudo como um exemplo. Já os resultados da seção 7.4 são específicos do mecanismo 2 RSS + PPaP, e a possibilidade de extensão desses resultados para toda família de mecanismos paralelos deve ainda ser explorada.

\subsection{IMPLEMENTAÇÃO DO SISTEMA DE CONTROLE PARA O MECANISMO PARALELO EM MATLAB}

\subsubsection{Procedimento de integração numérica de modelo e controlador}

As equações do modelo dinâmico do robô foram implementadas em conjunto com as equações de controladores utilizando-se o software Matlab. A integração numérica do movimento do robô controlado foi realizada pelo método de RungeKutta de quarta ordem, por rotina implementada especificamente para esse fim.

O modelo dinâmico do robô foi implementado com base no espaço dos atuadores, utilizando-se eliminação da derivada segunda de coordenadas redundantes de seu modelo dinâmico de forma similar a apresentada na seção 6.1. Foram consideradas como entrada a força e torques providos pelos atuadores. As saídas foram as posições e velocidades tanto das coordenadas dos atuadores como das coordenadas do efetuador, o que permitiu fechar a malha de controle de modos variados. 
A rotina de integração implementada permite a simulação do controlador em modo contínuo e em modo discreto. Nesse último caso, os valores de esforços dos atuadores são mantidos constantes durante o período de amostragem do controlador (que é independente do passo de integração do modelo da planta) e são defasados de um período de amostragem, para simular o tempo necessário para o cálculo dos esforços de controle.

Quando em modo discreto, é possível também executar o controle com duas taxas de amostragem diferentes, uma, mais lenta, para a parte de linearização do modelo dinâmico por realimentação (baseada no modelo do robô) e outra, mais rápida, para a parte de controle linear (baseada nos ganhos PD).

\subsubsection{Parâmetros nominais do modelo}

Para todos os cálculos e simulações apresentados neste capítulo, foram utilizados como parâmetros nominais do robô aqueles utilizados na seção 5.2, aqui reapresentados na tabela 7.1 .

Tabela 7.1 - Parâmetros geométricos e inerciais

\begin{tabular}{|c|c|c|}
\hline $\begin{array}{c}\text { Comprimentos } \\
{[\mathrm{mm}]}\end{array}$ & $\begin{array}{c}\text { Massas } \\
{[\mathrm{kg}]}\end{array}$ & $\begin{array}{c}\text { Momentos de inércia } \\
{\left[\text { [kg. } \mathrm{mm}^{2}\right]}\end{array}$ \\
\hline$a_{1}=350$ & $m_{1}=0,124$ & $I_{I_{x} x I}=1262$ \\
\hline \multirow{3}{*}{$a_{2}=450$} & \multirow{3}{*}{$m_{2}=0,102$} & $I_{2 \_x l}=1722$ \\
\hline & & $I_{2 \_x 2}=1,84$ \\
\hline & & $I_{2_{x} \times 3}=1722$ \\
\hline$l=80$ & $m_{3}=0,200$ & - \\
\hline$a_{4}=100$ & $m_{4}=0,391$ & - \\
\hline$a_{5}=380$ & $m_{5}=0,137$ & $I_{5_{-x l}}=1648$ \\
\hline$a_{6}=100$ & $m_{6}=0,235$ & - \\
\hline$L=160$ & - & - \\
\hline - & $M=0($ sem carga $)$ & - \\
\hline
\end{tabular}

Os valores de momentos de inércia das barras foram calculados utilizando os parâmetros listados na tabela 7.2. Tais parâmetros também foram utilizados para o cálculo de frequências de vibração estrutural do mecanismo, apresentado na próxima seção. 
Tabela 7.2 - Parâmetros geométricos e de materiais

\begin{tabular}{|c|c|c|c|}
\cline { 2 - 4 } \multicolumn{1}{c|}{} & Barras AC e BD & Barras CE e DF & Paralelogramo \\
\hline Material & AA 2024 & AA 2024 & AA 2024 \\
\hline Módulo de elasticidade [GPa] & 73,1 & 73,1 & 73,1 \\
\hline Coeficiente de Poison & 0,33 & 0,33 & 0,33 \\
\hline Densidade $\left[\mathbf{k g} / \mathbf{m}^{3}\right.$ ] & 2780 & 2780 & 2780 \\
\hline Seção transversal & Circular, tubular & Circular, tubular & Retangular \\
\hline Diâmetro externo [mm] & 15,88 & 12,00 & - \\
\hline Espessura de parede [mm] & 3,18 & 2,83 & - \\
\hline Largura [mm] & - & - & 60 \\
\hline Espessura [mm] & - & - & 2,10 \\
\hline
\end{tabular}

\subsubsection{Determinação de frequências estruturais do mecanismo 2 RSS + PPaP}

Algumas frequências naturais estruturais do mecanismo, que são balisadoras dos limites superiores de ganhos de controle, foram estimadas por meio da modelagem por elementos finitos, utilizando-se o software LISA (SONNENHOF HOLDINGS, 2013). Nesses modelos, os atuadores foram substituídos por engastamentos (restrição completa de graus de liberdade nas regiões de acoplamento com atuadores) para cada posição imposta ao efetuador, de forma a tornar o mecanismo equivalente a uma estrutura. Nota-se que as características de rigidez e distribuição de massas são dependentes da posição do efetuador, como mostra, por exemplo, o estudo realizado por Gonçalves (2009).

$\mathrm{Na}$ modelagem aqui desenvolvida, cujos detalhes estão disponíveis no Apêndice $\mathrm{G}$, foi avaliado o comportamento estrutural do robô com o efetuador posicionado em quatro regiões distintas do espaço de trabalho. A menor frequência natural identificada para o mecanismo, na ausência de carga manipulada, foi de 41,1 $\mathrm{Hz}$ e corresponde à vibração das barras $\mathrm{AC}$ e $\mathrm{BD}$ em fase, com o efetuador na posição dadas pelas coordenadas $\boldsymbol{x}=\left[\begin{array}{llll}280 & 140 & 480\end{array}\right]^{T} \mathrm{~mm}$. A figura 7.1 , em que 0 membro central foi suprimido (conforme simplificações explicadas no Apêndice $G$ ), ilustra o modo de vibração em questão. A inclusão de massa transportada tende a diminuir as frequências estruturais do mecanismo (ver tabela G.2 do Apêndice G), o que deve ser contabilizado no cálculo dos ganhos de controladores. 


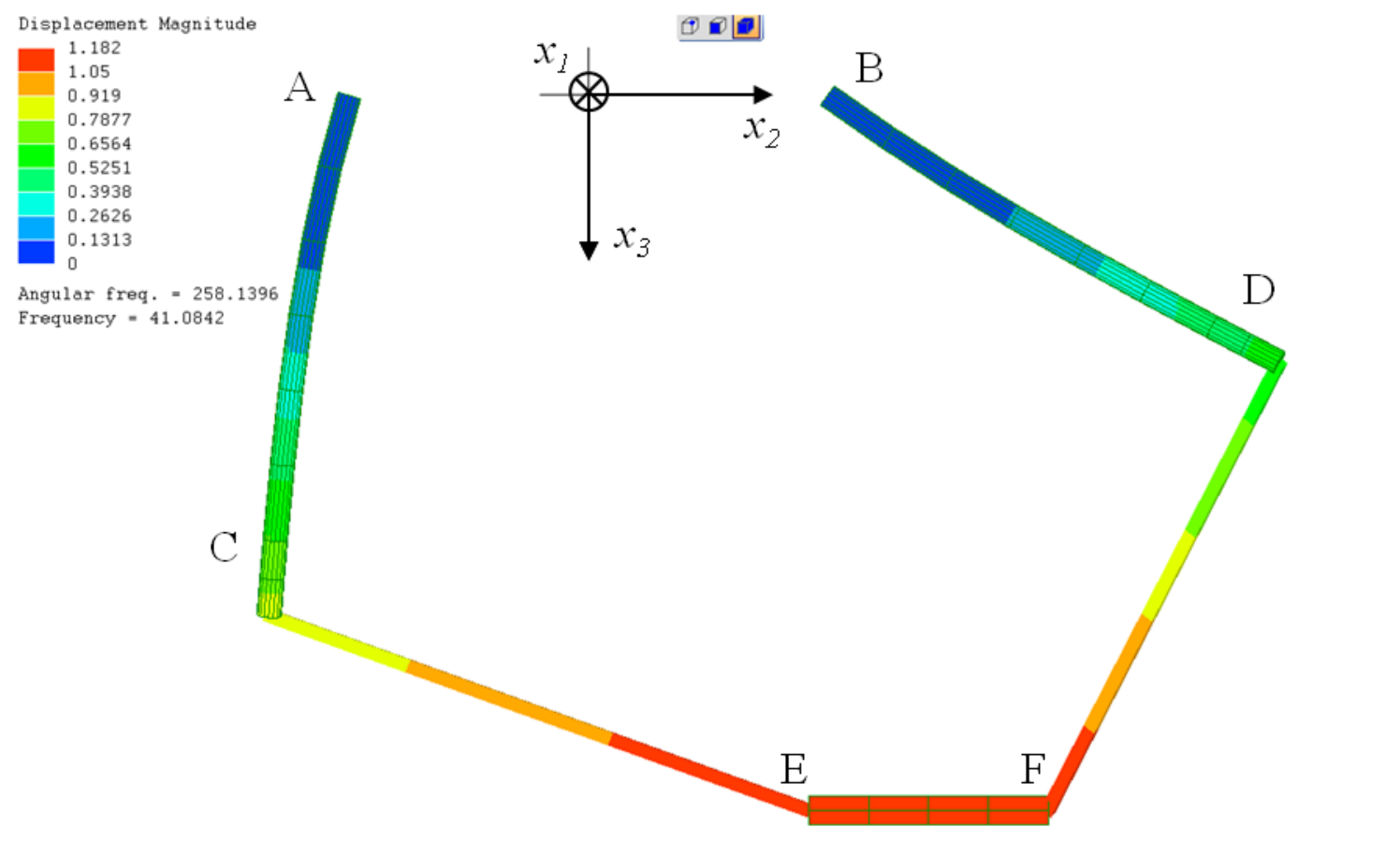

Figura 7.1 - Modo de vibração cuja frequência foi a menor identificada para o mecanismo

Ressalta-se que esse se trata de um modelo preliminar e que se recomenda aprofundamento futuro deste estudo, incluindo a execução de ensaios experimentais para a identificação dos modos de vibração e de suas frequências num protótipo do robô.

\subsubsection{Cálculo de ganhos de controle}

Os procedimentos de sintonização de controladores apresentados nas seções anteriores foram aplicados ao mecanismo em estudo com base em suas frequências estruturais.

A partir de sua menor frequência estrutural, de valor igual a $41,1 \mathrm{~Hz}$, foi definida a frequência máxima de $20 \mathrm{~Hz}$ para os polos da dinâmica do erro de posição do sistema em malha fechada. Assim, utilizando amortecimento crítico, os limites superiores para os ganhos a serem utilizados nos controladores por torque computado e por torque computado estendido estão calculados nas equações 7.1 a 7.3.

$$
\omega=2 \pi f=2 \pi .20=125,7 \mathrm{rad} / \mathrm{s}
$$

$$
k_{p}=\omega^{2}=1579
$$




$$
k_{d}=2 \zeta \omega=2 \cdot 1 \cdot 125,7=251,3
$$

Esses ganhos são utilizados como elementos da diagonal principal das matrizes $K_{p}$ e $K_{d}$, definidas usualmente no espaço do efetuador. Quando necessário, são empregadas as equações desenvolvidas no capítulo 6 para o cálculo dos ganhos no espaço dos atuadores em função dos ganhos no espaço do efetuador.

\subsubsection{Trajetória de referência}

$\mathrm{Na}$ maior parte das simulações executadas nas seções seguintes, foram executados ciclos de movimento correspondentes a tarefas de pega-e-põe.

As trajetórias para os ciclos pega-e-põe foram obtidas por sobreposição de movimentos baseados em equações do tipo cicloidal em relação ao tempo, conforme equação 7.4 .

$$
x=x_{0}+\Delta x\left(\frac{\left(t-t_{0}\right)}{T_{m}}-\frac{1}{2 \pi} \operatorname{sen}\left(\frac{2 \pi\left(t-t_{0}\right)}{T_{m}}\right)\right)
$$

em que $x_{0}$ e $t_{0}$ são a posição e o instante iniciais, $\Delta x$ é o deslocamento total no movimento, e $T_{m}$ o período do movimento.

A equação cicloidal é interessante pois faz com que a trajetória seja suave (derivada segunda contínua), inicie e termine com velocidade e aceleração iguais a zero, e tenha baixas velocidades e acelerações nos instantes finais do movimento.

Para todos os ciclos, foi admitido que o ponto inicial e o ponto final da trajetória possuíam mesma cota $x_{3}$. A trajetória do efetuador correspondia a deslocamento horizontal, resultante de movimentos cicloidais em relação às coordenadas $x_{1}$ e $x_{2}$, sobreposto a um movimento vertical composto por subida, repouso e descida. Para garantir que 0 início do movimento ocorresse exclusivamente na direção vertical, o deslocamento na direção horizontal teve seu início defasado e seu término adiantado em relação ao movimento vertical.

Assim, foram definidos os seguintes parâmetros para o cálculo da trajetória de cada ciclo pega-e-põe:

$\boldsymbol{x}_{\boldsymbol{i}}$ - ponto inicial; 
$\boldsymbol{x}_{\boldsymbol{f}}$ - ponto final;

$\Delta x_{3}$ - amplitude do deslocamento vertical;

$T$ - período total do ciclo;

$T_{v}$ - tempo de subida e de descida no movimento vertical;

$\Delta t_{h}$ - atraso no início do movimento horizontal (e adiantamento de seu término).

Como exemplo, as figuras 7.2 e 7.3 mostram a trajetória obtida para deslocamento entre os pontos $\boldsymbol{x}_{\boldsymbol{i}}=\left[\begin{array}{lll}0 & 0 & 480\end{array}\right]^{T} \mathrm{~mm}$ e $\boldsymbol{x}_{\boldsymbol{f}}=\left[\begin{array}{llll}280 & 140 & 480\end{array}\right]^{T} \mathrm{~mm}$, adotando-se os parâmetros listados na tabela 7.3.

Tabela 7.3 - Parâmetros utilizados para ciclos pega-e-põe

\begin{tabular}{|c|c|}
\hline Parâmetro & Valor \\
\hline$\Delta x_{3}[\mathrm{~mm}]$ & 50 \\
\hline$T[\mathrm{~s}]$ & 0,4 \\
\hline$T_{v}[\mathrm{~s}]$ & 0,1 \\
\hline$\Delta t_{h}[\mathrm{~s}]$ & 0,05 \\
\hline
\end{tabular}

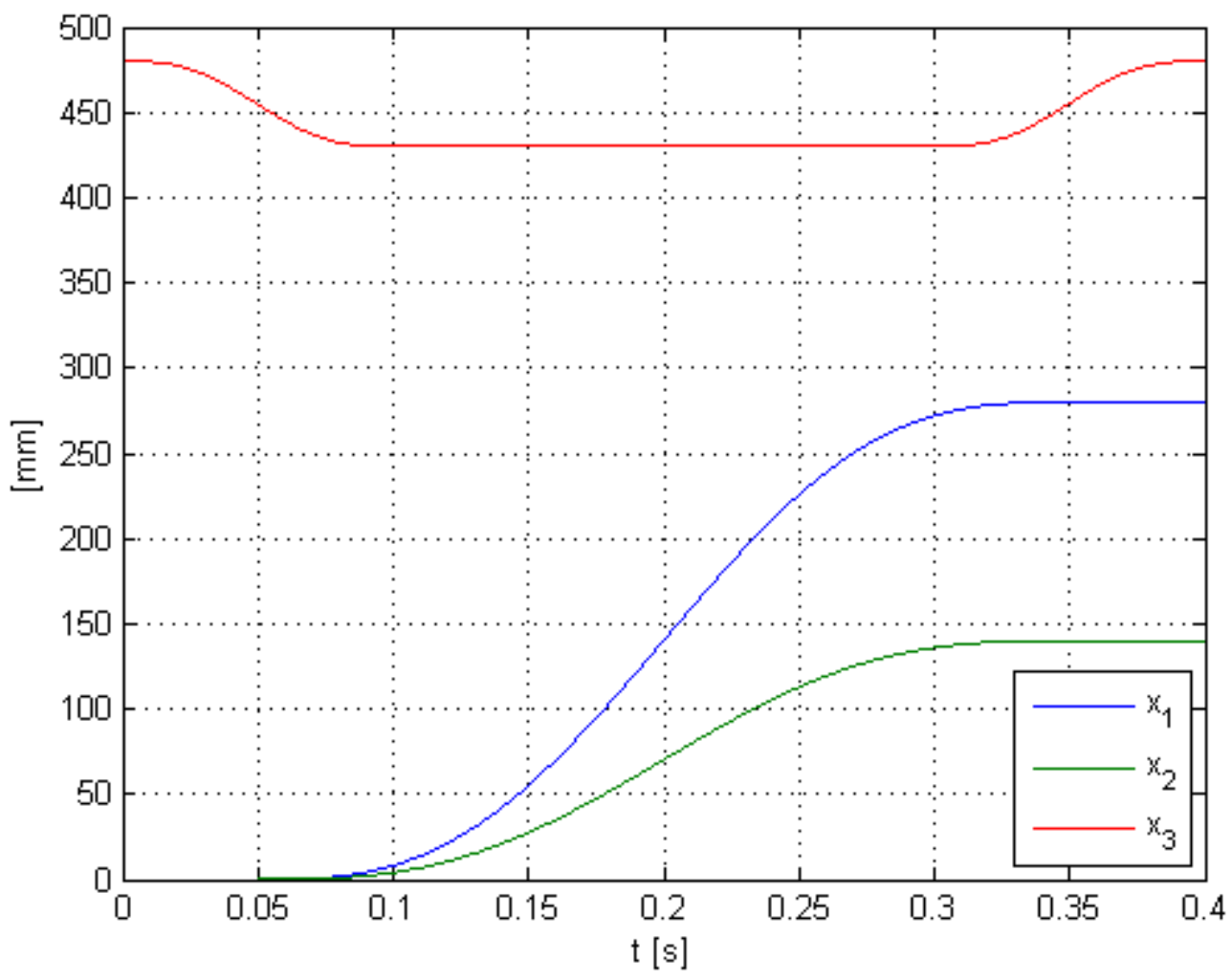

Figura 7.2 - Evolução das coordenadas $x_{1} x_{2}$ e $x_{3}$ em função do tempo em ciclo pega-e-põe 


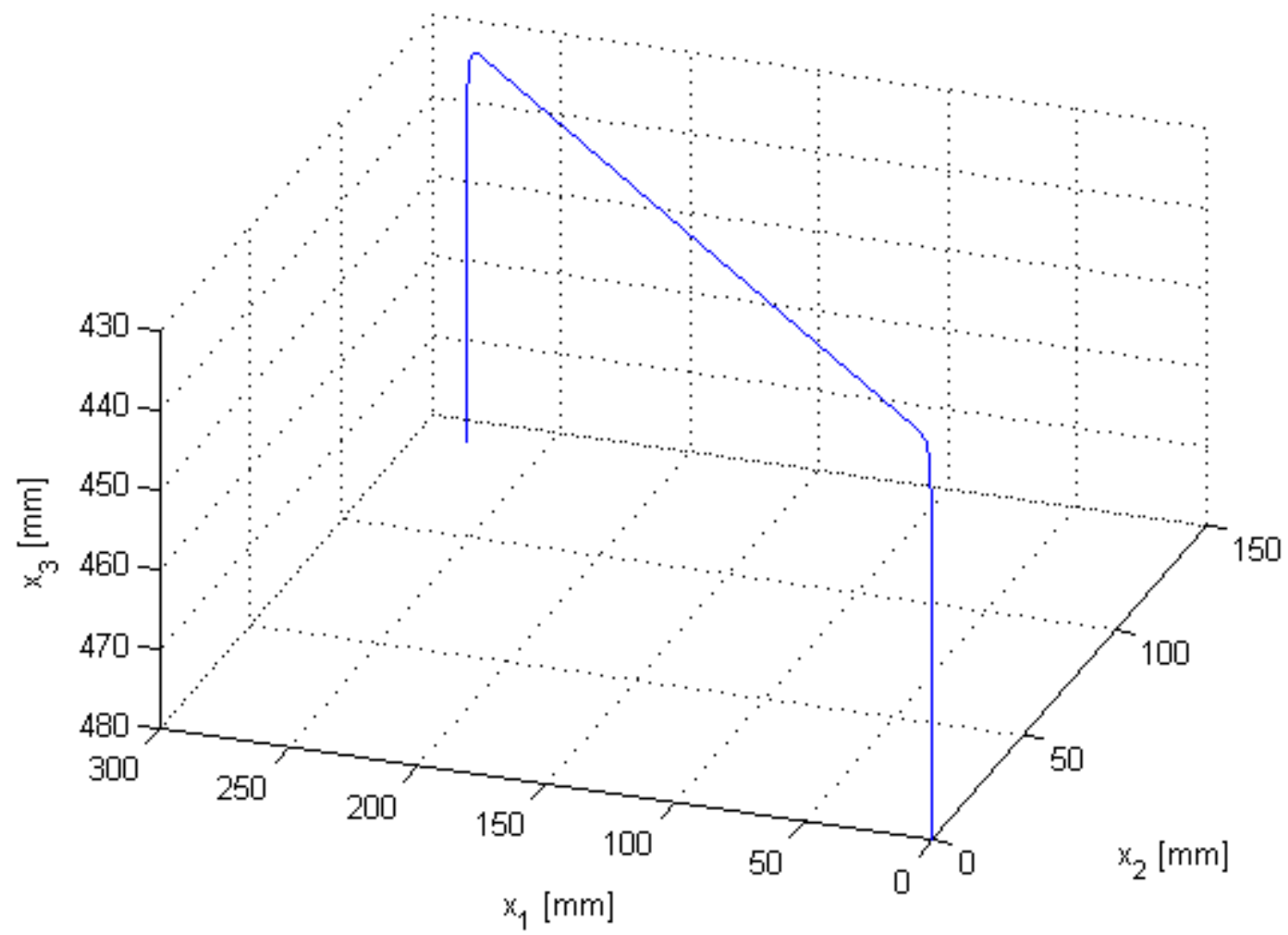

Figura 7.3 - Trajetória de ciclo pega-e-põe no espaço de trabalho do robô

Concatenando-se ciclos pega-e-põe, intercalados por repousos do efetuador (correspondentes a períodos de acionamento de uma garra ou dispositivo equivalente), foi definido um movimento de referência para execução de simulações de controle do mecanismo. A tabela 7.4 mostra os pontos de início e de fim de cada ciclo pega-e-põe. Esses ciclos foram intercalados com repousos de 0,1 $\mathrm{s}$ de duração. A vista superior da trajetória do efetuador para essa sequência de movimento pode ser observada na figura 7.4.

Tabela 7.4 - Sequência de pontos interconectados por ciclos pega-e-põe

\begin{tabular}{|c|c|c|c|c|c|c|c|}
\cline { 2 - 8 } \multicolumn{1}{c|}{} & $\mathbf{1}$ & $\mathbf{2}$ & $\mathbf{3}$ & $\mathbf{4}$ & $\mathbf{5}$ & $\mathbf{6}$ & $\mathbf{7}$ \\
\hline$x_{1}[\mathrm{~mm}]$ & 0 & 0 & 280 & -280 & 280 & -280 & 280 \\
\hline$x_{2}[\mathrm{~mm}]$ & -140 & 140 & 0 & 0 & 140 & -140 & -140 \\
\hline$x_{3}[\mathrm{~mm}]$ & 480 & 480 & 480 & 480 & 480 & 480 & 480 \\
\hline
\end{tabular}




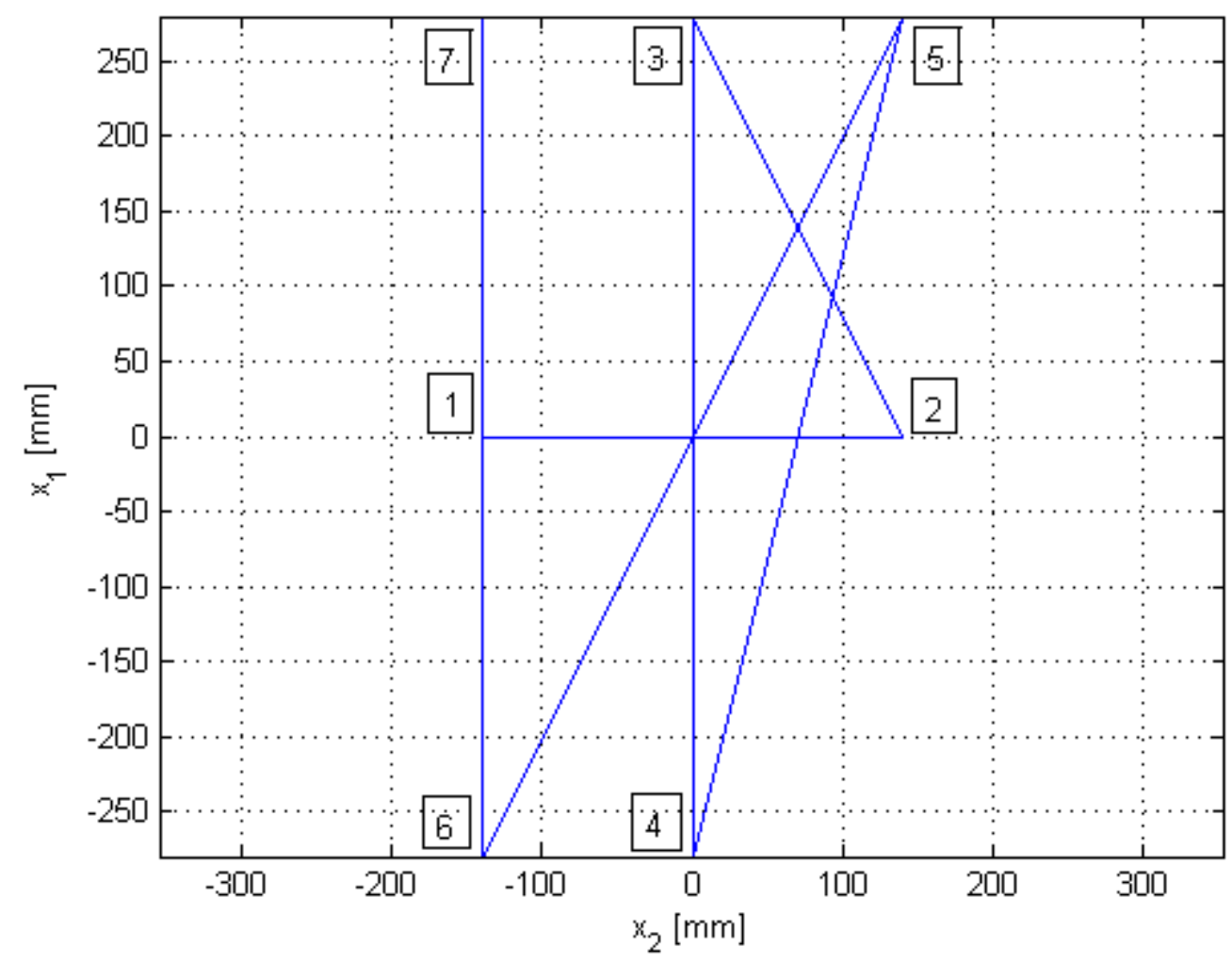

Figura 7.4 - Sequência de pontos de ciclos pega-e-põe sobre o espaço de trabalho do robô

\subsubsection{Critérios de cálculo de erros de controle}

Os erros de controle foram calculados como a distância entre os pontos da trajetória requerida e os pontos efetivamente atingidos pelo efetuador do robô, conforme a equação 7.5 .

$$
e=\left(\widetilde{\boldsymbol{x}}^{T} \widetilde{\boldsymbol{x}}\right)^{1 / 2}
$$

em $\widetilde{\boldsymbol{x}}$ se trata da diferença entre a posição desejada para o efetuador e sua posição efetivamente alcançada (conforme definido na equação 6.16).

Sobre os valores dos erros foram calculados os valores médios e máximos, para três diferentes intervalos da trajetória:

- Movimento - abrange todos os períodos em que a trajetória desejada para o efetuador possuía velocidade diferente de zero;

- Repouso - abrange todos os períodos em que a trajetória desejada para o efetuador possuía velocidade igual a zero; 
- Aproximação - abrange apenas os instantes finais de movimento do efetuador, precedentes a períodos de repouso.

Essa divisão foi fundamentada nos requisitos de desempenho para a aplicação de pega-e-põe. Normalmente, os erros de controle durante o movimento podem ser relaxados para se atingir altas velocidades e acelerações. Devem ser suficientes apenas para evitar colisão do robô (e da carga manipulada) com o ambiente e não são tão relevantes como em operações de usinagem. Porém, ao término do movimento e no período de repouso, deseja-se maior exatidão no controle de posição.

Sobre o movimento apresentado na seção anterior, foram definidos os períodos de aproximação como os instantes correspondentes aos $20 \%$ finais da descida do efetuador no decorrer da trajetória desejada.

\subsubsection{Definição de passo de integração e de frequências de amostragem}

Para a definição do passo de integração numérica do modelo dinâmico do robô, foram realizadas simulações do controle do robô em malha aberta numa abordagem feedforward. Assim, os esforços de controle, apresentados nas figuras 7.5 e 7.6, foram calculados previamente à execução das simulações, apenas em função das equações de dinâmica inversa do robô e da trajetória requerida (sequência de ciclos pega-e-põe apresentada na seção 7.1.5). Foi utilizado controle no modo contínuo (saída do controlador contínua ao longo do tempo). Os resultados obtidos nessas simulações são apresentados na figura 7.7.

Para um dado passo de integração, os erros médios e máximos correspondentes às três etapas de movimento ficam restritos a um pequeno intervalo. Por exemplo, para o passo de integração de $10^{-4} \mathrm{~s}$, os erros estão contidos no intervalo $\left[4,5.10^{-4} ; 9,5.10^{-4}\right] \mathrm{mm}$. 


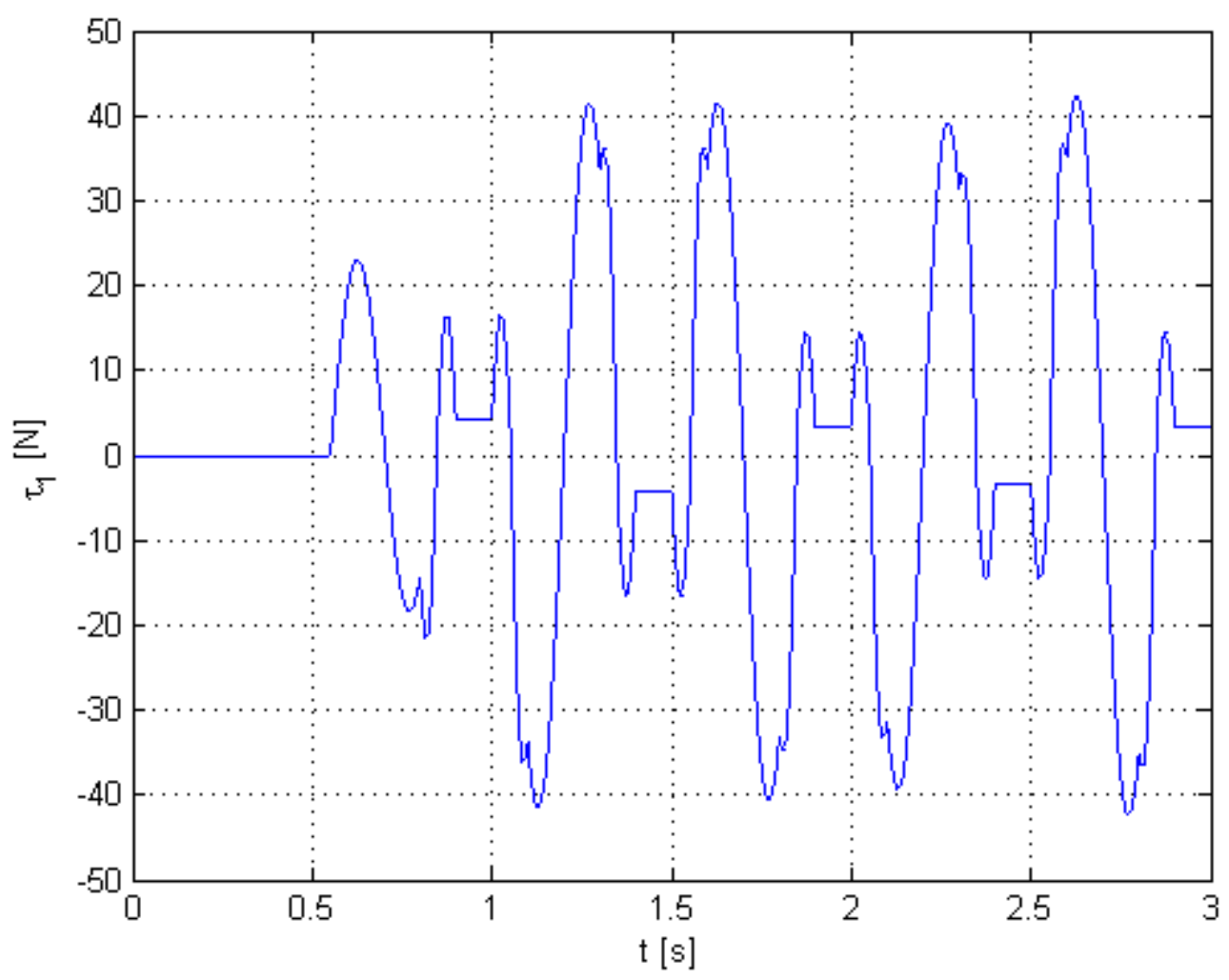

Figura 7.5 - Força $\tau_{1}$ utilizada no controle do mecanismo em malha aberta

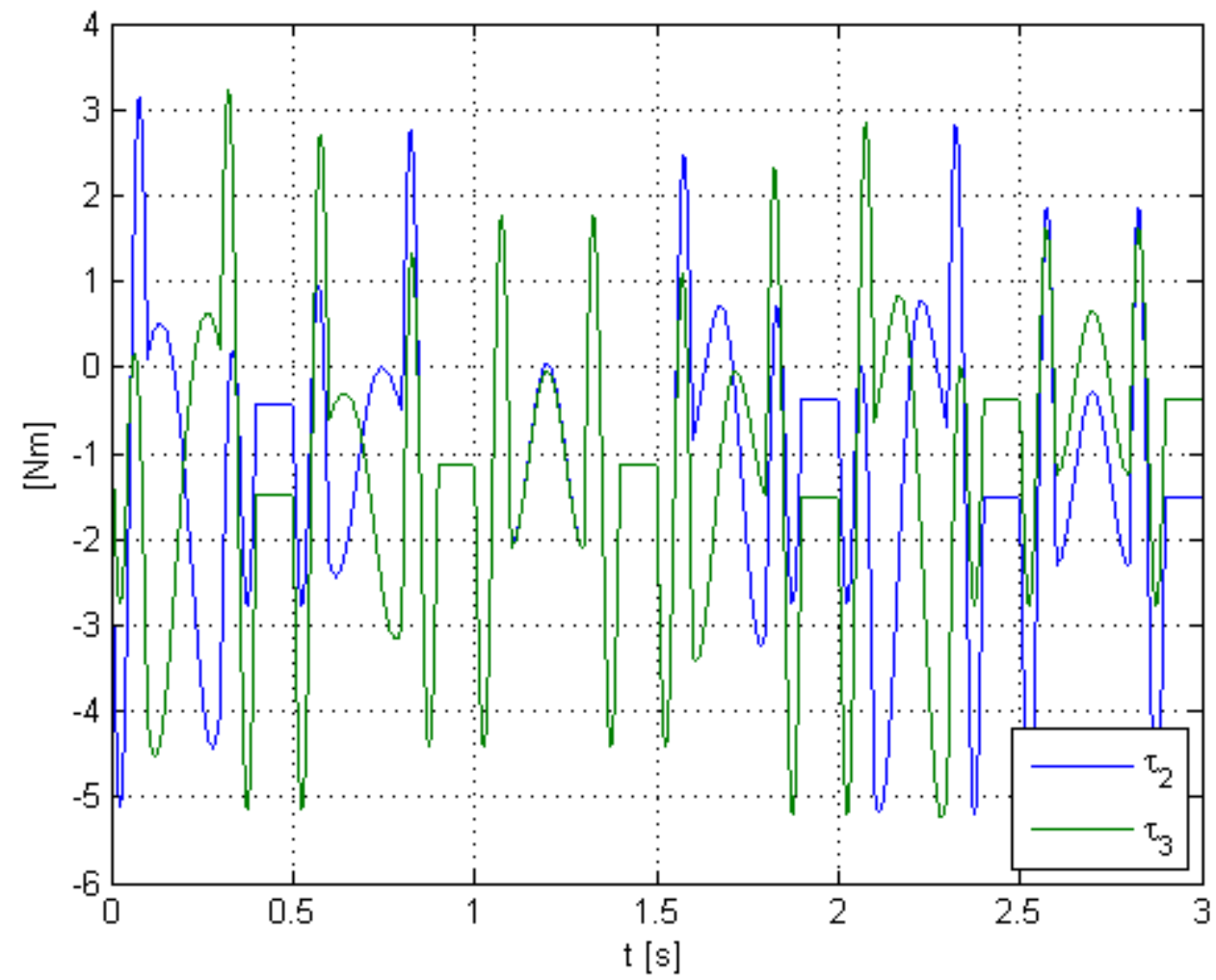

Figura 7.6 - Torques $\tau_{2}$ e $\tau_{3}$ utilizados no controle do mecanismo em malha aberta 


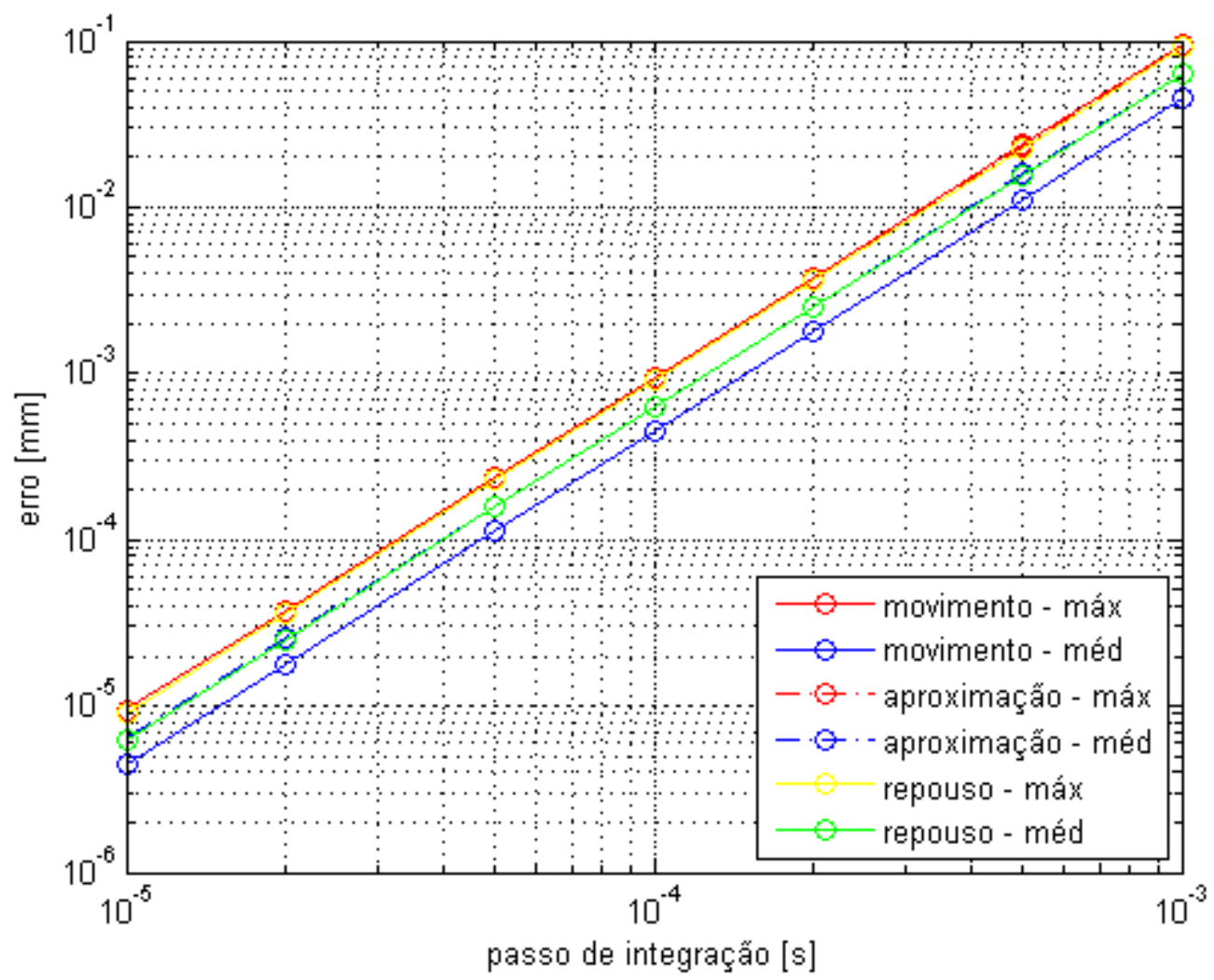

Figura 7.7 - Erros de controle em malha aberta em função do passo de integração numérica do modelo dinâmico, controle contínuo

Adotando-se $10^{-4} \mathrm{~s}$ como passo de integração, foram realizadas simulações em que o modo de controle foi alterado para discreto. Os resultados dos erros de controle do robô em malha aberta podem ser observados na figura 7.8.

Nota-se que os erros de controle diminuem com a diminuição do período de amostragem, mas, mesmo para o período de amostragem de $10^{-4} \mathrm{~s}$, que equivale a uma alta taxa de amostragem de $10000 \mathrm{~Hz}$, os erros são muito maiores que os obtidos na simulação do controlador em modo contínuo. Assim, a discretização do controlador não pode ser desprezada na análise (e no projeto) do robô em malha fechada. Além disso, fica evidente que, entre os períodos de movimento analisados, os erros nos repousos são os menores, seguidos pelos erros nas aproximações (baixas velocidades e acelerações) e pelos erros nos movimentos completos (abrangem altas velocidades e acelerações). 


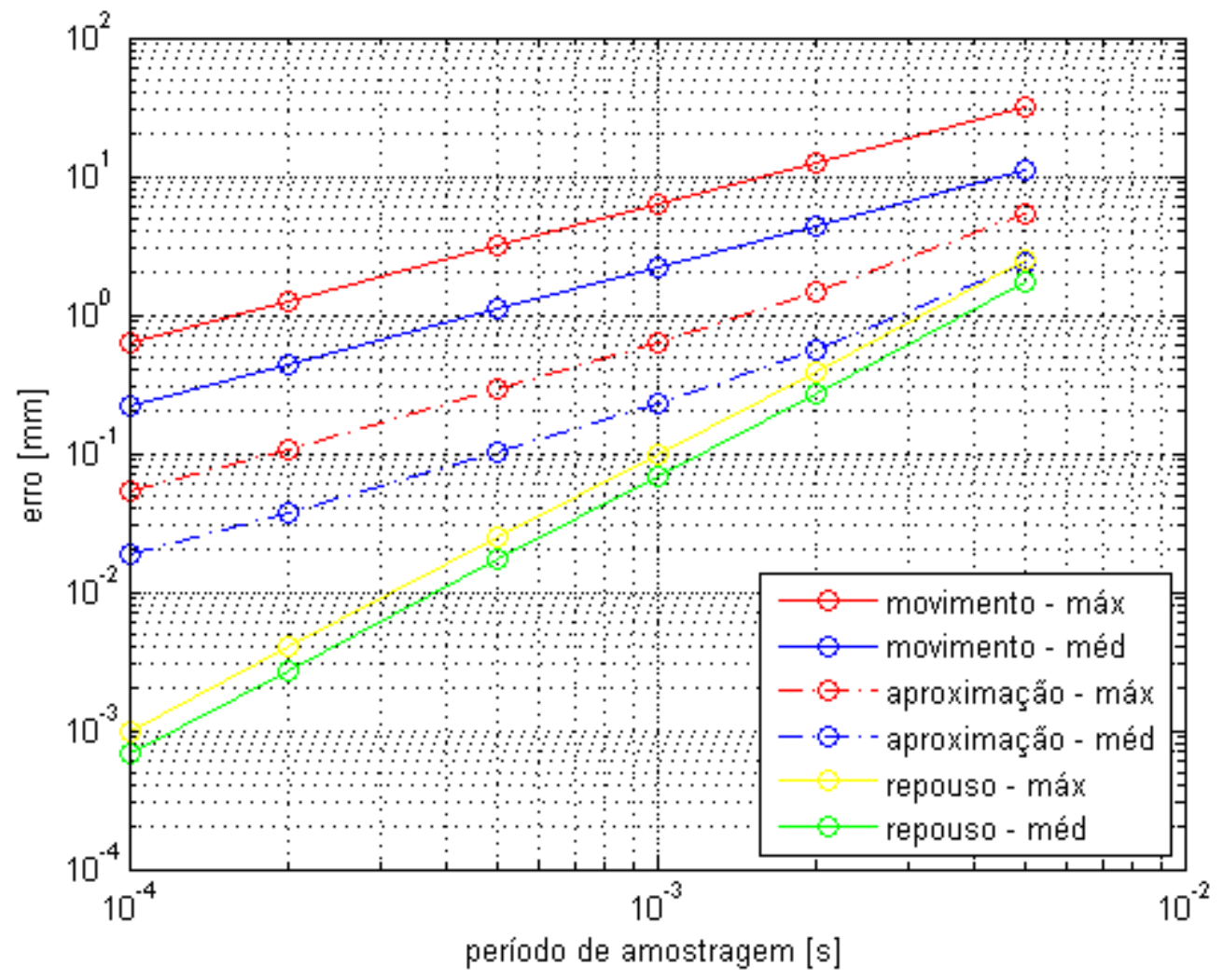

Figura 7.8 - Erros de controle em malha aberta em função do período de amostragem do controle discreto

Para verificar a influência do passo de integração do modelo do robô sobre os erros de controle quando utilizado controle discreto, foram realizadas simulações com variados passos de integração com controlador discreto operando a $10000 \mathrm{~Hz}$ e operando a $1000 \mathrm{~Hz}$. Seus resultados podem ser observados nas figuras 7.9 e 7.10.

Observa-se que os erros de controle ficam praticamente constantes com a variação do passo de integração, quando utilizado controle discreto.

Com base nesses resultados, foram fixados $10^{-4} \mathrm{~s}$ como passo de integração do modelo do robô e $10000 \mathrm{~Hz}$ como a taxa máxima do controlador para execução das simulações de controle apresentadas nas próximas seções. 


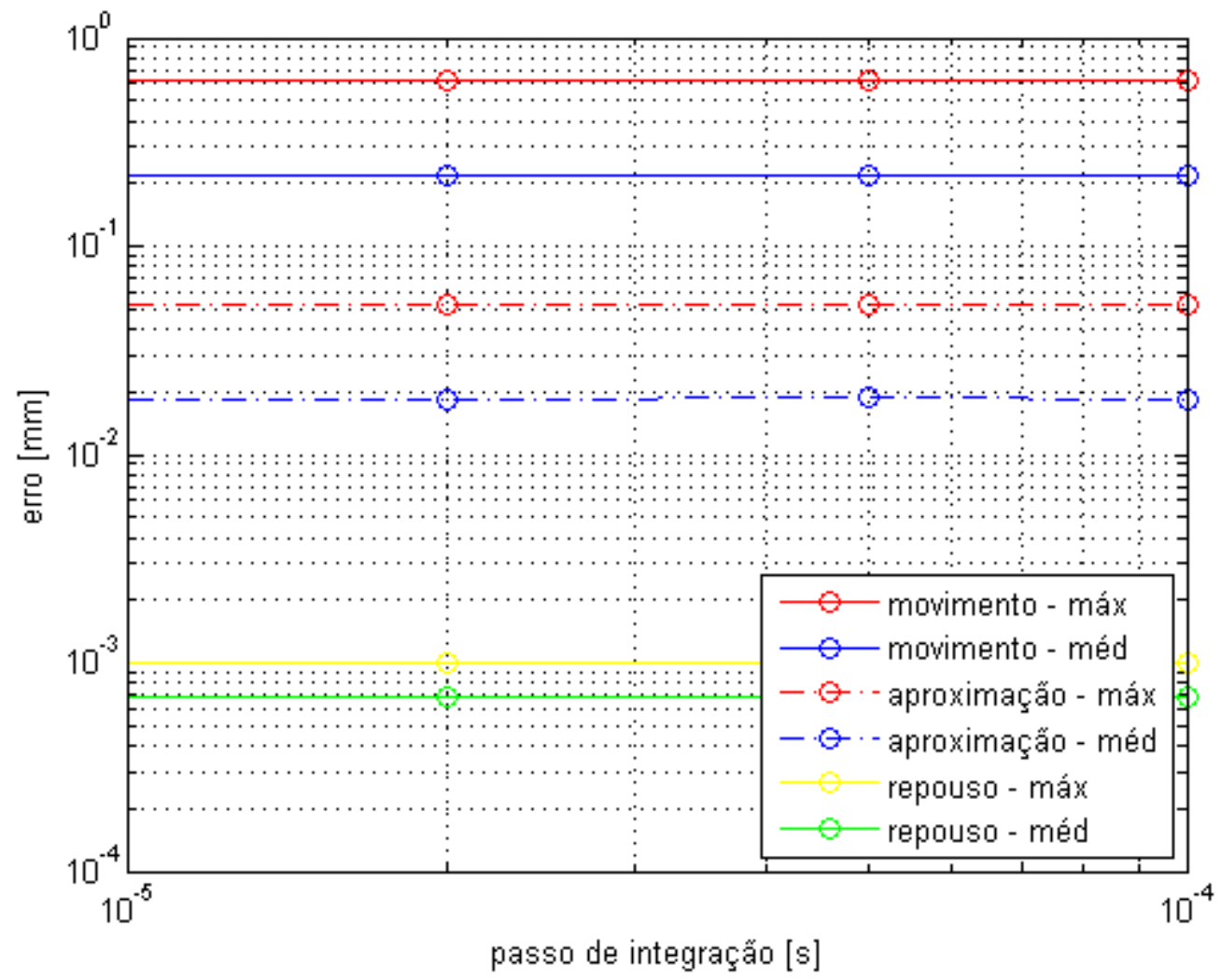

Figura 7.9 - Erros de controle em malha aberta em função do passo de integração numérica do modelo dinâmico, controle discreto a $10000 \mathrm{~Hz}$

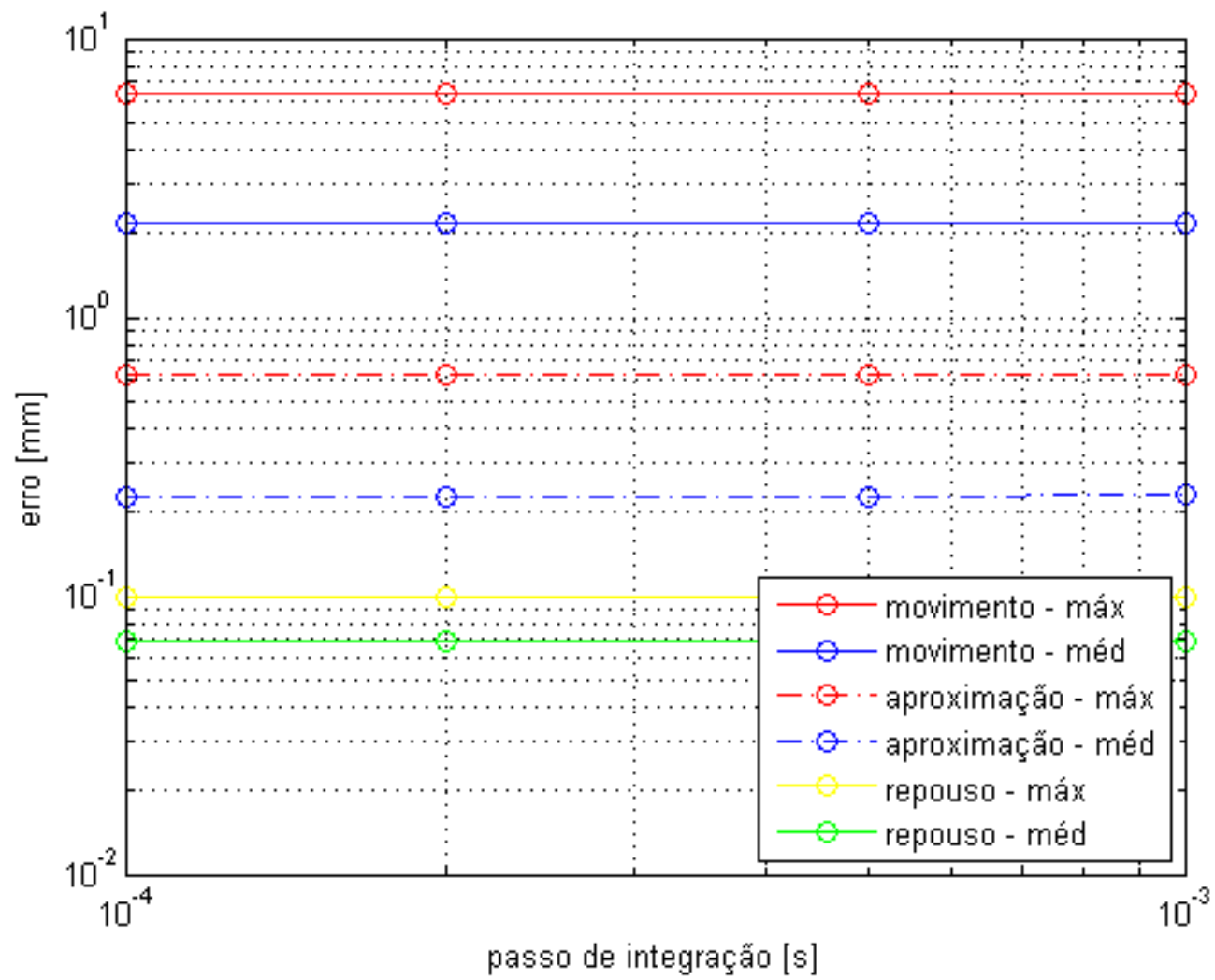

Figura 7.10 - Erros de controle em malha aberta em função do passo de integração numérica do modelo dinâmico, controle discreto a $1000 \mathrm{~Hz}$ 


\subsection{EQUIVALÊNCIA ENTRE CÁLCULO DE ESFORÇOS DE CONTROLE SOBRE VARIÁVEIS DOS ATUADORES E SOBRE VARIÁVEIS DO EFETUADOR NO CONTROLE POR TORQUE COMPUTADO}

\subsubsection{Ganhos iguais para todas as variáveis controladas}

Conforme demonstrado na seção 6.2, sob a hipótese de pequenos erros de controle, é possível fazer aproximações que levam à conclusão de que o controle realizado sobre as coordenadas dos atuadores $(\boldsymbol{q})$ é equivalente ao realizado sobre as coordenadas do efetuador $(\boldsymbol{x})$, se forem utilizadas matrizes de ganhos diagonais, com elementos iguais entre si.

Para exemplificar essa conclusão, foram realizadas simulações de resposta dinâmica do robô em malha fechada com trajetória do tipo degrau e controle executado em modo equivalente a contínuo. Foram utilizados os ganhos calculados na seção 7.1.4, baseados em amortecimento crítico e polos de frequência natural igual a $20 \mathrm{~Hz}$.

Primeiramente, afastando-se da hipótese de pequenos erros de controle, foi utilizada uma trajetória do tipo degrau entre os pontos $\left[\begin{array}{lll}-280 & -140 & 480\end{array}\right]^{T} \mathrm{~mm}$ e $\left[\begin{array}{lll}0 & 0 & 430\end{array}\right]^{T} \mathrm{~mm}$. As respostas do sistema em malha fechada para controle tanto no espaço dos atuadores como no espaço do efetuador podem ser observadas nas figuras 7.11 a 7.13 .

Para a coordenada $x_{1}$ não é possível notar diferenças pois, particularmente para o mecanismo em estudo, $x_{1}$ é igual a $q_{1}$. Em relação à coordenada $x_{2}$, são observadas pequenas diferenças nos comportamentos dinâmicos dos dois controles. Porém, as respostas dinâmicas obtidas para a coordenada $x_{3}$ divergem significadamente entre si. Nos instantes iniciais, $x_{3}$ chega a variar no sentido oposto ao que foi imposto o degrau, quando o robô é controlado no espaço dos atuadores. Assim, para grandes erros de controle, aqui representados pela amplitude do degrau da trajetória de referência, não há equivalência entre os controles realizados sobre as coordenadas dos atuadores e do efetuador. 


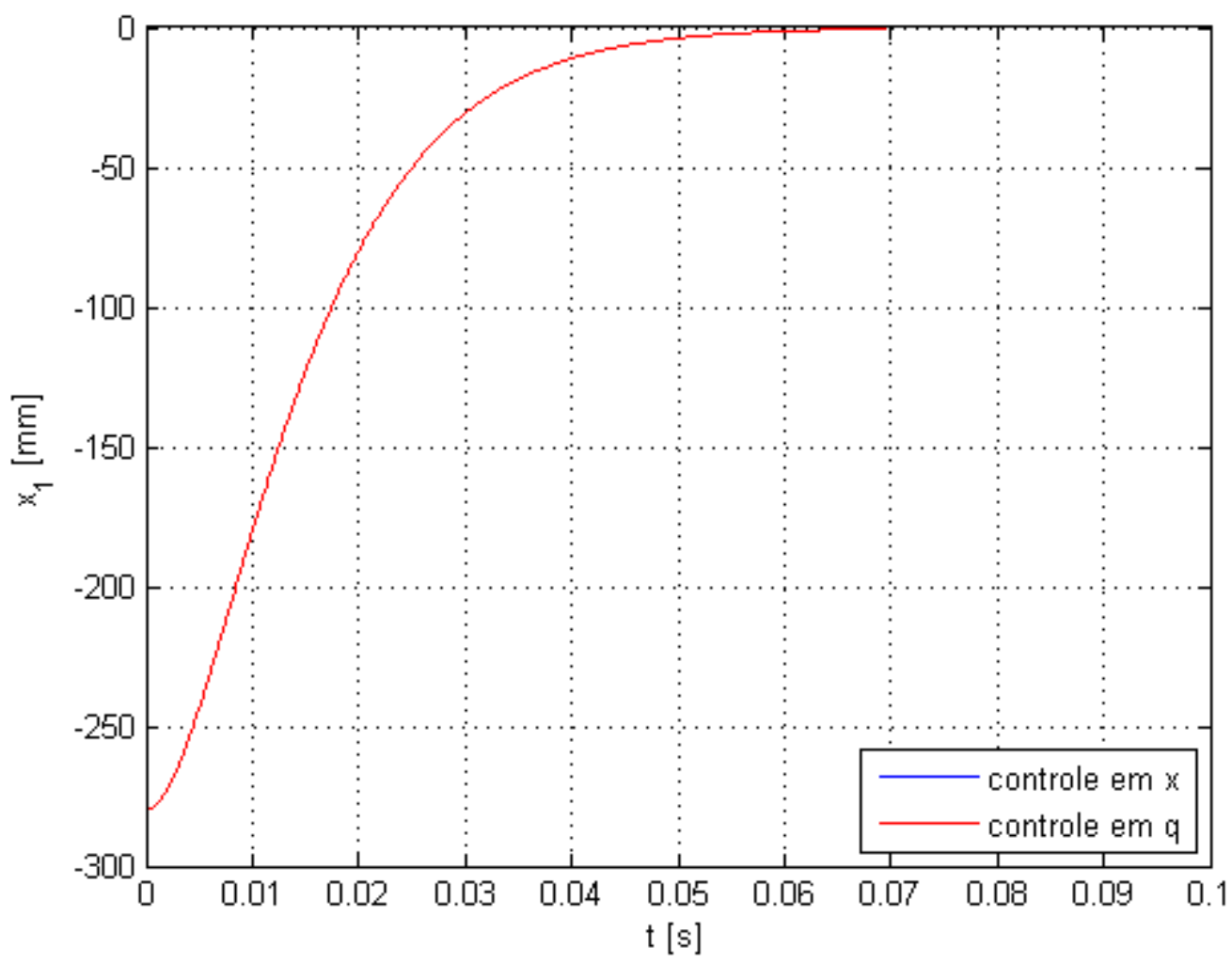

Figura 7.11 - Resposta na coordenada $x_{1}$ à entrada degrau

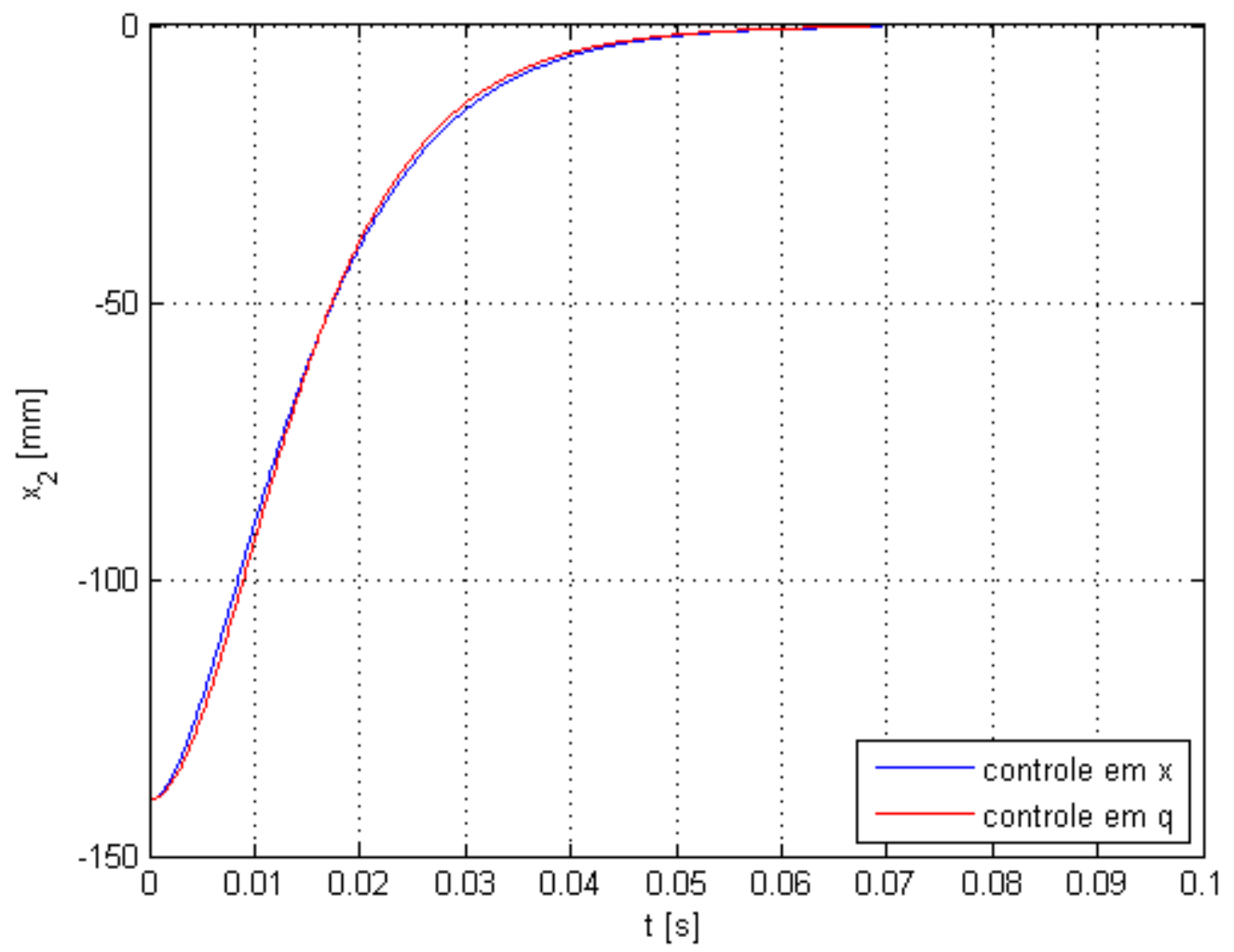

Figura 7.12 - Resposta na coordenada $x_{2}$ à entrada degrau 


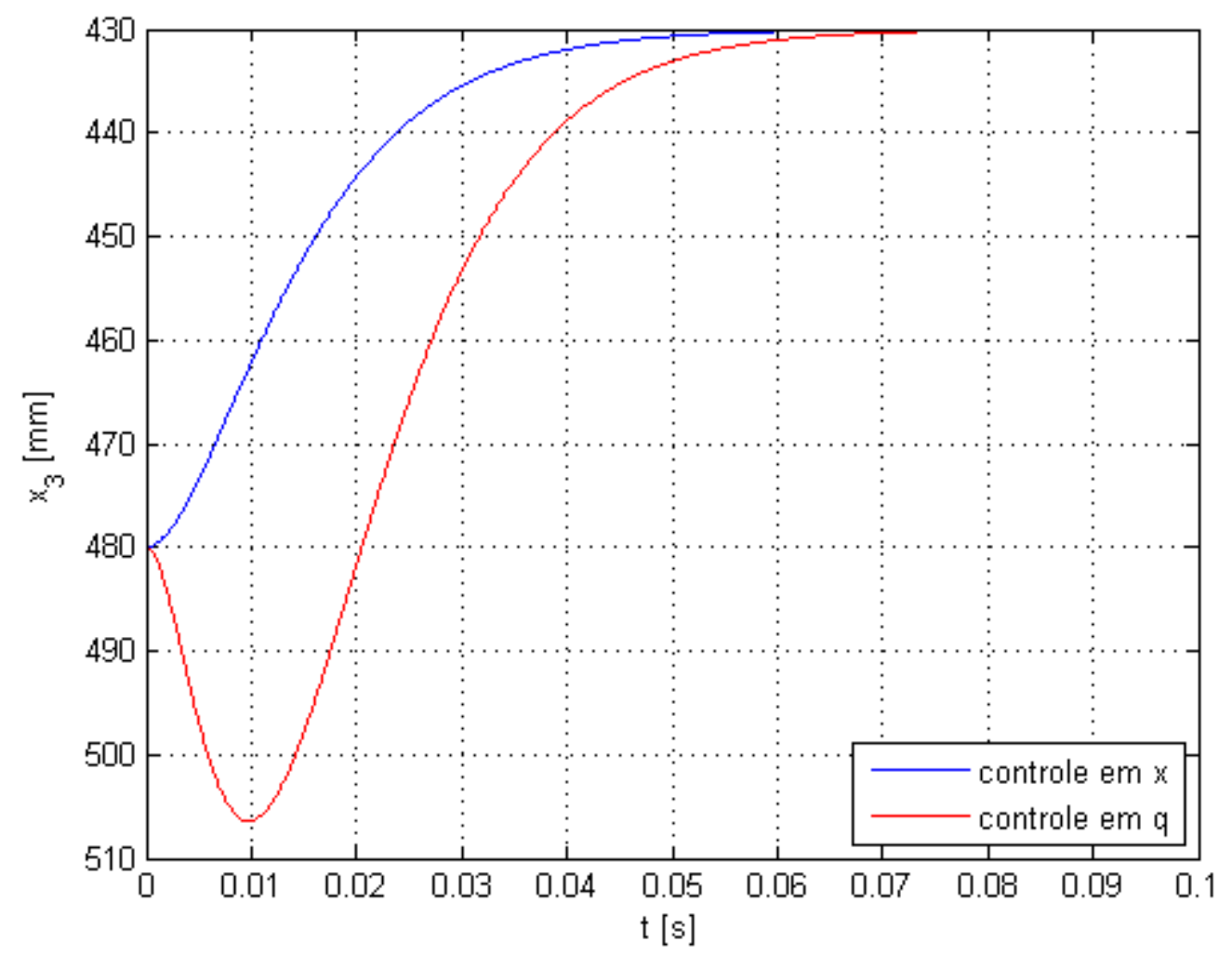

Figura 7.13 - Resposta na coordenada $x_{3}$ à entrada degrau

De fato, analisando a resposta temporal em $q_{2}$ consequente do controle realizado sobre as coordenadas do efetuador, apresentada na figura 7.14, observase que é necessário fazer uma manobra com o membro esquerdo do mecanismo, para que o efetuador tenha a resposta dinâmica projetada. Assim, confirma-se que não pode haver equivalência entre os controles realizados sobre as coordenadas dos atuadores e do efetuador em um sentido amplo.

A fim de se aproximar da condição de pequenos erros de controle, foram feitas simulações de resposta a entradas do tipo degrau de amplitudes variando entre $0,0001 \mathrm{~mm}$ e $50 \mathrm{~mm}$ (iguais para cada uma das direções $x_{1}, x_{2}$ e $x_{3}$ ), em quatro diferentes regiões do espaço de trabalho do robô, definidas por seus pontos finais de chegada listados na tabela 7.5. As diferenças médias e máximas entre as respostas dinâmicas dos controles realizados nos espaços dos atuadores e do efetuador podem ser observadas, respectivamente, nas figuras 7.15 e 7.16.

Nota-se que quanto menores são as amplitudes dos degraus impostos ao robô, menores são as diferenças entre as respostas dinâmicas do controle realizado em cada conjunto de coordenadas. Mesmo para um degrau de amplitude igual a 1 
$\mathrm{mm}$, que corresponderia a um erro de controle relativamente grande, as diferenças máximas obtidas entre as respostas dos controladores são da ordem de 0,001 mm.

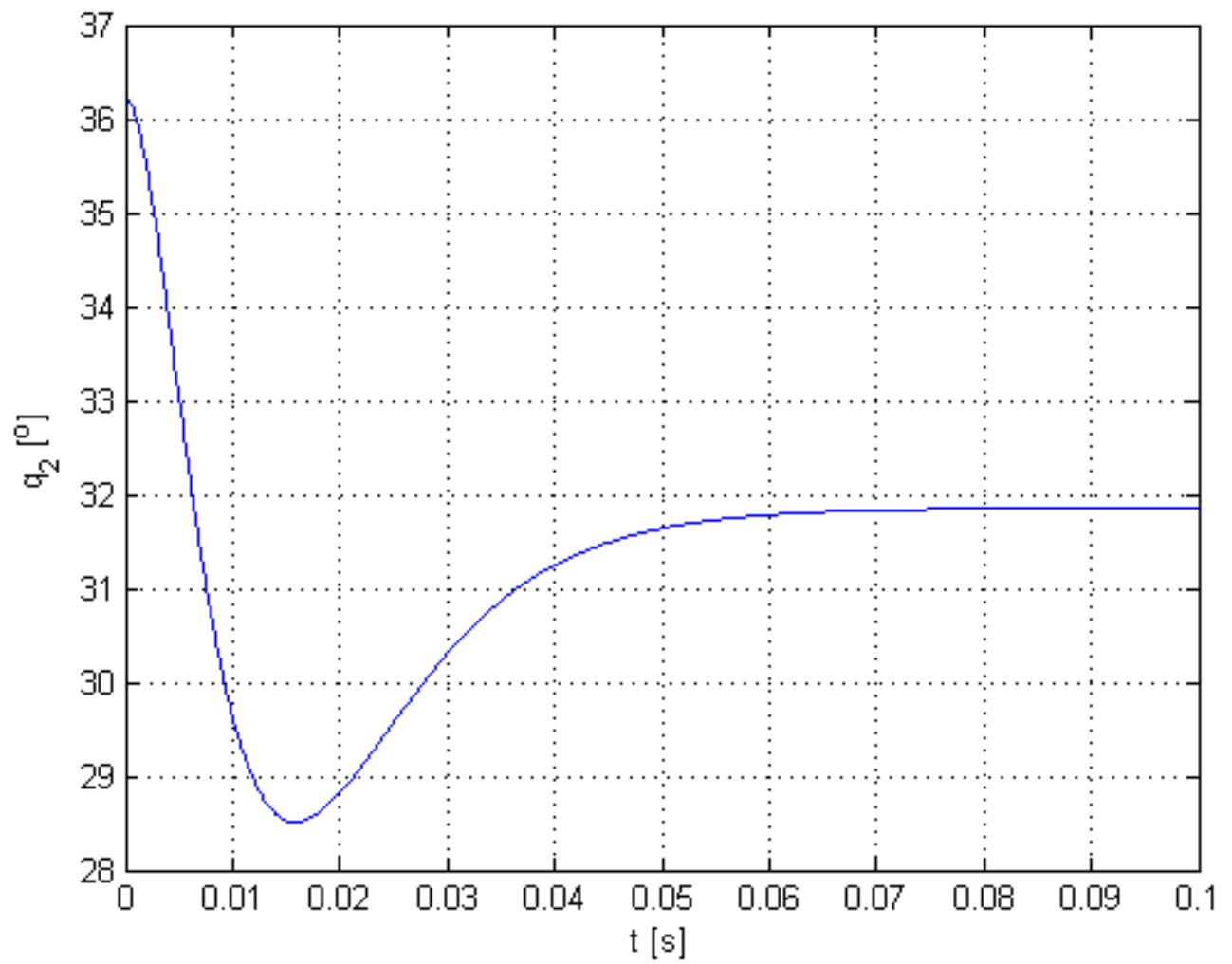

Figura 7.14 - Evolução da coordenada $q_{2}$ para controle executado sobre coordenadas do efetuador

Nas figuras 7.17 e 7.18 , os resultados são reapresentados com as diferenças entre respostas dinâmicas divididas pela amplitude do degrau. Observa-se que essa razão também diminui com a diminuição da amplitude do degrau, o que deixa evidente que, sob a hipótese de pequenos erros de controle, os controles executados sobre os dois espaços são equivalentes quando suas matrizes de ganhos são diagonais com elementos iguais entre si.

Tabela 7.5 - Pontos finais de degraus unitários impostos ao efetuador

\begin{tabular}{|c|c|c|c|c|}
\cline { 2 - 5 } \multicolumn{1}{c|}{} & Região 1 & Região 2 & Região 3 & Região 4 \\
\hline$x_{1}[\mathrm{~mm}]$ & 0 & 280 & 0 & 280 \\
\hline$x_{2}[\mathrm{~mm}]$ & 0 & 0 & 140 & 140 \\
\hline$x_{3}[\mathrm{~mm}]$ & 430 & 430 & 430 & 430 \\
\hline
\end{tabular}




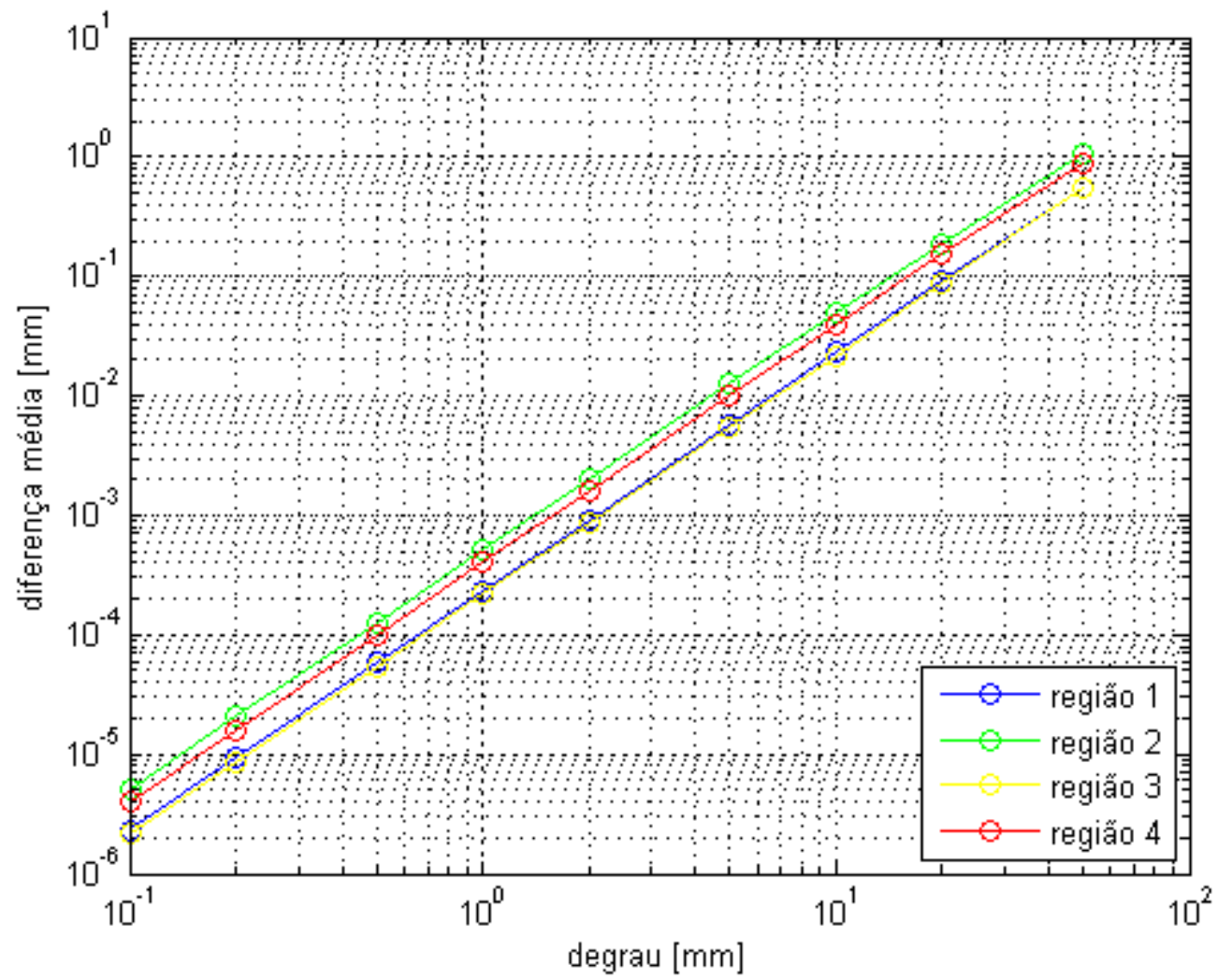

Figura 7.15 - Diferença média entre respostas dinâmicas de controles executados sobre as coordenadas dos atuadores e sobre as coordenadas do efetuador

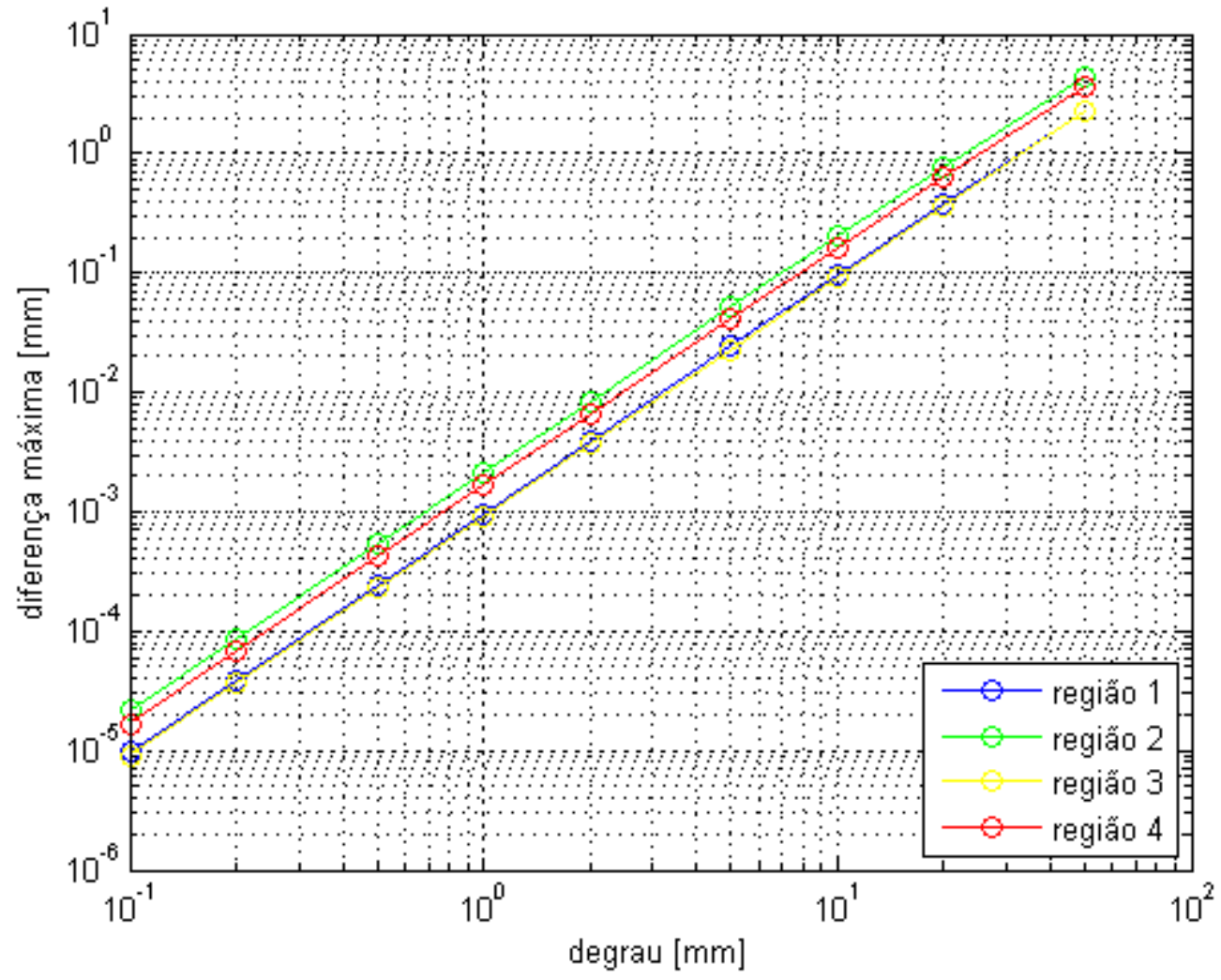

Figura 7.16 - Diferença máxima entre respostas dinâmicas de controles executados sobre as coordenadas dos atuadores e sobre as coordenadas do efetuador 


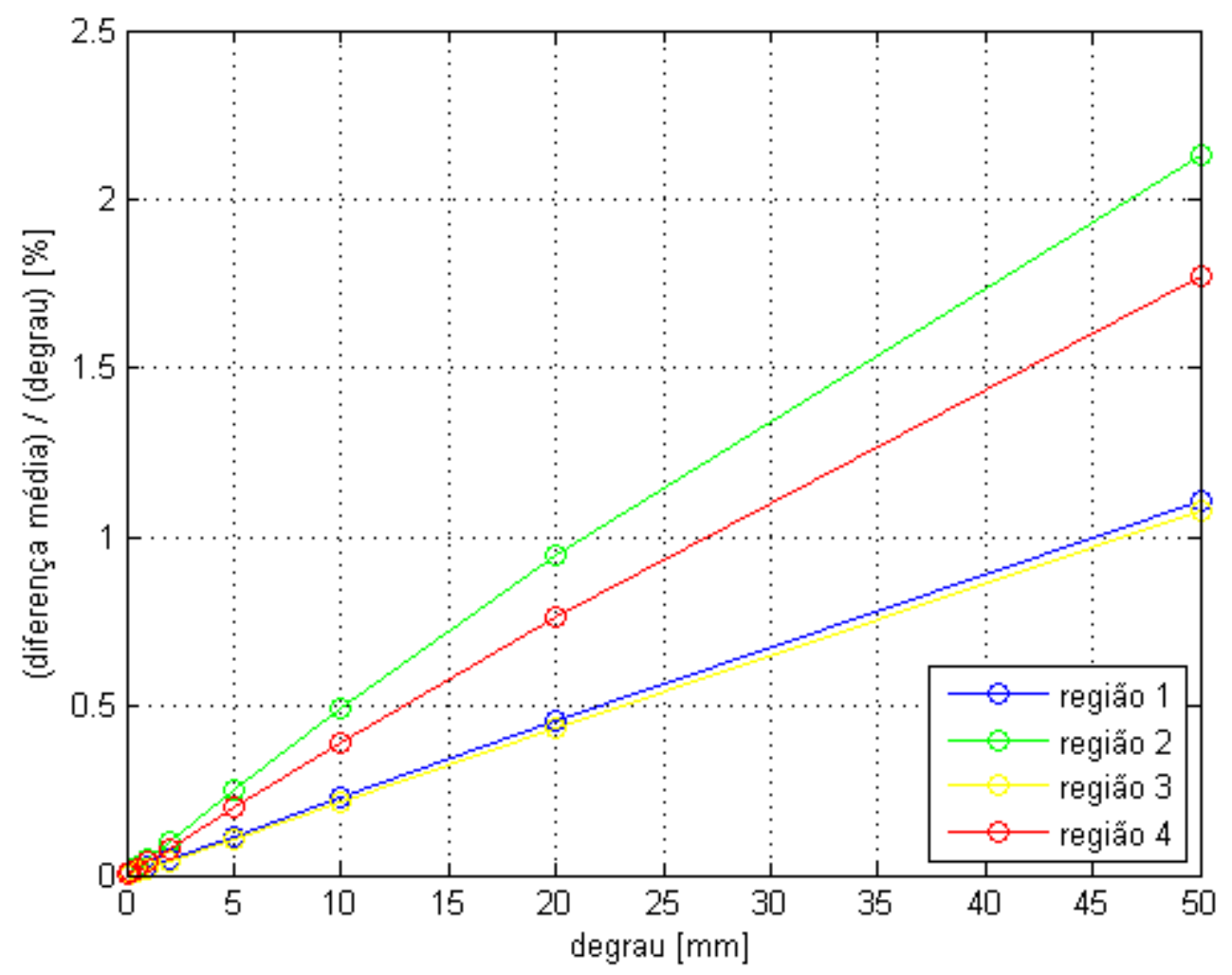

Figura 7.17 - Diferença média percentual entre respostas dinâmicas de controles executados sobre as coordenadas dos atuadores e sobre as coordenadas do efetuador

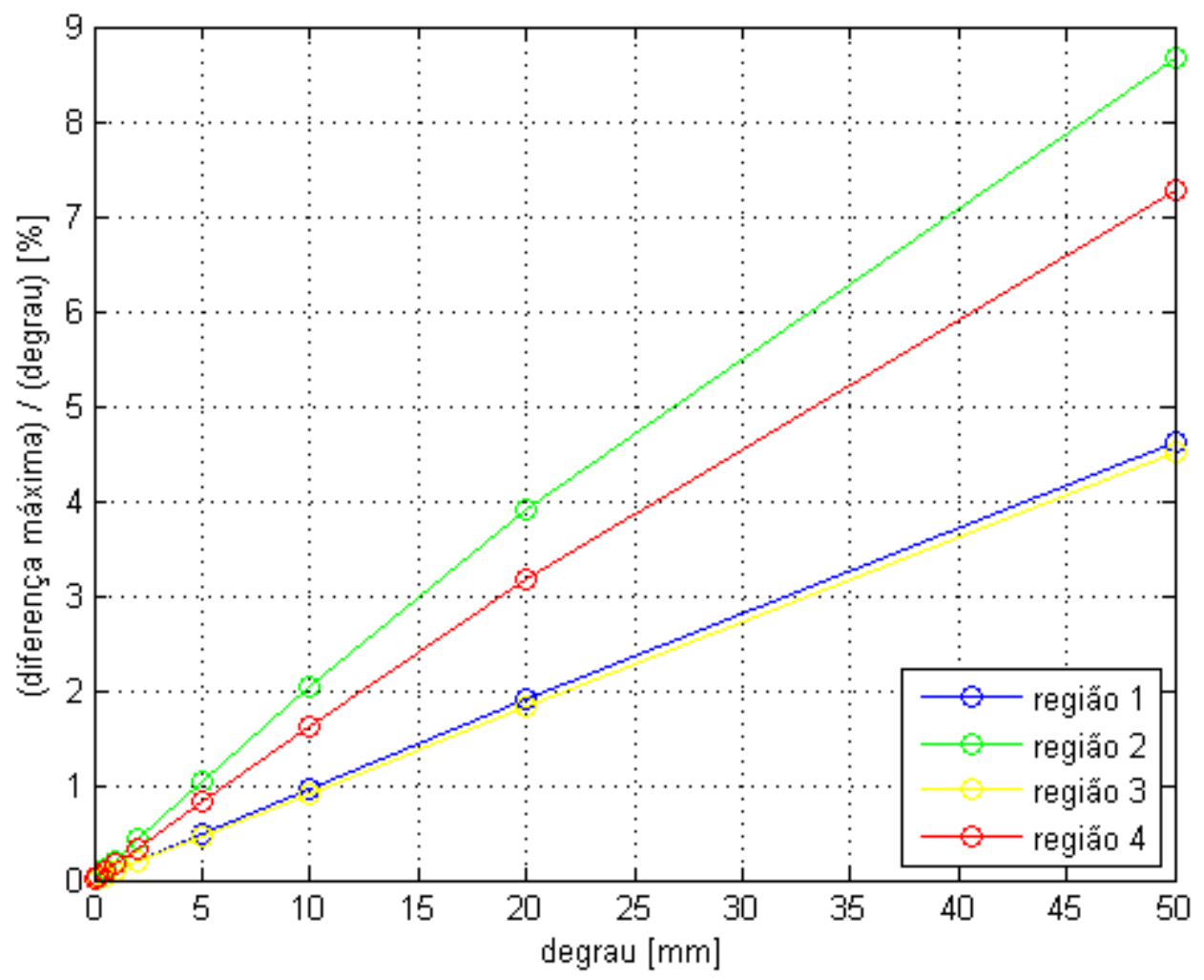

Figura 7.18 - Diferença máxima percentual entre respostas dinâmicas de controles executados sobre as coordenadas dos atuadores e sobre as coordenadas do efetuador 


\subsubsection{Ganhos diferentes entre variáveis controladas}

Tomando agora matrizes de ganhos com elementos diferentes entre si, foram realizadas simulações em que o controle sobre as coordenadas do efetuador foi feito com polos de frequências naturais iguais a $20 \mathrm{~Hz}$ para $x_{1}$ e $10 \mathrm{~Hz}$ para $x_{2}$ e $x_{3}$. Para o controle sobre as coordenadas dos atuadores, foram definidos dois conjuntos de ganhos. O primeiro, com ganhos constantes, foi projetado intuitivamente com polos de $20 \mathrm{~Hz}$ para $q_{1}$ e $10 \mathrm{~Hz}$ para $q_{2}$ e $q_{3}$, baseando-se no fato de que, especificamente para o robô em estudo, $x_{1}$ é igual a $q_{1}$. O segundo, de ganhos variáveis no tempo, foi calculado no laço de controle com base nas equações 6.37 e 6.38 .

As diferenças desses dois modos de controle nas variáveis dos atuadores em relação ao controle nas variáveis do efetuador para degraus impostos na região 4 , conforme tabela 7.5, estão apresentadas nas figuras 7.19 e 7.20.

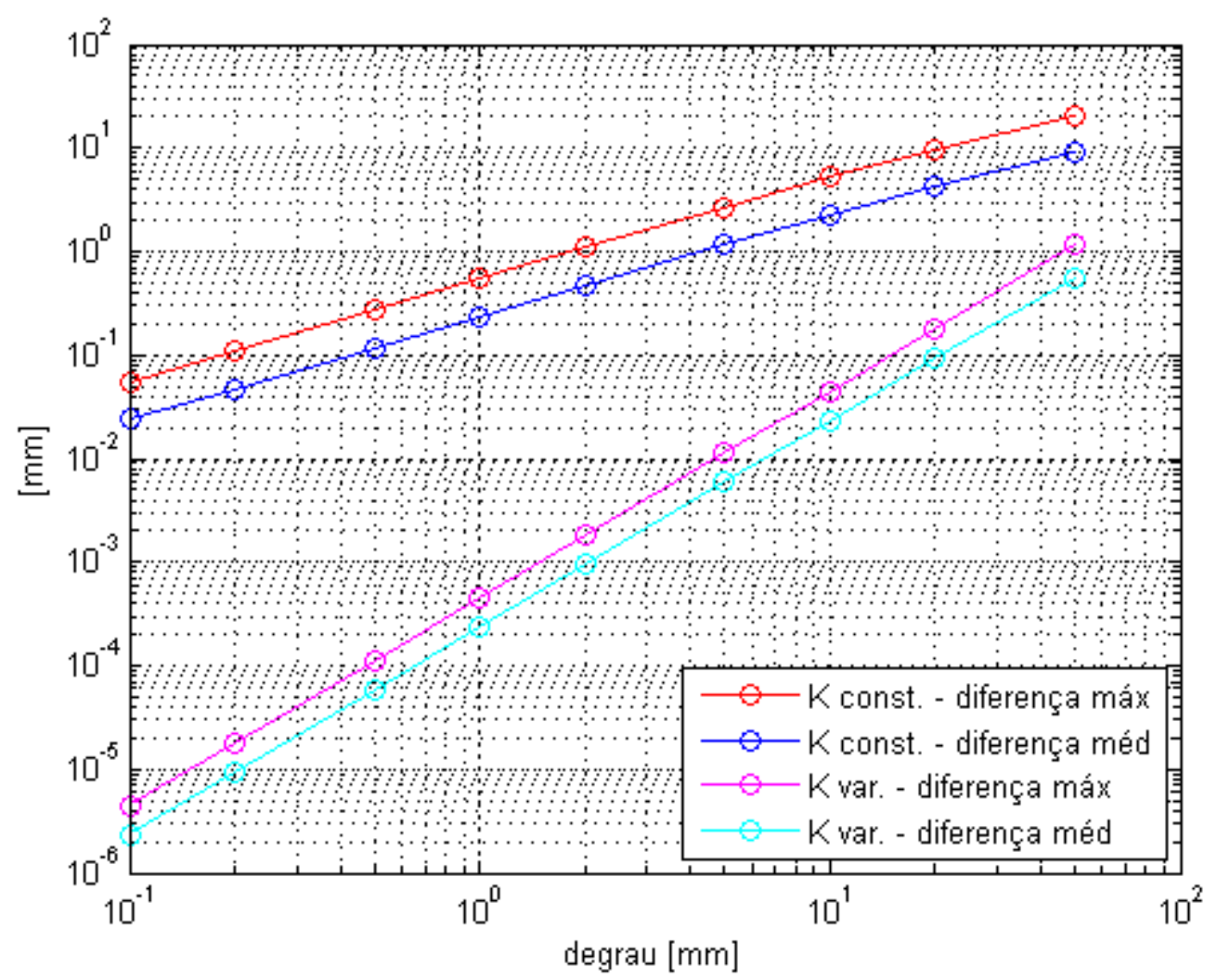

Figura 7.19 - Diferenças média e máxima entre respostas dinâmicas de controles sobre coordenadas dos atuadores e sobre coordenadas do efetuador, ganhos diferentes entre coordenadas 


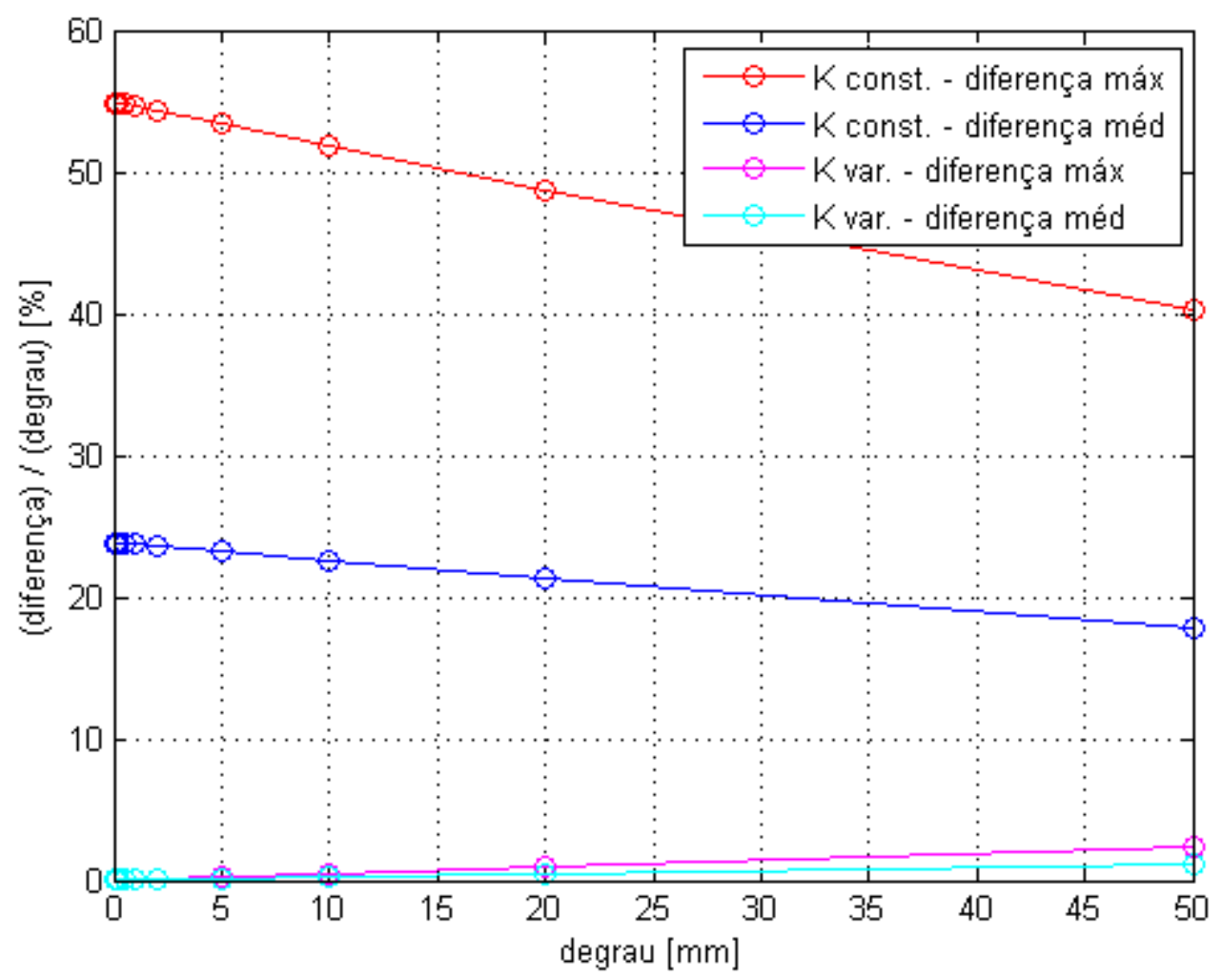

Figura 7.20 - Diferença máxima percentual entre respostas dinâmicas de controles sobre coordenadas dos atuadores e sobre coordenadas do efetuador, ganhos diferentes entre coordenadas

Observa-se que as diferenças obtidas pela definição de ganhos constantes para o controle no espaço dos atuadores são muito maiores que as obtidas com ganhos variáveis. Além disso, a razão entre as diferenças obtidas e as amplitudes das entradas degrau mostra que as diferenças entre o controle sobre o espaço dos atuadores com ganhos constantes e o controle sobre o espaço do efetuador chegam a aumentar mesmo com a diminuição das amplitudes dos degraus.

Nas figuras 7.21 a 7.24 pode-se se observar a evolução de valores de elementos selecionados das matrizes de ganhos variáveis $K_{p q}$ e $K_{d q}$, para o degrau de $50 \mathrm{~mm}$ de amplitude. Nota-se que, para esse caso específico, os ganhos da diagonal principal de $K_{p q}$ e $K_{d q}$ permanecem constantes. Porém, termos fora da diagonal principal tornam-se diferentes de zero e variáveis no tempo. 


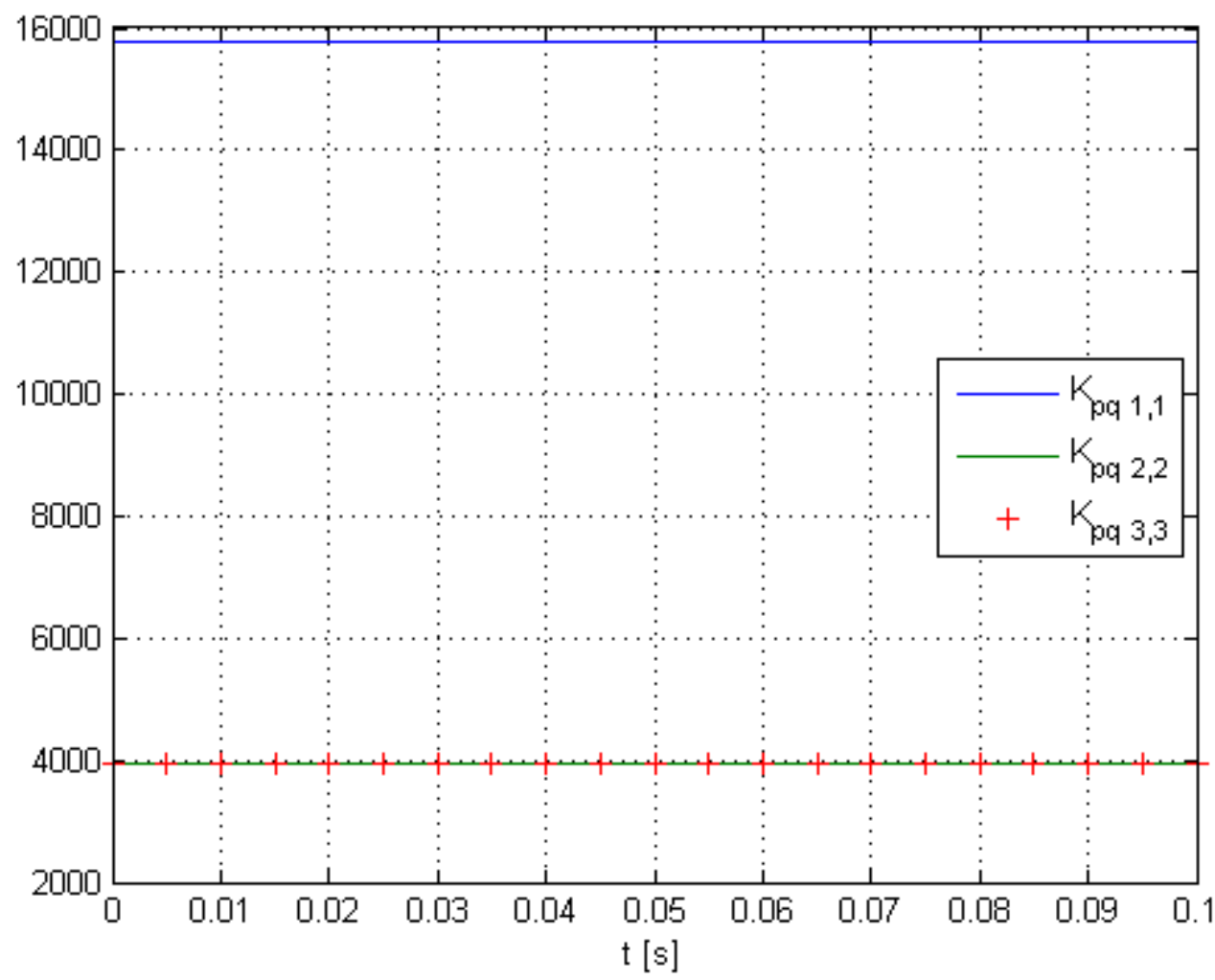

Figura 7.21 - Evolução de ganhos da diagonal principal de $K_{p q}$

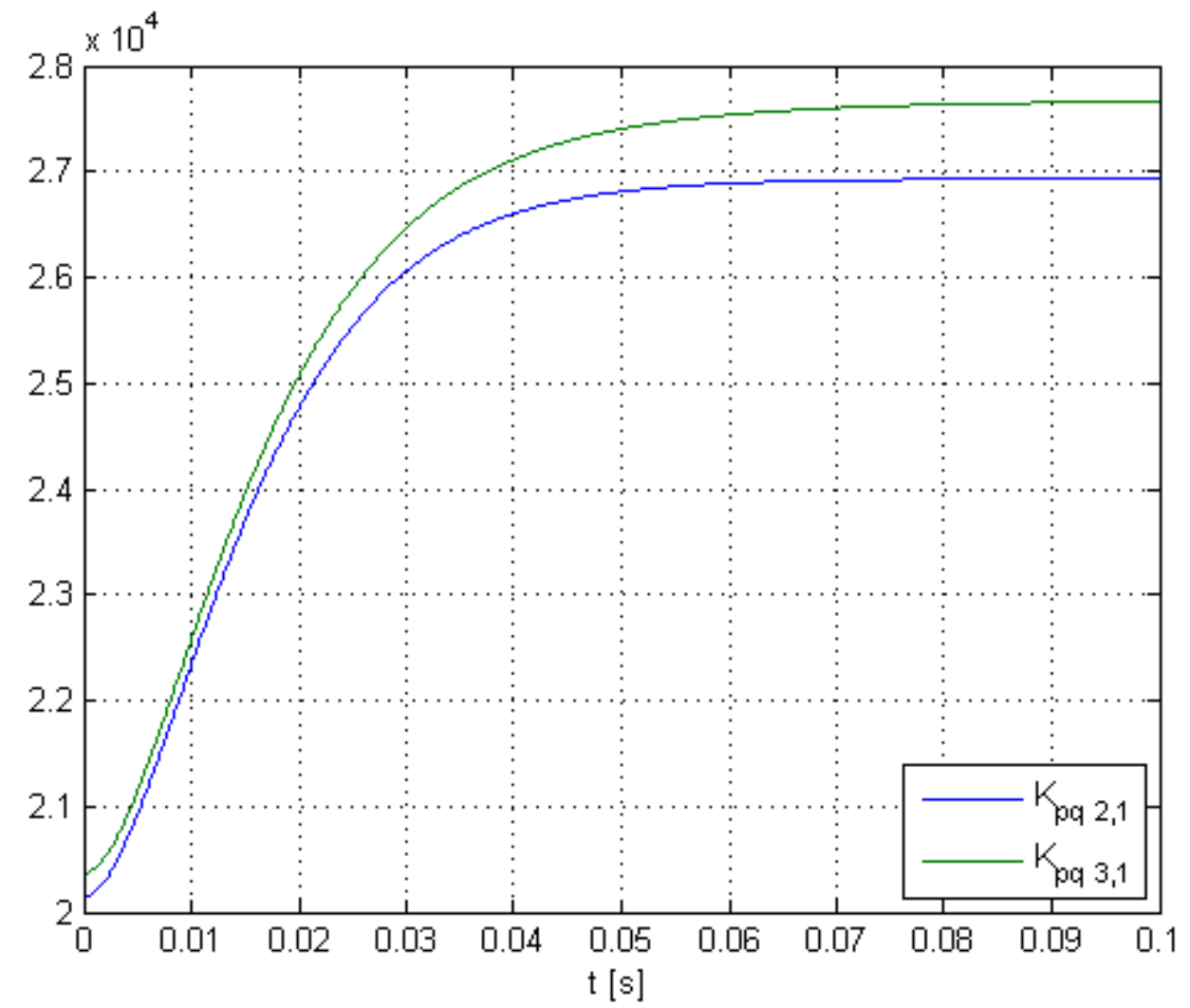

Figura 7.22 - Evolução no tempo de ganhos fora da diagonal principal de $K_{p q}$ 


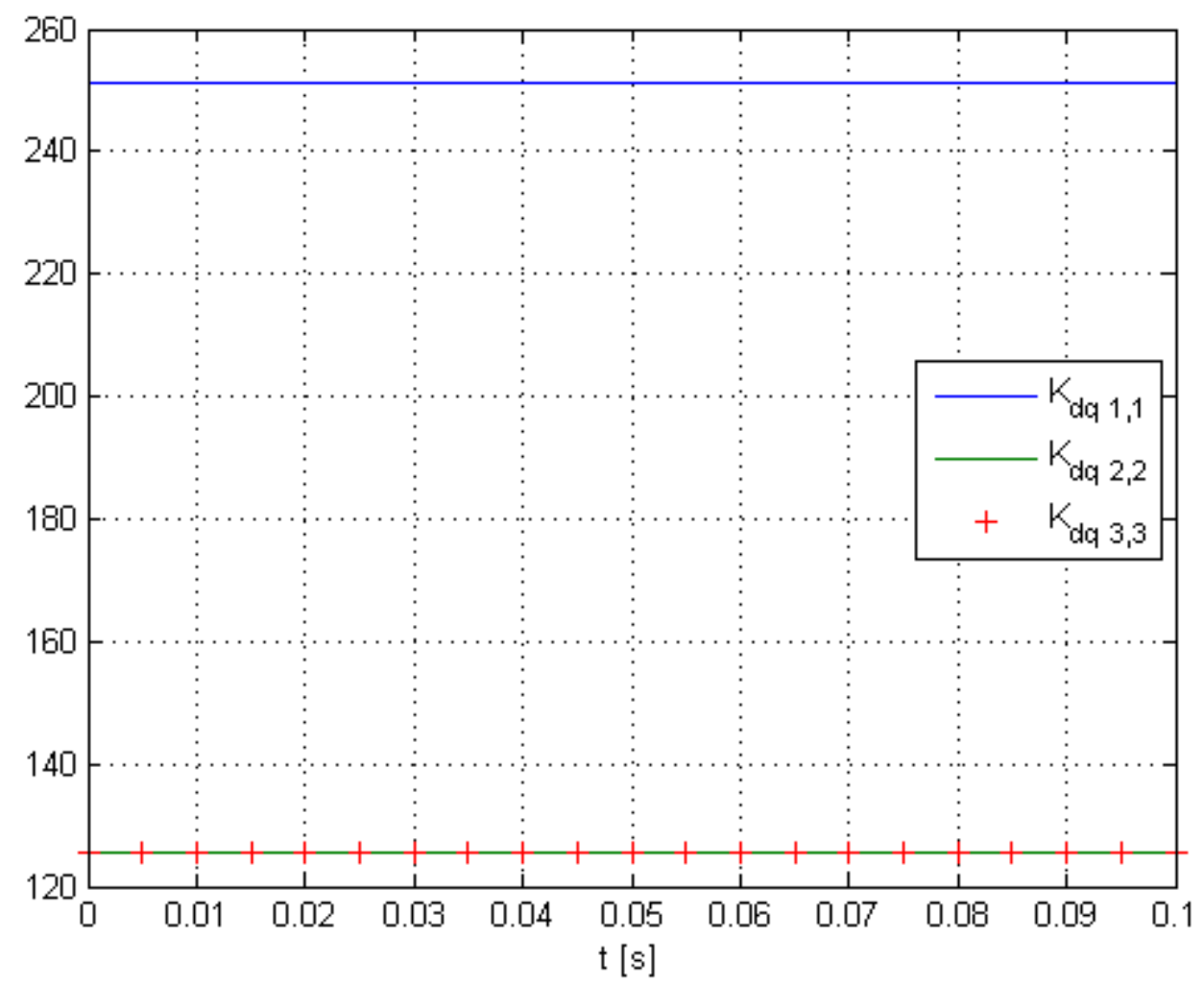

Figura 7.23 - Evolução de ganhos da diagonal principal de $K_{d q}$

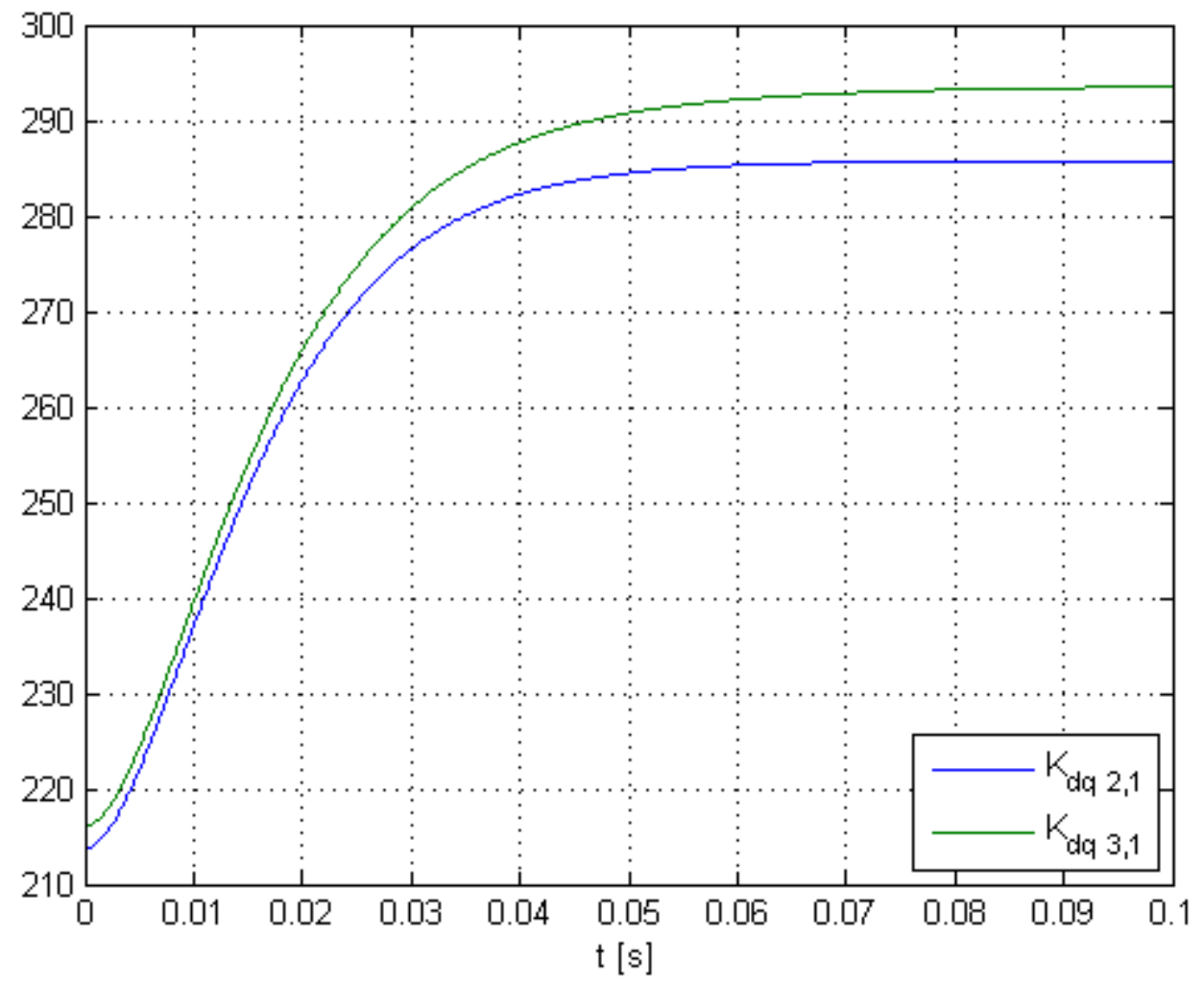

Figura 7.24 - Evolução de ganhos fora da diagonal principal de $K_{d q}$ 
Definindo-se agora ganhos para obtenção de polos de frequências naturais iguais a $20 \mathrm{~Hz}$ para $x_{1}, 5 \mathrm{~Hz}$ para $x_{2}$ e $10 \mathrm{~Hz}$ para $x_{3}$, não é possível estipular de forma intuitiva ganhos constantes para o controle sobre o espaço dos atuadores. Porém, utilizando-se as equações 6.37 e 6.38 , foi possível se fazer o controle com ganhos variáveis, cuja diferença para o controle sobre o espaço do efetuador está apresentada nas figuras 7.25 e 7.26 .

Novamente nota-se a equivalência entre as duas abordagens de controle, reforçando a validade das equações 6.37 e 6.38 .

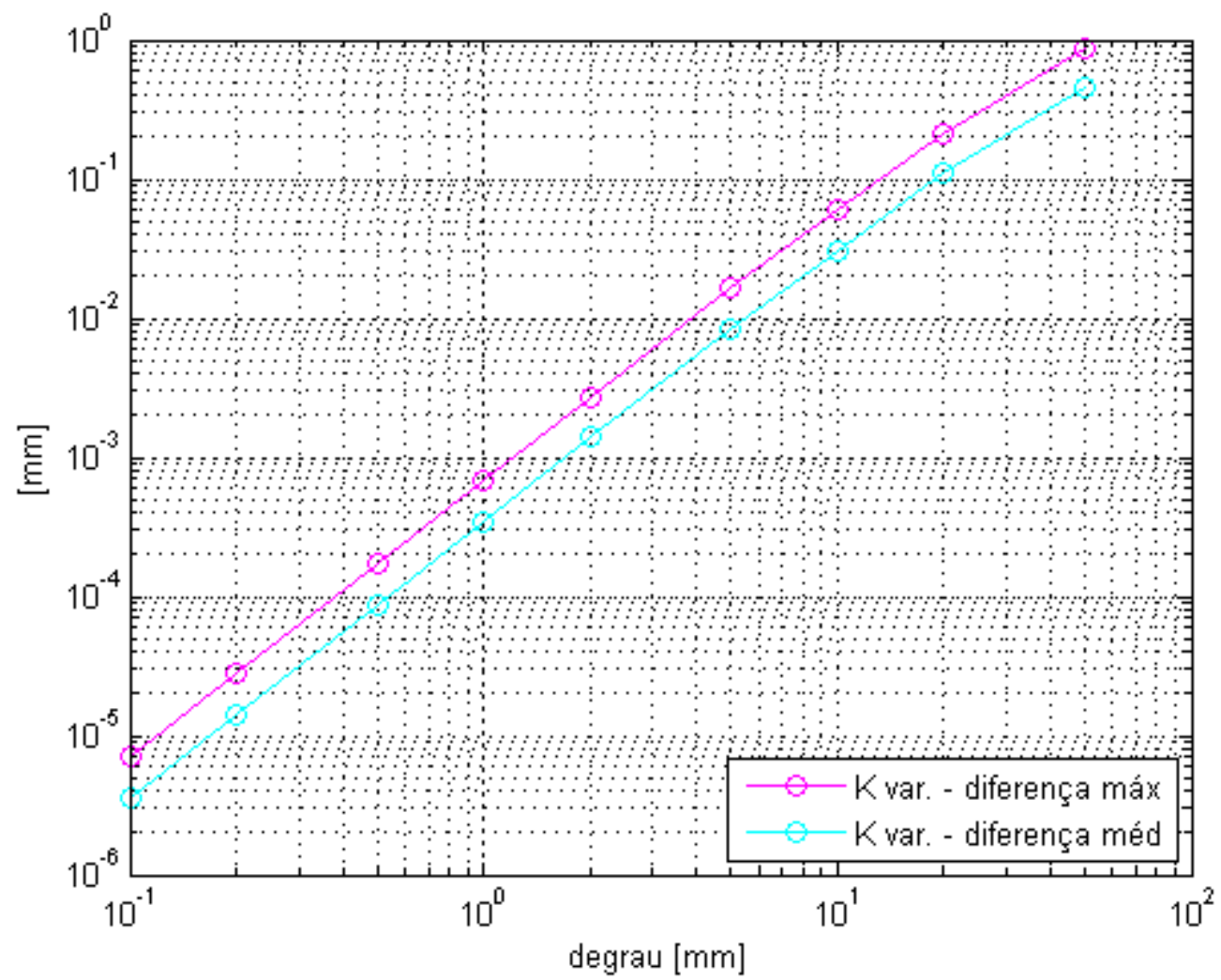

Figura 7.25 - Diferenças média e máxima entre respostas dinâmicas de controles sobre coordenadas dos atuadores e sobre coordenadas do efetuador, ganhos diferentes entre coordenadas 


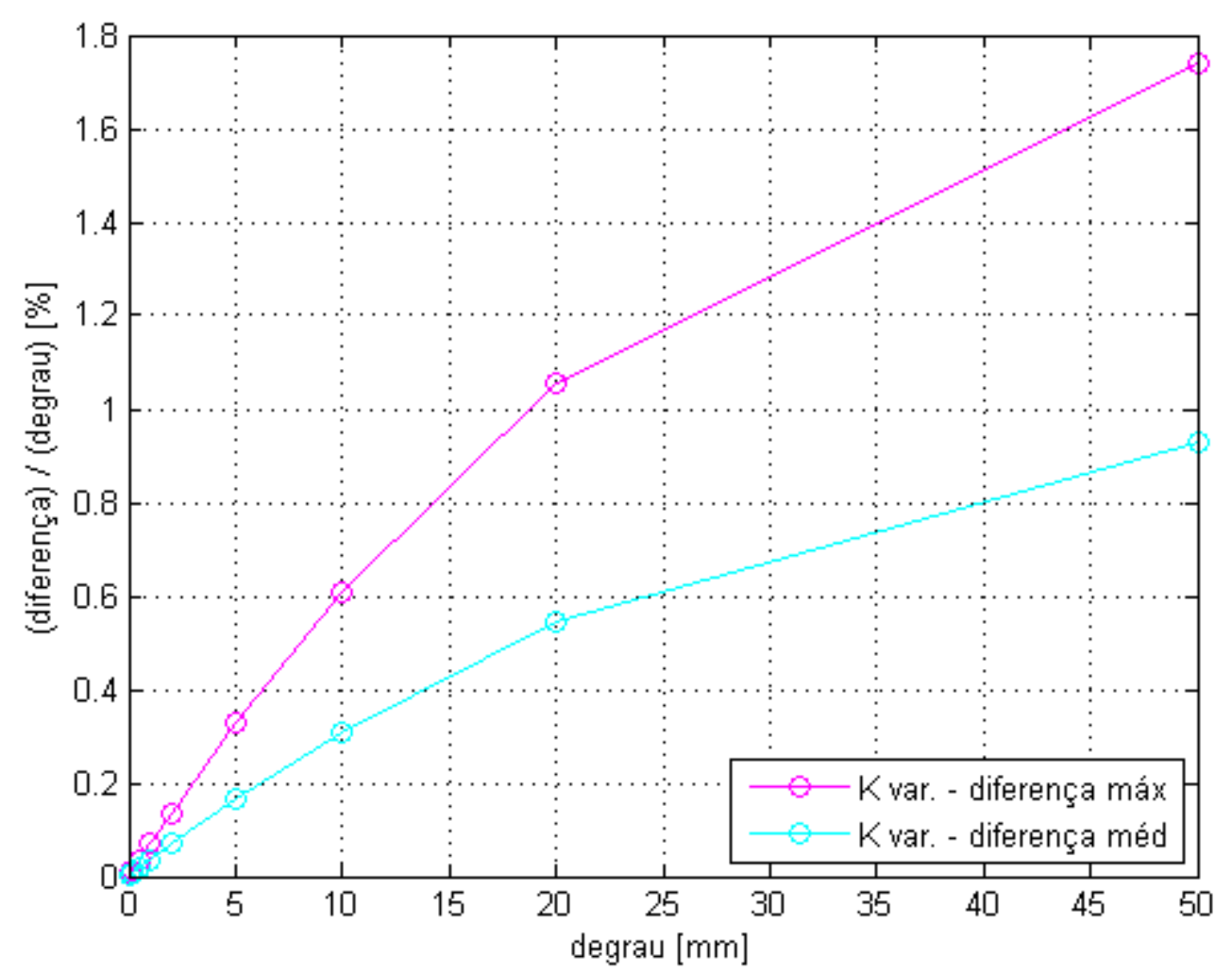

Figura 7.26 - Diferença máxima percentual entre respostas dinâmicas de controles sobre coordenadas dos atuadores e sobre coordenadas do efetuador, ganhos diferentes entre coordenadas

\subsection{EQUIVALÊNCIA ENTRE CONTROLE POR TORQUE COMPUTADO ESTENDIDO E CONTROLE POR TORQUE COMPUTADO}

De modo similar ao realizado na seção anterior, foram também executadas simulações de resposta dinâmica do robô a entradas do tipo degrau utilizando controle por torque computado estendido. As amplitudes dos degraus foram variadas entre $0,0001 \mathrm{~mm}$ e $50 \mathrm{~mm}$ (iguais para cada uma das direções $x_{1}, x_{2}$ e $x_{3}$ ). Foram analisadas quatro diferentes regiões do espaço de trabalho do robô, definidas por seus pontos finais de chegada listados na tabela 7.4. As diferenças médias e máximas entre as respostas dinâmicas do controle por torque computado no espaço dos atuadores e do controle por torque computado estendido, em que foram controladas tanto as coordenadas dos atuadores como do efetuador, podem ser observadas nas figuras 7.27 a 7.30 . 


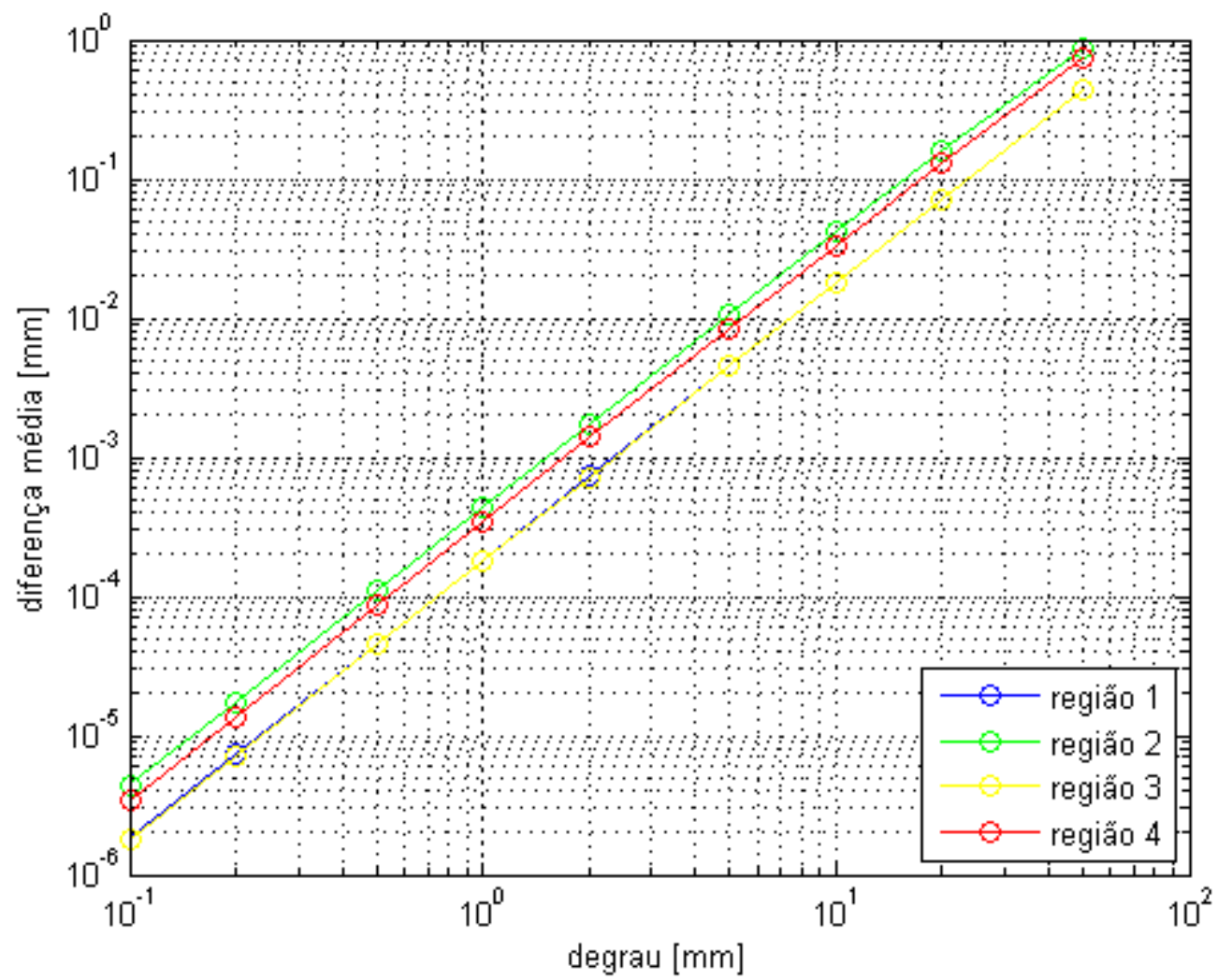

Figura 7.27 - Diferença média entre respostas dinâmicas de controle por torque computado e controle por torque computado estendido

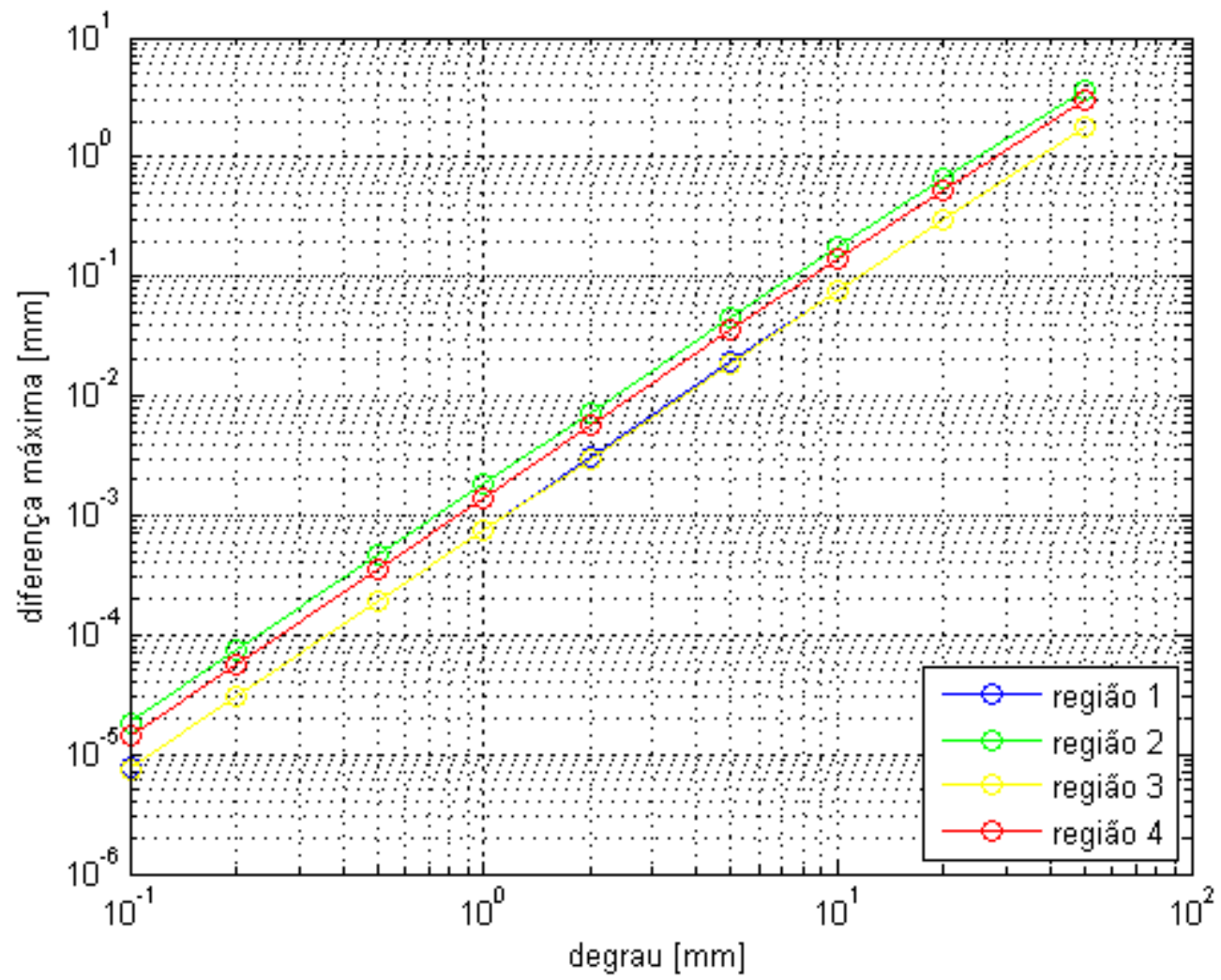

Figura 7.28 - Diferença máxima entre respostas dinâmicas de controle por torque computado e controle por torque computado estendido 


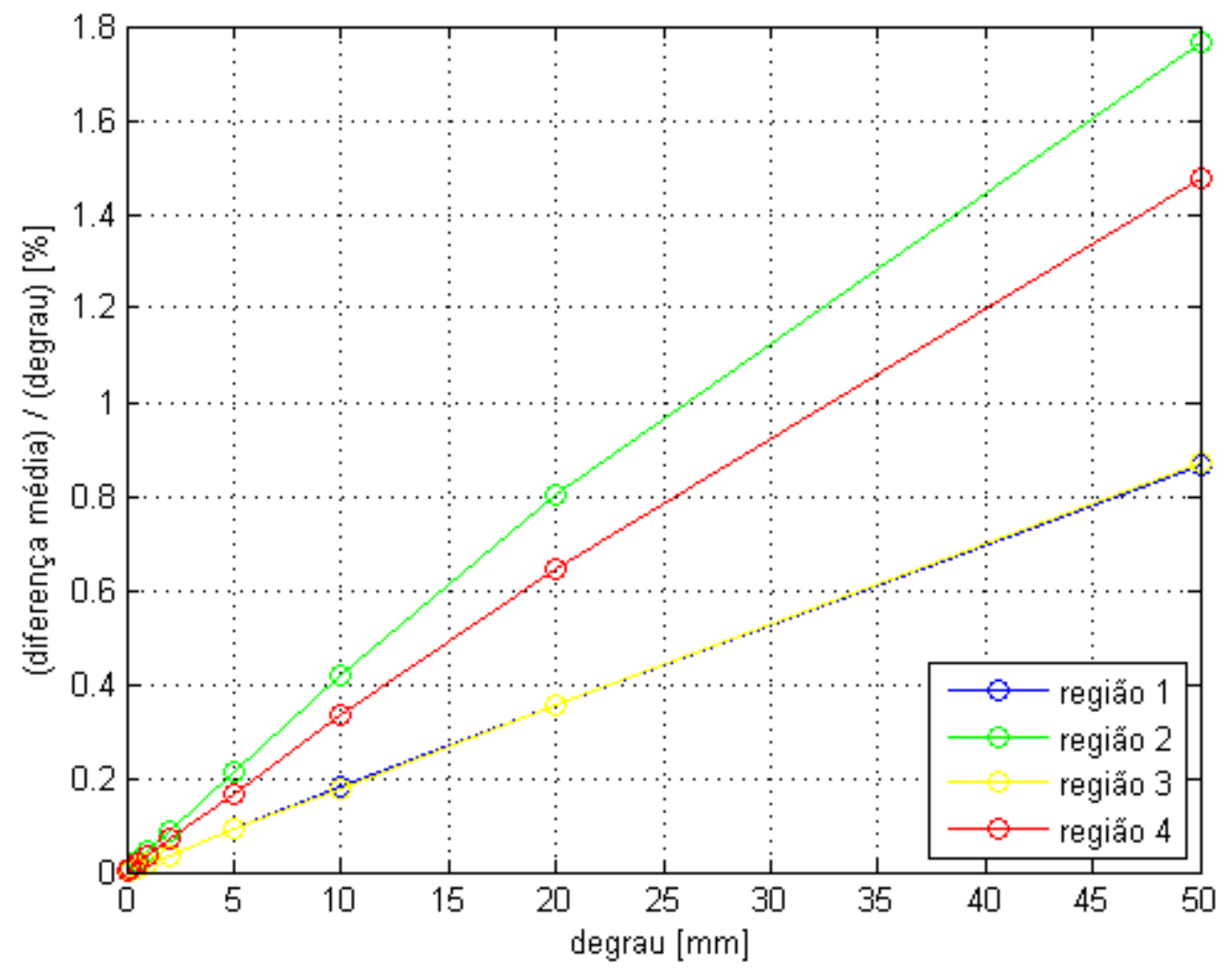

Figura 7.29 - Diferença média percentual entre respostas dinâmicas de controle por torque computado e controle por torque computado estendido

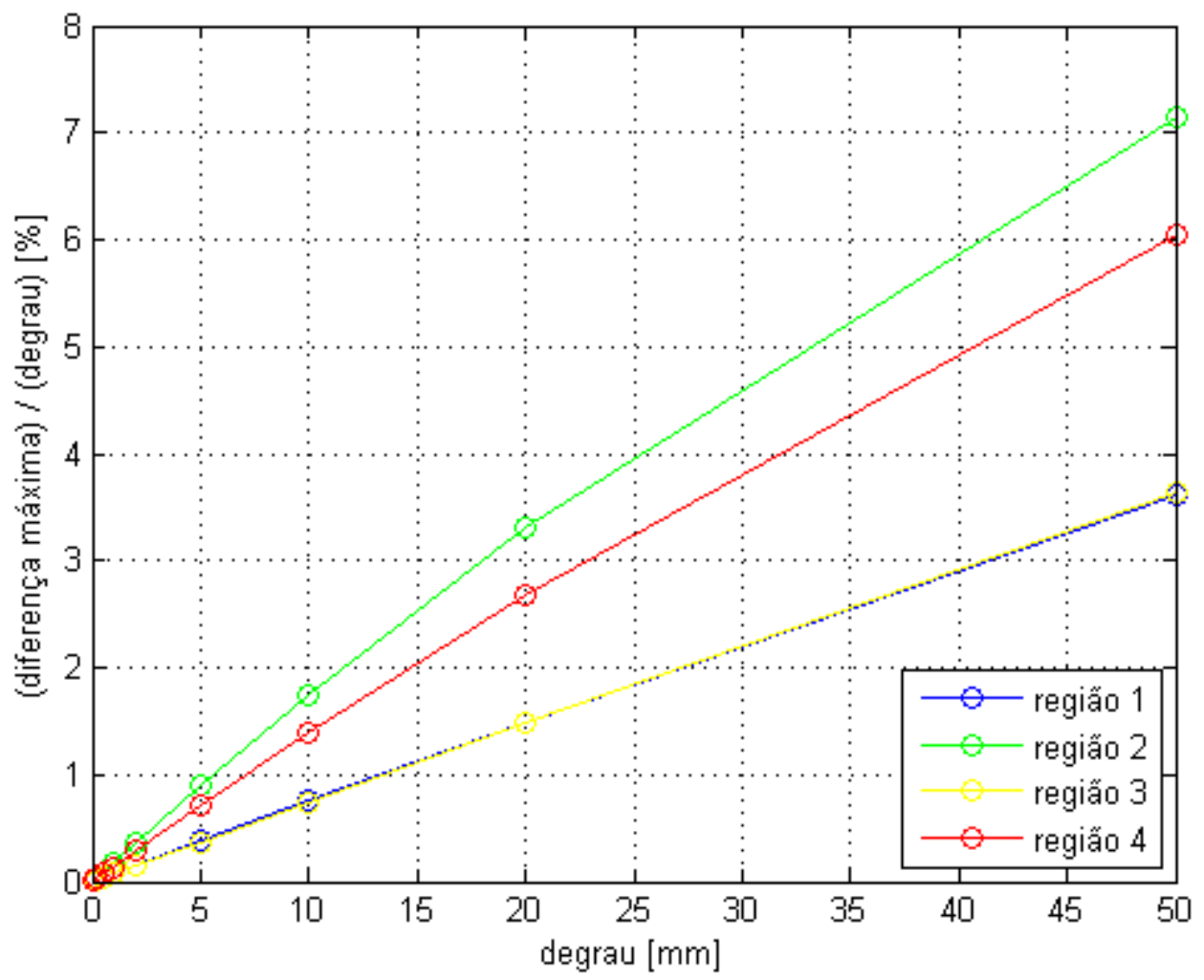

Figura 7.30 - Diferença máxima percentual entre respostas dinâmicas de controle por torque computado e controle por torque computado estendido 
Observa-se que quanto menor a amplitude dos degraus impostos às coordenadas do robô, mais próximas entre si são as respostas dinâmicas dos controles por torque computado tradicional e por torque computado estendido, independentemente da região do espaço de trabalho do robô. Mesmo para um degrau de $1 \mathrm{~mm}$, as diferenças médias entre respostas dinâmicas ficaram restritas a $0,004 \mathrm{~mm}$.

\subsubsection{Ganhos diferentes entre variáveis controladas}

Empregando ganhos correspondentes a polos de frequências naturais iguais a $20 \mathrm{~Hz}$ para $x_{1}$ e $10 \mathrm{~Hz}$ para $x_{2}$ e $x_{3}$, foram realizadas simulações em malha fechada que serviram de referência para o controle sobre as coordenadas dos atuadores com ganhos definidos intuitivamente, correspondentes a polos de $20 \mathrm{~Hz}$ para $q_{1}$ e de $10 \mathrm{~Hz}$ para $q_{2}$ e $q_{3}$, e calculados no laço de controle com base nas equações 6.44 e 6.45. As diferenças dos resultados de controle no espaço dos atuadores em relação ao controle no espaço do efetuador estão apresentadas nas figuras 7.31 e 7.32 .

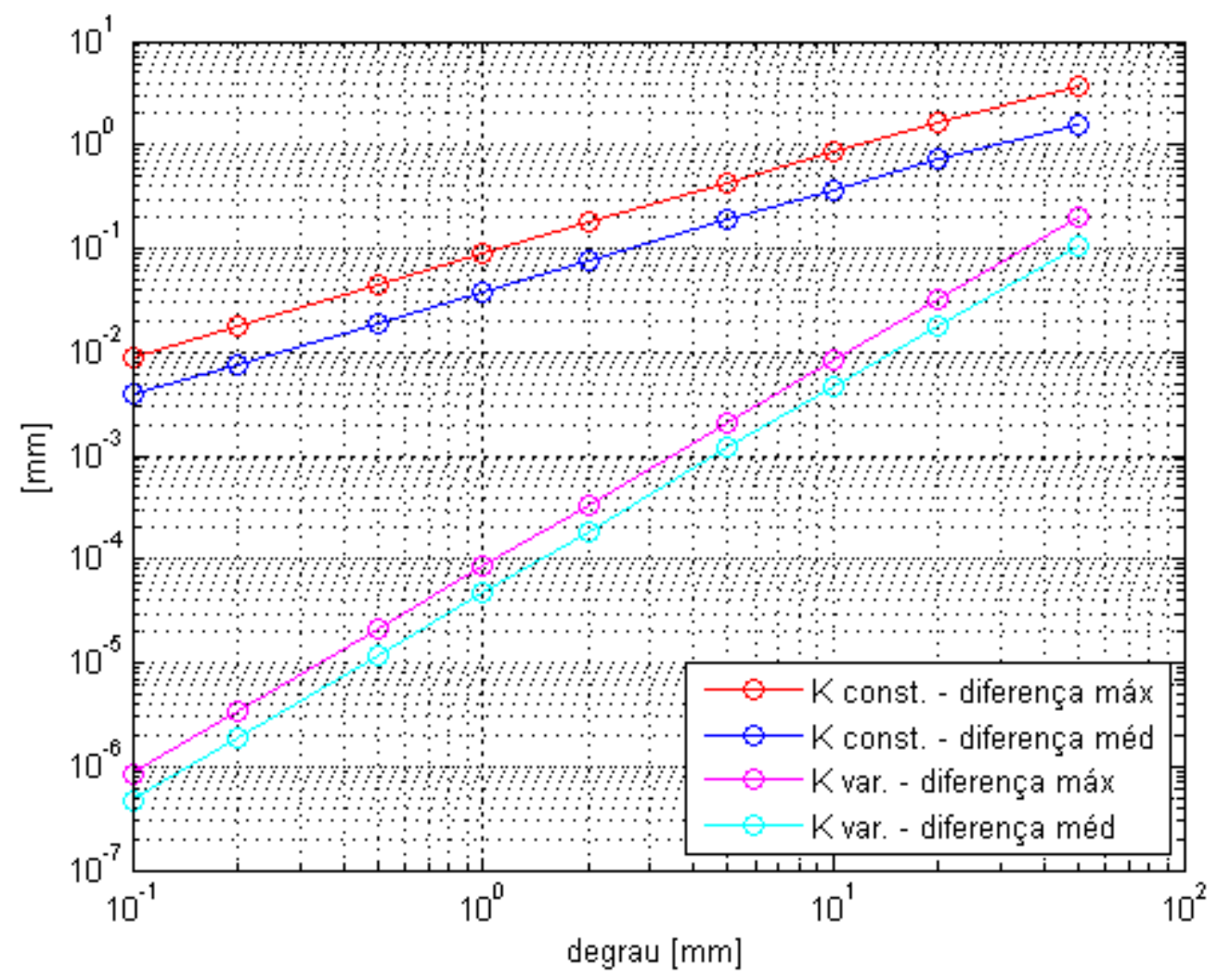

Figura 7.31 - Diferenças média e máxima entre respostas dinâmicas de controle por torque computado e controle por torque computado estendido, ganhos diferentes entre variáveis 


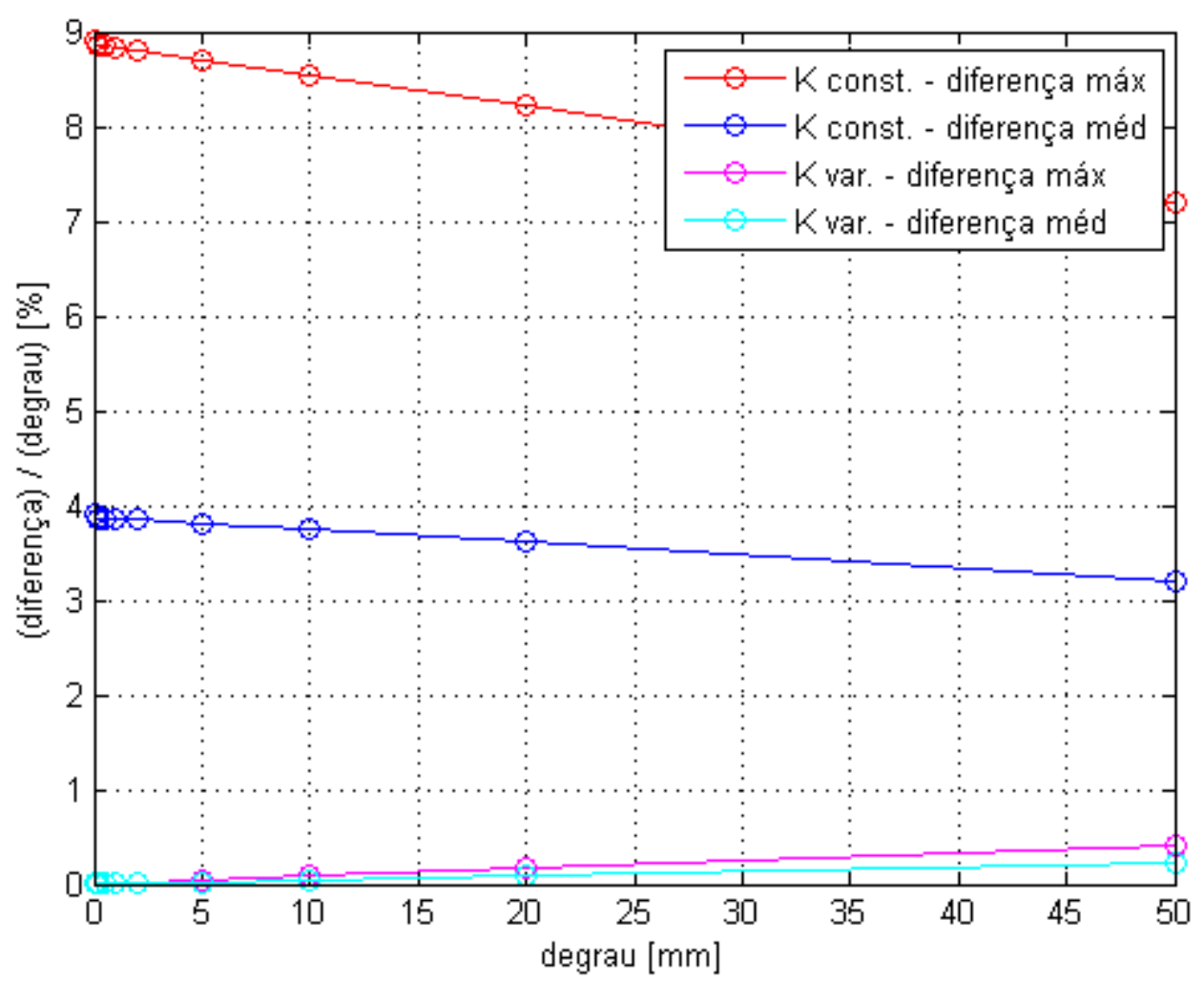

Figura 7.32 - Diferenças média e máxima percentual entre respostas dinâmicas de controle por torque computado e controle por torque computado estendido, ganhos diferentes entre coordenadas

Observa-se que os ganhos constantes, definidos intuitivamente, não são adequados, pois não resultam em controle no espaço dos atuadores equivalente ao controle no espaço do efetuador. Porém, tal equivalência é atingida com os ganhos variáveis, calculados com base nas equações 6.44 e 6.45 .

Definindo-se agora ganhos para obtenção de polos de frequência igual a 20 $\mathrm{Hz}$ para $x_{1}, 5 \mathrm{~Hz}$ para $x_{2}$ e $10 \mathrm{~Hz}$ para $x_{3}$, foi feito o controle com ganhos variáveis para aqueles correspondentes às coordenadas dos atuadores. A diferença entre o controle por torque computado estendido assim definido e o controle por torque computado tradicional sobre o espaço dos atuadores está apresentada nas figuras 7.33 e 7.34 .

Novamente nota-se a equivalência entre as duas abordagens de controle, reforçando a validade das equações 6.44 e 6.45 . 


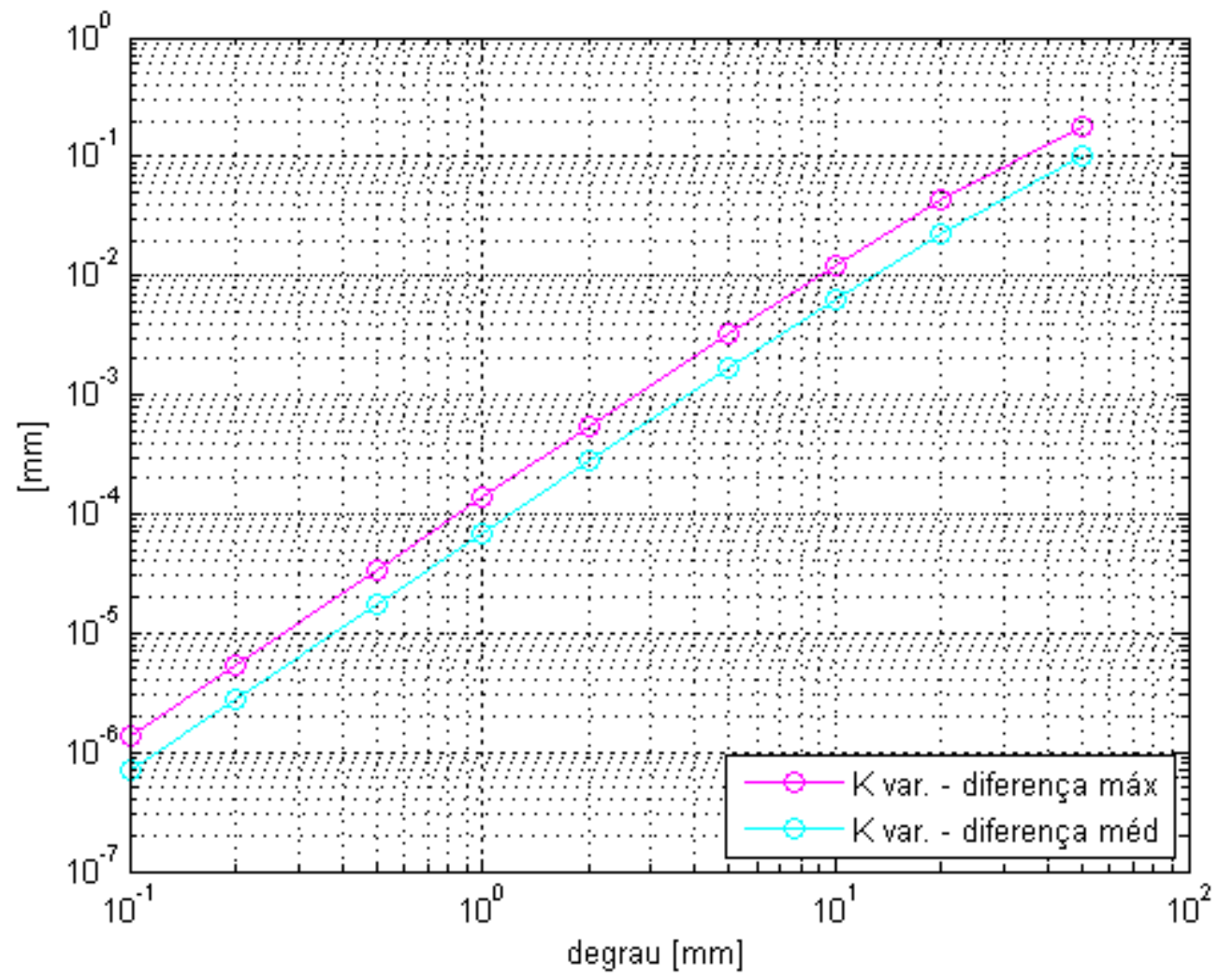

Figura 7.33 - Diferenças média e máxima entre respostas dinâmicas de controle por torque computado e controle por torque computado estendido, ganhos diferentes entre coordenadas

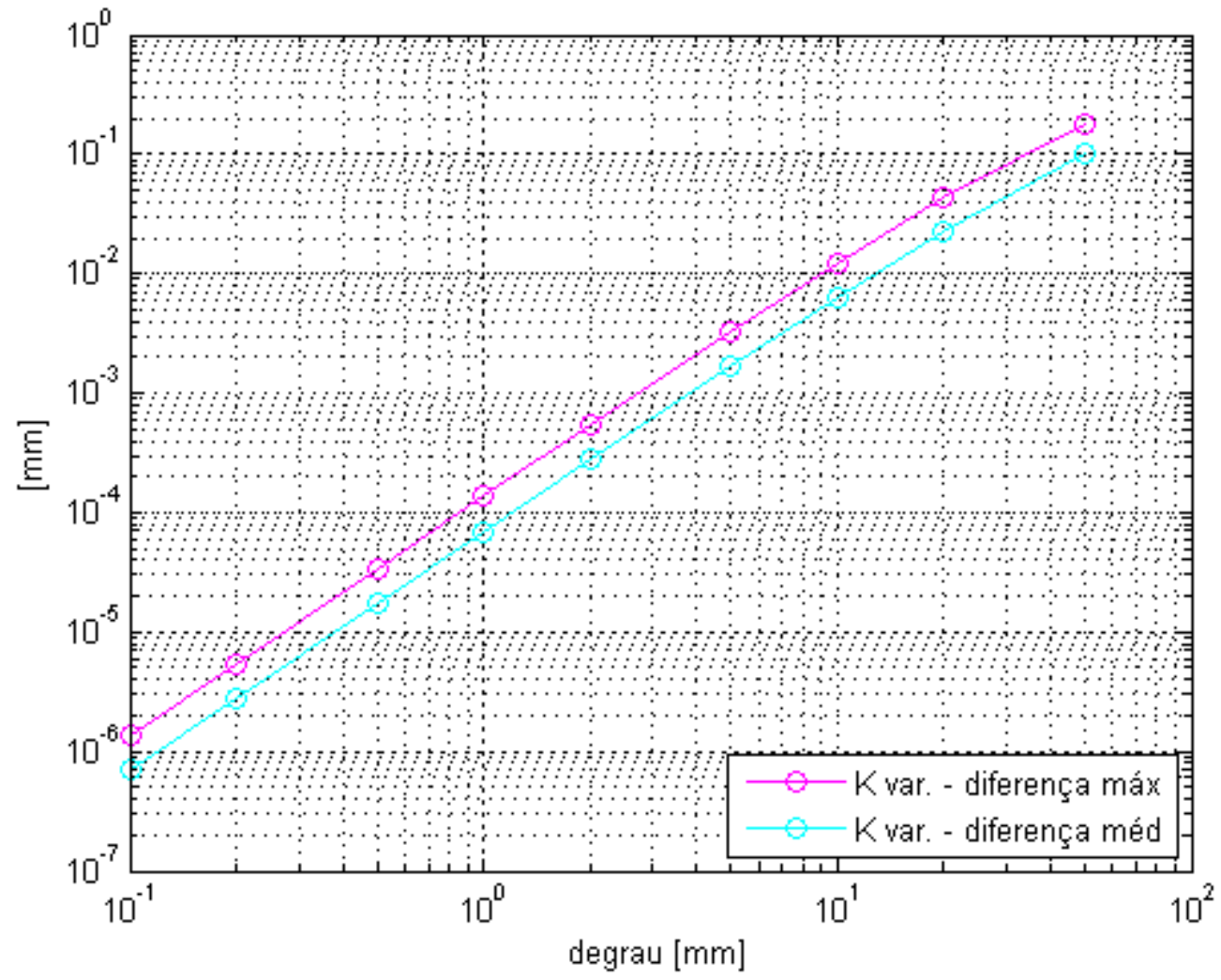

Figura 7.34 - Diferenças média e máxima percentual entre respostas dinâmicas de controle por torque computado e controle por torque computado estendido, ganhos diferentes entre coordenadas 


\subsection{EFEITOS DA SIMPLIFICAÇÃO DO MODELO E DA FREQUÊNCIA DE AMOSTRAGEM NOS ERROS DE CONTROLE}

Conforme apresentado nas seções 2.3 e 5.3, a simplificação do modelo dinâmico pode ser realizada antes do levantamento de equações matemáticas, com a adoção de hipóteses simplificadoras, ou após o equacionamento, com a identificação de seus termos predominantes. Busca-se um equilíbrio entre complexidade e acurácia do modelo. Quanto melhor o modelo representar o robô, menores tendem a ser os erros de controle, porém, os cálculos do esforços de controle demandam maior poder computacional do controlador ou ficam restritos a menores taxas de amostragem. Nas próximas seções são exemplificados esses efeitos sobre o robô em estudo.

\subsubsection{Efeitos da frequência de amostragem sobre o erro de controle em malha fechada}

\subsubsection{Frequência de amostragem única}

Utilizando a trajetória de ciclos pega-e-põe encadeados (seção 7.1.5), foram executadas simulações de controle de torque computado baseado no modelo de massas distribuídas, utilizando frequência de amostragem única para o controlador como um todo (mesma frequência para a parte de compensação de não linearidades e para a parte de controle linear), que foi avaliada no intervalo [100; 10000] Hz, como pode ser observado na figura 7.35.

Nota-se que quanto maior é o período de amostragem, maiores são os erros de controle, pois o atraso induzido pela discretização do controle afasta o controlador da condição original de tempo contínuo em que foi projetado. São necessários tempos de amostragem menores que $10^{-3} \mathrm{~s}$ para que os erros fiquem totalmente limitados a $0,1 \mathrm{~mm}$. Nota-se ainda que tempos de amostragem maiores que $3.10^{-3} \mathrm{~s}$ tornam o controle instável, como mostra a figura 7.36 , em que é apresentada a evolução temporal de $x_{1}, x_{2}$ e $x_{3}$. 


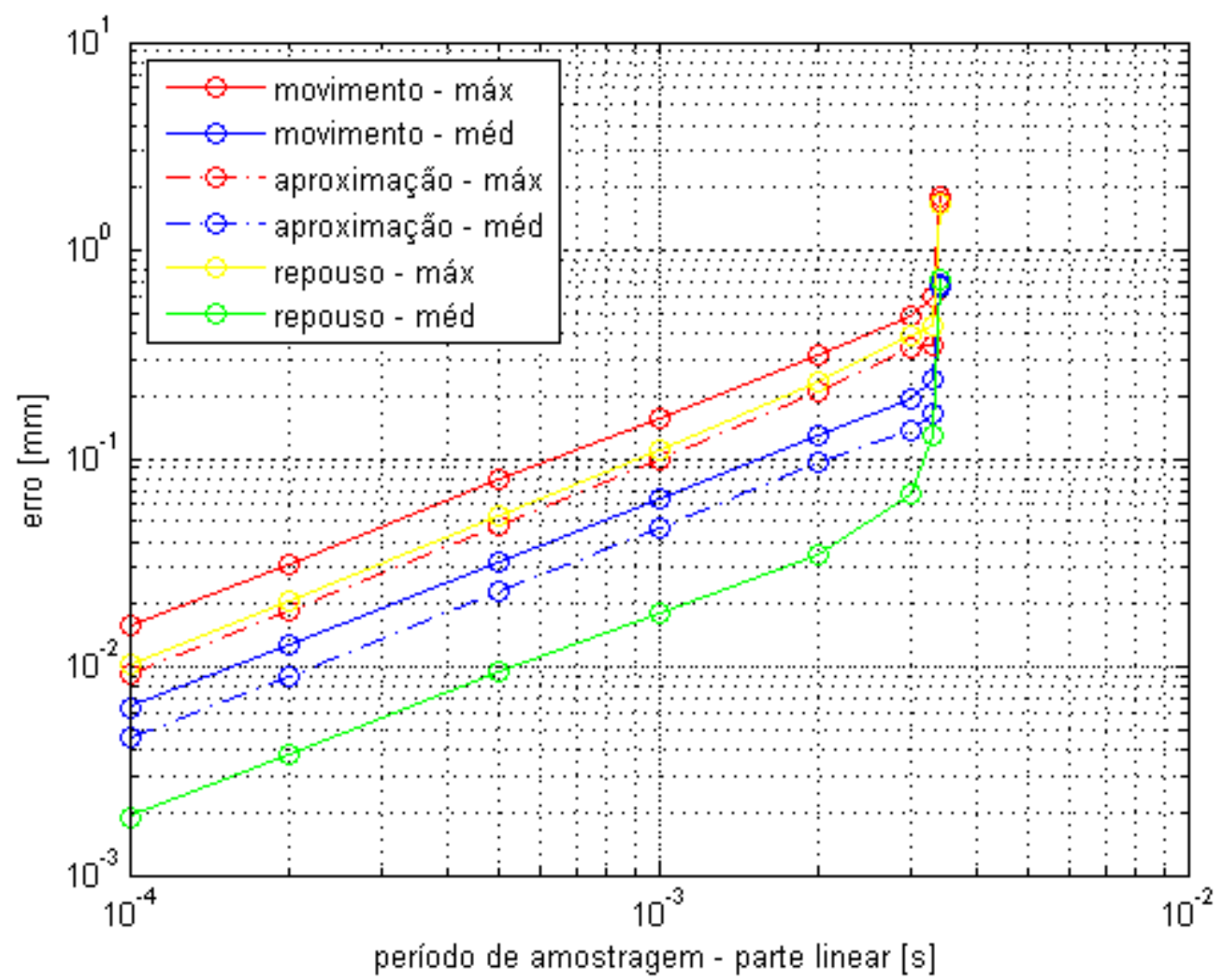

Figura 7.35 - Erros de controle em função do período de amostragem do controle discreto

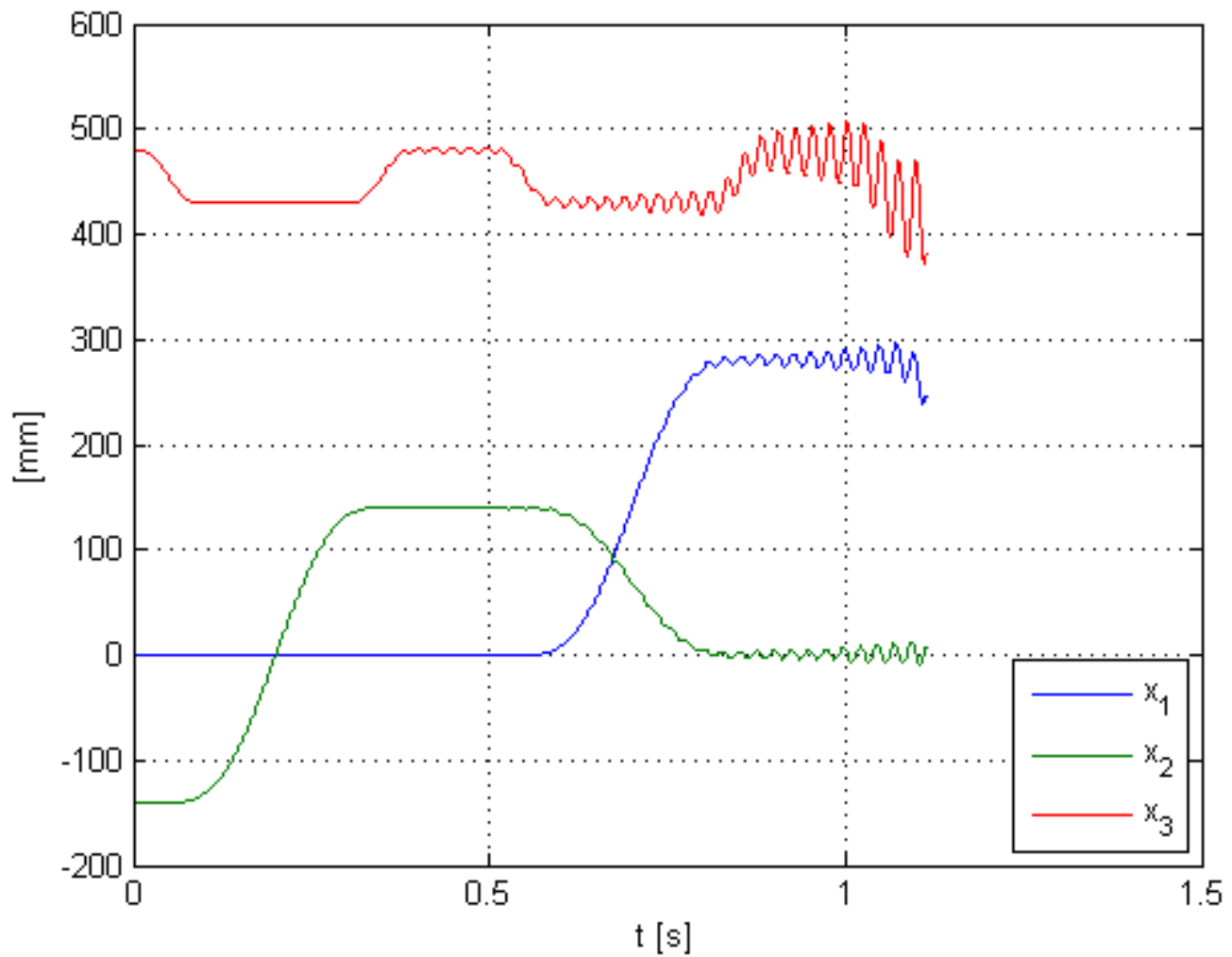

Figura 7.36 - Instabilidade do controle discreto sob período de amostragem de $3,5.10^{-3} \mathrm{~s}$ 


\subsubsection{Dupla frequência de amostragem}

Buscando-se aprimorar os resultados do controle, sem elevar o demasiadamente seu custo computacional, foram também executadas simulações com dupla frequência de amostragem: um mais lenta, correspondente à parte de compensação de não linearidades do modelo, e outra mais rápida, correspondente à parte linear do controlador.

$\mathrm{Na}$ figura 7.37 podem-se observar os erros de controle obtidos para parte linear do controle executado sob frequência de $10000 \mathrm{~Hz}$.

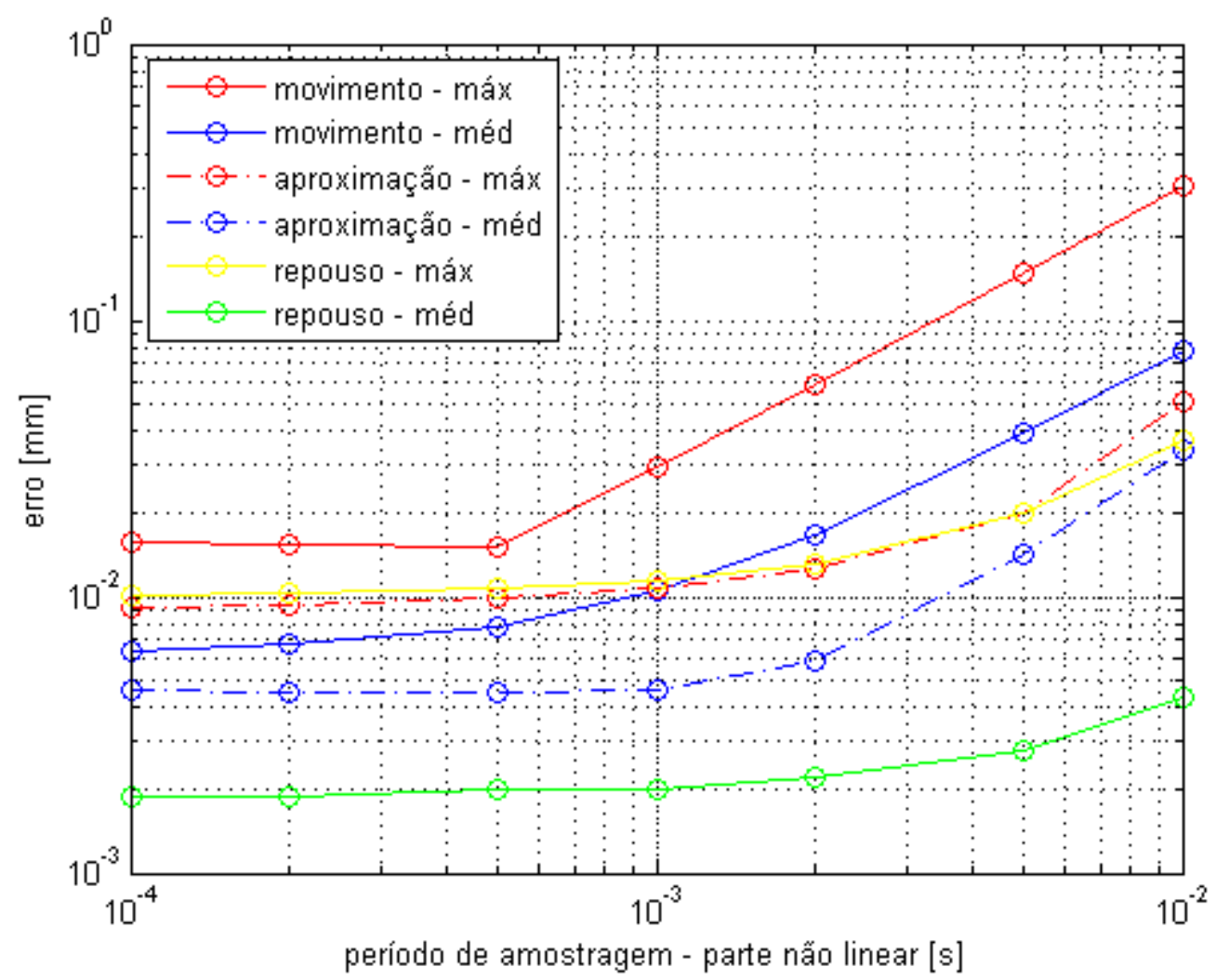

Figura 7.37 - Erros de controle em função do período de amostragem da parte não linear do controle discreto de dupla amostragem, parte linear amostrada a $10000 \mathrm{~Hz}$

Nota-se que menores períodos de amostragem levam a menores erros de controle. Porém, há uma região de saturação, a partir da qual não há melhoria dos erros com aumento da frequência de amostragem.

$\mathrm{Na}$ figura 7.38, é possível observar o efeito do período de amostragem da parte linear do controlador sobre os erros de controle. 


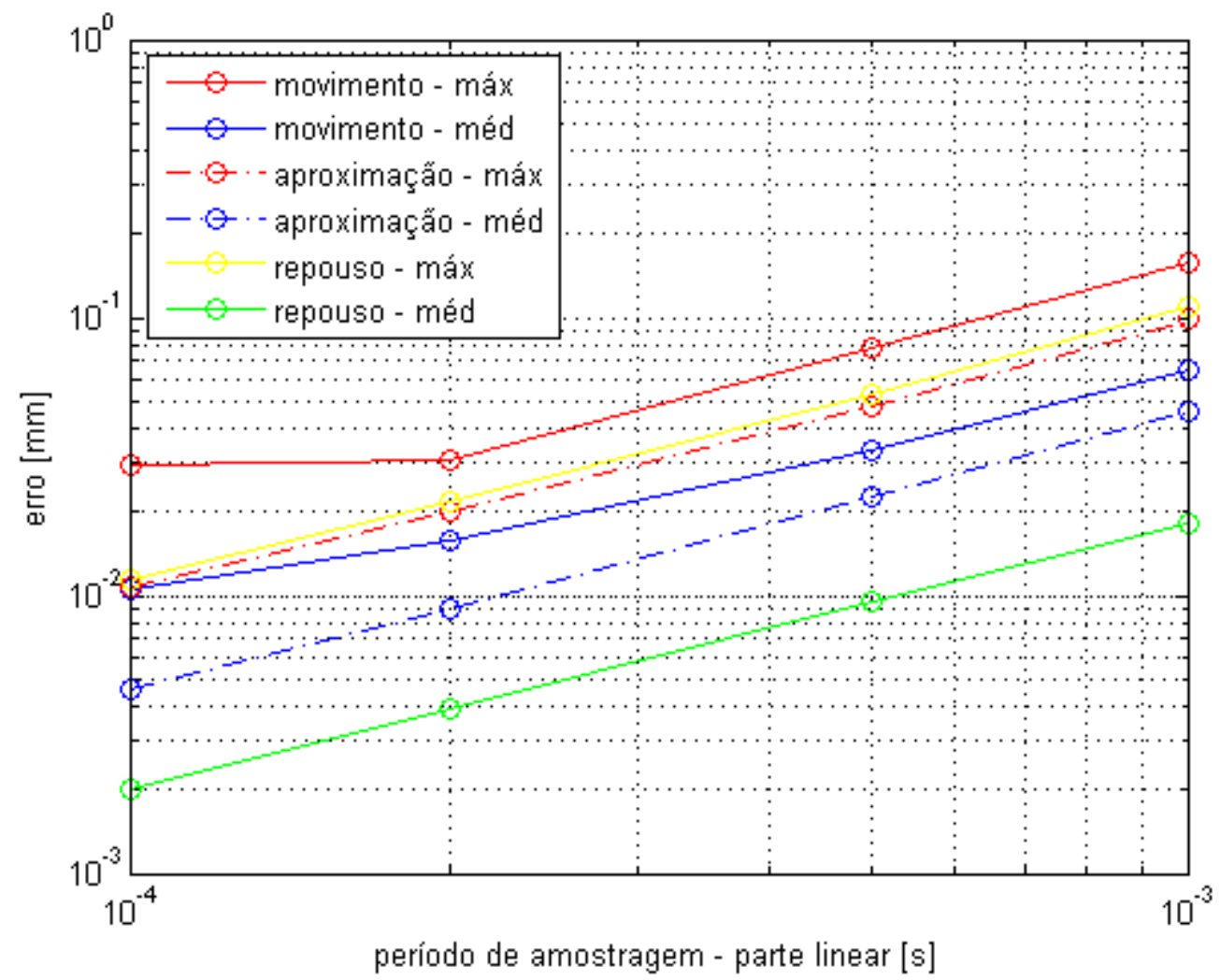

Figura 7.38 - Erros de controle em função do período de amostragem da parte linear do controle discreto de dupla amostragem, parte não linear amostrada a $1000 \mathrm{~Hz}$

Observa-se novamente uma diminuição dos erros de controle com a diminuição do período de amostragem, mas a região de saturação fica mais tênue.

Para que fosse possível comparar o efeito conjunto dos dois períodos de amostragem do controlador sobre os erros de controle, foram construídos os gráficos das figuras 7.39 a 7.41 .

Nota-se que o emprego do período de amostragem da parte não linear do controlador igual ao da parte linear leva o controlador ao seu limite de desempenho. Porém, para uma dada frequência de amostragem da parte linear, é possível diminuir a frequência de amostragem da parte não linear do controlador sem comprometimento dos erros de controle.

Nota-se ainda que quando a frequência de amostragem da parte linear é igual ou superior a $500 \mathrm{~Hz}$, é possível operar a parte não linear do controlador sob frequências de amostragem mais baixas que as frequências em que o controlador de única frequência de amostragem tornou o sistema instável. 


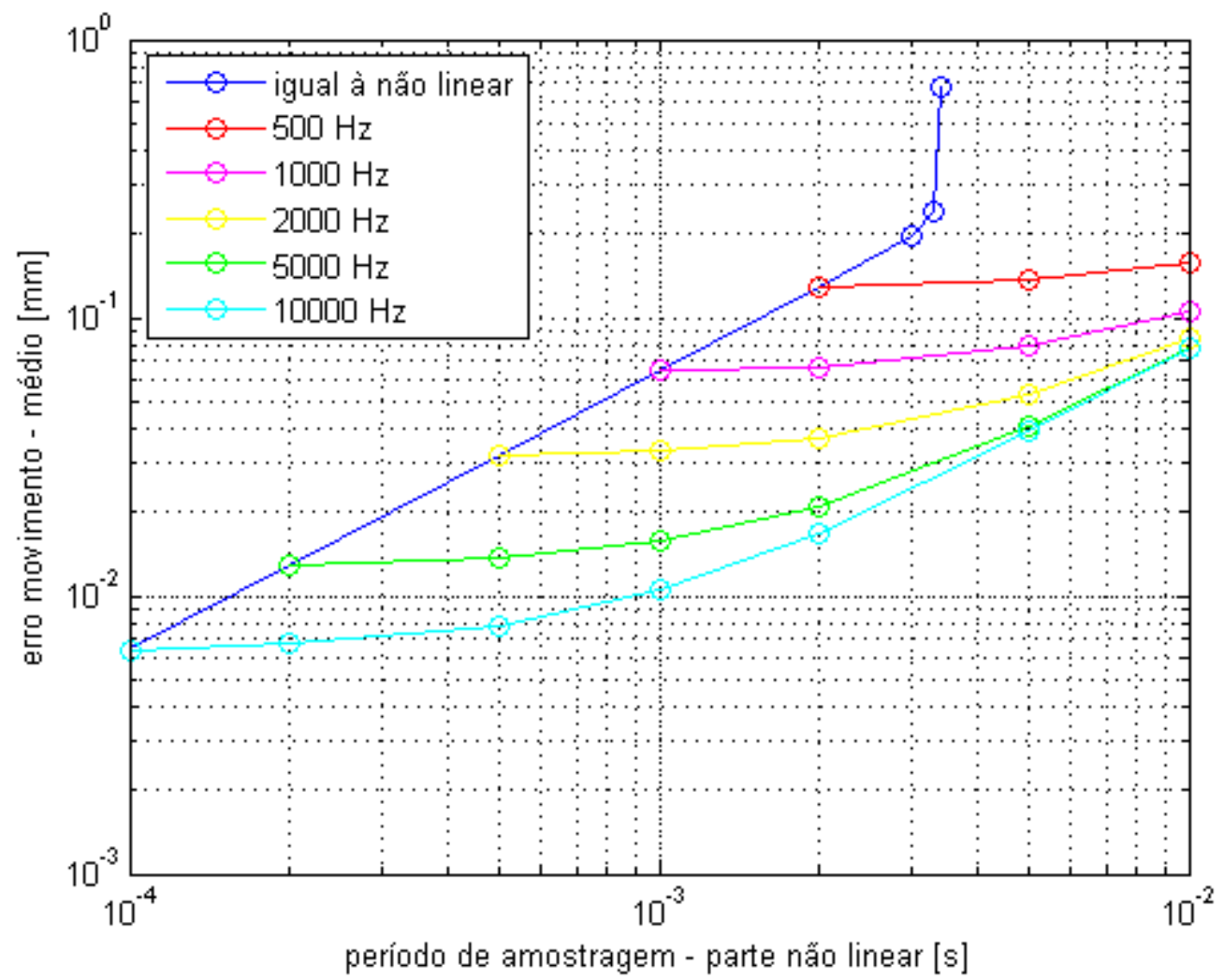

Figura 7.39 - Etapa de movimento: erros médios de controle em função do período de amostragem da parte não linear do controle discreto de dupla amostragem, diversas amostragens da parte linear

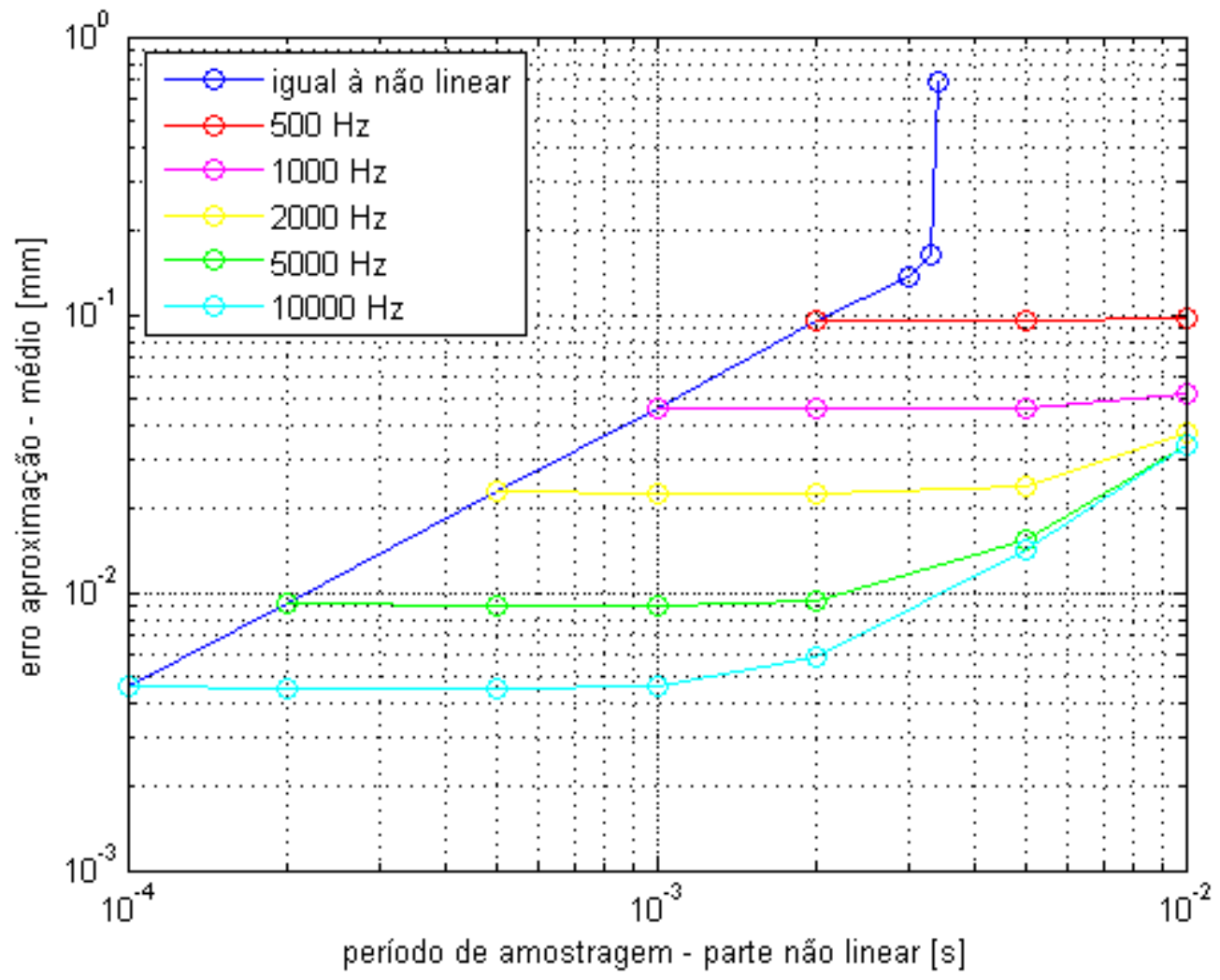

Figura 7.40 - Etapa de aproximação: erros médios de controle em função do período de amostragem da parte não linear do controle discreto de dupla amostragem, diversas amostragens da parte linear 


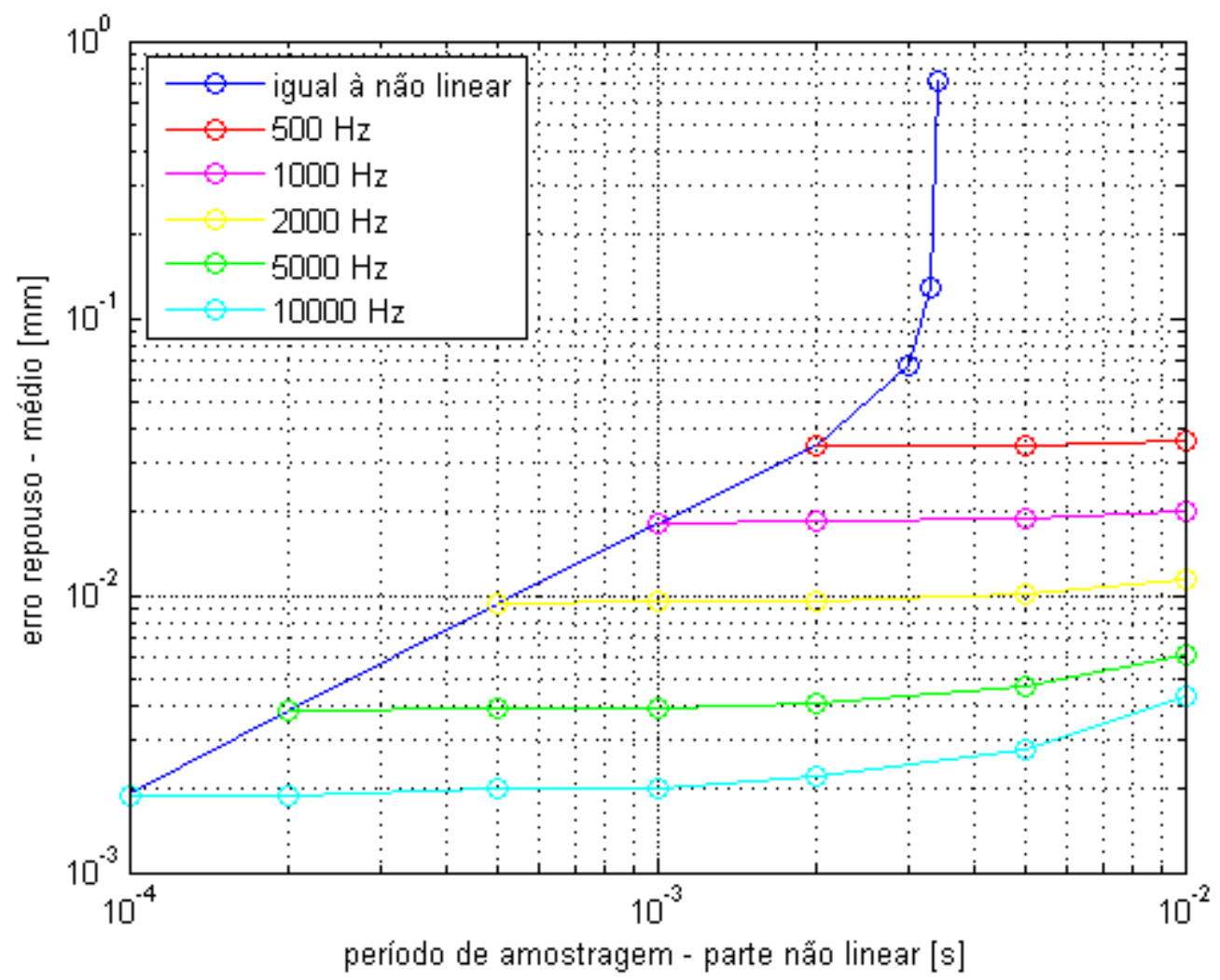

Figura 7.41 - Etapa de repouso: erros médios de controle em função do período de amostragem da parte não linear do controle discreto de dupla amostragem, diversas amostragens da parte linear

\subsubsection{Erros de controle e tempos de processamento em função da simplificação do modelo}

Baseando-se nos modelos de massas distribuídas (MD), massas concentradas nos centros das barras (MC), massas concentradas nas extremidades das barras ( $\mathrm{MCe}$ ) e modelos simplificados $A$ a $G$ listados na tabela 5.8, foram projetados controladores e executadas simulações em modo contínuo para verificação do efeito da simplificação dos modelos sobre os erros de controle (conforme definidos na seção 7.1.6), como mostram as figuras 7.42 a 7.44.

Observa-se que quanto maior a simplificação do modelo, maiores são os erros de controle. Especificamente, os erros de controle resultantes do modelo de massas concentradas nas extremidades das barras e dos modelos simplificados $\mathrm{A}$ a C não se mostram adequados para tarefas pega-e-põe.

Por outro lado, o custo computacional de cada proposta de controle é diferente, como pode ser visualizado na figura 7.45. Os tempos de processamento foram obtidos com a utilização de um microcomputador com processador AMD Sempron Mobile 3000, 1,8 GHz, com 2 GB de memória RAM, no ambiente computacional Matlab. 


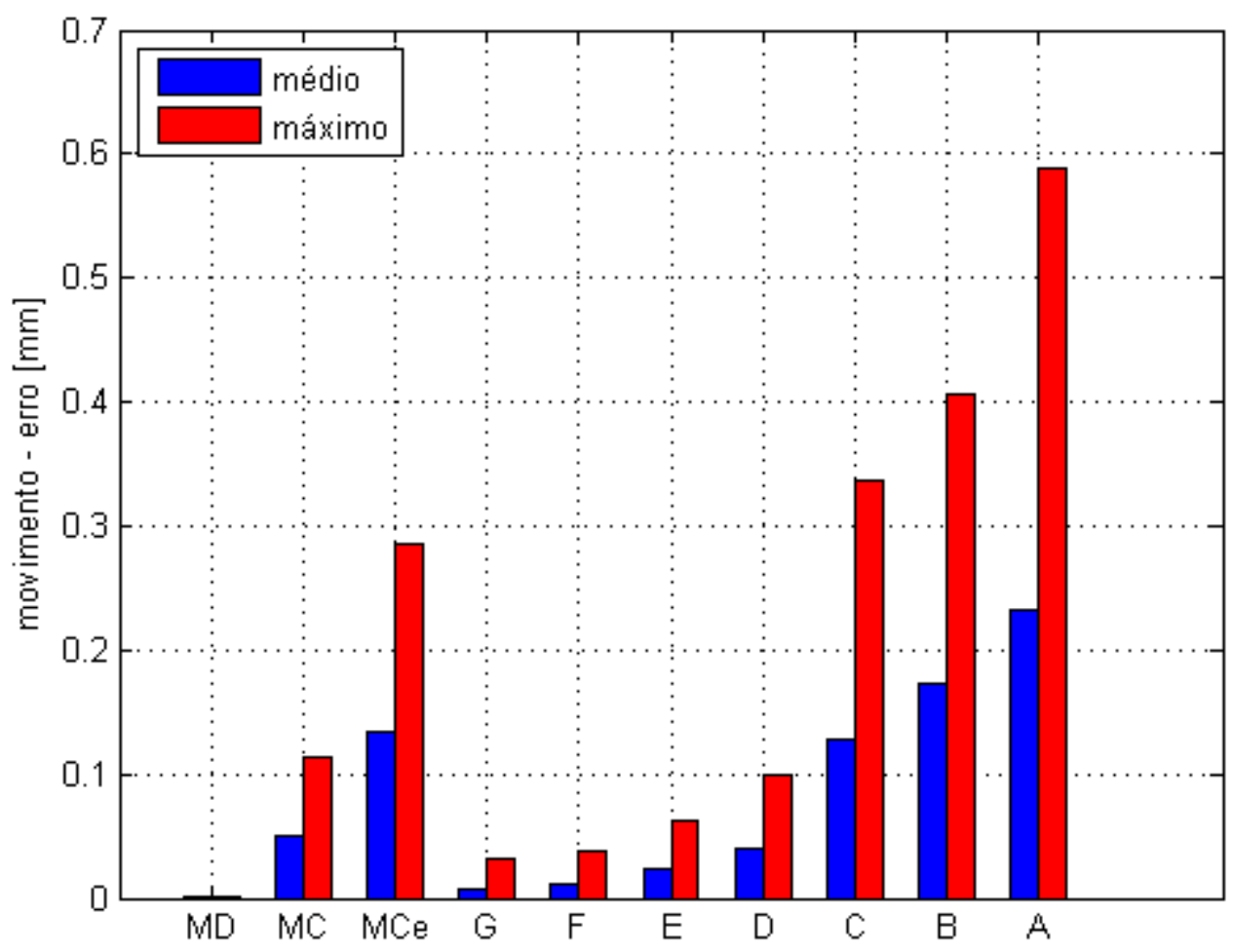

Figura 7.42 - Etapa de movimento: erros médios e máximos de controle contínuo em função da simplificação do modelo dinâmico do robô

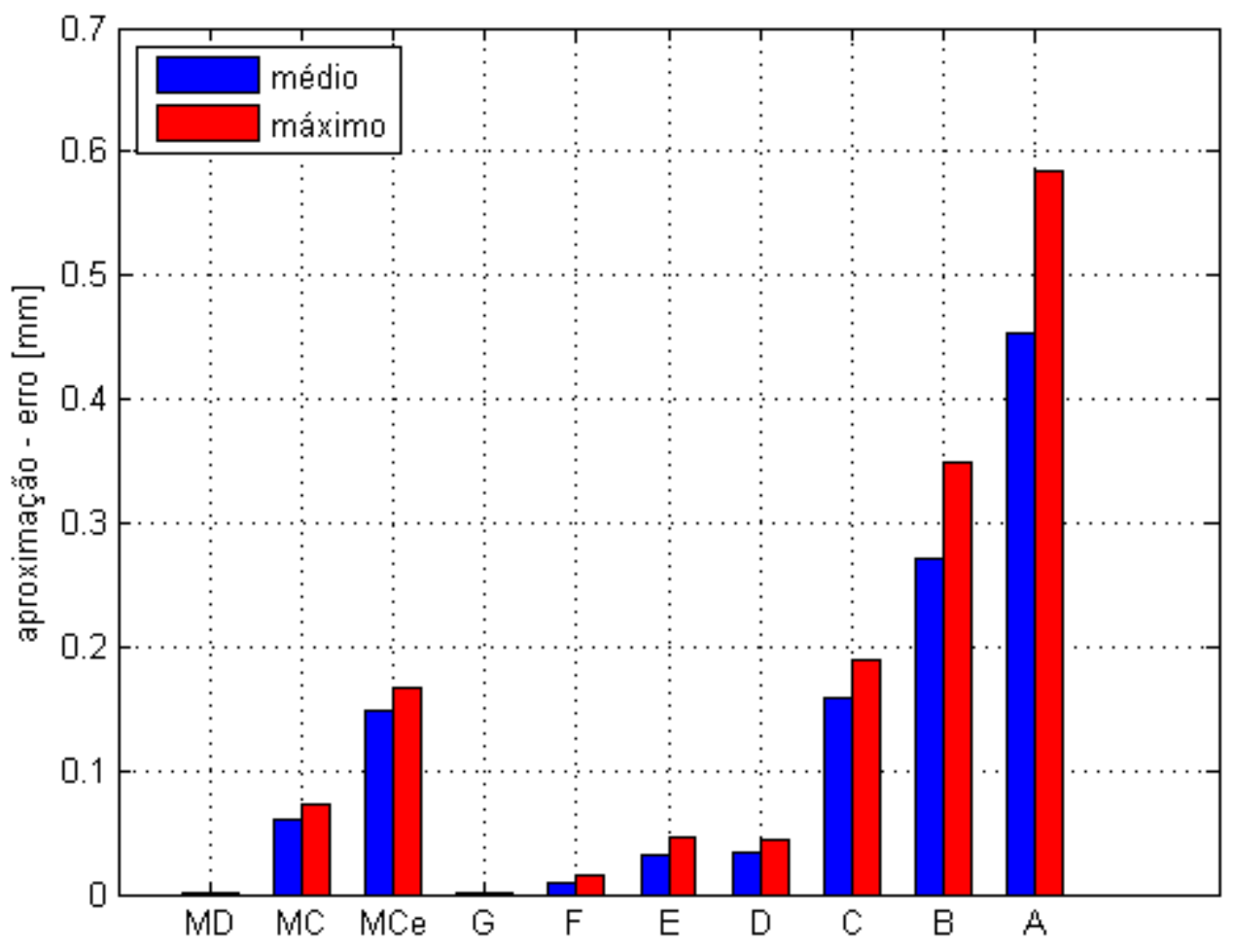

Figura 7.43 - Etapa de aproximação: erros médios e máximos de controle contínuo em função da simplificação do modelo dinâmico do robô 


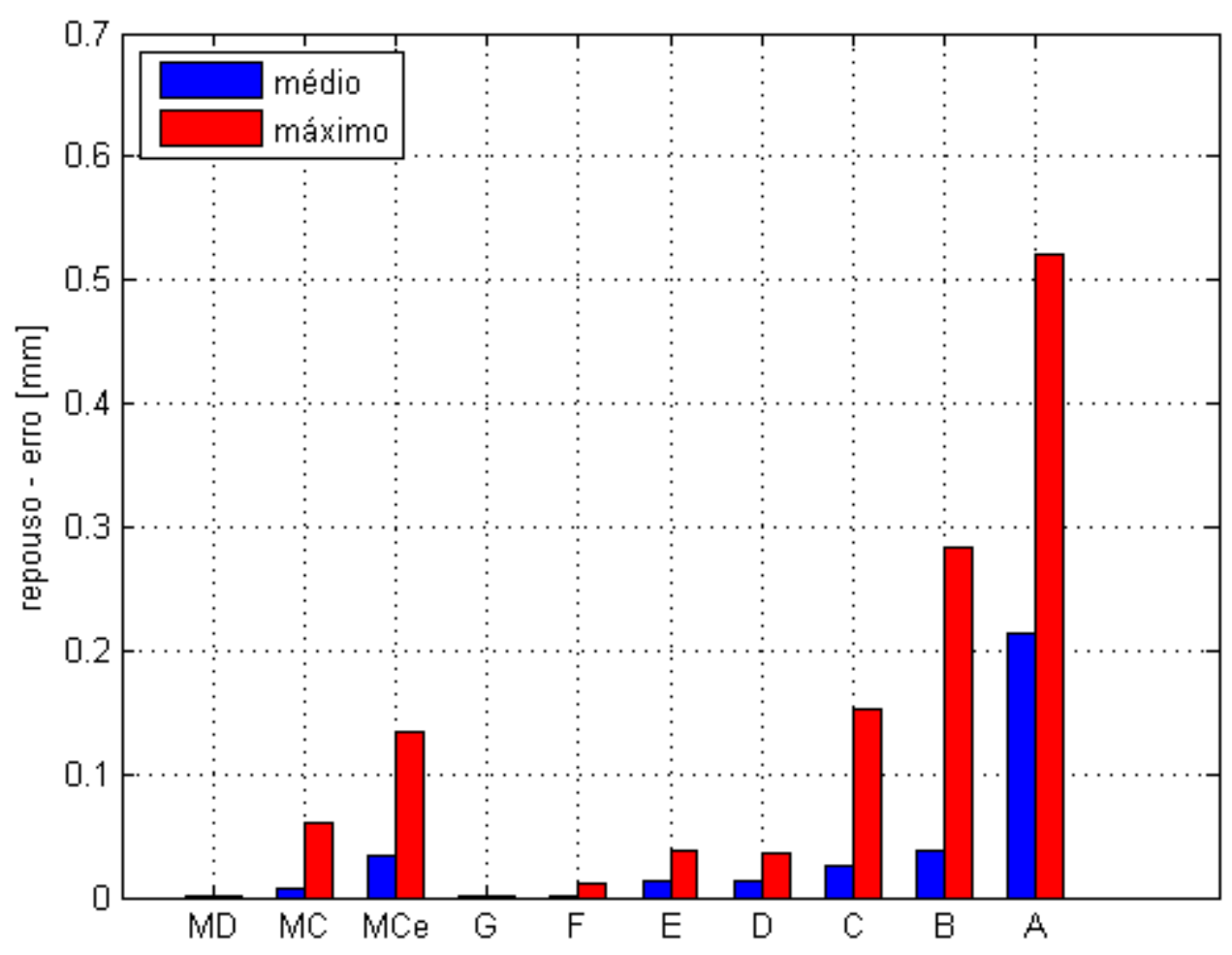

Figura 7.44 - Etapa de repouso: erros médios e máximos de controle contínuo em função da simplificação do modelo dinâmico do robô

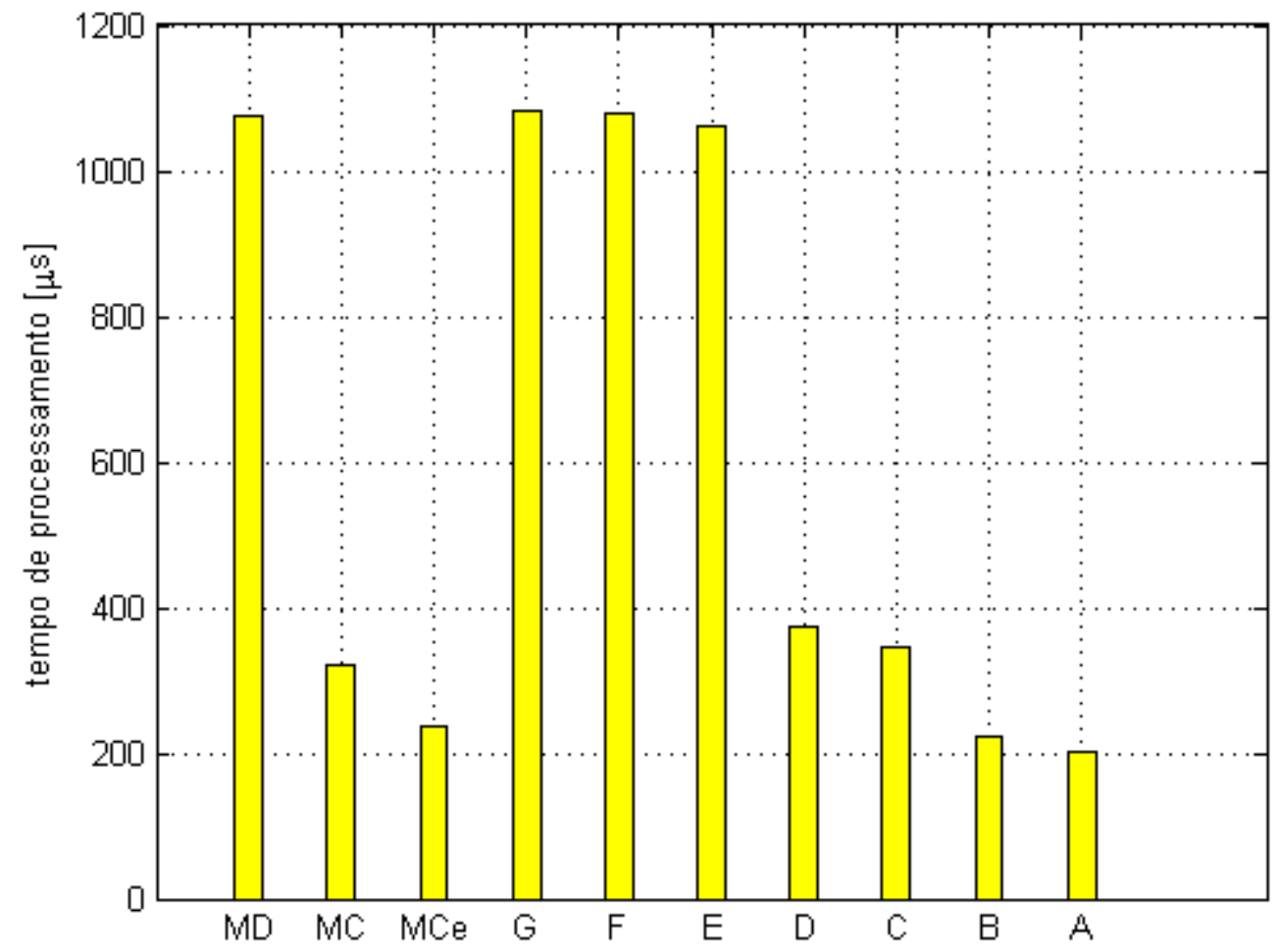

Figura 7.45 - Tempo de processamento de controle contínuo em função da simplificação do modelo dinâmico do robô 
Nota-se que o tempo de processamento do controle baseado no modelo de massas distribuídas é de aproximadamente 4 vezes o do controle baseado no modelo de massas concentradas no centro geométrico das barras. Percebe-se ainda que pouco se economiza em tempo para os controles simplificados G, F e E. Apenas a partir do controle simplificado $D$, em que não há mais termos correspondentes à inércia a rotação das barras CE e DF, obtém-se redução significativa do tempo de processamento.

Para que fosse possível comparar resultados de controladores limitados a uma mesma capacidade de processamento do hardware de controle, foram realizadas simulações com dupla frequência de amostragem em que o período da parte linear foi mantido a $10^{-4} \mathrm{~s}$ e da parte não linear foi estabelecido como indicado na tabela 7.6. Os resultados das simulações estão apresentados na figura 7.46.

Tabela 7.6 - Períodos de amostragem de mesmo custo computacional

\begin{tabular}{|c|c|}
\hline Modelo de base para controlador & Período de amostragem da parte não linear [ms] \\
\hline Massas distribuídas & 1,1 \\
\hline Massas concentradas & 0,3 \\
\hline Simplificação D & 0,4 \\
\hline
\end{tabular}

Observa-se que os resultados de controle baseado no modelo de massas concentradas é bastante inferior aos outros e apresenta valores inadequados para a aplicação de pega-e-põe sob altos requisitos de desempenho. Embora o controle baseado no modelo simplificado $D$ tenha atingindo razoáveis valores de erros, o controle baseado no modelo de massas distribuídas é mais vantajoso, mesmo sendo executado sob um maior período de amostragem. 


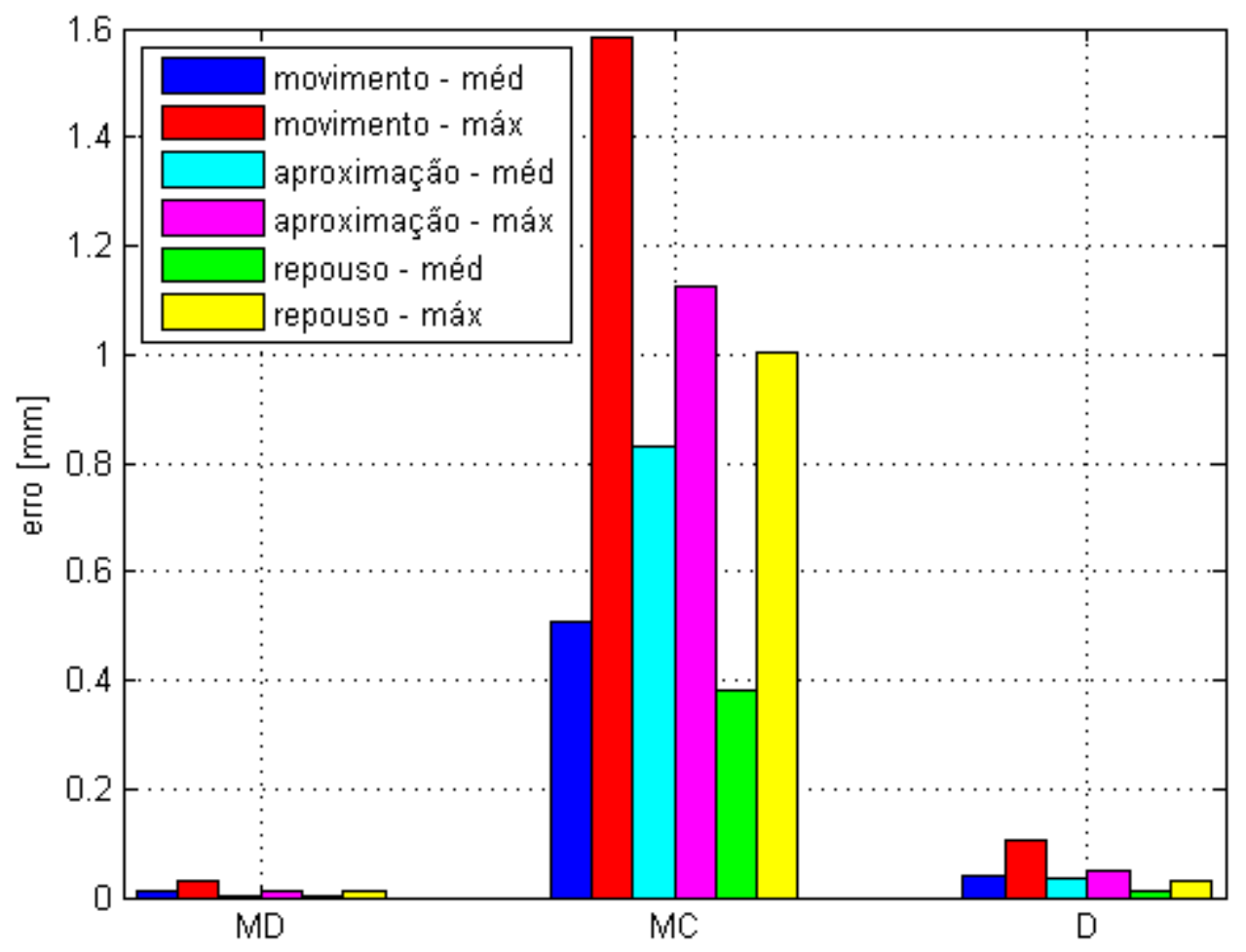

Figura 7.46 - Erros médios e máximos de controle discreto sob períodos de amostragem equivalentes de acordo com tempo de processamento de controladores 


\section{CONCLUSÕES}

A maioria das arquiteturas de robôs paralelos propostas para aplicações de pega-e-põe de alto desempenho é topologicamente simétrica, buscando-se isotropia no comportamento dinâmico do robô em seu espaço de trabalho, enquanto os requisitos de movimentação costumam ser diferentes para direções distintas. Neste trabalho foram exploradas características dinâmicas e de controle de uma arquitetura topologicamente assimétrica, que se mostra mais coerente com os requisitos anisotrópicos de movimentação.

Em relação às possíveis abordagens para sua modelagem dinâmica, foram utilizados o Método de Lagrange e o Princípio dos Trabalhos Virtuais, sendo que esse último se mostrou mais eficiente em termos de desenvolvimento analítico. Não se recomenda a formulação de Newton-Euler, pois essa envolveria o cálculo de muitos esforços vinculares, que não são de interesse para o desenvolvimento de leis de controle para o mecanismo. Nota-se que essas características não são decorrentes da particularidade do mecanismo ser assimétrico, mas do fato dele pertencer à família de mecanismos paralelos.

Para facilitar o equacionamento pelo Princípio dos Trabalhos Virtuais, foram utilizadas coordenadas redundantes para descrição do estado do mecanismo. Especificamente, foram empregadas as coordenadas dos atuadores e do efetuador. Ao mesmo tempo que facilitou o levantamento das equações dinâmicas, o uso de coordenadas redundantes tornou necessária a adequação dessas equações para que fossem compatíveis com técnicas de controle como a de torque computado. Isso foi realizado com a eliminação exclusiva de termos de derivada segunda das coordenadas redundantes, evitando-se a eliminação completa dessas coordenadas e de suas derivadas primeira devido à complexidade das equações cinemáticas, notadamente para posição, dos mecanismos de arquitetura paralela. Já para o emprego da técnica de torque computado estendido, não há necessidade de adequação das equações com coordenadas redundantes.

Foi demonstrado teoricamente e exemplificado com simulações que, sob a hipótese de pequenos erros de controle, há equivalência entre cálculo de esforços de controle sobre variáveis dos atuadores e sobre variáveis do efetuador no controle por torque computado, quando as matrizes de ganhos são definidas diagonais com elementos da diagonal principal iguais entre si. Sob as mesmas hipóteses, também 
foi demonstrada a equivalência entre o controle por torque computado estendido e o controle por torque computado tradicional.

Buscando explorar ao máximo a assimetria topológica do mecanismo, foi proposto o uso de ganhos diferentes entre variáveis controladas para sintonização dos controladores. Nessas condições, a escolha do conjunto de variáveis sobre o qual é executado o controle tem significativa influência na resposta dinâmica do mecanismo em malha fechada. Para que fosse possível definir os ganhos em um conjunto de coordenadas e executar o controle por torque computado sobre outro conjunto de coordenadas, foi proposto o uso de matrizes de ganhos variáveis no tempo, que são baseadas em matrizes de ganhos constantes multiplicadas por matrizes jacobianas. Essas têm a função de corrigir os ganhos de controle conforme a evolução do ganho mecânico entre coordenadas do mecanismo ao longo de sua trajetória. Enquanto o uso de ganhos variáveis no controle por torque computado é opcional, pois é possível definir os ganhos e executar o controle sobre o mesmo conjunto de coordenadas, o uso de ganhos variáveis para as coordenadas redundantes no controle por torque computado estendido é obrigatório para que seja obtida a requerida resposta dinâmica para o robô.

A avaliação dos efeitos de adoção de hipóteses simplificadoras sobre os erros de controle mostrou que a hipótese de massas concentradas inviabilizaria o projeto de controladores para os desejados altos níveis de desempenho. A simplificação do modelo dinâmico do mecanismo resultou em modelo de custo computacional mais baixo, e viável para servir de base para o projeto de controladores. Porém, o uso do controlador baseado no modelo completo do mecanismo se mostrou mais eficaz em relação aos erros de controle, mesmo executado a uma frequência de amostragem mais baixa, de acordo com sua maior demanda computacional.

A discretização dos controladores fez com que os erros de controle fossem aumentados significativamente comparados aos erros de controle contínuo. O emprego de dupla frequência de amostragem se revelou como uma boa prática, pois permitiu a redução da frequência de amostragem da parte não linear do controlador sem comprometimento dos valores de erros de controle. Além disso, fez com que fosse eliminada a instabilidade detectada quando empregada frequência de amostragem única para as partes linear e não linear do controlador. 
Como característica específica da arquitetura analisada, as acelerações máximas atingíveis pelo efetuador em função da saturação dos atuadores do robô revelaram que existe certa independência entre os desempenhos alcançados para direções distintas. Isso sugere que poderia ser utilizado um atuador de maior capacidade na junta prismática superior do mecanismo, obtendo-se melhor desempenho na direção correspondente a essa junta, independentemente da escolha dos atuadores para as juntas ativas dos dois membros laterais.

São sugeridos como trabalhos futuros a continuação da espiral de projeto do robô, dependente do término da construção de seu protótipo, com o desenvolvimento das etapas de identificação geométrica e dinâmica, e de implementação das leis de controle por torque computado e por torque computado estendido. Com o protótipo em funcionamento, deve-se também realizar análises de robustez dos controladores propostos e experimentos para identificação de modos de vibração do mecanismo e de suas correspondentes frequências naturais para servirem de base na sintonização dos controladores. E, principalmente, investigar a possibilidade de utilização de ganhos de controle calculados em função de polos de dinâmica de erro de controle cujas frequências sejam superiores ao limite hoje estabelecido de metade da menor frequência estrutural do mecanismo. Acredita-se que isso se justifica caso haja direções de movimentação do efetuador que não excitem de forma significativa o modo de vibração de menor frequência natural, o que se vislumbra ocorrer em mecanismos de arquitetura paralela assimétrica. 


\section{REFERÊNCIAS BIBLIOGRÁFICAS}

ABB ROBOTICS, IRB 360 FlexPicker, ROB0082EN_F, 2013. Disponível em: <http://new.abb.com/products/robotics/industrial-robots/irb-360>. Acesso em: 29 Jul 2013

ADEPT TECHNOLOGY, Adept Quattro s650H, 09366-004 Rev. E, 2010. Disponível em: <http://www.adept.com/products/robots/parallel/quattro-s650h/downloads>. Acesso em: 29 Jul 2013

AHMADI, M.; DEHGHANI, M.; EGHTESAD, M.; KHAYATIAN, A. R. Inverse Dynamics of Hexa Parallel Robot Using Lagrangian Dynamics Formulation. In: INTERNATIONAL CONFERENCE ON INTELLIGENT ENGINEERING SYSTEMS, 12, 2008, Miami. Proceedings... Miami: IEEE, 2008. pp.145-149

ALMEIDA, R. Z. H, HESS-COELHO, T. A., Dynamic Model of a 3-dof Asymmetric Parallel Mechanism, The Open Mechanical Engineering Journal, vol. 4, 2010

ALMEIDA, R. Z. H., HESS-COELHO, T. A., Structural synthesis, dynamic modeling and analysis of a 3-dof asymmetric parallel mechanism. In: IFTOMM WORLD CONGRESS, 13, 2011, Guanajuato. Proceedings... Guanajuato: UCEA, 2011

ALMEIDA, R. Z. H., HESS-COELHO, T. A., Structural synthesis, dynamic modeling and analysis of a 3-DOF asymmetric parallel mechanism, Journal of Mechanics Engineering and Automation, v. 1, pp. 481-490, 2011

ALMEIDA, R. Z. H., HESS-COELHO, T. A., Dynamic model simplification of an asymmetric parallel robot for the development of real time control system. In: INTERNATIONAL SYMPOSIUM ON DYNAMIC PROBLEMS OF MECHANICS DINAME, 15, 2013, Búzios. Proceedings... Rio de Janeiro: UFRJ, 2013

BÖHM, J., BELDA, K., VALÁSEK, M., Decentralized and Centralized Control of Redundant Parallel Robot Constructions. In: IEEE MEDITERRANEAN 
CONFERENCE ON CONTROL AND AUTOMATION, 2002, Lisboa. Proceedings... Lisboa: Instituto Superior Técnico, 2002

CAMACHO, E. F., BORDONS, C., Model Predictive Control. $2^{\text {nd }}$ ed. London: Springer-Verlag, 2000

CALLEGARI, M., PALPACELLI, M.C., PRINCIPI, M., Dynamics modeling and control of the 3-RCC translational platform, Mechatronics, v.16, 2006

CHEMORI, A., SARTORI-NATAL, G., PIERROT, F., Controlo f Parallel Robots: Towards Very High Accelerations. In: INTERNATIONAL MULTI-CONFERENCE ON SYSTEMS, SIGNALS \& DEVICES (SSD), 2013, Hammamet. Proceedings... Hammamet, 2013

CHOI, H. B., COMPANY, O., PIERROT, F., KONNO, A., SHIBUKAWA, T., UCHIYAMA, M., Design and Control of a Novel 4-DOFs Parallel Robot H4. In: IEEE INTERNATIONAL CONFERENCE ON ROBOTICS \& AUTOMATION, 2003, Taipei. Proceedings... Taipei: IEEE, 2003

CHOI, H. B., KONNO, A., UCHIYAMA, M., Design, implementation, and performance evaluation of a 4-DOF parallel robot, Robotica, 28, pp 107-118, 2010

CLARKE, D. W., MOHTADI, C., TUFFS, P. S., Generalized Predictive Control - Part I. The Basic Algorithm, Automatica, v. 23, n. 2, pp. 137-148, 1987

CLAVEL, R., DELTA - A fast robot with parallel geometry. In: INTERNATIONAL SYMPOSIUM ON INDUSTRIAL ROBOT, 1988, Lausanne. Proceedings... Lausanne: 1988

CODOUREY, A., Dynamic modeling and mass matrix evaluation of the DELTA parallel robot for axes decoupling control. In: IEEE INTERNATIONAL CONFERENCE ON INTELLIGENT ROBOTS AND SYSTEMS, 1996, Osaka. Proceedings... Osaka: IEEE, 1996 
CRAIG, J. J., Introduction to Robotics: Mechanics and Control. $3^{\text {rd }}$ ed. Upper Saddle River: Pearson Education, 2005

DASGUPTA, B., CHOUDHURY, P., A general strategy based on the Newton-Euler approach for the dynamic formulation of parallel manipulators, Mechanism and Machine Theory, v. 34, pp. 801-824, 1999

DA SILVA, M. M., Computer-Aided Integrated Design of Mechatronic Systems. 2009. 307 f. Tese (Doutorado em Engenharia) - Faculteit Ingenieurswetenschappen, Katholieke Universiteit Leuven, Cidade , 2009

DAVLIAKOS, I., PAPADOPOULOS, E., Model-based control of a 6-dof electrohydraulic Stewart-Gough platform, Mechanism and Machine Theory, 2008

DUCHAINE, V., BOUCHARD, S., GOSSELIN, C. M., Computationally Efficient Predictive Robot Control, IEEE/ASME Transactions on Mechatronics, v. 12, n. 5, pp. $570-578,2007$

FRANKLIN, G. F., POWELL, J. D., WORKMAN, M. L., Digital Control of Dynamic Systems. $2^{\text {nd }}$ ed. Addison-Wesley Publishing Company, 1992

GALLARDO-ALVARADO, J., AGUILAR-NÁJERA, C. R., CASIQUE-ROSAS, L., RICO-MARTÍNEZ, J. M., ISLAM, N. M, Kinematics and dynamics of 2(3-RPS) manipulators by means of screw theory and the principle of virtual work, Mechanism and Machine Theory, v. 43, n. 10, pp. 1281-1294, 2008

GEIKE, T., MCPHEE, J., Inverse dynamic analysis of parallel manipulators with full mobility, Mechanism and Machine Theory, v. 38, 2003

GILLESPIE, R. B., Kane's equations for haptic display of multibody systems, Haptics-e, v.3, n.2, 2003 
GONÇALVES, R. S., Estudo de rigidez de cadeias cinemáticas fechadas. 2009. 239 f. Tese (Doutorado em Engenharia Mecânica) - Faculdade de Engenharia Mecânica, Universidade Federal de Uberlândia, Uberlândia, 2009

GOUGH, V. E., Contribution to Discussion to Papers on Research in Automobile Stability and Control and in Tire Performance, Proceedings of the Automotive Division of the Institution of Mechanical Engineers, pp. 392-394, 1956

GUENTHER, R. SIMAS, H., CRUZ, D. F. M., MARTINS, D., A new integration method for differential inverse kinematics of closed-chain robots. ABCM Symposium Series in Mechatronics, v. 3, pp. 225-235, 2008

HAHN, H., Model Based Control of a Parallel Robot - A comparison of Controls Algorithms. Proceedings in Applied Mathematics and Mechanics, v. 2, pp. 124127, 2003

HESS-COELHO, T. A., An alternative procedure for type synthesis of parallel mechanisms, In: IFToMM WORLD CONGRESS, 2007, Besançon. Proceedings... Besançon: IFToMM, 2007

HESSElBACH, J., PIETSCH, I. T., BIER, C. C., BECKER, O. T., Model-based control of plane parallel robots - how to choose the appropriate approach, Parallel kinematic machines in research and practice, v. 24, pp. 211-232, 2004

HUNT, K. H., Don't Cross-Thread the Screw!, Journal of Robotic Systems, v. 20, n. 7, pp. 317-339, 2003

HUSTY, M., L., An algorithm for solving the direct kinematics of general StewartGough platforms, Mechanism and Machine Theory, v. 31, n. 4, pp. 365-380, 1996

IDER, S. K., KORKMAZ, O., Trajectory tracking control of parallel robots in the presence of joint drive flexibility, Journal of Sound and Vibration, v. 319, pp. 77-90, 2009 
JAZAR, R. N., Theory of Applied Robotics: Kinematics, Dynamics, and Control. Springer, 2010

KHALIL, W., DOMBRE, Modeling Identification and Control of Robots. Taylor \& Francis, 2002.

KIM, H. S., TSAI, L. W., Design Optimization of a Cartesian Parallel Manipulator. In: ASME DETC CONFERENCE, 2002, Montreal. Proceedings... Montreal: ASME, 2002

KONG, X., GOSSELIN, C., Forward displacement analysis of a quadratic 4-DOF 3T1R parallel manipulator, Meccanica, v. 46, pp. 147-154, 2011

KUMAZAWA, D. V., HESS-COELHO, T. A., RINALDI, D., CARBONE, G., CECCARELLI, M., Kinematic Analysis and Operation Feasibility of a 3-DOF Asymmetric Parallel Mechanism. In: COBEM - INTERNATIONAL CONGRESS OF MECHANICAL ENGINEERING, 2009, Gramado. Proceedings... Porto Alegre: UFRGS, 2009

LARA-MOLINA, F. A., Simulação e Implementação Experimental de um Controlador Preditivo Generalizado para um Robô Orgthoglide baseado na Modelagem Dinâmica. 2012. 170 f. Tese (Doutorado em Engenharia Mecânica) Faculdade de Engenharia Mecânica, Universidade Estadual de Campinas, Campinas, 2012

LI, Y., XU, Q., Dynamic modeling and robust control of a 3-PRC translational parallel kinematic machine, Robotics and Computer-Integrated Manufacturing, v. 25, 2009

MEIROVITCH, L., Methods of Analytical Dynamics. Dover Publications, 2003 
MOHAMED, M. G., DUFFY, J., A Direct Determination of the Instantaneous Kinematics of Fully Parallel Robot Manipulators, Journal of Mechanism Transmissions and Automation, v. 107(2), pp. 226-229, 1985

NEVES, L. C., PAIM, G. V., QUEINNEC, I., MORENO, U. F., PIERI, E. R., Passivity and Power Based Control of a Robot with Parallel Architecture. In: IFAC WORLD CONGRESS, 2011, Milano. Proceedings... Milano: IFAC, 2011

PACCOT, F., ANDREFF, N., MARTINET, P., A Review on the Dynamic Control of Parallel Kinematic Machines: Theory and Experiments, The International Journal of Robotics Research, v. 28, pp. 395-416, 2009

PIERROT, F., COMPANY, O., H4: A new family of 4-dof parallel robots. In: IEEE/ASME INTERNATIONAL CONFERENCE ON ADVANCED INTELLIGENT MECHATRONICS, 1999, Atlanta. Proceedings... Atlanta: IEEE, 1999

PIERROT, F., NABAT, V., COMPANY, O., KRUT, S., POIGNET, P., Optimal Design of a 4-dof Parallel Manipulator: From Academia to Industry, IEEE Transactions on Robotics, vol.25, no. 2, Apr 2009

SICILIANO, B., SCIAVICCO, L., VILLANI, L., ORIOLO, G., Robotics: Modeling, planning and control. Springer, 2009

SHANG, W., CONG, S., Nonlinear computed torque control for a high-speed planar parallel manipulator, Mechatronics, vol.19, pp. 987-992, 2009

SHIAU, T.N., TSAI, Y.J., TSAI, M.S., Nonlinear dynamic analysis of a parallel mechanism with consideration of joint effects, Mechanism and Machine Theory, Vol.43 (4), pp. 491-505, 2007

SLOTINE, J.J.E., LI, W., Applied nonlinear control. Upper Saddle River: PrenticeHall, 1991 
SOKOLOV, A., XIROUCHAKIS, P., Dynamic analysis of a 3-DOF parallel manipulator with R-P-S joint structure, Mechanism and Machine Theory, v. 42, 2007

SONNENHOF HOLDINGS, Tutorials and Reference Guide - LISA Finite Element Analysis Sofware Version 8.0.0, 2013. Disponível em: <http://lisafea.com/tutorials/>. Acesso em: $31 \mathrm{Jul} 2013$

SPONG, M. W., HUTCHINSON, S., VIDYASAGAR, M., Robot Modeling and Control. John Wiley \& Sons, 2005.

STAICU, S., Dynamics analysis of the Star parallel manipulator, Robotics and Autonomous Systems, v. 57, n.11, pp. 1057-1064, 2009

STEWART, D., A Platform with Six Degrees of Freedom, Proceedings of the Institution of Mechanical Engineers, v. 180, n. 15, pp. 371-386, 1965

TSAI, L. W., Robot Analysis: The Mechanics of Serial and Parallel Manipulators. John Wiley \& Sons, 1999

VIVAS, A., POIGNET, P., Predictive functional control of a parallel robot, Control Engineering Practice, v. 13, pp. 863-874, 2005

WANG, H., XIE, Y., Adaptive inverse dynamics control of robots with uncertain kinematics and dynamics, Automatica, v. 45, pp. 2114-2119, 2009

WANG, J., WU, J., WANG, L., LI, T., Simplified strategy of the dynamic model of a 6UPS parallel kinematic machine for real-time control, Mechanism and Machine Theory, v. 42, 2007

WANG, J., WU, J., WANG, L., YOU, Z., Dynamic feed-forward control of a parallel kinematic machine, Mechatronics, v. 19, pp. 313-324, 2009

YANG, C., HUANG, Q., JIANG, H., PETER, O., HAN, J., PD control with gravity compensation for hydraulic 6-DOF parallel manipulator, Mechanism and Machine Theory, v. 45, pp. 666-677, 2010 
YEN, P., LAI, C., Dynamic modeling and control of a 3-DOF Cartesian parallel manipulator, Mechatronics, v. 19, pp. 390-398, 2009

ZHU, Z., LI, J., GAN, Z., ZHANG, H., Kinematic and dynamic modeling for real-time control of Tau parallel robot, Mechanism and Machine Theory, v. 40, 2005

ZUBizarReta, A., CABANES, I., MARCOS M., PINTO, C., Control of parallel robots using passive sensor data. In: IEEE/RSJ INTERNATIONAL CONFERENCE ON INTELLIGENT ROBOTS AND SYSTEMS, 2008, Nice. Proceedings... Nice: IEEE, 2008

ZUBIZARRETA, A., MARCOS M., CABANES, I., PINTO, C., A procedure to evaluate Extended Computed Torque Control configurations in the Stewart-Gough platform, Robotics and Autonomous Systems, v. 59, pp. 770-781, 2011

ZUBizARRetA, A., MARCOS M., CABANES, I., PINTO, C., PORTILlO, E., Redundant sensor based control of the 3RRR parallel robot, Mechanism and Machine Theory, v. 54, pp. 1-17, 2012

ZUBIZARRETA, A., CABANES, I., MARCOS M., PINTO, C., A redundant dynamic model of parallel robots for model-based control, Robotica, v. 31, pp. 203-216, 2013 


\section{APÊNDICE A - DESENVOLVIMENTO DE EQUAÇÕES DE CINEMÁTICA INVERSA}

Desenvolvendo-se as potências da equação 3.3, encontra-se:

$$
\left\{\begin{array}{c}
q_{1}=x_{1} \\
-2 x_{3} a_{1} \operatorname{sen}_{2}+2\left(x_{2}-l+L\right) a_{1} \cos q_{2}+x_{1}^{2}+\left(x_{2}-l+L\right)^{2}+x_{3}^{2}+a_{1}^{2}-a_{2}^{2}=0 \\
2 x_{3} a_{1} \operatorname{sen}_{3}-2\left(x_{2}+l-L\right) a_{1} \cos q_{3}+x_{1}^{2}+\left(x_{2}+l-L\right)^{2}+x_{3}^{2}+a_{1}^{2}-a_{2}^{2}=0
\end{array}\right.
$$

Definindo-se:

$$
\begin{gathered}
k_{21}=-2 x_{3} a_{1} \\
k_{22}=2\left(x_{2}-l+L\right) a_{1} \\
k_{23}=x_{1}^{2}+\left(x_{2}-l+L\right)^{2}+x_{3}^{2}+a_{1}^{2}-a_{2}^{2} \\
k_{31}=-2 x_{3} a_{1} \\
k_{32}=-2\left(x_{2}+l-L\right) a_{1} \\
k_{33}=x_{1}^{2}+\left(x_{2}+l-L\right)^{2}+x_{3}^{2}+a_{1}^{2}-a_{2}^{2}
\end{gathered}
$$

a equação A.1 pode ser reescrita da seguinte maneira:

$$
\left\{\begin{array}{c}
q_{1}=x_{1} \\
k_{21} \operatorname{sen}_{2}+k_{22} \cos q_{2}+k_{23}=0 \\
k_{31} \operatorname{sen}_{3}+k_{32} \cos q_{3}+k_{33}=0
\end{array}\right.
$$

Note que o sistema algébrico está desacoplado. Assim o isolamento das incógnitas $q_{2}$ e $q_{3}$ pode ser feito separadamente. Utilizando as relações trigonométricas das equações A.9 e A.10, encontra-se uma equação de segundo grau em relação a $\operatorname{tg}\left(q_{2} / 2\right)$, conforme indica a equação A.11. 


$$
\begin{gathered}
\operatorname{sen}\left(q_{2}\right)=\frac{2 \operatorname{tg}\left(\frac{q_{2}}{2}\right)}{1+\operatorname{tg}^{2}\left(\frac{q_{2}}{2}\right)} \\
\cos \left(q_{2}\right)=\frac{1-\operatorname{tg}^{2}\left(\frac{q_{2}}{2}\right)}{1+\operatorname{tg}^{2}\left(\frac{q_{2}}{2}\right)} \\
\left(k_{23}-k_{22}\right) \operatorname{tg}^{2}\left(\frac{q_{2}}{2}\right)+2 k_{21} \operatorname{tg}\left(\frac{q_{2}}{2}\right)+\left(k_{22}+k_{23}\right)=0
\end{gathered}
$$

Resolvendo a equação de segundo grau e isolando $q_{2}$, encontra-se:

$$
q_{2}=2 \operatorname{arctg}\left(\frac{-k_{21} \pm \sqrt{k_{21}^{2}+k_{22}^{2}-k_{23}^{2}}}{\left(k_{23}-k_{22}\right)}\right)
$$

De forma análoga, o isolamento de $q_{3}$ resulta em:

$$
q_{3}=2 \operatorname{arctg}\left(\frac{-k_{31} \pm \sqrt{k_{31}^{2}+k_{32}^{2}-k_{33}^{2}}}{\left(k_{33}-k_{32}\right)}\right)
$$




\section{APÊNDICE B - DESENVOLVIMENTO DE EQUAÇÕES DE CINEMÁTICA DIRETA}

Especificamente para o mecanismo em análise, definindo-se:

$$
\begin{gathered}
k_{1}=q_{1}^{2}-a_{2}^{2} \\
k_{2}=-l+l+a_{1} \cos q_{2} \\
k_{3}=l-L-a_{1} \cos q_{3} \\
k_{4}=-a_{1} \operatorname{sen} q_{2} \\
k_{5}=-a_{1} \operatorname{sen} q_{3}
\end{gathered}
$$

a Equação 3.3 pode ser reescrita da seguinte maneira:

$$
\left\{\begin{array}{c}
x_{1}=q_{1} \\
\left(x_{2}+k_{2}\right)^{2}+\left(x_{3}+k_{4}\right)^{2}+k_{1}=0 \\
\left(x_{2}+k_{3}\right)^{2}+\left(x_{3}+k_{5}\right)^{2}+k_{1}=0
\end{array}\right.
$$

Desenvolvendo-se as potências da equação B.6, encontra-se:

$$
\left\{\begin{array}{c}
x_{1}=q_{1} \\
x_{2}^{2}+2 x_{2} k_{2}+k_{2}^{2}+x_{3}^{2}+2 x_{3} k_{4}+k_{4}^{2}+k_{1}=0 \\
x_{2}^{2}+2 x_{2} k_{3}+k_{3}^{2}+x_{3}^{2}+2 x_{3} k_{5}+k_{5}^{2}+k_{1}=0
\end{array}\right.
$$

Fazendo-se a subtração da segunda equação pela terceira equação do sistema, isola-se $x_{2}$ :

$$
x_{2}=c_{1}+c_{2} x_{3}
$$

em que,

$$
c_{1}=-\frac{\left(k_{2}^{2}+k_{4}^{2}+k_{1}-k_{3}^{2}-k_{5}^{2}-k_{1}\right)}{2\left(k_{2}-k_{3}\right)}
$$




$$
c_{2}=-\frac{\left(k_{4}-k_{5}\right)}{\left(k_{2}-k_{3}\right)}
$$

Substituindo a equação B.8 na segunda equação do sistema de equações B.7, encontra-se:

$$
\left(c_{2}+1\right) x_{3}^{2}+\left(2 c_{1} c_{2}+2 c_{2} k_{2}+2 k_{4}\right) x_{3}+\left(c_{1}^{2}+2 c_{1} k_{2}+k_{2}^{2}+k_{4}^{2}+k_{1}\right)=0
$$

Assim, encontra-se $x_{3}$ por solução de equação de segundo grau B.11 e calcula-se, em seguida, $x_{2}$ em função de $x_{3}$ utilizando-se a equação B.8. 
APÊNDICE C - DESENVOLVIMENTO DE EQUAÇÕES CINEMÁTICAS UTILIZADAS NA APLICAÇÃO DO PRINCÍPIO DOS TRABALHOS VIRTUAIS

Pelas restrições cinemáticas do mecanismo, encontram-se, geometricamente, as equações C.1 a C.8.

$$
\begin{gathered}
x_{C 2}=-a_{1} \cos q_{2} \\
x_{C 3}=a_{1} \operatorname{sen} q_{2} \\
x_{D 2}=a_{1} \cos q_{3} \\
x_{D 3}=a_{1} \operatorname{sen} q_{3} \\
x_{H 1}=x_{1} \\
x_{I 1}=x_{1} \\
x_{I 2}=x_{2} \\
x_{I 3}=\sqrt{a_{5}^{2}-x_{2}^{2}}
\end{gathered}
$$

Derivando-se as equações C.1 a C.8 em relação ao tempo, encontram-se as equações C.9 a C.16.

$$
\begin{gathered}
\dot{x}_{C 2}=a_{1} \dot{q}_{2} \operatorname{sen} q_{2} \\
\dot{x}_{C 3}=a_{1} \dot{q}_{2} \cos q_{2} \\
\dot{x}_{D 2}=-a_{1} \dot{q}_{3} \operatorname{sen} q_{3} \\
\dot{x}_{D 3}=a_{1} \dot{q}_{3} \cos q_{3}
\end{gathered}
$$




$$
\begin{gathered}
\dot{x}_{H 1}=\dot{x}_{1} \\
\dot{x}_{I 1}=\dot{x}_{1} \\
\dot{x}_{I 2}=\dot{x}_{2} \\
\dot{x}_{I 3}=\frac{-x_{2}}{\sqrt{a_{5}^{2}-x_{2}^{2}}} \dot{x}_{2}
\end{gathered}
$$

A partir das equações C.9 a C.16, conclui-se:

$$
\begin{gathered}
\delta y_{C 2}=a_{1} \operatorname{sen} q_{2} \delta q_{2} \\
\delta x_{C 3}=a_{1} \cos q_{2} \delta q_{2} \\
\delta x_{D 2}=-a_{1} \operatorname{sen} q_{3} \delta q_{3} \\
\delta x_{D 3}=a_{1} \cos q_{3} \delta q_{3} \\
\delta x_{H 1}=\delta x_{1} \\
\delta x_{I 1}=\delta x_{1} \\
\delta x_{I 2}=\delta x_{2} \\
\delta x_{I 3}=\frac{-x_{2}}{\sqrt{a_{5}^{2}-x_{2}^{2}}} \delta x_{2}
\end{gathered}
$$

Derivando-se as equações C.9 a C.16 em relação ao tempo, encontram-se as expressões de acelerações de pontos de interesse do mecanismo em função das acelerações nas coordenadas dos atuadores e do efetuador, apresentadas nas equações C.25 a C.32. 


$$
\begin{aligned}
& \ddot{x}_{C 2}=a_{1} \ddot{q}_{2} \operatorname{sen} q_{2}+a_{1} \dot{q}_{2}^{2} \cos q_{2} \\
& \ddot{x}_{C 3}=a_{1} \ddot{q}_{2} \cos q_{2}-a_{1} \dot{q}_{2}^{2} \operatorname{sen} q_{2} \\
& \ddot{x}_{D 2}=-a_{1} \ddot{q}_{3} \operatorname{sen}_{3}-a_{1} \dot{q}_{3}^{2} \cos q_{3} \\
& \ddot{x}_{D 3}=a_{1} \ddot{q}_{3} \cos q_{3}-a_{1} \dot{q}_{3}^{2} \operatorname{sen} q_{3} \\
& \ddot{x}_{H 1}=\ddot{x}_{1} \\
& \ddot{x}_{I 1}=\ddot{x}_{1} \\
& \ddot{x}_{I 2}=\ddot{x}_{2} \\
& \ddot{x}_{I 3}=-\left(\frac{\dot{x}_{2}^{2}+x_{2} \ddot{x}_{2}}{\sqrt{a_{5}^{2}-x_{2}^{2}}}+\left(x_{2} \dot{x}_{2}\right)^{2}\left(a_{5}^{2}-x_{2}^{2}\right)^{-3 / 2}\right)
\end{aligned}
$$




\section{APÊNDICE D - DESENVOLVIMENTO DE EQUACIONAMENTO DINÂMICO PELO MÉTODO DE LAGRANGE}

Conforme explicado na seção 4.1.3, os coeficientes $a_{l k}$, definidos na equação 4.20, são obtidos pela derivação das equações vinculares (equação 3.3).

Primeiro vínculo:

$$
\begin{gathered}
g_{1}=x_{1}-q_{1}=0 \\
\frac{\partial g_{1}}{\partial q_{1}}=-1 \\
\frac{\partial g_{1}}{\partial x_{1}}=1
\end{gathered}
$$

Segundo vínculo:

$$
\begin{gathered}
g_{2}=x_{1}^{2}+\left(x_{2}-l+L+a_{1} \cos q_{2}\right)^{2}+\left(x_{3}-a_{1} \operatorname{sen}_{2}\right)^{2}-a_{2}^{2}=0 \\
\frac{\partial g_{2}}{\partial q_{2}}=-2\left(x_{2}-l+L+a_{1} \cos q_{2}\right) a_{1} \operatorname{sen}_{2}-2\left(x_{3}-a_{1} \operatorname{sen} q_{2}\right) a_{1} \cos q_{2} \\
\frac{\partial g_{2}}{\partial x_{1}}=2 x_{1} \\
\frac{\partial g_{2}}{\partial x_{2}}=2\left(x_{2}-l+L+a_{1} \cos q_{2}\right) \\
\frac{\partial g_{2}}{\partial x_{3}}=2\left(x_{3}-a_{1} \operatorname{sen} q_{2}\right)
\end{gathered}
$$

Terceiro vínculo:

$$
\begin{gathered}
g_{3}=x_{1}^{2}+\left(x_{2}+l-L-a_{1} \cos q_{3}\right)^{2}+\left(x_{3}-a_{1} \operatorname{sen}_{3}\right)^{2}-a_{2}^{2}=0 \\
\frac{\partial g_{3}}{\partial q_{3}}=2\left(x_{2}+l-L-a_{1} \cos q_{3}\right) a_{1} \operatorname{sen}_{3}-2\left(x_{3}-a_{1} \operatorname{sen}_{3}\right) a_{1} \cos _{3}
\end{gathered}
$$




$$
\begin{gathered}
\frac{\partial g_{3}}{\partial x_{1}}=2 x_{1} \\
\frac{\partial g_{3}}{\partial x_{2}}=2\left(x_{2}+l-L-a_{1} \cos q_{3}\right) \\
\frac{\partial g_{3}}{\partial x_{3}}=2\left(x_{3}-a_{1} \operatorname{senq}_{3}\right)
\end{gathered}
$$

As derivadas parciais das energias cinética e potencial resultam em:

$$
\begin{aligned}
& \frac{\partial T}{\partial q_{1}}=\frac{\partial T}{\partial q_{2}}=\frac{\partial T}{\partial q_{3}}=\frac{\partial T}{\partial x_{1}}=\frac{\partial T}{\partial x_{3}}=0 \\
& \frac{\partial T}{\partial x_{2}}=-\frac{1}{2}\left(2 m_{5 e}+m_{6}\right) a_{5}^{2}\left(a_{5}^{2}-x_{2}^{2}\right)^{-2}\left(-2 x_{2}\right) \dot{x}_{2}^{2} \\
& \frac{\partial T}{\partial \dot{q}_{1}}=0 \\
& \frac{\partial T}{\partial \dot{q}_{2}}=\left(m_{1 e}+m_{2 e}\right) a_{1}^{2} \dot{q}_{2} \\
& \frac{\partial T}{\partial \dot{q}_{3}}=\left(m_{1 e}+m_{2 e}\right) a_{1}^{2} \dot{q}_{3} \\
& \frac{\partial T}{\partial \dot{x}_{1}}=\left(2 m_{2 e}+m_{3}+M+m_{4}+2 m_{5 e}+m_{6}\right) \dot{x}_{1} \\
& \frac{\partial T}{\partial \dot{x}_{2}}=\left(2 m_{2 e}+m_{3}+M\right) \dot{x}_{2}+\left(2 m_{5 e}+m_{6}\right)\left(\frac{a_{5}^{2}}{a_{5}^{2}-x_{2}^{2}}\right) \dot{x}_{2} \\
& \frac{\partial T}{\partial \dot{x}_{3}}=\left(2 m_{2 e}+m_{3}+M\right) \dot{x}_{3} \\
& \frac{d}{d t}\left(\frac{\partial T}{\partial \dot{q}_{2}}\right)=\left(m_{1 e}+m_{2 e}\right) a_{1}^{2} \ddot{q}_{2} \\
& \frac{d}{d t}\left(\frac{\partial T}{\partial \dot{q}_{3}}\right)=\left(m_{1 e}+m_{2 e}\right) a_{1}^{2} \ddot{q}_{3}
\end{aligned}
$$




$$
\begin{gathered}
\frac{d}{d t}\left(\frac{\partial T}{\partial \dot{x}_{1}}\right)=\left(2 m_{2 e}+m_{3}+M+m_{4}+2 m_{5 e}+m_{6}\right) \ddot{x}_{1} \\
\frac{d}{d t}\left(\frac{\partial T}{\partial \dot{x}_{2}}\right)=\left(2 m_{2 e}+m_{3}+M\right) \ddot{x}_{2}+\frac{2\left(2 m_{5 e}+m_{6}\right) a_{5}^{2}}{a_{5}^{2}-x_{2}^{2}} x_{2} \dot{x}_{2}^{2}+\left(2 m_{5 e}+m_{6}\right)\left(\frac{a_{5}^{2}}{a_{5}^{2}-x_{2}^{2}}\right) \ddot{x}_{2}
\end{gathered}
$$

$$
\frac{d}{d t}\left(\frac{\partial T}{\partial \dot{x}_{3}}\right)=\left(2 m_{2 e}+m_{3}+M\right) \ddot{x}_{3}
$$

$$
\frac{\partial V}{\partial q_{1}}=\frac{\partial V}{\partial x_{1}}=0
$$

$$
\frac{\partial V}{\partial q_{2}}=-\left(m_{1 e}+m_{2 e}\right) g a_{1} \cos q_{2}
$$

$$
\frac{\partial V}{\partial q_{3}}=-\left(m_{1 e}+m_{2 e}\right) g a_{1} \cos q_{3}
$$

$$
\begin{gathered}
\frac{\partial V}{\partial x_{2}}=\frac{\left(2 m_{5 e}+m_{6}\right) g x_{2}}{\sqrt{a_{5}^{2}-x_{2}^{2}}} \\
\frac{\partial V}{\partial x_{3}}=-\left(2 m_{2 e}+m_{3}+M\right) g
\end{gathered}
$$




\section{APÊNDICE E - EQUACIONAMENTO DE MATRIZES DE ROTAÇÃO ENTRE SISTEMA GLOBAL E SISTEMAS MÓVEIS}

Foi utilizado um método de duas rotações consecutivas para descrição da orientação das barras CE e FD no espaço (TSAI, 1999). A Figura E.1 ilustra o caso da barra $\mathrm{CE}$, em que algumas peças do mecanismo foram omitidas para simplificar o diagrama.

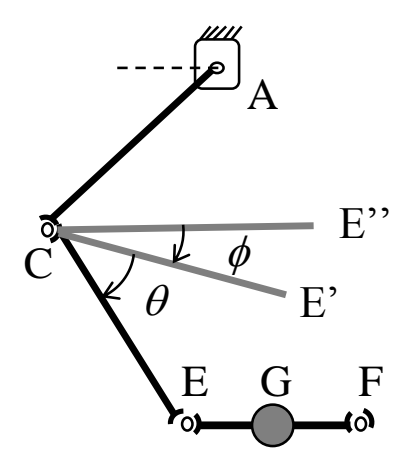

Figura E.1 - Ângulos $\boldsymbol{\phi}$ e $\boldsymbol{\theta}$ utilizados para descrição da orientação da barra CE

Para uma dada posição $C$ de uma extremidade da barra CE, o ponto E" representa a posição inicial da outra extremidade da barra CE numa orientação de referência, horizontal e contida no plano formado pelos eixos $x_{2}$ e $x_{3}$. Após uma primeira rotação de um ângulo $\phi$ em torno de um eixo vertical que passa por $C$, encontra-se uma posição intermediária da barra $\mathrm{CE}$, com uma das extremidades representada por E'. Com uma segunda rotação, de um ângulo $\theta$ em torno de um eixo que passa por $C$ e é normal ao plano vertical que contém CE', chega-se a orientação final da barra no espaço, descrita pelos ângulos $\phi$ e $\theta$.

A matriz de rotação de um sistema coordenado móvel, solidário à barra, para o sistema global fixo, baseada nos ângulos $\phi$ e $\theta$, pode ser obtida pela equação E.1 (TSAI, 1999).

$$
R=\left[\begin{array}{ccc}
\cos \phi & -\operatorname{sen} \phi \cos \theta & \operatorname{sen} \phi \operatorname{sen} \theta \\
\operatorname{sen} \phi & \cos \phi \cos \theta & -\cos \phi \operatorname{sen} \theta \\
0 & \operatorname{sen} \theta & \cos \theta
\end{array}\right]
$$

Utilizando-se relações trigonométricas, pode-se obter $\phi$ e $\theta$ em função das coordenadas dos atuadores e do efetuador $\boldsymbol{q}$ e $\boldsymbol{x}$. 
Para a barra CE,

$$
\begin{aligned}
& \operatorname{sen} \psi=\frac{x_{3}-a_{1} \operatorname{sen} q_{2}}{a_{2}} \\
& \operatorname{sen} \phi=-\frac{x_{1}}{a_{2} \cos \psi}
\end{aligned}
$$

Para a barra DF,

$$
\begin{gathered}
\operatorname{sen} \psi=-\frac{\left(x_{3}-a_{1} \operatorname{sen} q_{3}\right)}{a_{2}} \\
\operatorname{sen} \phi=\frac{x_{1}}{a_{2} \cos \psi}
\end{gathered}
$$

Assim, as matrizes de rotação dos sistemas solidários às barras CE e DF podem ser calculadas a partir das coordenas utilizadas na modelagem cinemática do robô em estudo. 


\section{APÊNDICE F - TABELAS COM IDENTIFICAÇÃO DE TERMOS DINÂMICOS E CLASSIFICAÇÃO DE TERMOS PREDOMINANTES}

A seguir são apresentadas as tabelas com a identificação dos termos dinâmicos das expressões de cálculos dos esforços nos atuadores e suas classificações em predominância, conforme apresentado na seção 5.3 .

Tabela F.1 - Identificação dos termos dinâmicos do cálculo de $\tau_{1}$

\begin{tabular}{|c|c|c|}
\hline $\begin{array}{l}\text { Número de } \\
\text { identificação } \\
\text { do termo }\end{array}$ & Expressão matemática & Natureza \\
\hline 1 & $\left(\frac{m_{2}}{4}+m_{3}+m_{4}+2 m_{5}+m_{6}+M\right) \ddot{q}_{1}$ & Inercial \\
\hline 2 & $\frac{m_{2} a_{1}}{4}\left(\ddot{q}_{2} \sin q_{2}\right) J_{x q 21}$ & Inercial \\
\hline 3 & $\frac{m_{2} a_{1}}{4}\left(\dot{q}_{2}^{2} \cos q_{2}\right) J_{x q 21}$ & Inercial, centrípeto \\
\hline 4 & $\frac{m_{2} a_{1}}{4}\left(-\ddot{q}_{3} \operatorname{sen}_{3}\right) J_{x q 21}$ & Inercial \\
\hline 5 & $\frac{m_{2} a_{1}}{4}\left(-\dot{q}_{3}^{2} \cos q_{3}\right) J_{x q 21}$ & Inercial, centrípeto \\
\hline 6 & $\left(\frac{m_{2}}{2}+m_{3}+\frac{m_{5}}{2}+m_{6}+M\right) \ddot{x}_{2} J_{x q 21}$ & Inercial \\
\hline 7 & $\left(\frac{m_{5}}{2}+m_{6}\right) \dot{x}_{2}^{2}\left(a_{5}^{2}-x_{2}^{2}\right)^{-1 / 2} x_{2}\left(a_{5}^{2}-x_{2}^{2}\right)^{-1 / 2} J_{x q 21}$ & Coriolis \\
\hline 8 & $\left(\frac{m_{5}}{2}+m_{6}\right) x_{2} \ddot{x}_{2}\left(a_{5}^{2}-x_{2}^{2}\right)^{-1 / 2} x_{2}\left(a_{5}^{2}-x_{2}^{2}\right)^{-1 / 2} J_{x q 21}$ & Inercial \\
\hline 9 & $\left(\frac{m_{5}}{2}+m_{6}\right)\left(x_{2} \dot{x}_{2}\right)^{2}\left(a_{5}^{2}-x_{2}^{2}\right)^{-3 / 2} x_{2}\left(a_{5}^{2}-x_{2}^{2}\right)^{-1 / 2} J_{x q 21}$ & Coriolis \\
\hline 10 & $\left(m_{5}+m_{6}\right) g x_{2}\left(a_{5}^{2}-x_{2}^{2}\right)^{-1 / 2} J_{x q 21}$ & Gravitacional \\
\hline 11 & $\frac{m_{2} a_{1}}{4}\left(\ddot{q}_{2} \cos q_{2}\right) J_{x q 31}$ & Inercial \\
\hline 12 & $\frac{m_{2} a_{1}}{4}\left(-\dot{q}_{2}^{2} \sin q_{2}\right) J_{x q 31}$ & Inercial, centrípeto \\
\hline 13 & $\frac{m_{2} a_{1}}{4}\left(\ddot{q}_{3} \cos q_{3}\right) J_{x q 31}$ & Inercial \\
\hline 14 & $\frac{m_{2} a_{1}}{4}\left(-\dot{q}_{3}^{2} \sin q_{3}\right) J_{x q 31}$ & Inercial, centrípeto \\
\hline 15 & $\left(\frac{m_{2}}{2}+m_{3}+M\right) \ddot{x}_{3} J_{x q 31}$ & Inercial \\
\hline
\end{tabular}




\begin{tabular}{|c|c|c|}
\hline 16 & $-\left(m_{2}+m_{3}+M\right) g J_{x q 31}$ & Gravitacional \\
\hline 17 & {$\left[\left(J_{\omega q}+J_{\omega x} J_{x}^{-1} J_{q}\right)^{T}\left(-\boldsymbol{I}_{C E} \dot{\boldsymbol{\omega}}_{C E}-\boldsymbol{\omega}_{C E} \wedge\left(\boldsymbol{I}_{C E} \boldsymbol{\omega}_{C E}\right)\right)\right]\left[\begin{array}{ll}1 & 0\end{array}\right]^{T}$} & Inercial \\
\hline 18 & {$\left[\left(J_{\omega q}+J_{\omega x} J_{x}^{-1} J_{q}\right)^{T}\left(-\boldsymbol{I}_{D F} \dot{\boldsymbol{\omega}}_{D F}-\boldsymbol{\omega}_{D F} \wedge\left(\boldsymbol{I}_{D F} \boldsymbol{\omega}_{D F}\right)\right)\right]\left[\begin{array}{lll}1 & 0 & 0\end{array}\right]^{T}$} & Inercial \\
\hline 19 & $-I_{H I x 1} \ddot{\theta}_{H} \frac{1}{a_{5} \sin \theta_{H}} J_{x q 21}$ & Inercial \\
\hline
\end{tabular}

Tabela F.2 - Identificação dos termos dinâmicos do cálculo de $\tau_{2}$

\begin{tabular}{|c|c|c|}
\hline $\begin{array}{l}\text { Número de } \\
\text { identificação } \\
\text { do termo }\end{array}$ & Expressão matemática & Natureza \\
\hline 1 & $\left(m_{1}+m_{2}\right)\left(\frac{a_{1}^{2} \ddot{q}_{2}}{4}\right)$ & Inercial \\
\hline 2 & $\frac{m_{2} a_{1}}{4}\left(\ddot{x}_{2} \sin q_{2}\right)$ & Inercial \\
\hline 3 & $\frac{m_{2} a_{1}}{4}\left(\ddot{x}_{3} \cos q_{2}\right)$ & Inercial \\
\hline 4 & $\left(m_{1}+m_{2}\right)\left(-\frac{g a_{1} \cos q_{2}}{2}\right)$ & Gravitacional \\
\hline 5 & $\frac{m_{2} a_{1}}{4}\left(\ddot{q}_{2} \sin q_{2}\right) J_{x q 22}$ & Inercial \\
\hline 6 & $\frac{m_{2} a_{1}}{4}\left(\dot{q}_{2}^{2} \cos q_{2}\right) J_{x q 22}$ & Inercial, centrípeto \\
\hline 7 & $\frac{m_{2} a_{1}}{4}\left(-\ddot{q}_{3} \operatorname{sen}_{3}\right) J_{x q 22}$ & Inercial \\
\hline 8 & $\frac{m_{2} a_{1}}{4}\left(-\dot{q}_{3}^{2} \cos q_{3}\right) J_{x q 22}$ & Inercial, centrípeto \\
\hline 9 & $\left(\frac{m_{2}}{2}+m_{3}+\frac{m_{5}}{2}+m_{6}+M\right) \ddot{x}_{2} J_{x q 22}$ & Inercial \\
\hline 10 & $\left(\frac{m_{5}}{2}+m_{6}\right) \dot{x}_{2}^{2}\left(a_{5}^{2}-x_{2}^{2}\right)^{-1 / 2} x_{2}\left(a_{5}^{2}-x_{2}^{2}\right)^{-1 / 2} J_{x q 22}$ & Coriolis \\
\hline 11 & $\left(\frac{m_{5}}{2}+m_{6}\right) x_{2} \ddot{x}_{2}\left(a_{5}^{2}-x_{2}^{2}\right)^{-1 / 2} x_{2}\left(a_{5}^{2}-x_{2}^{2}\right)^{-1 / 2} J_{x q 22}$ & Inercial \\
\hline 12 & $\left(\frac{m_{5}}{2}+m_{6}\right)\left(x_{2} \dot{x}_{2}\right)^{2}\left(a_{5}^{2}-x_{2}^{2}\right)^{-3 / 2} x_{2}\left(a_{5}^{2}-x_{2}^{2}\right)^{-1 / 2} J_{x q 22}$ & Coriolis \\
\hline 13 & $\left(m_{5}+m_{6}\right) g x_{2}\left(a_{5}^{2}-x_{2}^{2}\right)^{-1 / 2} J_{x q 22}$ & Gravitacional \\
\hline 14 & $\frac{m_{2} a_{1}}{4}\left(\ddot{q}_{2} \cos q_{2}\right) J_{x q 32}$ & Inercial \\
\hline 15 & $\frac{m_{2} a_{1}}{4}\left(-\dot{q}_{2}^{2} \sin q_{2}\right) J_{x q 32}$ & Inercial, centrípeto \\
\hline
\end{tabular}




\begin{tabular}{|c|c|c|}
\hline 16 & $\frac{m_{2} a_{1}}{4}\left(\ddot{q}_{3} \cos q_{3}\right) J_{x q 32}$ & Inercial \\
\hline 17 & $\frac{m_{2} a_{1}}{4}\left(-\dot{q}_{3}^{2} \sin q_{3}\right) J_{x q 32}$ & Inercial, centrípeto \\
\hline 18 & $\left(\frac{m_{2}}{2}+m_{3}+M\right) \ddot{x}_{3} J_{x q 32}$ & Inercial \\
\hline 19 & $-\left(m_{2}+m_{3}+M\right) g J_{x q 32}$ & Gravitacional \\
\hline 20 & $-I_{A C x 1} \ddot{q}_{2} \delta q_{2}$ & Inercial \\
\hline 21 & {$\left[\left(J_{\omega q}+J_{\omega x} J_{x}^{-1} J_{q}\right)^{T}\left(-\boldsymbol{I}_{C E} \dot{\boldsymbol{\omega}}_{C E}-\boldsymbol{\omega}_{C E} \wedge\left(\boldsymbol{I}_{C E} \boldsymbol{\omega}_{C E}\right)\right)\right]\left[\begin{array}{lll}0 & 1 & 0\end{array}\right]^{T}$} & Inercial \\
\hline 22 & {$\left[\left(J_{\omega q}+J_{\omega x} J_{x}^{-1} J_{q}\right)^{T}\left(-\boldsymbol{I}_{D F} \dot{\boldsymbol{\omega}}_{D F}-\boldsymbol{\omega}_{D F} \wedge\left(\boldsymbol{I}_{D F} \boldsymbol{\omega}_{D F}\right)\right)\right]\left[\begin{array}{lll}0 & 1 & 0\end{array}\right]^{T}$} & Inercial \\
\hline 23 & $-I_{H I x 1} \ddot{\theta}_{H} \frac{1}{a_{5} \sin \theta_{H}} J_{x q 22}$ & Inercial \\
\hline
\end{tabular}

Tabela F.3 - Identificação dos termos dinâmicos do cálculo de $\tau_{3}$

\begin{tabular}{|c|c|c|}
\hline $\begin{array}{l}\text { Número de } \\
\text { identificação } \\
\text { do termo }\end{array}$ & Expressão matemática & Natureza \\
\hline 1 & $\left(m_{1}+m_{2}\right)\left(\frac{a_{1}^{2} \ddot{q}_{3}}{4}\right)$ & Inercial \\
\hline 2 & $\frac{m_{2} a_{1}}{4}\left(-\ddot{x}_{2} \sin q_{3}\right)$ & Inercial \\
\hline 3 & $\frac{m_{2} a_{1}}{4}\left(+\ddot{x}_{3} \cos q_{3}\right)$ & Inercial \\
\hline 4 & $\left(m_{1}+m_{2}\right)\left(-\frac{g a_{1} \cos q_{3}}{2}\right)$ & Gravitacional \\
\hline 5 & $\frac{m_{2} a_{1}}{4}\left(\ddot{q}_{2} \sin q_{2}\right) J_{x q 23}$ & Inercial \\
\hline 6 & $\frac{m_{2} a_{1}}{4}\left(\dot{q}_{2}^{2} \cos q_{2}\right) J_{x q 23}$ & Inercial, centrípeto \\
\hline 7 & $\frac{m_{2} a_{1}}{4}\left(-\ddot{q}_{3} \operatorname{sen}_{3}\right) J_{x q 23}$ & Inercial \\
\hline 8 & $\frac{m_{2} a_{1}}{4}\left(-\dot{q}_{3}^{2} \cos q_{3}\right) J_{x q 23}$ & Inercial, centrípeto \\
\hline 9 & $\left(\frac{m_{2}}{2}+m_{3}+\frac{m_{5}}{2}+m_{6}+M\right) \ddot{x}_{2} J_{x q 23}$ & Inercial \\
\hline 10 & $\left(\frac{m_{5}}{2}+m_{6}\right) \dot{x}_{2}^{2}\left(a_{5}^{2}-x_{2}^{2}\right)^{-1 / 2} x_{2}\left(a_{5}^{2}-x_{2}^{2}\right)^{-1 / 2} J_{x q 23}$ & Coriolis \\
\hline 11 & $\left(\frac{m_{5}}{2}+m_{6}\right) x_{2} \ddot{x}_{2}\left(a_{5}^{2}-x_{2}^{2}\right)^{-1 / 2} x_{2}\left(a_{5}^{2}-x_{2}^{2}\right)^{-1 / 2} J_{x q 23}$ & Inercial \\
\hline
\end{tabular}




\begin{tabular}{|c|c|c|}
\hline 12 & $\left(\frac{m_{5}}{2}+m_{6}\right)\left(x_{2} \dot{x}_{2}\right)^{2}\left(a_{5}^{2}-x_{2}^{2}\right)^{-3 / 2} x_{2}\left(a_{5}^{2}-x_{2}^{2}\right)^{-1 / 2} J_{x q 23}$ & Coriolis \\
\hline 13 & $\left(m_{5}+m_{6}\right) g x_{2}\left(a_{5}^{2}-x_{2}^{2}\right)^{-1 / 2} J_{x q 23}$ & Gravitacional \\
\hline 14 & $\frac{m_{2} a_{1}}{4}\left(\ddot{q}_{2} \cos q_{2}\right) J_{x q 33}$ & Inercial \\
\hline 15 & $\frac{m_{2} a_{1}}{4}\left(-\dot{q}_{2}^{2} \sin q_{2}\right) J_{x q 33}$ & Inercial, centrípeto \\
\hline 16 & $\frac{m_{2} a_{1}}{4}\left(\ddot{q}_{3} \cos q_{3}\right) J_{x q 33}$ & Inercial \\
\hline 17 & $\frac{m_{2} a_{1}}{4}\left(-\dot{q}_{3}^{2} \sin q_{3}\right) J_{x q 33}$ & Inercial, centrípeto \\
\hline 18 & $\left(\frac{m_{2}}{2}+m_{3}+M\right) \ddot{x}_{3} J_{x q 33}$ & Inercial \\
\hline 19 & $-\left(m_{2}+m_{3}+M\right) g J_{x q 33}$ & Gravitacional \\
\hline 20 & $-I_{B D x 1} \ddot{q}_{3} \delta q_{3}$ & Inercial \\
\hline 21 & {$\left[\left(J_{\omega q}+J_{\omega x} J_{x}^{-1} J_{q}\right)^{T}\left(-\boldsymbol{I}_{C E} \dot{\boldsymbol{\omega}}_{C E}-\boldsymbol{\omega}_{C E} \wedge\left(\boldsymbol{I}_{C E} \boldsymbol{\omega}_{C E}\right)\right)\right]\left[\begin{array}{lll}0 & 0 & 1\end{array}\right]^{T}$} & Inercial \\
\hline 22 & {$\left[\left(J_{\omega q}+J_{\omega x} J_{x}^{-1} J_{q}\right)^{T}\left(-\boldsymbol{I}_{D F} \dot{\boldsymbol{\omega}}_{D F}-\boldsymbol{\omega}_{D F} \wedge\left(\boldsymbol{I}_{D F} \boldsymbol{\omega}_{D F}\right)\right)\right]\left[\begin{array}{lll}0 & 0 & 1\end{array}\right]^{T}$} & Inercial \\
\hline 23 & $-I_{H I x 1} \ddot{\theta}_{H} \frac{1}{a_{5} \sin \theta_{H}} J_{x q 23}$ & Inercial \\
\hline
\end{tabular}

Tabela F.4 - Classificação final de termos de cálculo de $\tau_{1}$, altas velocidades e acelerações

\begin{tabular}{|c|c|c|c|c|c|}
\hline $\begin{array}{c}\text { Número de } \\
\text { identificação do } \\
\text { termo de } \tau_{1}\end{array}$ & $\begin{array}{c}\text { Classificação } \\
\text { Inicial }\end{array}$ & $\begin{array}{c}\text { Número do } \\
\text { termo } \\
\text { correspondente } \\
\text { no cálculo de } \\
\tau_{1}\end{array}$ & $\begin{array}{c}\text { Classificação } \\
\text { inicial do termo } \\
\text { correspondente }\end{array}$ & $\begin{array}{c}\text { Média de } \\
\text { Classificações }\end{array}$ & $\begin{array}{c}\text { Classificação } \\
\text { final }\end{array}$ \\
\hline 1 & $1^{\circ}$ & - & - & 1 & $1^{\circ}$ \\
\hline 2 & $15^{\circ}$ & 4 & $16^{\circ}$ & 15,5 & $15^{\circ}$ \\
\hline 3 & $18^{\circ}$ & 5 & $19^{\circ}$ & 18,5 & $18^{\circ}$ \\
\hline 4 & $16^{\circ}$ & 2 & $15^{\circ}$ & 15,5 & $16^{\circ}$ \\
\hline 5 & $19^{\circ}$ & 3 & $18^{\circ}$ & 18,5 & $19^{\circ}$ \\
\hline 6 & $4^{\circ}$ & - & - & 4 & $4^{\circ}$ \\
\hline 7 & $12^{\circ}$ & - & - & 12 & $11^{\circ}$ \\
\hline 8 & $5^{\circ}$ & - & - & 5 & $5^{\circ}$ \\
\hline 9 & $17^{\circ}$ & - & - & 17 & $17^{\circ}$ \\
\hline 10 & $9^{\circ}$ & - & - & 9 & $10^{\circ}$ \\
\hline 11 & $7^{\circ}$ & 13 & $8^{\circ}$ & 7,5 & $6^{\circ}$ \\
\hline 12 & $11^{\circ}$ & 14 & $13^{\circ}$ & 12 & $12^{\circ}$ \\
\hline
\end{tabular}




\begin{tabular}{|c|c|c|c|c|c|}
\hline 13 & $8^{\circ}$ & 11 & $7^{\circ}$ & 7,5 & $7^{\circ}$ \\
\hline 14 & $13^{\circ}$ & 12 & $11^{\circ}$ & 12 & $1^{\circ}$ \\
\hline 15 & $2^{\circ}$ & - & - & 2 & $2^{\circ}$ \\
\hline 16 & $3^{\circ}$ & - & - & 3 & $3^{\circ}$ \\
\hline 17 & $6^{\circ}$ & 18 & $10^{\circ}$ & 8 & $8^{\circ}$ \\
\hline 18 & $10^{\circ}$ & 17 & $6^{\circ}$ & 8 & $9^{\circ}$ \\
\hline 19 & $14^{\circ}$ & - & - & 14 & $14^{\circ}$ \\
\hline
\end{tabular}

Tabela F.5 - Classificação final de termos de cálculo de $\tau_{2}$ e de $\tau_{3}$, altas velocidades e acelerações

\begin{tabular}{|c|c|c|c|c|c|}
\hline $\begin{array}{l}\text { Número de } \\
\text { identificação do } \\
\text { termo de } \tau_{2}\end{array}$ & $\begin{array}{c}\text { Classificação } \\
\text { Inicial }\end{array}$ & $\begin{array}{c}\text { Número do } \\
\text { termo } \\
\text { correspondente } \\
\text { no cálculo de } \\
\tau_{3}\end{array}$ & $\begin{array}{l}\text { Classificação } \\
\text { inicial do termo } \\
\text { correspondente }\end{array}$ & $\begin{array}{c}\text { Média de } \\
\text { Classificações }\end{array}$ & $\begin{array}{c}\text { Classificação } \\
\text { final }\end{array}$ \\
\hline 1 & $6^{\circ}$ & 1 & $7^{\circ}$ & 6,5 & $6^{\circ}$ \\
\hline 2 & $11^{\circ}$ & 2 & $11^{\circ}$ & 11 & $11^{\circ}$ \\
\hline 3 & $9^{\circ}$ & 3 & $9^{\circ}$ & 9 & $9^{\circ}$ \\
\hline 4 & $7^{0}$ & 4 & $6^{0}$ & 6,5 & $7^{0}$ \\
\hline 5 & $13^{\circ}$ & 7 & $13^{\circ}$ & 13 & $13^{\circ}$ \\
\hline 6 & $21^{\circ}$ & 8 & $23^{\circ}$ & 22 & $23^{\circ}$ \\
\hline 7 & $15^{\circ}$ & 5 & $15^{\circ}$ & 15 & $15^{\circ}$ \\
\hline 8 & $20^{\circ}$ & 6 & $22^{\circ}$ & 21 & $22^{\circ}$ \\
\hline 9 & $1^{\circ}$ & 9 & $1^{\circ}$ & 1 & $1^{\circ}$ \\
\hline 10 & $8^{\circ}$ & 10 & $8^{\circ}$ & 8 & $8^{\circ}$ \\
\hline 11 & $4^{\circ}$ & 11 & $4^{\circ}$ & 4 & $4^{\circ}$ \\
\hline 12 & $17^{\circ}$ & 12 & $20^{\circ}$ & 18,5 & $18^{\circ}$ \\
\hline 13 & $5^{0}$ & 13 & $5^{0}$ & 5 & $5^{\circ}$ \\
\hline 14 & $12^{\circ}$ & 16 & $12^{\circ}$ & 12 & $12^{\circ}$ \\
\hline 15 & $19^{\circ}$ & 17 & $21^{\circ}$ & 20 & $20^{\circ}$ \\
\hline 16 & $14^{\circ}$ & 14 & $14^{\circ}$ & 14 & $14^{\circ}$ \\
\hline 17 & $18^{\circ}$ & 15 & $19^{\circ}$ & 18,5 & $17^{\circ}$ \\
\hline 18 & $2^{0}$ & 18 & $2^{0}$ & 2 & $2^{0}$ \\
\hline 19 & $3^{\circ}$ & 19 & $3^{\circ}$ & 3 & $3^{\circ}$ \\
\hline 20 & $23^{\circ}$ & 21 & $18^{\circ}$ & 20,5 & $21^{\circ}$ \\
\hline 21 & $22^{\circ}$ & 20 & $17^{\circ}$ & 19,5 & $19^{\circ}$ \\
\hline 22 & $16^{\circ}$ & 22 & $16^{\circ}$ & 16 & $16^{\circ}$ \\
\hline 23 & $10^{\circ}$ & 23 & $10^{\circ}$ & 10 & $10^{\circ}$ \\
\hline
\end{tabular}




\section{APÊNDICE G - IDENTIFICAÇÃO DE FREQUÊNCIAS NATURAIS ESTRUTURAIS DO MECANISMO 2 RSS + PPaP}

Utilizando-se o software LISA, foram feitos modelos preliminares para o levantamento das frequências naturais estruturais do mecanismo. O efetuador e as barras $\mathrm{AC}$ e $\mathrm{BD}$ foram modeladas com elementos hexaédricos e as barras $\mathrm{CE}$ e DF como elementos de treliça. A utilização dos elementos de treliça inclui, por consequência, o modelo de juntas esféricas entre as barras do mecanismo. $O$ membro central do mecanismo foi suprimido devido à incapacidade de representação da junta prismática nesse pacote de modelagem de elementos finitos. Para que o conjunto restante (sem o membro central) permanecesse isoestático e tivesse similaridade à estrutura original, foram impostas restrições de movimento no efetuador de acordo com o modo de vibração que se desejava caracterizar. A massa do efetuador também foi modificada para compensar a ausência das massas das peças do membro central. Um dos modelos simplificados pode ser observado na Figura G.1.

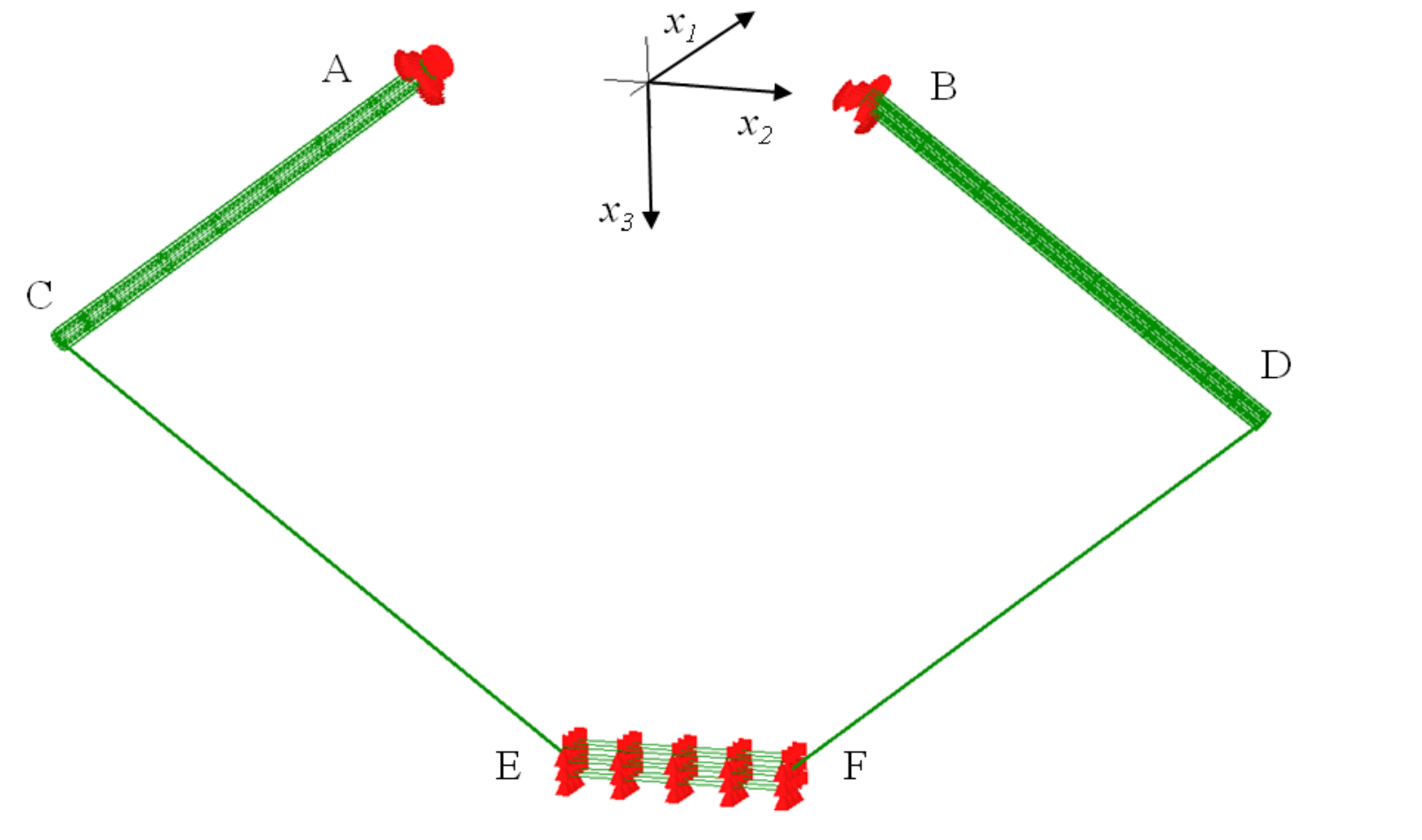

Figura G.1 - Modelo simplificado para determinação de frequências estruturais do mecanismo 
Partindo de uma posição em que o efetuador tivesse coordenadas $x_{1}$ e $x_{2}$ iguais a zero, foi intuído que os modos de vibração de frequências naturais mais baixas do mecanismo corresponderiam à vibração das barras $A C$ e $B D$ em fase e em oposição de fase, com movimentos restritos ao plano formado pelos eixos $x_{2} \mathrm{e}$ $x_{3}$. Com a vibração das barras $A C$ e $B D$ em fase, o efetuador se deslocaria predominantemente na direção $x_{2}$ e deslocaria conjuntamente a posição do centro de massa do membro central. Já em oposição de fase, o efetuador se deslocaria apenas na direção $x_{3}$ e não haveria alteração na posição do centro de massa do membro central. Dessa forma, foram feitas as seguintes simplificações:

- Para vibração em fase: restrição do movimento dos nós do efetuador nas direções $x_{1}$ e $x_{3}$, e adição da massa da barra inferior do paralelogramo articulado e metade das massas das barras laterais do paralelogramo articulado à massa do efetuador;

- Para vibração em oposição de fase: restrição do movimento dos nós do efetuador nas direções $x_{1}$ e $x_{2}$, sem modificações de massas.

Dessa maneira, o mecanismo correspondia a estruturas isoestáticas e foram encontrados os dois modos de vibração ilustrados nas Figuras G.2 e G.3.

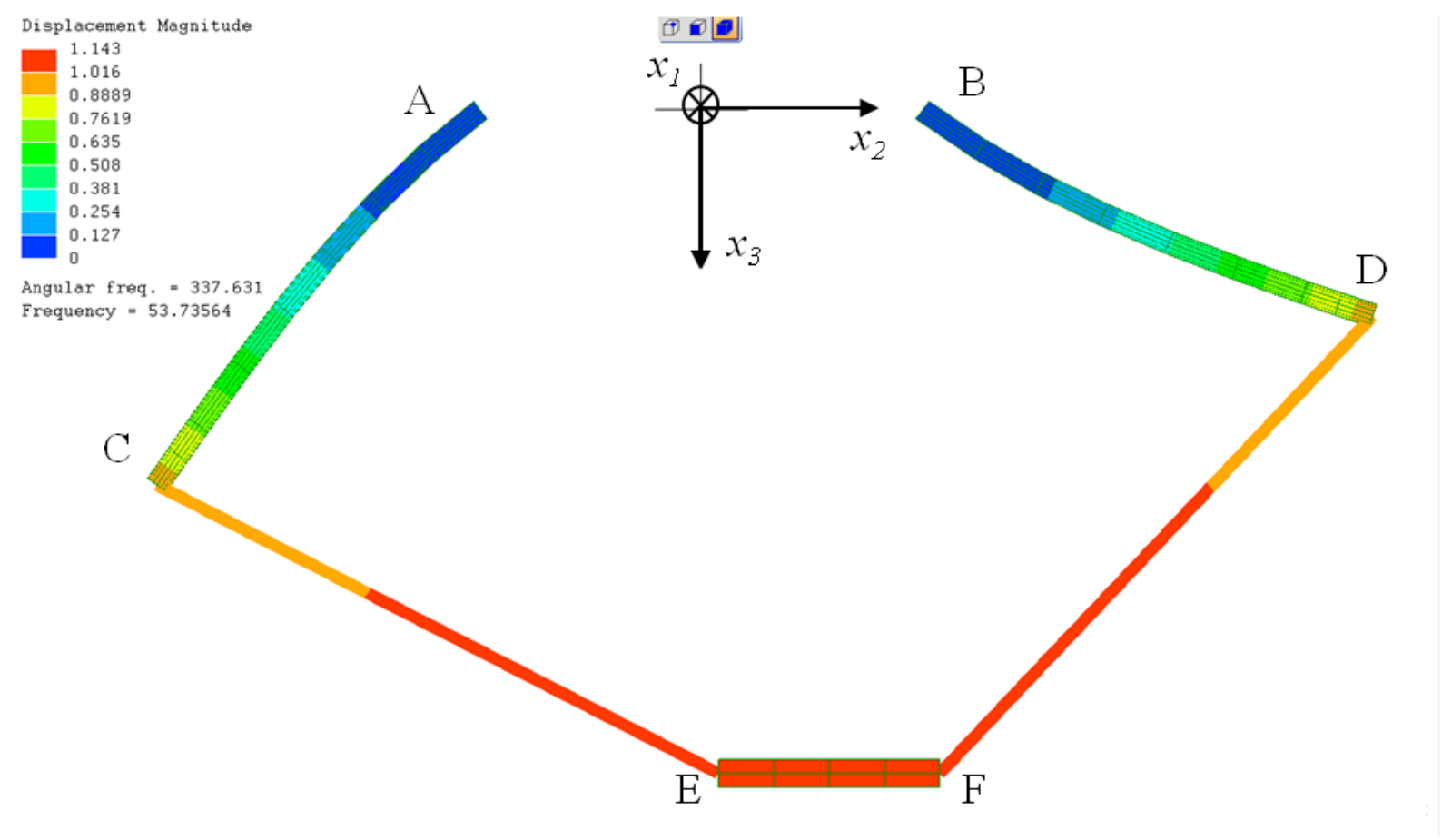

Figura G.2 - Modo de vibração com movimento das barras AC e BD em fase 


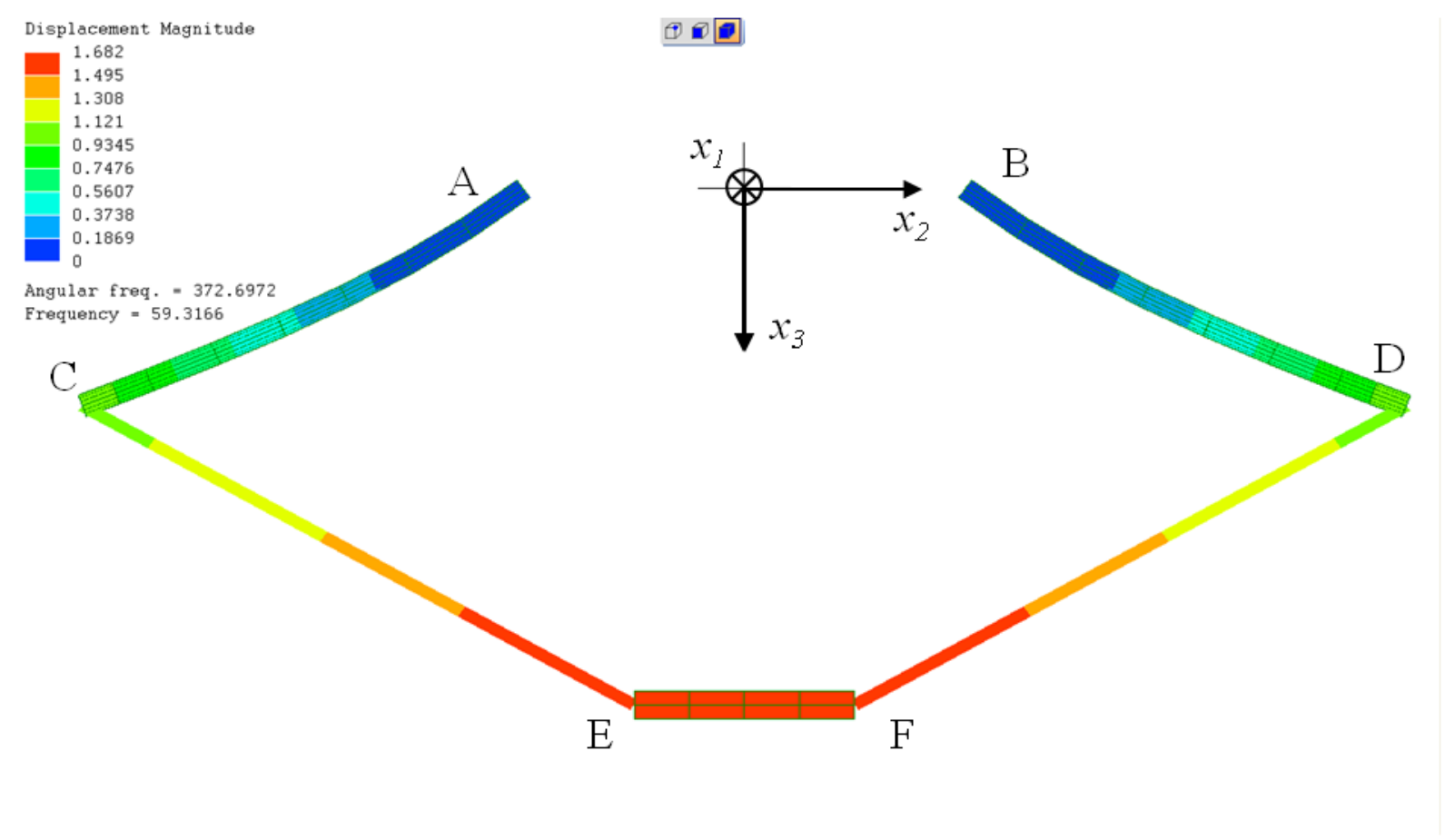

Figura G.3 - Modo de vibração com movimento das barras AC e BD em oposição de fase

Uma vez que as frequências estruturais do mecanismo dependem de sua posição, foram utilizados os dois modelos anteriores para identificação de frequências para as posições listadas na Tabela G.1.

Tabela G.1 - Parâmetros otimizados de comprimentos e massas

\begin{tabular}{|c|c|c|}
\hline $\begin{array}{c}\text { Posição do efetuador [mm] } \\
\left(\boldsymbol{x}_{\mathbf{1}} ; \boldsymbol{x}_{\mathbf{2}} ; \boldsymbol{x}_{\mathbf{3}}\right)\end{array}$ & $\begin{array}{c}\text { Frequência de vibração em } \\
\text { fase }[\mathrm{Hz}]\end{array}$ & $\begin{array}{c}\text { Frequência de vibração em } \\
\text { oposição de fase [Hz] }\end{array}$ \\
\hline$(0 ; 0 ; 480)$ & 53,7 & 59,3 \\
\hline$(280 ; 0 ; 480)$ & 51,0 & 62,2 \\
\hline$(0 ; 140 ; 480)$ & 42,8 & 45,2 \\
\hline$(280 ; 140 ; 480)$ & 41,1 & 49,0 \\
\hline
\end{tabular}

Observa-se que a menor frequência natural identificada para o mecanismo, considerando as quatro posições analisadas e ausência de carga manipulada, foi de $41,1 \mathrm{~Hz}$ e corresponde à vibração das barras $\mathrm{AC}$ e BD em fase, com o efetuador na posição dadas pelas coordenadas $\boldsymbol{x}=\left[\begin{array}{llll}280 & 140 & 480\end{array}\right]^{T} \mathrm{~mm}$. Para essa posição, foi também avaliado o efeito da adição de carga manipulada à frequência de vibração natural da estrutura. Os resultados podem ser observados na tabela G.2. 
Tabela G.2 - Evolução da frequência estrutural com a adição de massa manipulada

\begin{tabular}{|c|c|c|c|c|c|}
\hline $\mathbf{M}[\mathbf{k g}]$ & 0 & 0,1 & 0,2 & 0,3 & 0,4 \\
\hline Frequência [Hz] & 41,4 & 38,5 & 36,3 & 34,5 & 32,9 \\
\hline
\end{tabular}

Observa-se, como esperado, que a adição de massa diminui a frequência natural estrutural do mecanismo e, assim, diminui a faixa em que se podem ajustar os ganhos de controladores. 
ANEXO A - ESPECIFICAÇÕES DO ROBÔ ABB IRB360 FLEXPICKER 


\section{IRB 360 FlexPicker ${ }^{T M}$}

\section{Main Applications \\ Assembly \\ Material handling \\ Picking \\ Packing}

Features

- High speed flexibility

- High capacity - up to $8 \mathrm{~kg}$ payload

- Hygienic design for wash down applications

- Superior tracking performance

- Integrated vision software

- Integrated control of indexing belts

For nearly 15 years, ABB's IRB 360 FlexPicker has been the leader in state-of-the-art picking and packing technology. The robot has outstanding motion performance with the shortest cycle times, precision accuracy and high payloads. PickMaster software was developed for ease-of-use and simplifies the robot integration.

The IRB 360 range consists of four variants. The compact variant, IRB 360-1/800, has a 800 mm diameter work area and its small footprint saves floor space and makes it easy to fit into compact packaging machines.

The IRB 360-1/1130 (standard version) which has a working range optimized for the fastest picking applications. To extend the usefulness of this proven robot, $A B B$ has increased the IRB 360 FlexPicker's top payload to 8kg. Optimized for both picking and packing applications, the robot is now able to pick up heavier items, handling up to 100 cycles per minute. Its average throughput capacity also is radically improved, an average of 33 percent, thanks to the IRB 360's combined speed and payload performance.

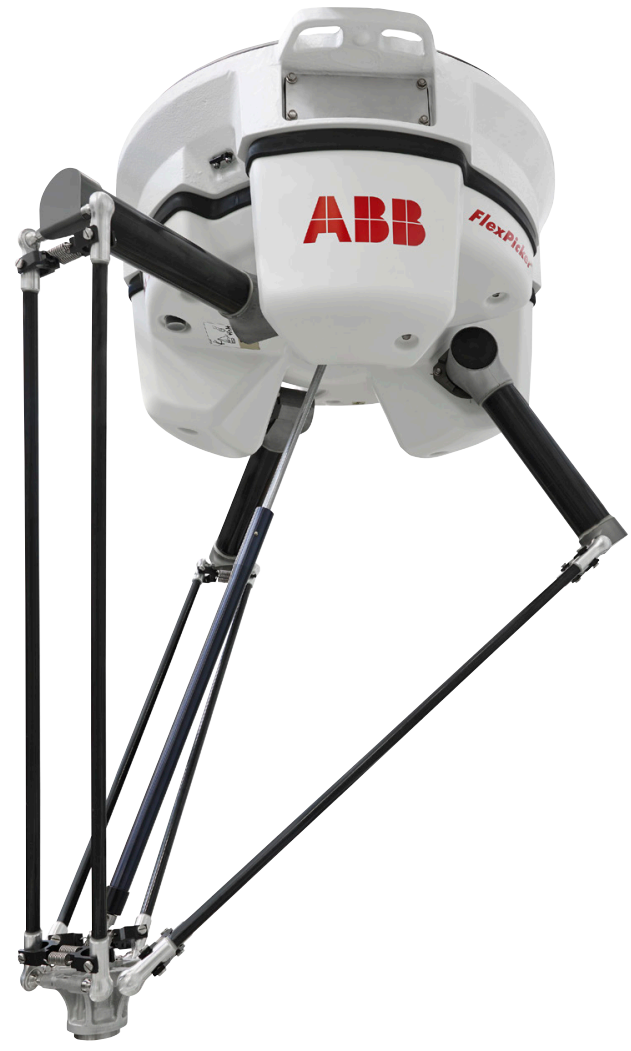

The IRB 360 is designed to work in meat and dairy applications. A stainless option with all metal parts in stainless is IP69K validated so that it can be washed down with industrial detergents and high pressure hot water. The robot is also designed with smooth and rinse-off surfaces and lubricant free joints that are resistant to most corrosives.

Setting up an application becomes easy using PickMaster software which has evolved into an invaluable help for integrators and users of IRB 360. It simplifies the vision configuration and offers the application tools needed for an efficient high speed picking application.

The reliable, market leading IRC 5 controller is also an integral part of the FlexPicker ${ }^{\mathrm{TM}}$ robot solution. The IRC 5 with TrueMove ${ }^{\mathrm{TM}}$ and QuickMove ${ }^{\mathrm{TM}}$ guaranteeing that the highest speeds together with path following facilities - allowing the robot to track fast moving conveyor belts with extreme accuracy. The IRC 5 also is available in a panel-mounted version that offers substantial space savings and easy integration into machines and production lines. 


\begin{tabular}{|c|c|c|c|}
\hline \multicolumn{4}{|l|}{ Specification } \\
\hline Robot versions & $\begin{array}{l}\text { Handling } \\
\text { capacity }\end{array}$ & Diameter & No. Axes \\
\hline IRB 360-1/800 & $1 \mathrm{~kg}$ & $800 \mathrm{~mm}$ & 4 \\
\hline IRB 360-1/1130 * & $1 \mathrm{~kg}$ & $1130 \mathrm{~mm}$ & $3 / 4$ \\
\hline IRB 360-3/1130 & $3 \mathrm{~kg}$ & $1130 \mathrm{~mm}$ & $3 / 4$ \\
\hline IRB 360-1/1600 & $1 \mathrm{~kg}$ & $1600 \mathrm{~mm}$ & 4 \\
\hline IRB 360-8/1130 & $8 \mathrm{~kg}$ & $1130 \mathrm{~mm}$ & 4 \\
\hline \multicolumn{4}{|l|}{ Supplementary load } \\
\hline on upper arm & \multicolumn{3}{|l|}{350 gram } \\
\hline on lower arm & \multicolumn{3}{|l|}{350 gram } \\
\hline Integrated signal supply & \multicolumn{3}{|c|}{12 poles $50 \mathrm{~V}, 250 \mathrm{~mA}$} \\
\hline Integrated vacuum supply & \multicolumn{3}{|c|}{ Max. 7 bar/max vacuum 0.75 bar } \\
\hline \multicolumn{4}{|l|}{ * Tested by IPA, all axes } \\
\hline \multicolumn{4}{|l|}{ Physical } \\
\hline Robot mounting & \multicolumn{3}{|l|}{ Inverted } \\
\hline \multirow[t]{2}{*}{ Weight } & \multicolumn{3}{|c|}{$120 \mathrm{~kg}$ (Standard \& Wash-down) } \\
\hline & \multicolumn{3}{|c|}{145 kg (Stainless Wash-down) } \\
\hline \multicolumn{4}{|l|}{ Performance } \\
\hline Position repeatibility & \multicolumn{3}{|l|}{$0.1 \mathrm{~mm}$} \\
\hline \multicolumn{4}{|l|}{ Angular repeatability } \\
\hline Standard \& stainless axis 4 & \multicolumn{3}{|l|}{$0.4^{\circ}$} \\
\hline Wash-down axis 4 & \multicolumn{3}{|l|}{$1.5^{\circ}$} \\
\hline
\end{tabular}

\section{Cycle time*}

Typical cycle time for $\varnothing 1130 \mathrm{~mm}$ standard variants

\begin{tabular}{lllll}
\hline Cycle & $0.1 \mathrm{~kg}$ & $\mathbf{1} \mathrm{kg}$ & $3 \mathrm{~kg}$ & $\mathbf{8 ~ k g}$ \\
\hline 25/305/25 & & & & \\
IRB 360-1/1130 & 0.30 & 0.36 & & \\
IRB 360-3/1130 & 0.40 & 0.40 & 0.52 & \\
IRB 360-8/1130 & & 0.38 & 0.42 & 0.60 \\
$90 / 400 / 90$ & & & & \\
IRB 360-1/1130 & 0.44 & 0.51 & 0.70 & 0.92 \\
IRB 360-3/1130 & 0.60 & 0,60 & 0.75 & \\
IRB 360-8/1130 & & 0.55 & 0.65 & 0.92
\end{tabular}

The cycle times in the table are measured under real conditions but cycle times may vary depending on the actual application (tool data, path radius, gripper activation etc.)

* Cycle times for IRB 360-1/800 and IRB 360-1/1600 differ in cycle time.

Please use RobotStudio or real cycle time tests to verify actual cycle time.

\section{Conveyor tracking**}

\begin{tabular}{ll} 
Constant conveyor & Conveyor speed \\
speed $[\mathrm{mm} / \mathrm{s}]$ & Repeatability $[\mathrm{mm}]$ \\
200 & 1.0 \\
$350-750$ & 1.5 \\
$800-1400$ & 5.0 \\
\hline Start/stop conveyor $[\mathrm{mm} / \mathrm{s}]$ & Repeatability $[\mathrm{mm}]$ \\
500 (start/stop in $0.2 \mathrm{sec})$ & 3.5 \\
Indexing conveyor control & Repeatability [mm] \\
3.5 g acceleration/deceleration & 2 \\
${ }^{* *}$ The tracking performance is measured under real conditions with IRB $360-1 / 1130$ and \\
PickMaster. The figures may vary depending on the actual robot max. speed and acceleration \\
performance in relation to what the application demands.
\end{tabular}

performance in relation to what the application demands.

\begin{tabular}{ll}
\hline Electrical Connections & \\
\hline Supply voltage & $200-600 \mathrm{~V}, 60 \mathrm{~Hz}$ \\
$\begin{array}{l}\text { Rated power } \\
\text { Transformer rating }\end{array}$ & $7.2 \mathrm{kVA}$ \\
$\begin{array}{l}\text { Power consumption at max load } \\
\text { Type of Movement }\end{array}$ & IRB $360 / 1$ \\
Typical pick - and - place & $0.477 \mathrm{~kW}$ \\
cycle with 1 kg payload & \\
\hline \hline
\end{tabular}

The base box and the arm system can be ordered independent of each other in standard, wash-down or stainless design. Depending on the combination the robot fulfils protection classes IP 55, IP 67 or IP 69K. If wash-down or stainless axis 4 is choosen, the robot can be washed down accordding to industrial standard.

Ambient temperature

IRB 360 manipulator $\quad \pm 0^{\circ} \mathrm{C}$ to $+45^{\circ} \mathrm{C}$

Relative humidity

Max. $95 \%$

Noise level

$<70 \mathrm{~dB}(\mathrm{~A})$

Safety

Double circuits with supervision,

emergency stops and safety

functions, 3-position

enabling device

Emission

Clean Room options axis 4

EMC/EMI shielded

Standard - Clean room 7

Wash-down- Clean room 5

(certified by IPA)

Stainless - Clean Room class 5

(certified by IPA)

Option

Collision detection

Data and dimensions may be changed without notice

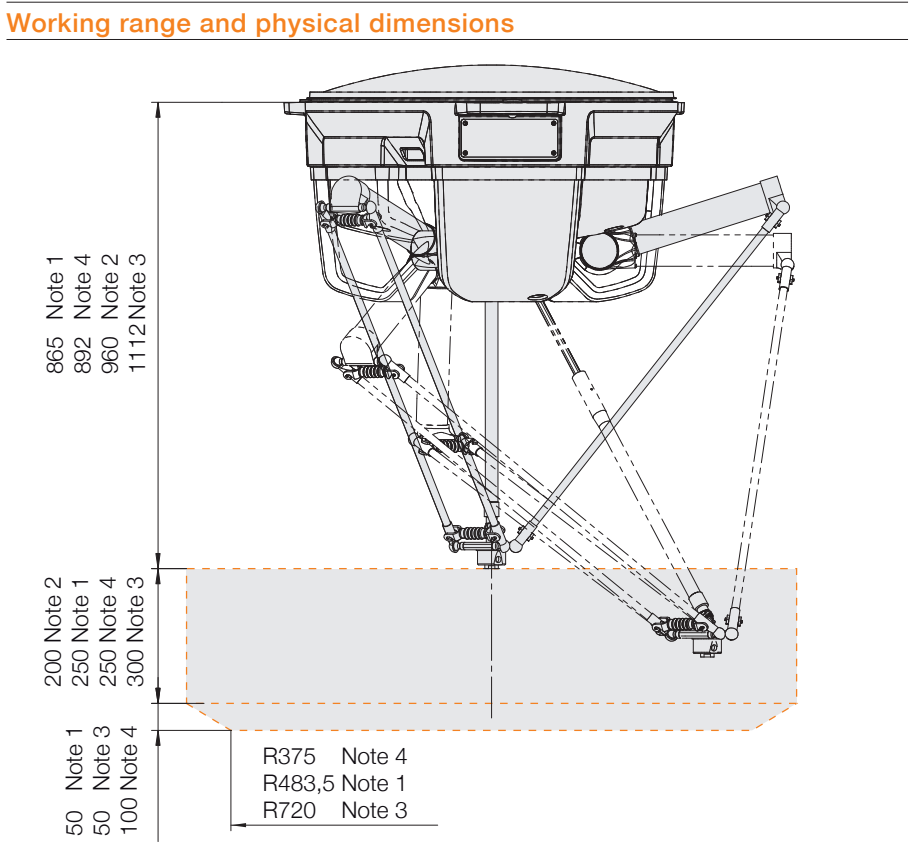

Note 1: IRB 360-1/1130 and IRB 360-3/1130

Note 2: IRB 360-1/800

Note 3: IRB 360-1/1600

Note 4: IRB 360-8/1130 
ANEXO B - ESPECIFICAÇÕES DO ROBÔ ADEPT QUATTRO s650H 


\section{adept}

\section{Ad e p t Quattro ${ }^{\text {Tm }}$ s $650 \mathrm{H}$}

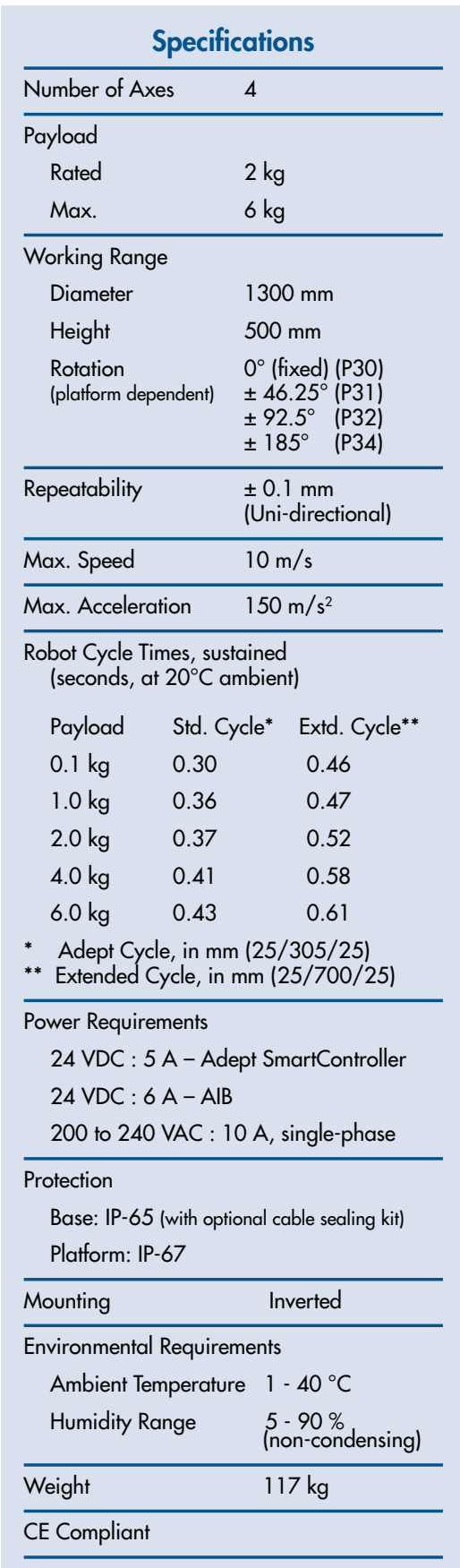

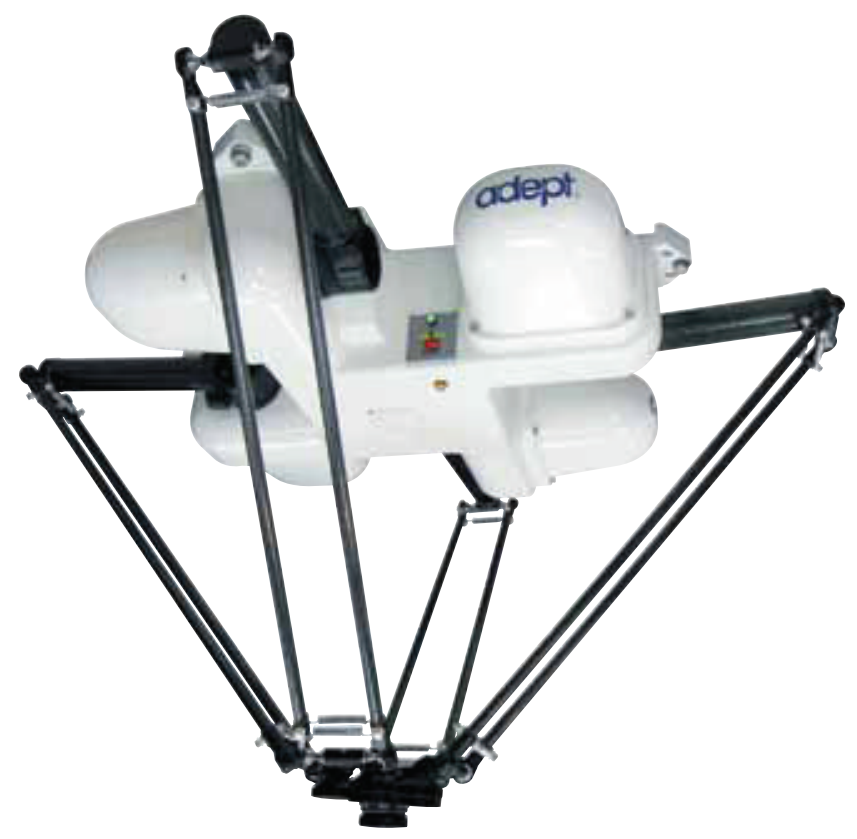

The Adept Quattro s650H is a parallel robot specifically designed for high-speed applications in packaging, manufacturing, assembly, and material handling. The patented four-arm design, advanced control algorithms, and large work envelope make the Adept Quattro the ideal overhead-mount robot for smooth motion, high-throughput applications. The Adept Quattro is powered by ultra-compact controls and embedded amplifiers, which reduces the cycle time and improves footprint efficiency.

\section{Product Features and Benefits}

- Patented four-arm design delivers consistent speeds for higher throughputs

- Robust components and design reduce maintenance costs with maximum uptime

- Distributed SmartServo architecture decreases integration costs

- Conveyor tracking with integrated vision guidance ensures accurate part location for increased yields

- High-resolution, absolute encoders provide high accuracy, superior slow-speed following, and easy calibration

- High-efficiency, low-inertia drives and lightweight arms deliver maximum acceleration
- $8 \mathrm{kHz}$ servo update rate for improved pathfollowing and control

- Integrated temperature sensors monitor heat in servo motors to prevent damage

- Diagnostic display on robot enables faster troubleshooting

- Embedded amplifiers and compact controls maximizes space efficiency

- Adept $\mathrm{ACE}^{\mathrm{TM}}$ software simplifies development for faster time to market

- Ethernet TCP/IP and DeviceNet capabilities 


\section{AdeptQuattros $650 \mathrm{H}$}

\section{Dimensions: Adept Quattro s650H (mm)}

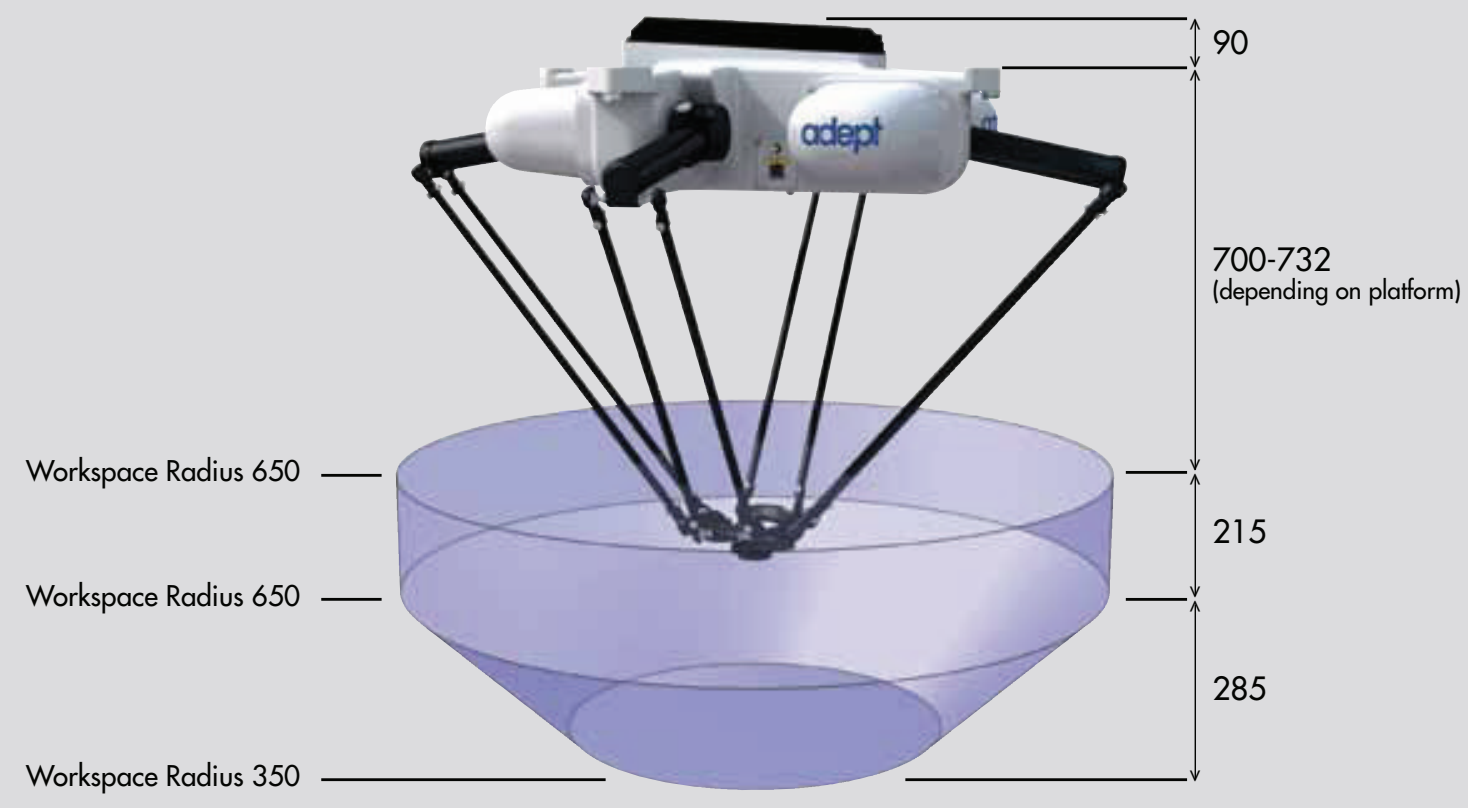

Dimensions: Flange $(\mathrm{mm})$

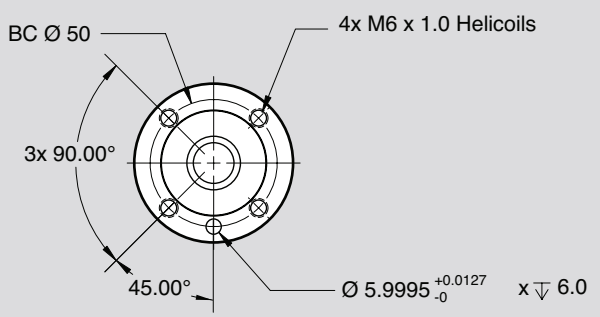

The Adept Quattro system includes the following:

- Adept Quattro robot with AIB (Amplifiers in Base)

- Adept SmartController ${ }^{\mathrm{TM}}$ motion controller (with V+ software installed)

- P30 (fixed), P31, P32, or P34 rotational platform

- Front Panel with E-Stop

- Adept ACE software

- User documentation

The user must supply the following:

- Power to SmartController motion controller (DC)

- Power to AIB (AC and DC)

- Emergency-stop wiring at each workcell

- End-effector

- Frame (for mounting the Adept Quattro robot)
Options:

- ACE PackXpert ${ }^{\mathrm{TM}}$ application development software

- AdeptSight ${ }^{\mathrm{TM}} 3.0$ vision guidance and inspection system (requires a PC Adept recommends using the Adept SmartVision ${ }^{\mathrm{TM}} \mathrm{EX}$ vision processor)

- Cameras for vision guidance

- V+ Extensions license for conveyor tracking

- T2 manual control pendant

- IP-65 Cable-Seal Kit

\section{adept}

Adept Technology, Inc. 5960 Inglewood Drive, Pleasanton, CA 94588 Tel: 925-245-3400 Fax: 925-960-0452 Email: info@adept.com www.adept.com

Specifications subject to change without notice.

O2010 Adept Technology, Inc. ALL RIGHTS RESERVED. The information provided in this communication or document is the property of Adept Technology, Inc. and is protected by copyright and other intellectual property laws. In addition, any references to any Adept Technology, Inc. products are the marks and property of Adept Technology, Inc. [and may be registered trademarks]. All other trademarks or tradenames are the property of their respective holders. 